\title{
DISCOURSES OF GLOBAL QUEER MOBILITY AND THE MEDIATIZATION OF EQUALITY
}

\section{Joseph Comer}

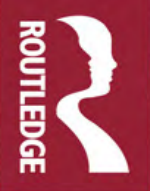




\section{Discourses of Global Queer Mobility and the Mediatization of Equality}

This book critically unpacks the why and how around everyday rhetorics and slogans promoting global LGBTQ equality. Examining the means by which particular discourses of progress and hope are circulated globally, it offers unique insights into how LGBTQ livelihoods, relationships, and social movements are legitimated and valued in contemporary society.

Adopting an innovative critical discourse-ethnographic approach, Comer draws on scholarship from the sociolinguistics of global mobility, queer linguistics, and digital media studies, offering in-depth analyses of representations of LGBTQ identity across a range of domains. The volume examines semiotic linkages between LGBTQ tourism marketing; Cape Town, South Africa, as a locus for contemporary ideologies of global mobility and equality; diversity management practices framing LGBTQ equality as a business imperative; and humanitarian discourses within transnational LGBTQ advocacy. Autoethnographic vignettes and principles from within queer theory are incorporated by Comer's critical discourse-ethnographic approach, giving voice to personal experience in order to sharpen scholarly understanding of the relationships between everyday 'social voices', globalized neoliberal political economy, and the media.

Taken together, the volume expansively (if queerly) maps what Comer refers to as 'the mediatization of equality', and will be of interest to graduate students and scholars in critical discourse studies, sociolinguistics, and linguistic anthropology, as well as those working across such fields as media studies, queer studies, and sociology.

Joseph Comer completed his $\mathrm{PhD}$ in English Linguistics (Language and Communication) at the University of Bern, Switzerland, in 2019. He is now an associated researcher with the Centre for the Study of Language and Society at the University of Bern. 


\section{Routledge Critical Studies in Discourse}

Edited by Michelle M. Lazar, National University of Singapore

\section{Discourses of Denial}

The Rhetoric of American Academic Labor

Thomas A. Discenna

Discourses of (De)Legitimization

Participatory Culture in Digital Contexts

Edited by Andrew S. Ross and Damian J. Rivers

\section{Academic Irregularities}

Language and Neoliberalism in Higher Education

Liz Morrish and Helen Sauntson

The Discourse of Perceived Discrimination

Perspectives from Contemporary Australian Society

Sol Rojaz-Lizana

\section{Multimodal Legitimation}

Understanding and Analysing Political and Cultural Discourse Rowan R. Mackay

Discourses of the Arab Revolutions in Media and Politics

Stefanie Ullmann

Discourses of Global Queer Mobility and the Mediatization of Equality

Joseph Comer

For more information about this series, please visit: https://www.routledge .com/Routledge-Critical-Studies-in-Discourse/book-series/CDA 


\section{Discourses of Global Queer Mobility and the Mediatization of Equality}

\section{Joseph Comer}

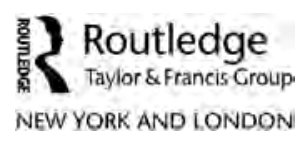


First published 2022

by Routledge

605 Third Avenue, New York, NY 10158

and by Routledge

2 Park Square, Milton Park, Abingdon, Oxon, OX14 4RN

Routledge is an imprint of the Taylor \& Francis Group, an informa business

(C) 2022 Taylor \& Francis

The right of Joseph Comer to be identified as author of this work has been asserted by him in accordance with sections 77 and 78 of the Copyright, Designs and Patents Act 1988.

All rights reserved. No part of this book may be reprinted or reproduced or utilised in any form or by any electronic, mechanical, or other means, now known or hereafter invented, including photocopying and recording, or in any information storage or retrieval system, without permission in writing from the publishers.

Trademark notice: Product or corporate names may be trademarks or registered trademarks, and are used only for identification and explanation without intent to infringe.

Library of Congress Cataloging-in-Publication Data

Names: Comer, Joseph, author.

Title: Discourses of global queer mobility and the mediatization of equality/Joseph Comer.

Description: New York, NY: Routledge, 2021. | Series: Routledge critical studies in discourse | Includes bibliographical references and index. |

Summary: "This book critically unpacks the why and how around everyday rhetorics and slogans promoting global LGBTQ equality"-Provided by publisher.

Identifiers: LCCN 2021012657 | ISBN 9780367521721 (hardback) |

ISBN 9781032072838 (paperback) | ISBN 9781003087960 (ebook)

Subjects: LCSH: Gays. | Sexual minorities. | Equality. | Equality in mass

media. | Cosmopolitanism. | Globalization-Social aspects. |

Queer theory.

Classification: LCC HQ76.25 .C657 2021 | DDC 306.76/6-dc23

LC record available at https://lccn.loc.gov/2021012657

ISBN: 9780367521721 (hbk)

ISBN: 9781032072838 (pbk)

ISBN: 9781003087960 (ebk)

DOI: $10.4324 / 9781003087960$

Typeset in Bembo

by Deanta Global Publishing Services, Chennai, India 
For my family - given, found and chosen 
;

Taylor \& Francis

Taylor \& Francis Group

http://taylorandfrancis.com 


\section{Contents}

List of figures viii

Acknowledgements $\quad \mathrm{x}$

Copyright acknowledgements xii

Notes on orthography and terminology xiii

San Francisco, January 2016

1 Introduction: The mediatized mobility of people, politics, and pride 5

Cape Town, April 2016

2 'Equality on the sea': Interrogating LGBTQ privilege in the tourism discourse of 'Africa's gay capital'

3 Representing the Spectrum: The discursive production of queer heterotopia at an LGBTQ tourism convention 84

London, June 2016

4 Counting 'the cost of discrimination': Managing LGBTQ diversity at The Economist's Pride and Prejudice

5 Sloganizing and 'materializing' equality: Scales of solidarity in the discourse of transnational LGBTQ advocacy 160

Sydney, February 2017

6 Conclusion: Queer cosmopolitanism and the scaling of utopia 205

Melbourne, August 2020

References $\quad 229$

Index 247 


\section{Figures}

2.1 Back cover of Spartacus guide 2016, ad for Air Berlin 60

2.2 Excerpt from Out2Africa's homepage 71

2.3 Excerpts from the Out2Africa website: sensuality, equality, luxury

2.4 Excerpts from the Out2Africa website: infinite experiences, fabulous consultants

2.5 Montage of MisterBnB media: 'create a welcoming world' 80

3.1 Preferred Pride media: 'travel with pride' 85

3.2 Materializing 'travel with pride' at Spectrum 86

3.3 Situated, aural, gustatory, and high-end resources at Spectrum 90

3.4 WTTC: 'I am travel' 97

3.5 The multimodal representation of 'escape' (2016) 107

3.6 Excerpts from the Spectrum promotional video 111

3.7 Montage of carnivalesque aspects of Spectrum's staging 113

4.1 The Economist's claims to prosperity and/as equality 124

4.2 Pride and Prejudice: a sophisticated presentation of 'the business case'

4.3 Excerpt from the Pride and Prejudice event booklet 128

4.4 Pride and Prejudice: 'discrimination is expensive' 139

4.5 Pride and Prejudice: the cost of homophobia 141

4.6 The Economist's claims to boundless prospects for prosperity 143

4.7 Montage of performed slick, luxury, and cool branding at Pride and Prejudice

4.8 'Diversity beans' with an uplifting message 152

5.1 OutRight and UNFE: 'the price/cost of exclusion' 161

5.2 A 'fabulous' life 173

5.3 'Become an equality champion': the technologization of action 176

5.4 All Out: 'Be like Alex!' 178

5.5 'Whichever' - 'a manifesto, a campaign tool, a conversation starter'

5.6 Montage of materialization and mobilization as a discursive strategy 
Figures ix

5.7 \#BETRUE, 'Be You' - similar sales pitches 184

5.8 Montage of scalar work: building a transnational, convivial collective

5.9 The scalar and embodied affordances of gifs 190

5.10 The infinite, ultimate scaling of/for LGBTQ futures 198 


\section{Acknowledgements}

Like almost everything I ever write, the acknowledgements of the $\mathrm{PhD}$ thesis on which this book is based were rather lengthy. I will try to be more succinct now, although there are a great many people to thank. Without them, this book would not be here.

This book would not be here were it not for the intellectual guidance, personal support, and 'ambition on my behalf of Crispin Thurlow. I am forever grateful for the opportunity you gave me: to come to Bern, to change my life. Thank you for your mentorship. Really. This book would not be here without the added support and supervision of Tommaso Milani - a 'troublesome' queer scholar whose voice inspires my own greatly. This book would not be here without a vast network of supportive sociolinguists and discourse scholars. To belong to such a network - to improve my own work through theirs - is a source of great pride.

I am very grateful for the patience and editorial support of Michelle Lazar, Elysse Preposi, and Helena Parkinson and others at Routledge for their hard work helping this book arrive.

This book would not be here if I had not been fortunate enough to join the community of scholars at the Department of English, University of Bern. I am hugely grateful for the encouragement of my colleagues - more than I can say. I am of course especially grateful for the lifelong friends I have made, who I can't thank enough for distracting me when I needed it, cheering me on when I really needed it and hearing me out when I really needed it. From Sattler to Marzili to 'Melrose Place', you made this book's development joyful, and I cannot thank you all enough. I must express particular gratitude to my friend and office-mate Gwynne Mapes. This book would not be here were it not for your grace, fierce intelligence, and humour, all of which continue to inspire me greatly.

As critical as I am of the 'mediatization of equality', I am still a proud queer (or try to be), in conversation with my forebears. And I will always be unwaveringly thankful to anyone who advocates for this beautiful community I belong to (in whatever form, with whatever label, wherever, however it meets): including delegates at Spectrum and Pride and Prejudice, and the champions who work for and support LGBTQ rights worldwide. I am extremely thankful to 
the city of Cape Town for welcoming me; to its dancefloors, to its complex story.

Speaking of dancefloors, I dedicated my PhD thesis to the 49 lives taken on one at Pulse on June 12, 2016, and I dedicate this book to them as well - and to anyone who ever wants to join them, and me, on a dancefloor. Despite all I write here (in the words of Whitney Houston), love will save the day.

Love will save the day, and I am in love, with a person who provides me with more love, perhaps, than I could ever have imagined possible. Noah, the comfort, warmth and care you provide are beyond measure. This book would most certainly not be here were it not for you, and for that, and so much else, I love you. Thanks for buying your bike. 


\section{Copyright acknowledgements}

I gratefully acknowledge the permission of the following copyright holders for the permission to reproduce materials.

Chapter 2: Air Berlin (Figure 2.1); Rhino Africa (Figures 2.2-2.4).

A version of this chapter was previously published, (C) Equinox Publishing Ltd 2018: Comer, J., 'Equality on the sea': Interrogating LGBTQ privilege in the tourism discourse of 'Africa's gay capital'. Gender and Language 12(4). https://doi.org/10.1558/genl.33353

Chapter 3: World Tourism and Travel Council and Fin London (Figure 3.4); St. Pete-Clearwater Pride Toronto and Destination Ontario (Figure 3.5); Rhino Africa (Figure 3.6). http://visitstpeteclearwater.com/

Chapter 4: (C) The Economist Group Limited, London 2016 (Figures 4.14.6, closing illustration).

Chapter 5: All Out (Figures 5.2, 5.3, 5.4, 5.6, 5.8, 5.9, 5.10); UNFE (Figures 5.1, 5.6, 5.10); OutRight International (Figures 5.1, 5.2, 5.10); Stonewall (Figure 5.5); It Gets Better (Figures 5.5, 5.6).

Figure 5.7 displays apparel produced by NIKE, Inc. under fair use principles.

Every reasonable attempt was made to contact other copyright-holders with regard to remaining copyrighted material. At all times, the purposes of its reproduction here is fair use, for scholarly comment and critique, of a transformative nature. 


\section{Notes on orthography and terminology}

My inclusion in this book of a 'Q' in 'LGBTQ' when referring to those members of society identifying with a sexual/gender-based alterity may at first seem to reflect a hollow 'rhetoric of queer' - an improperly 'hollow' appropriation of a critical term (cf. Sicurella 2016). I might be criticised for using 'queer' as a general referent for sexually or gender-diverse people. However, quarrels about what constitutes 'queer' are themselves evidence for the dynamism, 'messiness', and hence productiveness of the term. Moreover, 'queer' as used to signal identity outside of academic contexts warrants its inclusion in my terminology, given that individuals identifying as such will often do so in order to reject fixed placement within ' $L$ ', 'G', 'B' or ' $T$ ' identity categories or to avoid use of the 'LGBT' acronym. There is no language that sufficiently captures the myriad sexual and gendered realities that are possible, but it is nonetheless clear that queer-identifying individuals may also 'travel with pride', believe that 'love always wins' and be hailed by the data I examine. Those who reject 'queer' are likewise still hailed by this cosmopolitan, convivial rhetoric.

Some scholars capitalize 'Queer Linguistics' when denoting this emergent approach to language, sexuality, and normativity. For many, however including me - the productive capacity of queer theory (and therefore queer linguistics) lies in its inherent fluidity and lack of orthodoxy - even to the extent that 'it is not useful to consider queer theory a thing, especially one dignified by capital letters' (Berlant and Warner 1995:343). Overall, in this book I purposely avoid capitalization as much as possible, including with dyadic relationships that are often nowadays capitalized, such as black/white (for racialized categories). Writing specifically about the South African context, I capitalize 'Coloured', but do not capitalize 'black'. I wish to inhabit a space with as few capital letters, as few norms and as few misbegotten categories as possible. I do this not to deny the fundamentally constructed nature of these social categories, but to deny that construction the 'dignity' of capital letters, following Berlant and Warner (1995). 


\section{$\Rightarrow$ Taylor \& Francis Taylor \& Francis Group http://taylorandfrancis.com}




\section{San Francisco, January 2016}

I can see it on the horizon.

The flag. And all it stands for. A proud history; a community, whose visibility and political influence have risen steeply in recent decades. I am in the world-famous Castro, gazing up at the massive pride flag overlooking the district.

To get here after leaving my hotel, I had walked up Market Street away from the city centre. Along the way, and during the entirety of my stay in San Francisco, I saw landscapes of urban decay and disenfranchisement - several people I took to be homeless and/or mentally ill, sitting on cardboard boxes, begging for change or lying in a stupor. Though these kinds of scenes are nowadays widespread in any given 'global city', in San Francisco they are both strikingly common and particularly alarming.

And they have peculiar resonance in a city like San Francisco; a city with heightened counter-cultural renown, and a progressive history, as well as some of the most expensive rents in the United States. But what can I, as an individual, do to help these people's plight?

I pop into a Whole Foods store and buy a ginger beer, hoping to ease the beginnings of a sore throat. I ask the cashier if he's tried it, making a joke about how I hoped I wasn't getting sick in the midst of my holiday. We share a smile and a knowing look when he says I hope I enjoy my time there. How nice it is, I think, to begin my trip with a little flirting with a cute dude at a supermarket.

The street crossing uses the vibrant colours of the pride flag - brightening up the wet pavement. I also notice a pride flag hung in the window of a Bank of America branch. Alongside the powerful statement of the flag flying on high, these signs stand out as, if not quite 'banal nationalism' and not quite banal 'homonationalism', not all that far away from it either.

This village makes a statement of place, pride, and purpose. But it also winks at me, entices me, plays with me. One pizzeria offers food baked with love, served with pride'; another is called the Sausage Factory. I see a nail spa called Hand Job, a noodle bar called Slurp and an ice cream parlour called Hot Cookie. All seem to invoke the same kind of 'knowingness' I shared with the cashier earlier; a camp sensibility, a playfulness. A sports bar called Hi Tops advertises itself as offering 'cool pitchers' and 'hot catchers'.

The village also offers comfort - a sense of security, a recognition that this is a place for those like me. Digital advertising for a health and wellness centre for gay, bi and trans men pledges, in turn, 'more support ... more tools ... more belonging'. Its name is 


\section{San Francisco, January 2016}

Strut. There, you can 'be uplifted, get equipped, be yourself'. The well-built man whose tools I am invited to equip myself with is naked.

Next door to these banal sexed signs (both implicit and explicit), the brightly lit store for Human Rights Campaign (HRC) stands out. Above its door, a mural of Harvey Milk stares out over the district - which makes sense, given that the store is located in his former camera shop. I step inside. I consider buying a t-shirt; a take-home souvenir, a memento of my trip to a centre of queer liberation, a statement of pride and perhaps, a virtuous materialization of change in becoming.

In the end, however, I settle on a simple pin. I am, after all, near the beginning of my PhD journey, eager to collect whatever data I can, and something about it strikes me. That elusively profound word, and even more elusive idea/l - one that seems increasingly to be everywhere, all at once, yet without (in my view) a clear referent.
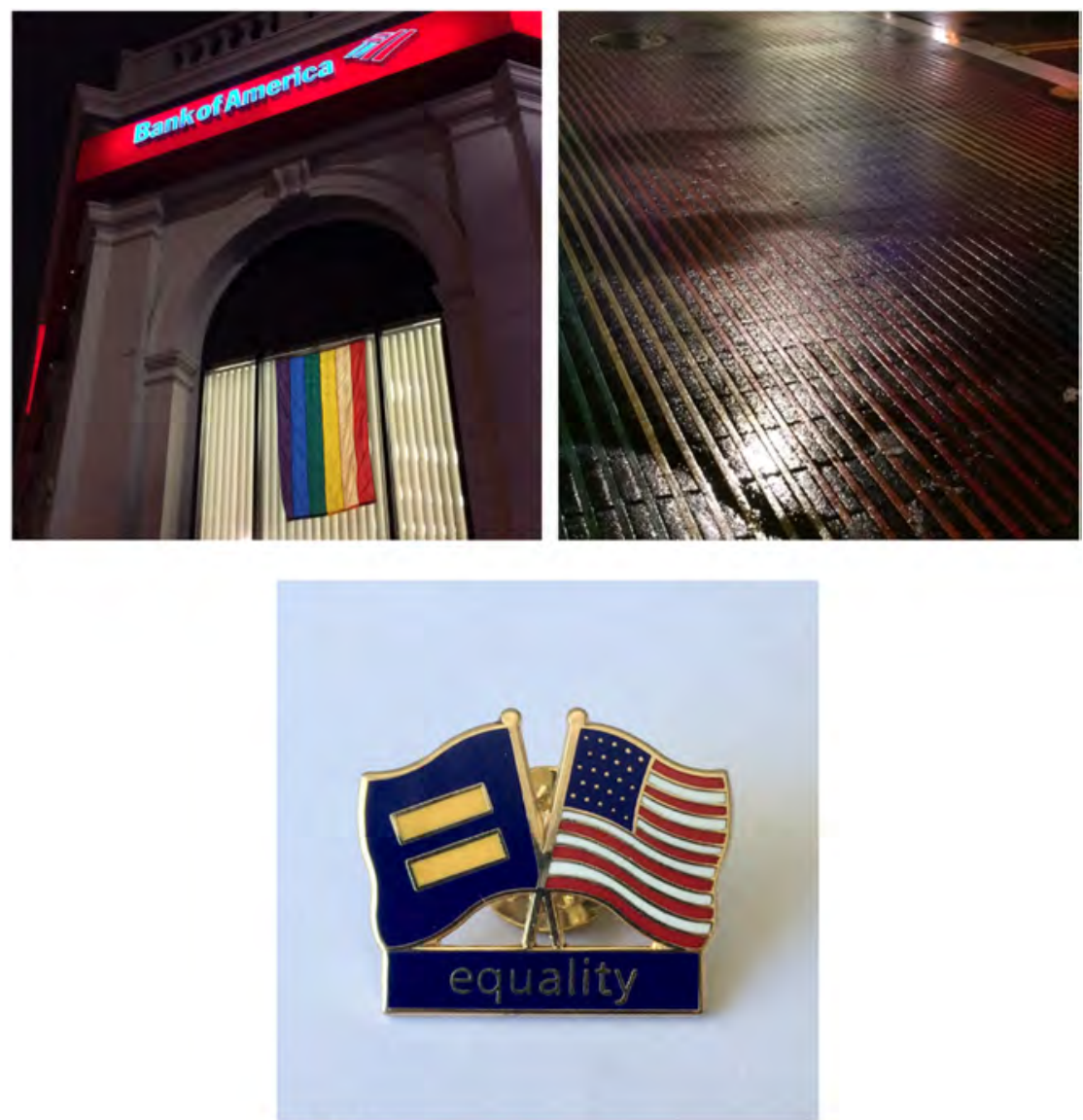
According to an ad in the 'Funmaps' guide to the city I pick up in the Castro, this is 'the city that practically invented gay'. And certainly, there is great heritage here, laying the foundation for a proud community and undoubtedly, a positive shift in social relations in recent decades, in the United States and elsewhere. But how could the city practically invent 'gay', if at other times such an identity is understood as borderless and immanent - coming from within? What is the currency of such a claim?

Where is equality, in the production, purchase, and prideful wearing of HRC's pin? What does it look like? The colourful corner of Market and Castro, and the material deprivation alongside?

These thoughts run through my head as I walk back down Market Street.

They run through my head still as I head out on the town later that week, taking heed of the Funmaps ad's closing words: 'Whatever you're hungry for this weekend, San Francisco can show you just how fabulous 49 hours can be'.

How could I say no? 


\section{$\Rightarrow$ Taylor \& Francis Taylor \& Francis Group http://taylorandfrancis.com}




\section{Introduction \\ The mediatized mobility of people, politics, and pride}

\section{\#LoveTravels: Queer mobilities in a world on the move}

Love is in the air, and love is on the move. The globalized world now finds itself at a moment of profound cultural-political and political-economic shift with regard to love. Often taken for granted as a simple emotion, love is of course by its very essence a distinct, visceral, and uniquely affecting experience: pre-reflexive, 'beyond words' (cf. Thurlow 2016). Increasingly, it is no longer (or not solely) articulated in a simple, easy-to-apprehend manner in everyday media. Quite the opposite: just as discourse-oriented scholars have begun to turn to love (and other emotions) as a vital object of empirical research, 'love' appears to be ever-expanding, taking on new forms, being deployed in new ways, and, perhaps, taking on new meaning. Borrowing Blommaert's (2010:1) comments about globalization writ large, this is a process that even if 'not new in substance ... [is] new in intensity, scope, and scale'.

'Love' and its free movement are now the subject of hashtags, a tool for advertising and an intrinsic aspect of the globalized expression of hope for a better world, (purportedly) across geographic, cultural, and economic boundaries. The \#LoveTravels campaign launched by the Marriott International hotel group in 2014 offers insight into this phenomenon. ${ }^{1}$ In the advertising produced through this campaign, not just love, but lovers are represented as an embodied and personalized representation of an aspiration for better life for all LGBTQ people. The story of two men, Chad and Scott (and their twins, Olivia and Lucas), offers an emblematic example. Chad and Scott's family featured prominently in Marriott's \#LoveTravels campaign; just one of a diverse cohort of celebrities and 'ordinary' Americans asked to share their stories of how travel connects them to the wider world. They featured in a banner on Marriott's \#LoveTravels microsite, accompanied by a bold assertion: 'Marriott welcomes all'.

Through an elementary analysis typifying the multimodal principles adopted in this book, it is possible to glean a great deal of information about the \#LoveTravels campaign's producer, target audience, and ideological underpinnings. Dressed casually but neatly, Chad and Scott, both white men, and their two children seem to exemplify the class status of many of Marriott's 


\section{Introduction}

customers. Three of the family's closed eyes, indexing sleep and/or comfort, invoke a sense of safety, togetherness, and peace. The exception, Olivia, has her eyes wide open as she dreamily gazes upwards at her paper plane - a standin for the possibilities that (global) mobility affords. Likewise, the flower in her long blonde hair points to a youthful, boundless optimism. Hope. Love. The written text also indexes comfort and endless opportunity. Encountering Chad and Scott through their first names is emblematic of the process Fairclough (2001) refers to as 'synthetic personalization' - the strategic simulation of interpersonal meaning in discourse, on the basis of a desired effect. 'After the twins were born', the viewer is told, '[Chad and Scott] celebrated the true meaning of unconditional love'. The viewer immediately feels bonded with these men, introduced to their family - but they do so bound 'together with Marriott'. As a family, through Marriott's assistance, 'they're showing the world how love travels'. The interests of this multinational corporation are thus intimately tied to the welfare of this family, as a stand-in for all queer families, and tied to the clever pun that 'there is no room for inequality' at its hotels. With that said, of course, the fact 'every guest, whoever they are, wherever they go' can feel equal does not change the fact that Marriott hotels are high-end, and thus inaccessible to a vast majority of the United States' and the world's LGBTQ people. The political-economic implication of these rhetorical claims is, effectively, to send a message of 'equality' only to those affluent enough to enter the hotel. \#LoveTravels thus speaks directly to the central concern of this book: global capital's power to determine how we conceive of, and strive for, equality.

The way in which love is described, perceived, circulated, and 'stuck' to objects and social actors - 'a way of bonding with others in relation to an ideal, which takes shape as an effect of such bonding' (Ahmed 2014:124) - is an important vector for social-scientific research in an age of unprecedented globalization, technological advancement, and social inequality. In this book, I respond to the acute need for conceptualizations of love and sex/uality as relational and political phenomena, following the lead of scholars within both broader cultural studies and social-semiotic/sociolinguistic analysis (e.g. Ahmed 2004, 2014; Milani 2014). Massive shifts in the scope, intensity, and scale of contemporary human interaction, often premised upon social relations like 'love', desire, sexuality, and other 'positive' attachments (e.g. with one's family, nation or the entire globe) have rightly prompted theorists such as Sara Ahmed (2014:123) to ask: 'What does the language of love do?' At its heart, as a guiding ethos, this book is written in order to contribute to this queer, feminist, and critical discussion on the uses and abuses of the language of love; the consequences of powerful actors' common framing of love as an unconditional, everlasting, and globally homogenous feeling, articulated through those actors' actions.

By no means are Marriott alone (in the tourism/hospitality industry, or any other) in how they pursue customers through virtuous campaigning. The discursive production of affective resonances and authentic, 'person-to-person' 
bonds between brand and consumer is a ubiquitous feature of contemporary LGBTQ pride. As just one other example, Hyatt hotel group launched their \#stayasyouare campaign in 2019 with this message: 'At Hyatt, our purpose is to care for you so you can be your best, and being your best means being your most authentic self. Hyatt hence frames itself as an arbiter of care, worldwide. An associated campaign told customers, 'Don't Get A Room': 'Instead, get out and proudly share your love and yourself with the world'. ${ }^{2}$

From a critical perspective, love therefore nowadays seems to float all around us, signifying little, or nothing at all. Affective and discursive (or both at once, cf. Wetherell 2013), it adds value to otherwise standardized, massproduced goods in the globalized, flexibilized economy (Heller 2003, 2010), sometimes materialized in what Jaworski (2015a) calls 'language objects'. In such cases, the language of love is a commodity, a vehicle for the self-styling of social actors as contemporary consumer-citizens. This phenomenon is typical of what many critics see as the collapse of the boundaries between economic and cultural/semiotic processes in late-capitalist society (e.g. Featherstone 1991; Lash and Urry 1994): the aestheticization of everyday economic and cultural life. For some, this collapse has also brought about an era of 'liquid love' (Bauman 2003) and the 'transformation of intimacy' (Giddens 1992). In this view, processes of individualization and technological advancement (e.g. in sexual health, transportation, and communication) have underpinned (and are accelerated by) a profound change in how humans build intimate bonds. The result is a vision of 'love' and intimacy dislodged from a dependence on reproduction and instead reliant on mutual self-satisfaction. The concepts of love, sex, families, and care for others are thus made 'fluid': dynamic, flexible, and independent of one another. Giddens' (1992) notion of 'plastic sexuality' describes a democratization of intimate life in the public sphere, so that open same-sex practices and relationships became not only legible and identifiable, but (to an extent) legitimate lifestyles for individuals to lead.

Giddens' theory leaves out much of the historical/economic contingencies of the emergence - or 'liberation' - of lesbian, gay, bisexual, transgender, and otherwise 'queer' (LGBTQ) sexual identities (D'Emilio 1983; Weeks 2007). Theorists like Foucault (e.g. 1978) and Butler (e.g. 1990, 1997a) also provide an important counterpoint. They account for the extent to which sexuality and gender, respectively, are by no means naturally given or chosen, but rather the result of historical invention, (bio-)power, discipline, and performance. Regardless, theories of the transformation and liquidity of love in late modernity offer a valuable, preliminary insight on the modern-day 'lifestylization' of sexuality and sexual politics (Bell and Binnie 2000), by which intimate life and love can hence become commodities. Through this lifestylization, sexuality is another resource for reflexive self-cultivation and realization - functioning alongside, but also separate from, the effects of disciplinary power (cf. Green 2010). In this way, it is not only the language of/about 'love' that is commodified in late modernity. Rather, love and intimacy become value-adding resources themselves - 'thingified' love that can be 'projected, felt, displayed, touched, embraced, bought, and sold as 


\section{Introduction}

never before' (Jaworski 2015a:91). Forms of non-heterosexuality, in particular, can become liveable and enlivening experiences for social actors to reflexively make use of in crafting an image of one's 'authentic' self as loving, sexy, 'out' or proud - or as tolerant and gay friendly (cf. Puar 2007). In other words, social actors - whether individuals or institutions - can bring forth chronotopic representations (i.e. representations of time and space as intrinsically connected, cf. Bakhtin 1981) of a spatialized 'global' progress and a 'global' future in which they, as individuals, are central.

In this book, I wish to revise Ahmed's (2014) question, 'what does the language of love do', to ask specifically: what does 'love' (or 'equality, 'diversity' or other evocative forms) do when taken up by some of the most powerful social actors in a time of globalization? What is the use (and value) of queerness and queer 'love' to these actors? Leaving aside the problematic claim that 'the true meaning' of unconditional love comes about through child-rearing (see Edelman 2004), \#LoveTravels also contains the more troubling claim that this family, through its mobility, can 'show the world how love travels'. Marriott boldly assert that this family's privileged practices of touristic consumption - and the love they show for one another on these trips - can change the world. Thus, as well as serving as an intimate semiotic resource, here 'love' is politicized and ideologically bound - profoundly imbricated in a project of neoliberal globalization that uses 'psychic and affective registers' to orient individuals' conduct and govern their lifestyles, desires, and movements (Gill and Kanai 2018:319). The 'equality' that figures like Chad and Scott enjoy is tied to an unsustainable culture of consumption, yet this is framed as a message to the world; an instantiation of cosmopolitan 'progress'. Perhaps this is unsurprising. As the South African media scholar Mehita Iqani has eloquently described, matters of consumption and quality of life are profoundly (that is, materially) interlinked:

No question of equality is ever only a matter of principle, philosophy, ideology or rights. It is always a matter of who has what and who does not. Equality is a question of access to material resources and the chance for enjoyable, comfortable lifestyles. Quality of life takes material form, and accessing that quality - especially in capitalist societies - requires some or other form of consumption.

(Iqani 2016:16)

Extract 1.1, taken from the homepage banner of the \#LoveTravels microsite, makes the sentiment of the campaign clear:

\section{Extract 1.1: lovetravelswithme.com (n.d.)}

Love is a universal language understood by all, and when it travels, it has the power to bridge cultures and inspire discovery around the world connecting people, place, and purpose. 
In \#LoveTravels, we find a distillation of the political-economic underpinnings of modern-day equality: as a product. Travel, to give one's life quality. Travel, to inspire others to do the same. Consume, that you may do good; that you may make the world better. Fairer (somehow). The campaign provides initial insight into the broader ways that 'love', 'pride', 'equality', and other unremarkably positive, affirmative tokens of discourse are nowadays wielded in the service of capitalism. They flow through and across mediated, material, embodied, and spatial contexts, in culture and commerce. Each chapter in this book describes how this positive affirmation is wielded, to provide guidance for how the LGBTQ community (and society writ large) should cohere, consume, and perform identity in the process. In Extract 1.1, the language of love that Ahmed (2014) has questioned and framed as functioning within an 'affective economy' is rhetoricized as 'universal': a bridge across culture, 'connecting purpose'. ${ }^{3}$ In reality, as this book will ultimately argue, it functions more like a lock: holding flows in place, with the sole purpose of determining the course of social, economic, and transnational change, 'discovering' new ways to exploit social life for profit. It is a valuable currency in a global affective culture industry in which forms of 'happiness' (Ahmed 2010) and 'positivity' (Ehrenreich 2010) are already heavily exploited. There/here/everywhere, the forces of neoliberal capital operate at a banal, everyday scale, offering us a commodified vision of love, pride, and hope for a better world: 'equality', at least for some.

\section{Objectives and purpose of this book}

Sexuality is an important axis of differentiation, and one of many that produce the friction in which mobilities scholars have shown much interest. Mobility is indeed differentially accessed, in part according to sexual norms. So we need to both consider 'queer' lives as mobile lives and to critique the heteronormative limits of mobility.

(Oswin 2014:91)

This book is anchored by theoretical discussion of processes of LGBTQ identity affiliation and affirmation, and the ways these processes are shaped by the economic and political reorderings of globalization. At the heart of these reorderings lie varied facets of mobility: transnational flows of people, information and ideologies across varied 'scapes' (Appadurai 1996); especially, the global semioscape: 'the globalizing circulation of symbols, sign-systems, and meaning-making practices' (Thurlow and Aiello 2007:308). Thurlow and Aiello draw a connection between this semioscape and the globally distributed visuals produced by image banks like Getty Images (Machin 2004; Aiello and Woodhouse 2016); 'a globalized visual language predicated on the absence of specificity and descriptive detail' (Thurlow and Aiello 2007:308). Accordingly, I characterize the semioscape as a banal, deterritorializing tool for global capital, intertwined with the imaginary of market globalism (Steger 2008, 2009). It 
is a loosely structured set of symbols, sign-systems, and meaning-making practices that is strategically deployed to sustain the hegemony of market-driven political-economic frameworks, often supported and circumscribed by a salient, categorical positivity (Machin 2004).

Following Cresswell's early writing at the onset of the 'mobilities turn' across the social sciences, I understand mobility here as a kind of (valorized) displacement: an 'unspecified ... blank space ... [standing] as an alternative to place, boundedness, foundations, and stability' (Cresswell 2006:2). As well as signifying movement from A to B, mobility is a product of representation, of power, which is often (though not always) treated as a signifier of modernity and progress. I thus understand transnational mobilities as being fundamentally impacted by the 'mediatization' of society, as outlined by scholars like Agha (2011b) within linguistic anthropology, and Hjarvard (2013) within media studies. Mediatization describes institutionalized, commodity-driven processes of mediation and communication, in which the media are central to habitus formation in late modernity, and guide the norms offered as direction for legitimate livelihood. It is through mediatization that I understand (and justify) my own representation here of 'love', 'equality', 'diversity', 'pride', and 'inclusion' (among other terms) as: (a) conceptually and theoretically intertwined phenomena; (b) salient and meaningful 'tokens' of everyday discourse for/about LGBTQ people; and (c) moving political articulations, either of the 'world we have won' (Weeks 2007) or the world-in-becoming.

Said differently, the recurrent and interrelated use of these evocative words in the media signifies their strategic importance for the development of a globalized world that is friendly to LGBTQ people. These words signify vitally important, abstract concepts, 'felt' relations within social life and sloganeering, at once. 'Love' in transit is equated with love, the essential, felt relation, as ascendant and triumphant; and the presence of the felt relation is framed as a manifestation of 'equality'. This sequential framing (and teleological narrative), I argue, requires serious examination with regard to its influence by the workings of capital. Following Thurlow and Jaworski (2017a:192), these are 'word-things': signifiers that are 'unmeasurable, but deliberately intangible', as well as marketable, whose meaning shifts in context and serves to naturalize the practices in which they are used (see also Urcioli 2003, 2016). Within the approach to mediatization taken in this book (explained in further detail later in this chapter), these word-things hold semiotic-material value, as the smallest rhetorical building blocks of the larger discourse/s (and ideolog/ies) I aim to describe, interpret, and critique in this book, serving as evidence for the ways in which 'the relation between material conditions and cultural-cum-communicative formations is nowadays fully blurred' (Thurlow and Jaworski 2017a:186). Love, pride, and hope for equality are inarguable, evocative phenomena - and as this book contends, this is precisely why they hold such appeal to the institutions whose media I examine. Flowing from marketing departments through to the informal meaning-making practices 
of everyday people worldwide, this affective-discursive 'language of love' defines how LGBTQ rights and social progress are articulated.

Following Oswin's epigraph above, they are also the means by which 'the heteronormative limits of mobility' are challenged. LGBTQ people, their lifestyles and the discourses which produce them are nowadays in constant motion. Oswin's (2014:85) discussion of the intersection of queer theory and the study of mobilities aptly notes that a great deal of the latter 'attends to the differentiated politics of movement'. In this book, my primary objective is to examine the 'differentiated politics' of movement influencing how powerful discourses/ideologies and inarguable word-things of LGBTQ equality circulate, as well as to locate the mobility of a privileged few LGBTQ people within these flows. In a world on the move, when Chad and Scott (and I) are free to see our love travel, it is important to ask what our love in motion performs, as well as how it is 'non-performative' (Ahmed 2012): following Sara Ahmed's influence, what it does not do.

The word-things I denote above are by no means the only ones used across the contexts I examine (or in tangential contexts across global commerce, civil society or social justice). Although I engage a 'global' perspective, based on the orientation of texts examined, it should be made clear that my viewpoint is tied to my white, Australian, male personhood, and I describe only the idea/l of 'globality', rather than any real globality (if such a thing is possible). In other words, I focus on understanding how privileged LGBTQ consumer-citizens such as myself are compelled to understand themselves in relation to iconic figures like Chad and Scott, and to understand the world as global. Therefore, eschewing comprehensiveness, I rather wish to open up discussion, leaving room for queer linguists, discourse scholars, and others to further unpack discursive practices: (a) in which equality for LGBTQ people is a central concern; and (b) where forms of mobility are salient (e.g. global tourism, social mobility and/or the transnational circulation of mediatized texts). The book is structured into four case study analyses. Across all four, these two foci of equality and mobility are at the forefront of the data examined. There are, however, clear differences and disjunctures between the case studies explored. As the chapters progress, I engage (following the data examined) in clear 'scale-jumps', e.g. from local to global, intimate to institutional, though not in a clear or mono-directional manner. I consider this reflective of the material-semiotic complexity of my objects of study, and my complex imbrication with them. In other words, situating myself (broadly) in a sociolinguistics of globalization, my research naturally treats 'globalization' as both real and rhetorically produced, both external to myself, and part of my innermost subjectivity; a messy 'complex of processes, evolving, and developing at different scale-levels, with differences in scope, speed and intensity' (Blommaert 2010:17).

Overall, this book is a critical investigation into a discursive formation: of LGBTQ equality and identity as mobility across the global semioscape. The object of my critical gaze is thus a vision of equality as that which entitles 
privileged LGBTQ individuals to move freely, and that found in media which facilitate top-down discourses of 'pride' which play into the hands of global capital. This book begins with a focus on rhetorics of Cape Town, South Africa as an LGBTQ tourism destination, then, as it progresses, examines rhetorics of LGBTQ equality as 'good for business' and as a global human rights imperative. (See later in this chapter for a definition of 'rhetorics' vs. 'discourses'.) All told, these case studies reveal the ideologies of globally influential media and civil society institutions that discuss - and discursively construct - the lives of marginalized LGBTQ people, and envision their future in/as 'diversity'.

The following research questions provide insight into the over-arching objectives of each case study, and the purpose of the book as a whole:

1. Given the intensity and scope of globalization, what typifies globalized, mediatized discourse describing the mobility of queer people, their material conditions and their future? Are certain voices, ideologies and/or representations privileged?

2. How does the global LGBTQ ('pink') tourism sector rely upon - and contribute to - this set of privileged, totalizing discourses, and discursive strategies, that might be characterized as the 'global queer semioscape' (cf. Thurlow and Aiello 2007)?

3. How is Cape Town represented as a LGBTQ-friendly destination - or 'gay capital' - in touristic media, and what rhetorics are used to attract LGBTQ tourists there?

4. How do powerful, globalized media institutions and the corporate sector also rely upon and contribute to the global queer semioscape - especially, via the world of 'diversity management'?

5. How does the mediatized development of global LGBTQ advocacy frameworks (under the leadership of transnational civil society organizations) also rely upon and contribute to the global queer semioscape?

6. How am I, as a queer person from the global North, implicated in and hailed by these mediatized discourses of mobility, equality, and diversity?

The interdisciplinary theoretical landscape the book explores traverses complex interconnections between 'liberated' queer lives, the media that represent these lives and the globalized, late-capitalist context in which they are lived. As this introduction makes clear, it is tied up with 'queer mobilities in a world on the move': the need to consider queer lives as mobile, and to critique the normative limits of mobility (Oswin 2014). As I seek to problematize it, the notion of global queer mobilities - hinging on some form of shared identity - comes about through the nowadays almost-total mediatization of mine and other (Western) social lives. Neither globalization nor sexuality - nor global queer mobilities - can nowadays be understood without attention to how the media 'guide' their representation and ongoing transformation. The world's 'global citizens' could not understand love, equality or progress as they do, were it not for the media that facilitate that understanding. Media like \#LoveTravels thus 
have a hugely impactful role in 'enworlding' queer lives (like mine), and making a mobile, consumptive life seem natural and desirable. As much as I want to celebrate Chad and Scott's family - their rights, their freedom, their love - I also want to unpack what lies beneath a campaign like Marriott's. What kind of inequality is there no room for in this vision? Echoing Extract 1.1, which people are connected? How is place made meaningful; how is it packaged? What is the purpose of 'love' in motion; what do media about global queer mobility do?

\section{Banal globalization, (queer) political economy and the mediatization of social life}

Sloganized sentiments like \#LoveTravels are ultimately the foundation of this book's theoretical framework, with (banal forms of) 'globalization', 'sexuality', and the (power of) 'media' as its cornerstones. I now seek to address the first of these concepts.

\section{Market globalism, 'banal globalization' and the cosmopolitan idea/l of tourism}

For love to travel, it must be mobile - and the contemporary world provides many ways for it to move. Technological advancements across aviation, telecommunication, international trade, and other services mean that social lives and their feelings now connect more often, and in more ways, than ever before. This is globalization, and scholars' attempts to apprehend this dense network of transnational flows and concentrations - of 'people, technologies, financial resources, information, media images, ideologies, and symbolic resources' (Thurlow and Jaworski 2010a:4) - form my first theoretical pillar.

In this section, I elaborate on what it means to discuss the centrality of mobility/ies in the contemporary era, relating such mobility to 'globalization' as an everyday, discursive accomplishment, whose sociocultural dimensions are deeply bound up with the forces of global capitalism. I introduce tourism as a major locus for this iterative reproduction of the globalized world (cf. Thurlow and Jaworski 2010a). There are many forms that mobilities can take. There are some that are personal, embodied, and phenomenological, and some that are mediated, incorporeal and epistemological; mobilities that encompass our movement, and semiotic mobilities that structure a world that is perpetually in motion around us. This book addresses both kinds, and seeks to do so at a global scale - responding to the way that these mobile flows of people, resources, media, and ideologies seem increasingly (though not completely) unfettered by national boundaries, vast distances, religious differences or political conditions (Appadurai 1996, 2001). Residents of Western societies are told every day that we live in a 'globalized' world. But what does this mean? How does it differ from a simple sense of globality, 'the world as one place' (cf. Jaworski 2015b)? Furthermore, how does it differ from 'cosmopolitanism' 


\section{Introduction}

- a concept which in consumer media is generally depicted as inarguably virtuous, 'a fundamental orientation to the stranger, a welcoming of difference' (Ong 2009:450)? In truth, 'globalization' means many things, and to some extent multiple things at once, to laypeople and the scholars studying societal interpretations of it: a 'double hermeneutic', in Giddens' (1984) terms. This lack of fixedness is perhaps the hallmark of the globalized era for the social sciences - why Bauman (2000) calls it 'liquid modernity'. However, this is not to say that everything is now unfixed, mobile, and/or borderless. Rather, it indicates that understanding social, economic, political, and cultural processes now requires an understanding of global (and regional, and local) mobility flows - as a foundation for how these processes get articulated. Yet for all the people, products, and cultural artefacts that this era displaces and deterritorializes, there is much that is static and unchanged. It is important to avoid seeing mobility as a teleological 'grand narrative' of contemporary life (or to romanticize its consequences). Rather, we need questions, theories, and methodologies that take mobilities into account, a 'mobilization' of the sociological imagination: such as that of the 'new mobilities paradigm' (Sheller and Urry 2006).

As Sheller and Urry remarked when accounting for the 'mobilities turn', 'all the world seems to be on the move'. Rather than unduly privileging mobile subjectivities, however, the 'new mobilities paradigm' is an intellectual project aimed at tracking the power of discourses and practices of mobility - what mobilities enact in the world. Although there is no question of the intensity and scope of both material and communicative mobilities for millions globally, there are many (most of 'us') who are immobile. A great many people never come close to crossing a national border - people often unaddressed, unheard, and unspoken-for in countless texts transmitted across the world daily. While millions fly overhead, a great deal more are still standing still - disconnected from the frenzied movement of people, place, and product around the globe. As Doreen Massey powerfully remarked many years ago:

The borders of the world's greatest ocean have been joined as never before. And Boeing has brought these people together. But what about those they fly over on their islands five miles below? Has the mighty 747 brought them greater communion with those whose shores are washed by the same water? It hasn't, of course.

(Massey 1994:148)

Ultimately, mobility is innately tied to political economy: one's mobility is directly related to their access to and ability to exploit economic resources. Still, the overall movement and interconnectedness of peoples is more extensive than in the not-too-distant past. As Thurlow and Jaworski (2010a:92) aptly note, 'many people experience themselves being interconnected with far-flung people and places through face-to-face or mediatized contact'. And as Arjun Appadurai puts it, 'we are functioning in a world fundamentally characterized 
by objects in motion. These objects include ideas and ideologies, people and goods, images and messages, and technologies and techniques. This is a world of flows' (Appadurai 2001:5).

Writing at around the same time, Szerszynski and Urry (2002) also noted along similar lines how 'banal globalism' and 'global citizenship' have emerged in the media produced within the global culture industry - the aestheticized economy of late modernity (cf. Featherstone 1991; Lash and Urry 1994; Lash and Lury 2007). For Szerszynski and Urry (2002:467),

images of the earth, including the mimetic blue earth; long, often aerial images of generic 'global' environments ... images of the family of man sharing a global product ... [and] images of relatively exotic places that suggests the endless possibilities of global mobility

are among the fleeting and innocuous means by which we become global and are told that we are already global. Representations of the globe 'as one place' compel us to think of ourselves as worldly and urbane, alongside such phenomena as the globalizing visual language of corporate image banks (Machin 2004), tourist guidebooks (Jaworski and Thurlow 2010) and countless more forms of (trans-)national marketing. They represent individuals as intimately connected to distant and diverse places and lifestyles, free to encounter, and profit from them as they please. The semiotic resources that link ideology, culture, and consumer media (e.g. language, images, everyday symbols, sign systems, hashtags, and other informal meaning-making practices) prompted Thurlow and Aiello (2007) to add the global semioscape to Appadurai's (1996) schema of overlapping ethnoscapes, mediascapes, technoscapes, financescapes, ideoscapes. Overall, these scapes provide a heuristic for understanding the overlapping, unequally distributed flows of globalization in (or as) an age of unprecedented mobility - with the semioscape aiding our understanding of how normative idea/ls of global society and political economy are (re-)negotiated in discourse. Thus, in this book, I critically examine these flows' importance in making market globalist, neoliberal governmentality seem normal, common-sense, and inarguable (following Foucault 1980; Martín Rojo and Del Percio 2019).

The (comparatively) wealthy individuals on the Boeing jet Massey describes - reading inflight magazines, watching Hollywood movies, glancing at the route map to identify anonymous islands below - are 'emblematic of modernity' (Lash and Urry 1994:253). They are told they are residents in a 'global village', belonging to a world on the move, coming together as one and celebrating 'the idea (and ideal) of the world as one place' (Jaworski 2015a:219). Importantly, these people do not simply sit in the nose of the plane; if you are on the plane, you are elite and privileged. And we are all encouraged to stay there. Compounding this fact is another: no matter how immobile a person might be, the flows of these scapes are inescapable. Their impacts are unyielding. As Frello (2008:26) aptly remarks, tweaking Sheller and Urry's 
claim, 'the world is on the move, and so are we, whether we want to be or not'. Appropriating Bauman's (1998) terms, it is self-evident that 'tourists' (the voluntary mobile) and 'vagabonds' (enforced mobile subjects like migrants and refugees) are on the move, but there are also a great many in a state of 'involuntary immobility' who aspire to migrate, and are practically unable to, yet fashion their lives according to this absence of movement (cf. Carling 2002). Of course, as well, the ecological consequences of discourses and practices of mobility are increasingly severe, and largely indifferent to people's nationality, status or capacity to move (Stibbe 2015). There is much to say about mobility - not least that the difference between mobility and immobility is itself discursively constructed. It is often difficult to know where exactly stasis ends and movement begins (Frello 2008). It is therefore important to recognize how, why, and where flows and objects in motion are 'moored' - tied to spaces and infrastructures that are perceived as immobile - and why. In other words, what is important is the production and reception of discourses of mobility and globalization; questioning who stands to benefit from a singular, simplistic story of 'global citizenship', held by 7+ billion people.

Broadly, the 'new mobilities paradigm' constitutes an epistemological shift, which endeavours to replace sedentary social science 'that treats as normal stability, meaning, and place, and treats as abnormal distance, change, and placelessness' (Sheller and Urry 2006:208). It likewise questions all reductive approaches which treat 'liquidity' as the all-encompassing state of affairs (cf. Bauman 2003), or mobility as a 'new normal'. Rather, it is an attempt to connect mobility to discussions of power and representation, to analyse it as an object of knowledge (Cresswell 2010; Frello 2008); an approach which emphasizes the social, cultural, and political production of movement and attends to the 'fragile entanglement of physical movement, representations, and practices' (Cresswell 2006, 2010:18). In simple terms, much work in this new paradigm attends to the unevenly distributed cultural politics of movement; this includes the different ways in which access to mobility transforms itself into further economic and social capital (i.e. 'motility', cf. Kaufmann et al. 2004). It focuses on the ways mobility is a central (and unavoidable) element of contemporary life, in order to grant perspective on late modernity; to understand the uneven ways that nowadays 'mobility, multiplicity, and fluidity are the normal state of affairs, rather than simply marked processes to be explained' (Heller et al. 2014:428). It is an entry-point to investigating how the transnational movement of humans, objects, capital, and information is iteratively represented via the discursive formation of 'globalization'.

Globalization is by definition omnipresent, and has been happening for some time, but beyond these facts, scholars across the social sciences are divided in their approach to the phenomenon. Where some approach this rapid movement of bodies, voices, and things as fundamentally contemporary, new to the late 20 th/early 21 st century, others take a historical or sceptical approach in which globalization is just the latest (re)configuration of cultural and social worlds; albeit one whose scope, environmental impact, and ideological, political force 
have never before been witnessed. The latter grouping tend to interrogate the cultural ramifications of globalization - to question what it means to be 'global' in late modernity, and who gets to be (cf. Bauman 1998). For many scholars, such as Bourdieu and Wacquant (2001) and Harvey (1995), there is very little that is new about globalization, apart from the way rhetorics of 'globalization' are nowadays invoked by states and other institutional actors as a way to disguise their 'surrender' to free market governance. As Harvey (1995:8) himself admits:

In my more cynical moments I find myself thinking that it was the financial press that conned us all (myself included) into believing in 'globalization' as something new when it was nothing more than a promotional gimmick to make the best of a necessary adjustment in the system of international finance.

For Harvey (1995) and other Marxist scholars of his ilk, globalization is essentially an iterative process, rather than any new kind of political-economic condition. Sitting on either side of this divide, scholars within the interdisciplinary field of global studies have compellingly examined the development of a global imaginary; how 'we' - the members of a purported global society, or human community - fit together, how things go on between us, the expectations we have of each other and the deeper normative notions and images that underlie those expectations (Steger 2008, following Taylor 2004; Anderson 1991). In this book, I follow scholars like Steger (2008, 2009:20) in critiquing the (neo-) colonial practices underlying globalizing processes, and hone in on market globalism as a central capitalist belief system which translates the global imaginary into 'concrete political programs and agendas', in which: (a) globalization is about the liberalization and global integration of markets; (b) globalization is inevitable and irreversible; (c) nobody is in charge; (d) everyone benefits; and (e) democracy is spread worldwide.

This ideology of market globalism is reasonably congruent with the commonest/earliest definitions of 'neoliberalism', as a political project that proposes that human wellbeing is best advanced through 'the re-structuring and re-scaling of social relations in accordance with the demands of an unrestrained global capitalism' (Fairclough 2003:4; so-called 'accumulation by dispossession', cf. Harvey 2005). It is right to note, as Block (2018) does, that it is rare to hear a politician or economist describe themselves as a 'card-carrying neoliberal'. This points to longstanding debates about whether 'neoliberalism' is a trivial term used to describe any aspects of global political economy which an author finds objectionable: not 'neo' at all, but rather classical liberalism in its purest form (cf. Milani 2018). Through this book, I intend to very clearly elucidate what is 'new' about neoliberalism; to outline the ways that neoliberalism (as a market globalist political project) coalesces all aspects of subjectivity with the figure of the entrepreneurial self, and is increasingly seen as a desirable, totalizing 'global rationality' (cf. Foucault 1980; Dardot and Laval 2013). 
Contrary to the clarion call of numerous corporations, with vested interests in building a global marketplace, it is clear that globalization, regardless of when (or if) it 'began', is neither an impartial nor comprehensive process. The global social imaginary associated with it - 'a new sense of a global social whole' (Steger and James 2013:30) - is one which actively functions to elide this fact from otherwise positive rhetorics of 'global citizenship'. Taylor (2004:23) argues that social imaginaries, as the common-sense background of lived experience, are reliant on 'the ways people imagine their social existence ... and the deeper normative notions and images that underlie these expectations'. ${ }^{4}$ Steger (2009) cites Bourdieu (1990:54) when he describes processes of social imagining as products of history that 'generate individual and collective practices - more history - in accordance with the schemes generated by history'. The social imaginary is therefore described here in a way akin to the well-known concept of habitus: 'embodied history, internalized as a second nature and so forgotten as history' (Bourdieu 1990:56), or simply, 'socialized subjectivity' (Bourdieu and Wacquant 1992:126). Like Steger, for the purposes of this book, habitus and the social imaginary are nowadays roughly coterminous, if not wholly synonymous (at least for Western subjects). This is a response to the general conditions of flux in a global ethnoscape, described above (Appadurai 1996), and the conditions of mediatization (Hjarvard 2013), in which media are central to habitus formation in late modernity, and which increasingly normalize the material inequality that that habitus pre-reflexively maintains (see Jaworski and Thurlow 2017). It is the pre-reflexive, imagined character of a habitus of globality and inequality that I wish to underline here - sustained through a discourse of globalization which 'unavoidably establishes relations of power and inequality that inevitably favour capital' (Thurlow and Jaworski 2010a:227). As Fairclough (2003) aptly remarks with regard to Bourdieu and Wacquant's (2001) critical stance on 'globalization' as rhetorically constructed, in the service of global capitalism, it is not enough to characterize the "new planetary vulgate' as a simple 'vocabulary'. 'We need to analyse texts and interactions to show how some of the effects which Bourdieu and Wacquant identify are brought off (Fairclough 2003:204). In short, social research on globalization needs the contribution of discourse analysis. Sociolinguists and discourse analysts are compelled to unpack the role of language/s in globalization, and to ask whether dominant rhetorics of the 'global' are representative and/or constitutive of flows across the world today. Close analyses of the (re) production, adaptation, and (re)circulation of globalizing discourse and the development of a 'globalizing habitus' (see Jaworski and Thurlow 2010) are essential to critiquing the inequalities sustained in (or by) globalization.

In this book, I describe how banal expressions of the global imaginary are brought to the surface in the service of LGBTQ equality. I argue that such rhetorics, while empowering and replicating themselves through teleological framings of the world to come for LGBTQ people, enshrine other forms of material inequality as a common-sense, unavoidable outcome of cosmopolitan progress. In every respect, I seek to follow Fairclough's (e.g. 2003) call for a 
thoroughgoing engagement of social theory with the empirical detail of sociolinguistic and discourse-analytical analysis, and vice versa. In so doing, I seek to provide critical insights into the dialectical relationship between semiosis and society: e.g. the 'banal globalism' and banal expressions of global citizenship that Szerszynski and Urry (2002) discuss; or alternatively, as a holistic guiding framework, banal globalization (see Thurlow and Jaworski 2010a, 2015). These terms owe a debt to Billig's (1995) thesis regarding 'banal nationalism' - the unassuming, unnoticed, but ideologically loaded national flag above a porch. The so-called global banality referred to here, 'everyday representations and discursive accomplishments', in Thurlow and Jaworski's (2010a:225) words, is an accelerant for mundane cosmopolitan ideals. Word-things and hashtag slogans like \#LoveTravels are just one articulation of this. A world on the move under a cosmopolitan framework, under 'banal globalization', is a sleight of hand - unquestionably a world of globalist, neo-colonial, and neoliberal ideology, and a thoroughly unequal one. As evidence, we may simply return to Massey's metaphor of the Boeing: those on the plane, and those that it passes by underneath (bypassed in more ways than one). Although not all travellers on planes are tourists, of course (and not all travellers travel willingly), every occupant of the jet is still exposed, subjected, and witness to the globalizing discourses and practices onboard - disposed to the rituals of their boarding class and compelled to journey onward, to exercise their privileged mobility (cf. Thurlow 2016).

A process in becoming, globalization is not yet complete (inasmuch as it could be completed) but still rapidly and iteratively subsumes individuals, nation-states, and societies within it. Technological advancements - airliners, smartphones, the internet allowing you to book one spontaneously by using the other - mean that more and more people, businesses, and institutions are now communicating on a worldwide scale. It is now difficult to describe the lives, lifestyles, and livelihoods of those with privilege - those 'on the move' in the Boeing - or the lives of those without it - those below - without recourse to the discourse of the global. All are affected by it; perhaps especially, the immobile, who have no say in determining how and where 'we' all move toward. It is clear how 'global society' is an all-encompassing object - one we confront every day, one which (re-)enacts its social and material conditions through its adoption by a set of relatively (or absolutely) dominant individual and collective subject positions (Law and Urry 2004). The world's people are therefore subject to the 'globalizing habitus' Jaworski and Thurlow (2010) have discussed: a globalized/ing iteration of 'that system of internalized, durable, and transposable dispositions which generates similar practices and perceptions in agents belonging to the same class, and which can be adjusted to specific situations' (Bourdieu 1990:53).

Jaworski and Thurlow's (2010) description of a 'globalizing habitus' is tied to their expansive examination of the global service industry of tourism: 'an influential, privileged lens through which many people make sense of not only a particular destination or culture, but the world at large' (Thurlow and Jaworski 
2015:50). Tourism is a key manifestation of globalization, and key to how it is articulated and justified. In other words, if globalization is realized through 'innocent' texts and 'harmless' interactions, the textual and interactive practices of tourism sit at the core of globalizing discourse. As Heller et al. (2014:427) argue, tourism can be used as a valuable lens for 'a broader discussion of the sociolinguistics of late modernity'. At one level, this is simply because tourism is such a vast, worldwide industry. International tourist arrivals reached 1.235 billion people in 2016, according to the UN World Tourism Organization (2017) - a massive number, although it is certain that many of these arrivals are made by the same individuals; truly globe-trotting 'tourists' (cf. Bauman 1998). The reason tourism attracts such a vast number of people is the other key driving force between its value for sociolinguistic and sociological inquiry: it is an aestheticized and semioticized 'culture industry' par excellence. It is one of the leading ways that human beings come to know the diversity of the planet's landscapes and inhabitants - and is profoundly intersected with its unequal relations of power, access, mobility, and wealth.

The many scholars exploring the social and cultural implications of touristic practices have shown that global tourism has a powerful role in establishing and reinforcing hierarchies of status, ideologies of difference and markets of 'culture'. As Franklin and Crang (2001:10) sum up well, 'touristic culture is ... the preparation of people to see other places as objects as tourism, and the preparation of those people and places to be seen'. Tourism is typified by its habitual representations of 'the world as one place' (cf. Szerszynski and Urry 2002; Jaworski 2015b), in which those who tour are compelled to think of themselves as 'global', and of touristic practices as a romanticized form of global belonging: as curiosity, wanderlust, adventure. A noble pursuit, and noble product. We are continually compelled to consume the places and individuals we visit, and to feel good about doing so. In Zygmunt Bauman's words, the 'tourist syndrome' is one perpetual, embodied 'grazing' through the world (Franklin 2003). 'We' - privileged Westerners who profit from the legacy of colonial practice, elites from the marginalized and postcolonial 'global South' and every tourist in between - are all engaged in a complex semiotic interplay through which the 'globe' comes to know itself and its organizing frameworks. It is almost or wholly inescapable (cf. Frello 2008). As Gogia (2006) has noted, at times the most cosmopolitan, friendly face of tourism (e.g. Canadian backpackers heading south) is dependent on involuntary mobility and forms of endemic immobility (e.g. Mexican workers migrating north, temporarily, and insecurely): '[the] relationship between Southern [i.e. non Euro-Atlantic] tourist economies and Western mobile bodies posits the balance of power in the hands of the tourists who bring in much of the needed foreign currency and revenues to struggling social systems' (Gogia 2006:371). Tourism provides scholars with a wealth of resources for understanding the already discussed aestheticization/semioticization of late modernity (e.g. Featherstone 1991; Lash and Urry 1994). Following this lead, work in the sociolinguistics of tourism provides evidence for the fundamentally symbolic nature of tourism in the 
following areas of research (see Heller et al. 2014): the staging of interactions between consumers/tourists and producers/hosts; the packaging of cultural practices - including languages - as products for consumption; semiotic framing and the management of space and place; the remediation of embodied tourist practices beyond their immediate contexts of enactment (e.g. newspaper travelogues, TV holiday programmes, online reviews or the posting of tourist videos and photos online). Overall, although it has clear material aspects (and consequences), a great deal of touristic culture subsists on matters of representation; the tourist imagination is always informed and prefigured by the mediatized content of brochures, newspaper travelogues, guidebooks, postcards, blogs and/or the feeds of social networking sites (Thurlow and Jaworski 2010a).

Tourism's heuristic value for the study of globalization and global mobility (and the role of language therein) is indisputable. It seems clear that, for those of us that travel (for leisure or business - all of us on the Boeing) 'the touristic gaze and imaginary shape and mediate our knowledge of and desires about the rest of the planet' (Franklin and Crang 2001:10). But they can also tell us something about home, and the way it is conceived. Studying tourism also indexes matters of space, place, and spatialization: the embodied and multisensory ways in which destinations emerge, shift, merge, and return home with tourists (Lefebvre 1991). Through the new mobilities paradigm, studying tourism thus becomes a way to apprehend social relations that encompass and surpass material environments and distances. In Sheller and Urry's (2006:214) words,

places are like ships, moving around and not necessarily staying in one location ... places are about relationships, about the placing of peoples, materials, images, and the systems of difference that they perform. We understand 'where' we are through 'vision in motion' practiced through the alignment of material objects, maps, images, and a moving gaze.

The 'tourist syndrome' of temporary grazing on people, places, and experiences that are somehow different or other (cf. Franklin 2003) - put simply, imagining how exotic, exhilarating or distant they must be - must therefore be understood as an inherently place-making phenomenon. Touristic space, like all space, emerges in the dialogue between space as it is perceived, conceived and lived-in (cf. Lefebvre 1991): i.e. the norms, images, and mistruths/fantasies underlying our expectations of other people and spaces across the globe. This dialogue, circulating between hosts and visitors, insiders and outsiders, people and companies, serves as a reminder of the discursive and embodied, intercorporeal nature of the fantasies and falsehoods of tourism and globalization writ large (cf. Thurlow and Jaworski 2010a).

Tourism is instrumental in producing the differences it profits from, just as much as it is in marketing and selling them. For this reason, Favero (2007) has written of tourism as a 'cultural industry of otherness', in which a quest to find 
and reinforce difference is governed by and reliant upon the disciplining and containment of all involved; the learning to imagine destinations, be a tourist (Urry 2002), and the learning to be 'toured' and seen (as above, in Franklin and Crang 2001). The global tourism industry is thus geared to serve the privileged, mobile, 'global citizens' of the world - purportedly cosmopolitan manifestations of the globalizing discourse that the industry itself calls into being. Its contribution to billions of dollars' worth of GDP attests to the material significance of tourism as an aestheticized economy of people, places, and objects. In addition, there is tourism's real significance as a cultural behemoth; a vehicle for the cosmopolitan rhetoric of a 'global village', larger and more connected each day (distilled in Steger's (2009) fourth market globalist principle, 'globalization benefits everyone'). Although the 'global village' is a privileged conceit - for banal globalization, for the everyday perpetuation of capitalist ideology - it is not entirely false. Tourism reveals the lie in this imagined unity. In many ways, beyond the idyllic and idealistic gloss of 'a world on the move' coming together, tourism is just another industry, through which many of the world's citizens are rendered subservient and/or voiceless. Mobile as it now is, the world does not move in unison. In many ways, it is shifting and splitting further apart - at least in economic terms. In truth, despite the discursive construction of a cosmopolitan 'wonderful world' (Favero 2007), in motion and in greater understanding and dialogue with itself, there are a great many individuals and communities the tourist gaze does not see, and whose voices we do not hear. Through an examination of queer mobilities, this book seeks to capture tensions between the cosmopolitan idea/l of the 'global', its spatial enactment and the material and structural inequalities iteratively disguised by that idea/l. In detail, I explore tourism discourse's inherent contradictions and paradoxes with particular regard to the sub-sector of LGBTQ (aka 'pink') tourism. As well as providing historical background to the development of this sub-sector, I am interested to examine LGBTQ tourism's cultural meanings. Echoing Heller et al.'s (2014:433) apt point that through tourism discourse, material goods can index 'meanings beyond their use value' like 'rebelliousness', the foundational rhetorics of LGBTQ tourism imbue the material good of touristic practice with meanings akin to 'revolt' and 'liberation'. Again, it is (apparently) a way that \#LoveTravels.

My mobilities approach has as its structuring centre a commitment to accounting for how the often moving (i.e. evocative, emotional) discourses of mobile queer lives and futures perform aspects of LGBTQ identity into being, as well as structure relationships with capital. My approach thus behoves attention to three facets of global queer mobility, of love's travel: the corporeal mobility of LGBTQ tourists; the upward social mobility brought about by de jure protection for the rights of queer people in various national contexts; and the transnational mobility of texts which advocate for those rights. These three facets of queer mobility are necessarily loosely drawn.

But what is 'queer', really? How does it inform my attempts to apprehend the power of these moving discourses? I now turn to answering these questions 
and outlining the second pillar of my theoretical framework: queer linguistics (and political economy), and the study of language, identity, and sexuality.

\section{Queer theory, queer linguistics, and the spectre of homonormativity}

The language we have access to in a particular time and place for representing sex and sexuality exerts a significant influence on what we take to be possible, what we take to be 'normal', and what we take to be desirable.

(Cameron and Kulick 2003:12)

Much critical discourse-analytical research follows the footsteps of Michel Foucault and his poststructuralist theory of discourse: 'practices which systematically form the objects of which they speak' (Foucault 1972:149). In this book, discourses regarding LGBTQ subjects in a globalized era are seen to administer the conditions through which sexual alterity is nowadays recognized and valued. Suffice to say, much of Foucault's oeuvre is devoted to articulately describing the ways in which sexuality is 'a historically shaped series of possibilities, actions, behaviours, desires, risks, identities, norms, and values that can be reconfigured and recombined but cannot be simply unleashed' (Weeks 2007:5; cf. Foucault 1972, 1978). For Foucault, discussion of sexuality is thus discussion of the ways in which 'normal' behaviour and 'deviance' from heterosexuality are constructed by structures of power; not a discussion of an essential identity, e.g. 'gay'/'homosexual'. In short it is vital that identities are conceptualized so that 'sexual and gender discourses can function as both building blocks of subjectification and pliable identity schemas ... for selfdevelopment' (Green 2010:318). ${ }^{5}$ We can and should strive to craft identities for ourselves, discursively formed through active processes of identification and self-awareness (cf. Blommaert 2005; Brubaker and Cooper 2000). Even when scholars understand identities as contingent, however, they are often called upon to fulfil an analytical role that they cannot, tending 'to mean too much ... too little ... or nothing at all' (Brubaker and Cooper 2000:1). If identity is little more than a single plurality, a 'suggestive oxymoron' (Brubaker and Cooper 2000:34), then its critical function is diminished. At least, it is then better to explore identities' intersections, rather than their unique lineages (cf. Crenshaw 1991). Despite this, research on language and sexuality has historically conceptualized sexuality exclusively in terms of identity categories: showing 'how people with particular identities [i.e. who identity as homosexual] signal those identities to others ... [and conflating] the symbolic position of queerness with the concrete social practices of men and women who selfdefine as gay and lesbian' (Kulick 2003:121; Cameron and Kulick 2003). This may be a consequence of the productivity of the operations of power that Foucault (1978) described. For Foucault (1978:101), sexual alterity found the defence to charges of indecency in those charges themselves: 'homosexuality began to speak on its own behalf, to demand that its legitimacy or "naturality" 


\section{Introduction}

be acknowledged, often in the same vocabulary, using the same categories by which it was medically disqualified'. An unfortunate side effect of this strategic essentialism - what Butler calls the 'strategic provisionality' of identity categories - has been to endorse the notion of homosexuality as coherent and definitional (as 'L', 'G', 'B', 'T', etc.). The creation of the homosexual as a 'deviant' category thus provided the lexicon for resistance, but also compelled narrow forms of subjectivity: 'a dangerous consensus of knowingness' (Sedgwick 1990:45).

In response to an over-emphasis on identity in prior language and sexuality research, Cameron and Kulick (2003:94) suggested a psychoanalytic reorientation to desire, and a renewed focus on 'the semiotic processes through which desire, of all kinds ... is constituted and communicated'. This centring of desire was in turn contested by Bucholtz and Hall (2004), who argued that this approach overlooks the close relationship between identity and desire; the ways identity is analytically viable as 'social intersubjectivity', 'understood as the outcome of intersubjectively negotiated practices and ideologies' (Bucholtz and Hall 2004:469). Desire is thus considered an intersubjective practice. In contrast, Cameron and Kulick (2003) see identities as emerging in part through pre-reflexive desire, iteratively performed. These scholars eventually remarked that their conceptions of desire and identity are insufficiently consistent with each other for it to be possible to work out which precedes the other. Ultimately, a balance is required, and in this book, the co-dependent and metonymic relation of desire and identity is my focus. It is important to foreground desire as preceding sexual practice, and to abrade essentialist identity categories. However, it is just as important to focus on the material, real conditions and consequences of enacting these desires. Bucholtz and Hall's (2004:470) helpful, open definition of sexuality reflects this: 'the systems of mutually constituted ideologies, practices, and identities that give sociopolitical meaning to the body as an eroticized and/or reproductive site'. Given Cameron and Kulick's (2003:4) view that sexuality should be understood broadly as 'the socially constructed expression of erotic desire', it seems unproductive to further question whether desire or identity is sexuality's primary vehicle. Rather, it is most productive to explore tensions between the desirous and identificatory. Like 'globalization', one's 'identity' is imagined but not imaginary - another double hermeneutic - intersubjectively produced, but by virtue of that performed production, a tangible, consequential 'thing' in the world, that individuals across the world cherish absolutely. Globalized forms of 'sexual identity' therefore have a complicated place within the context of this book: both precisely what I seek to investigate, and something I disavow because of their misrepresentation as universal, stable and essential, in media such as \#LoveTravels.

Many critical studies of the sexualized ideologies, practices, and identities Bucholtz and Hall refer to have been productively undertaken via queer linguistics, as 'an approach to language and sexuality that incorporates insights from feminist, queer, and sociolinguistic theories to analyse sexuality as a broad 
sociocultural phenomenon' (Bucholtz and Hall 2004:469). Its practitioners (ideally) challenge the bounds of what is possible, 'normal' and desirable (echoing Cameron and Kulick in the epigraph above). Here I elucidate the 'queer' meaning within the context of this book: as a convenient way to denote sexual minorities; as an attitude that defies any and all normative standpoints on social practice; and, as the subjective positionality of myself, Joe Comer, the researcher and man. Matters of political economy are central to my queer theoretical framework. I thus also seek to outline how queerness and queer linguistic undertakings can speak back to the norms inherent to a habitus of market globalism, as well as a habitus in which media institutions guide our everyday life (Hjarvard 2013). Whether queer linguistics is considered a proxy for all anti-essentialist language and sexuality research (cf. Motschenbacher and Stegu 2013), a form of critical discourse analysis (cf. Leap 2015), or something rather more affecting and undisciplined (cf. Thurlow 2016), I ultimately contend that its purpose is of positionality: standing against norms that treat queer identities as stable, and that articulate queer futures (or queer political economy) in narrow, non-transformative ways. Advocating for a verb-like usage - queering - I consider it most productive to think of queer academic practice as a set of orientations.

The nature of queer intent is captured well by these Brazilian scholars (notably, external to the Euro-Atlantic 'centre' of queer inquiry):

Queering social life requires epistemological and political stances that must face the complex and layered power relations running through all spheres of social life. The challenge, rather than being limited to enduring dichotomies, it is vigorously dependent on disturbing them.

(Fabrício et al. 2014:10)

Since even before the coining of 'queer theory' as a uniting frame of reference, the reclaimed slur 'queer' has been used to signal a multitude of intellectual projects and individual positions. These are all united by a commitment to poststructuralist critique, a standing apart from order, a bending (if not breaking) of convention and an agitation with the current day, particularly with regard to how hierarchies of gender and sexuality are formed. From the early 1990s to the current day, 'queer' has marked projects which challenge 'normative consolidations of sex, gender, and sexuality - and that, consequently, [are] critical of all those versions of identity, community, and politics that are believed to evolve "naturally" from such consolidations' (Jagose 1996:99). While accurate, this summary does little to highlight the fundamentally anti-categorizing, trouble-making stance of queer theory. Answers to queries about what it means to speak or act queerly (or queer something), or how queer relates to other sexual identifications, orientations, and subjectivities are inevitably, purposely unclear. In truth, the boundaries, outcomes, and undertakings of queer scholarship are if nothing else - and by definition - indistinct. For queer theorists (in word, if not always in deed), 'queer' functions less as identity than as the 
critique of identification (Jagose 1996; Halperin 1995). Judith Butler, one of queer inquiry's seminal theorists, has remarked that it indexes collective practice: 'a good term to invoke as we make uneasy and unpredictable alliances in the struggle for social, political, and economic justice' (Butler 2015:70). There are clear parallels between these accounts of queer thought, and Brubaker and Cooper's (2000:36) more broad statement that the social sciences should 'go beyond "identity", not in the name of an imagined universalism, but in the name of the conceptual clarity required for social analysis and political understanding alike'. Queer can be said to provide such clarity, by unshackling social research and critique from historically embedded norms of Western thought, including identity. ${ }^{6}$

With that said, queer theory would not exist without the pioneering work of 20th century activists whose core impulse was 'the assertion of the validity of same-sex desire and love, and the shaping of a viable sense of self, of identity' (Weeks 2007:81). However, this inherited focus on identity prompted later scholars and activists to decry contemporary LGBT(Q) politics as exemplifying a narrow politics of recognition, blind to material inequality (Harvey 2005; Fraser 1995, 2000). Under this schema, the recognition of identity obfuscates changes to the conditions which generate and reinforce axes of inequality. This book aims to contribute and lend nuance to this discussion, with specific reference to the globalization of LGBTQ rights. For many (e.g. Butler 1997b; Ahmed 2012), and in my view, the ongoing scepticism about (normative) identity entailed by queer scholarship signifies a vital move away from recognition toward the more radical and transformative class politics of redistribution: 'remedies aimed at correcting inequitable outcomes precisely by restructuring the underlying generative framework' (Fraser 1995:82). In simple terms, this book intends to demonstrate how media recognizing consumerist, normative or passive forms of globalized LGBTQ identity play a part in encouraging them. I believe that a queer orientation for analysis can help trouble this insolvent 'global imaginary' in a way that offers hope for processes of intersubjective identity formation, rather than denying their value. One could characterize the verb-like, alliance-building approach to queering taken in this book as valuing it as an affirmative being - living a queer life - and a transformative doing - a disruption of established norms of sexual/social life, and of socioeconomic stratification.

Queer theory has received criticism. Many see it as an elitist project, spearheaded by affluent and overwhelmingly white academics who cannot - do not - effectively undermine structures of material inequality (e.g. Anzaldúa 1991). In addition, there are some who dismiss queer theory because of how it has become normalized and institutionalized over time. It is certainly true that queer inquiry must grapple with the necessarily 'anti-identitarian' and 'antinormative' identity formation that can occur through reifying anti-essentialist stances; in effect, the creation of anti-identity identities, fixed formations of what 'queer' is (Wiegman 2012). One may again take heed in Judith Butler's words in suggesting that queer must remain 'never fully owned, but always and only redeployed, twisted, queer from a prior usage in the direction of urgent 
and expanding political purposes, and perhaps also yielded in favour of terms that do [its] political work more effectively' (Butler 1993:19). The only certainty in queer is its uncertainty. It can be replaced. Now, however, may not be the time to 'throw the queer baby out with the institutional bath water', in Milani's (2018) words. As Browne (2006:888) states, 'queer enquiries ... entail radical (re)thinkings, (re)drawings, (re)conceptualisations, (re)mappings that could (re)make bodies, spaces, and geographies'. It stands to reason that some of those rethinkings may render 'queer' obsolete or moribund, but as long as the people and institution/s employing it aspire for transformative change, it should be used (cf. Sicurella 2016). Butler's (1993) perspective on 'queer' as an ever-evolving form of radical political possibility hints at the ways queer perspectives cohere with Southern and postcolonial critique, like those by Fabrício et al. (2014) above. For these Brazilian scholars, the word 'queer' has less traction than in the North - but at the same time, they are highly cognisant of the potential of perspectives which foreground anti-normativity, visceral experience and corporeality, provocation, and marginal processes of consumption and production. Queer thinking bears witness to the unequal power relations that overlap with, influence or exacerbate the negative consequences of sexual dissidence, such as race, gender, age, nationality, ability, and perhaps especially, class. Overall, as this book deploys it, queer inquiry is well-placed to address the unjust conditions and livelihoods of people affected by (neo-)colonialism, economic divides between global North and South and the transnational asymmetries of globalizing processes. Because of queer's 'radical requirement to question normativities and orthodoxies' (Browne 2006), queer linguistics must be understood as agitated, upset; dissatisfied with the inequalities caused by global economic orthodoxy, and attuned to its semiotized, mediatized legitimation.

Queerness is as affective as it is transformative - as dependent on orienting to one's emotions as it is on orienting to a political or theoretical position - and for me, queer linguistics has a utopian and aspirational nature. The work of the theorist Jose Esteban Muñoz is key, in this respect. For Muñoz (2009:1), queerness is at once an agitation and dissatisfaction with what we have, and an abstract longing for something else; 'that thing that lets us feel that this world is not enough, that indeed something is missing'. Queerness is in Muñoz's terms as much of a challenge to embrace feeling - hope - as it is a determination to engage in sustained and meaningful critique. Queer encourages scholars to conceive of new ways of being, becoming and thinking; of thinking the world into being. And nearly two decades ago, Barrett (2002) recognized that it offers a great deal to sociolinguistics:

[If] our desire is to truly understand the role of language in society without simply reproducing cultural ideology (and the prejudice, exclusionary practices, and methods of social domination inherent in that ideology) then queer theory might indeed prove to be very important.

(Barrett 2002:39) 
Barrett's quote reveals why he and other language scholars seek to introduce queer perspectives: a desire to avoid reinforcing marginalizing or exploitative ideologies, by studying the relation of semiosis to those ideologies. Nevertheless, scholars vary in how they approach 'queer linguistics' as a field. In Motschenbacher and Stegu's (2013:521) description, it rather simply 'provides analyses of language data that are informed by the insights of queer theory [and is] the most prevalent paradigm within the larger field of language and sexuality studies'. However, what exactly do the 'insights of queer theory' prompt within studies of language? In my view, a rather too broad theorization of 'queer linguistics' may be insufficiently attuned to queer theory's deep-seated perspective on material (re)distribution, and therefore ignore the manner in which normativity - both hetero and homo - manifests through political-economic structures like market globalism. These matters of queer political economy - the nature of 'homonormativity' - round out this second pillar of my theoretical framework. Before I move on to the third, I close this section by situating myself in this book, as a queer man, and scholar, with regard to the mediatized landscapes of global queer mobility.

Hall's (2013) cogent 'revisiting' of queer linguistics' relation to queer theory discusses the 'new intelligibility' of sexual others vis-á-vis heteronormativity, and the importance of 'communal imaginings' as a fulfilling source of intersubjectivity. In other words, she notes that queer people are always engaged in normative practices of identity-formation - they always desire identity, if unpredictably, and in non-essential forms. In Hall's (2013:636) words, 'identity just is'. She suggests that whatever queer linguistics can become will inevitably be at odds with queer theory, because of the latter's insistent anti-identitarian stance. She is rightly concerned that strident queer critiques of identity might ignore acts of subversive identity, and 'the subjectivity of those [that research] was initiated to defend' (Hall 2013:640, cf. Wiegman 2012). Notwithstanding Hall's (2013) apt comments about the (institutionalized) 'disciplinary normativity' imperilling queer critique, however, this book's analysis relies upon an understanding of normativity which differs from that of many professed queer linguists. Particularly, this book adds texture to multiple 'senses' of the concept of homonormativity (Motschenbacher forthcoming), by underlining queer theory's roots in both the critique of normative identity and of normative political collectivity. I am here inspired by the words of Michael Warner, from a landmark piece of queer theory:

Every person who comes to a queer self-understanding knows in one way or another that her stigmatization is connected with gender, the family, notions of individual freedom, the state ... consumption and desire ... class identity ... and deep cultural norms about the bearing of the body. Being queer means fighting about these issues all the time, locally and piecemeal but always with consequences ... Queers do a kind of practical social reflection just in finding ways of being queer.

(Warner 1992:xiii) 
Twisting Hall's (correct) observation above, somewhat, queer is not just identity; as I see it (and feel it), queer research is undergirded by reflection 'on the conditions that make the current practices of queer politics possible' (Warner 1992:xvi).

Clearly a central focus of critique within queer scholarship, normativity manifested in queer scholarship first as a way to challenge heteronormativity: paying attention to axes of discrimination in sexual practice and intimate life, and reflecting upon the ways that sexual identities, desires, and practices are made to seem 'normal', i.e. normativized. As the name suggests, heteronormativity is linked to the inscription of heterosexuality as an unmarked form of sexuality (and the male/female gender binary as essential). What term, then, can scholars use to describe the emergence of normativity in queer individuals? Motschenbacher and Stegu (2013), Hall (2013), and Koller (2013) suggest that homonormativity might be an appropriate cover-all term for the process whereby notions of sexual alterity become normativized. In this regard, Koller (2013:574) describes homonormativity as 'non-heteronormative discourses paying lip service to performative and fluid notions of identity but lapsing into fixing alternative identities in a normative fashion, privileging certain identity performances and marginalizing others'. It is important to note that I share Koller's 'disillusionment' with these practices. Homonormativity, however, is a contested notion. Prior to these linguistic engagements with the terminology, 'homonormativity' had been formulated as by Duggan (2003:50) as the development of an assimilationist LGBTQ politics, 'that does not contest dominant heteronormative assumptions and institutions, but upholds and sustains them while promising the possibility of a demobilized gay constituency and a privatized, depoliticized gay culture anchored in domesticity and consumption'. 7 This is now a commonly cited definition within queer theoretical literature, but Motschenbacher and Stegu (2013:525) have provided a number of reasons to dispute this definition, from the morphological to the anti-assimilationist (see also Motschenbacher forthcoming). Most importantly, in the latter, they assert that assuming an anti-assimilationist mindset for all gay men and lesbians is questionable, and point out that 'assimilating' into a normatively white, middle-class lifestyle can in fact directly challenge the heteronormative status quo. For this reason too, Brown (2009, 2012) claims that the concept denigrates 'ordinary' lives. Hall (2013) agrees with these points, arguing that Duggan's explication of the term is 'puzzling'. Simplifying homonormativity to mean to 'the appropriation of heterosexual normativity', she asks, if the concept is 'owned by heterosexuality, what should we call these kinds of normativity?' (Hall 2013:637). I would suggest that the more pertinent questions for politically motivated queer linguists are rather: how do these two senses of homonormativity cohere in contemporary discursive practice? What norms guide the intersubjective, mediatized formation of globalized LGBTQ lifestyles? How are these norms exclusionary? Echoing Sara Ahmed again, what does a politically and economically normative 'language of love' achieve, and enact within LGBTQ lives? 
Although Duggan's (2003) terminology is specific, I would dispute the contention that her definition is restricted in its specificity; i.e. linguists' complaints that it does not simply denote practices that construct certain forms of homosexuality as the norm. In fact, I believe it does precisely that by describing 'the sexual politics of neoliberalism' within the context of the totalizing politics of banal globalization. Leaving aside the fact that Duggan's conception of homonormativity is more nuanced than 'the appropriation of heterosexual normativity', an assertion that 'heteronormativity' simply means 'heterosexual normativity' elides the fact that Warner's (1992) popularizing discussion of the topic was explicitly political. (Note, too, that Duggan explicitly remarks that homo- and heteronormativity are not parallel; that one riffs from the other, but they are not equivalent.) As the extended quote above shows, Warner viewed struggles over sexuality as intersecting with normative arrangements of social institutions; with economic conditions, freedom, and the lived body. To be clear, however, queer studies has often left it there: at the de rigueur, nominal listing of class as an index of structures of oppression; i.e. 'race, gender, class, etc.' (Brim 2020). Although well-established scholarship on (late) capitalism and LGBTQ identities the material foundations of 'sexual citizenship' (and the classed dimensions of homophobia) (e.g. D'Emilio 1983; Hennessy 2000; Evans 1993; Field 2016) open up discussion for studying struggles for queer liberation as material, queer scholars too often 'mark ourselves in queer terms as we unmark ourselves in class terms' (Brim 2020:16). This tendency, perhaps, is reduced in the work of scholars of colour like Muñoz, for whom queerness is essentially about hope for the future, building a 'collective temporal distortion' and '[vacating] the here and now for a then and there' (Muñoz 2009:185), precisely because of how the 'pragmatic presentism' of mainstream politics ignores redistributive concerns. Likewise, with queerness is understood as 'mess, disgust, dirt, and chaos', Manalansan (2015) describes other ways of being global for peripheral migrant queers, besides the metro-normative, upwardly mobile, affluent 'global gay' lifestyle (cf. Altman 1997, see also Benedicto 2014).

Overall, while queerness has not always lived up to the materialist aspects of its aspirational origins, there is not denying the fact that scholarship in queer studies can and does engage with the global political-economic articulations of hetero- and homonormativities. There is no reason, necessarily, to see normative consolidations of sexual identity as any more the focus of queer critique than the normative consolidations of politics that make those identities manifest (echoing Jagose, above). Thus, we shouldn't deny opportunities for queer to be 'queered from a prior usage', redeployed anew (or not-so-new) as the study of sexual identities governed by consolidations of a totalizing politics (neoliberalism, as an example). Within queer linguistics, Milani (2018:23, following Mieli 1980) has recently made similar points with regard to the utility of queer studies in 'a critical monitoring of how capitalism incorporates non-normative identities and desires in order to reproduce itself. If understanding 'the messy art of being global' or the insolvency of 'presentism' rewards attention 
to political economy, then so too might the study of global queer mobilities. As I make clear in this book, understanding \#LoveTravels and the allure of Chad and Scott's mobile lives can benefit from the integration of Duggan's 'sense' of homonormativity, rather than dismissal (pace Lazar 2017). Mine is a class-conscious queer critique: not just of LGBTQ people's 'appropriation of heterosexual normativity' but of the ways that mediatized homo-norms allow neoliberal institutions to 'govern through liberty' (Dardot and Laval 2013: 11; Martín Rojo and Del Percio 2019). To exploit, through the allure of liberty.

Following Butler (1997b:40), 'struggles to transform the social field of sexuality ... cannot be understood without an expansion of the "economic" sphere itself to include both the reproduction of goods as well as the social reproduction of persons'. And as Duggan (2003:3) recognizes, 'neoliberalism was constructed in and through cultural and identity politics and cannot be undone [without] analyses that respond directly to that fact'. Therefore, the 'depoliticization' Duggan speaks of is not a lack of politics entirely, but rather an iterative shaping of political action in support of what she (and I) consider an insolvent, non-transformative politics. These are the politics on display in contexts such as Wilton Manors, Fort Lauderdale, described in Motschenbacher (2020). While, certainly, Wilton Manors (and De Waterkant in Cape Town for that matter) is notable for the ways its 'gay signage' carries 'a novel form of predominance that possesses a confrontational value' (Motschenbacher 2020:41), I do not think this should be seen simply as politicized action; but rather as politicized action that conditions the potentiality of queer politics (echoing Warner, above). In my impression, certain modes of depoliticization are inherent to the intelligibility' of sexual identities seen in local and national imaginings (Hall 2013). It is not that we, as scholars or queer people, cannot celebrate LGBTQ identity or pride practices; it is that we have an obligation to call out the imbrication of our own 'regimes of the normal' with unjust economic orthodoxy (Warner 1992). In simply defining heteronormativity as 'the discursive construction of certain forms of heterosexuality as natural, normal or preferable' and back-forming homonormativity as 'practices that construct certain forms of homosexuality as the norm' (Motschenbacher and Stegu 2013:520), my (humble) concern is that queer linguists re-articulate (and reinforce) a politics that constrains the true potential of queer inquiry. My argument in this book is ultimately about charting the relationship between localized 'normative' politics like those seen in metropolitan gay villages and across the Western semioscape, and their concurrent status as a globalized politics of 'non-performativity' described by Ahmed (2012): a politics I see campaigns like \#LoveTravels exploiting. But I have a lot of ground to cover to reach this point. And on the way, I seek to avoid re-articulating my own 'unmitigated normative stance in favour of antinormativity' (Milani forthcoming).

There is no question that homonormativity requires a nuanced perspective, bearing in mind LGBTQ people's potential to resist unjust power structures, or embrace certain relations of power for strategic ends (cf. Lazar 2017, for an enlightening study of the tactical repurposing of homonormative and 
homonationalist discourse). Studies by Smith (2016), McDermott (2011), and Oswin (2005b) index this nuanced perspective through studying the expression of LGBTQ identities, both normative and transgressive, in peripheral spaces. Furthermore, studies such as those by Badgett et al. (2014) and Carpenter and Eppink (2017) show that economic conditions for queer people are still broadly precarious - and the success of one identity group does not benefit the LGBTQ 'spectrum' writ large. Motschenbacher's (forthcoming) description of the multiple 'senses' of the term is an appropriate one; it makes sense to highlight how homonormativity is 'invariably a phenomenon that is valid at the local level, namely in contexts in which heterosexuality is not the unquestioned norm'. That is why Brown's $(2009,2012)$ criticisms are compelling. Broadly, Brown (2009:1497) is concerned about how theorizing homonormativity as uniform, all-powerful neoliberalism in intimate life and applying it to 'mainstream expressions of lesbian and gay culture ... [might] stoke its discursive power'. He rightly notes how 'mainstream media portrayals' problematically centre the figure of the 'affluent gay customer', and acknowledges the complicity of 'ordinary' gay lives in 'ordinary' locations in neoliberal violences. $\mathrm{He}$ also asserts the 'importance of being ordinary' (Weeks 2007:9), rightly cautions against ascribing one bold political-economic framework across uneven spatial contexts and encourages scholars to reflect on how the 'homonormative' gay citizen may still establish quotidian relations of queer interdependence. However, at no point does Brown $(2009,2012)$ clarify exactly what counts as 'mainstream' or 'ordinary' in the global North countries he names (to say nothing of elsewhere), nor does he consider in detail how neoliberal media might progressively alter our subjective response to capitalist logics, and impede our recognition of them as anything other than 'the way things are' the 'mainstream'. Even though he and his metropolitan habitat are disavowed, the unspoken protagonist of Brown's $(2009,2012)$ defence is still a man, living an 'urban gay life in the global North' - is it really so unfair to point to how this life is sold as 'ordinary' and desirable (cf. Ludwig 2016), and how its 'mainstreamness' has political-economic consequences?

Overall, I agree that we should aim to 'transcend binary oppositions of homonormative gay life and transgressive, resistant queer lives, by recognising the complicity of all gay spaces in the reproduction of a range of normative practices (not limited to those directly related to sexual norms)' (Brown 2009:1508). Still, this book seeks to particularly highlight how economic injustices might be concealed through the iterative acts of identity (and collectivity) of 'mainstream' LGBTQ people as these identities are built (whoever, wherever they might be). ${ }^{8} \mathrm{I}$ am interested not just in the quotidian ways in which figures like Chad and Scott engage in acts of mobilized queer interdependence - homonormative or not - but in the ways that media texts like \#LoveTravels compel these acts of solidarity to emerge in particular ways in their audience. This is where theories of mediatization become key. I seek to underline the fact that any discussion of normativity in the current day, and especially under a rubric of 'queer', is obligated to understand that any normativity, however 
subversive it is, must still be understood as an effect of disciplinary power, of governmentality (cf. Foucault 1978) - through the market, state, and in small moments of intersubjective identity formation. Challenges to normativity are thus innately tied to questions of political economy, which in the current day are innately scaled transnationally, via the all-encompassing free-market rhetoric of globalization. In this respect, 'to place queer politics under the label of a purely "cultural" politics of identity/recognition' (as Motschenbacher and Stegu 2013 seem to) denies that 'queer analysis addresses political economy, material life, and the history of modes of production and reproduction, at the centre of analysis' (Duggan 2003:83; Butler 1997b). Duggan's (2003) conception of homonormativity provides a way to describe the interplay of semiotic, affective, and material conditions in globalized queer lives: 'homonormativity derives its power not simply from the material wherewithal of its proponents, but from its ability to shape desire by making itself synonymous with modernity, giving it mass appeal or, in a word, hegemony' (Rao 2015:42; my emphasis). It exposes, therefore, the disciplining role of liberatory, individualist discourse the hidden effects of queers' so-called 'folding into life', much in the same way that Puar (2007:36) has exposed the darker, nationalist face of queer liberation in the United States and Israel.

While engaging in queer theoretical analysis, a scholar's complicity in the object of critique (cf. Oswin 2005b) presents a challenge to many of the strongest traditions and pedagogies of academia. That is, queer scholarship 'disrupts and challenges the received "here-and-now" wisdoms of academic theory and promotes a more self-reflexive, openly subjective role for the scholar' (Thurlow 2016:490). Its 'disturbing' of definition, to quote Fabrício et al. (2014) again, is a vigorous challenge to dichotomies of urban/rural, elite/working class, margin/centre, cosmopolitan/traditional, educated/uneducated, and North/ South. In this respect, queer scholarship is ipso facto the study of mobilities. However, while the intersections of globalization and queerness have already been studied in some detail, some time ago (e.g. Altman 1997; CruzMalavé and Manalansan 2002; Boelstorff and Leap 2004), queer movements and trajectories through globalized space are less theorized. As Oswin (2014) suggests, 'new' mobilities research has tended to neglect sexuality and queer subjectivity, at least as a critical concern. How might queer research begin to account for mobility, including the inherent mobility (and privilege) of academic practice? As a first step, I would suggest that queer scholarship, including attention to queer mobilities, behoves mobile queer scholars to embrace their 'trouble-making' instincts and subjectivity - to disrupt the normativity present within academic frameworks and methodologies (Adams et al. 2014; Thurlow 2016). This disruption is, importantly, carefully measured. As Cameron, et al. (1999:141) remind us, 'even the most iconoclastic scholar is always in dialogue with those who went before'. Ultimately, however, the trouble-making instincts invite me - or rather compel me - to make myself, my own mobility, a part of my analysis. Specifically, I am open to forms of autoethnography as a queer method, as one way of taking up Hall's suggestion of ethnography 


\section{Introduction}

as a way to the capture 'semiotic flux', wherein 'even the most vociferously articulated anti-normative positions produce their own normativity ... [and how identity] emerges in all interactions, even very queer ones, in fleeting and often unpredictable ways' (Hall 2013:636).

As a globally mobile academic who moved from Australia to Switzerland and visited South Africa through my research, I am undoubtedly complicit in homonormativity. It is through doing a mobile, privileged, but marginalized life that I have become 'queer' and not simply bisexual (itself a somewhat marginalized space), that I have embraced queer politics, and eventually chose to research queer mobility. My sexual identity has an indelible impact on my orientation to the world and love of travel - and arguably, prompts me to 'think otherwise' (Pennycook 2012) about my place in it, as a materially privileged traveller (a 'tourist' in Bauman's terms). That is how I got here. In the words of Adams, et al. (2014:8),

if our task as [social scientists] ... is to study the social lives of humans, then we cannot relegate elements of human lives or experiences to the periphery nor can we bracket out the ways our lives and experiences are intertwined with our research projects.

The reasoning for the personalized voice I adopt throughout this book is therefore clear: my argument is about people like me. Or perhaps more accurately: people I am compelled to consider like me, and people I am compelled to desire to be like. I write this book in part out of a desire to understand my desire to belong - to excel - at the living of a proud queer life, worldwide. To be 'enworlded', to feel belonging in a world that's my own. Thus, in adopting a 'queer' positionality, I open myself up - if only partly - to critical reflection on the homonormative limits of my own global mobility, to rework Oswin's (2014) expression above.

'Queer' indexes an opposition to that which is 'not enough' (Muñoz 2009). It offers a way to challenge the banal representations which insist on a unidirectional path to progress - currently, one overwhelmingly mediated through the individualist logics of neoliberalism. Within this totalizing habitus of neoliberal capitalism, it is increasingly challenging to discern the norms of market society from the norms of intimate life, and I now seek to elaborate on this point. This brings me to mediatization; this extent to which Western queer subjects are deeply affected and guided by media texts, often to some degree reliant upon them to forge their own way in the world. My theoretical framework is reliant on the fact that 'as the media become resources for the development of lifestyle and moral orientation, and for sustaining social relationships, they serve to reproduce and renew the habitus of the individual' (Hjarvard 2013:152). The conclusions drawn in this book depend upon an understanding of this mediatization of habitus: the mediatization of cosmopolitan LGBTQ lifestyles; or as I call it, the mediatization of equality. 


\section{Language commodification and the mediatization of social (and sexual) life}

Modern media are increasingly flooding our lives with an unprecedented array of social and sociolinguistic representations, experiences and values, to the extent that (to put the case negatively) it is inconceivable that they have no bearing on how individuals and communities position themselves and are positioned sociolinguistically.

(Coupland and Kristiansen 2011:31)

The above remark by Coupland and Kristiansen provides a neat introduction to approaches to mediatization: a concept with great currency in recent sociology of the media, sociolinguistic, and linguistic anthropological research (see Deacon and Stanyer 2014 for a summary, and criticism). Mediatization is central to the claims made in this book, as the globalizing mechanism through which decidedly neoliberal discourses of equality are produced, organized, and distributed. In so doing, I align myself with those who have studied the increased commodification of language and semiotic processes in late capitalism (cf. Heller 2003, 2010; Duchêne and Heller 2012). The broader strokes of mediatization theory/ies, as employed in this book, provide a way to link textual practices to wider political economies: to articulate the ways that commodified 'tokens' of language and discourse are legitimated through the media, and to describe the cumulative impacts of individual and collective reliance on commodified media. Coupland and Kristiansen, above, foreground mediatization as a notion that describes how media 'position' individuals and communities. Similarly, in this book my focus is on media as it impacts everyday habitus - our 'enduring orientation to how to make sense of the world and what to value in it' (Heller and McElhinny 2017:210) - with specific regard for the representation of globalized LGBTQ lifestyles. In other words, my focus is on accounting for how global queer mobilities (their form, value and meaning to individuals) are oriented by and through media.

Some time ago, under the influence of Bourdieu, scholars of language began paying attention to language as a form of symbolic capital, arguing that 'the study of language needs to be framed in terms of not only the making of meaning, of social categories (or identities), and of social relations, but also the political-economic conditions that constrain the possibilities for making meaning and social relations' (Heller 2010:102; Gal 1989). Language was thus no longer understood primarily as a marker of ethnonational identity, but also as a marketable commodity. Linking this process with globalization, Heller describes how language-as-commodity is inflected by, but distinct from, identity: a way of reinforcing and negotiating imagined communities, at a time when globalization has brought about a 'tension between local solidarities and transnational affiliations' (Heller 2003:489). Studies of language and society have made great strides in advancing non-essentialist discussions of language as a resource, noting, for example: the value of certain linguistic styles in certain 
workplaces (e.g. Cameron 2000), the production of valuable linguistic forms/ styles as material commodities (e.g. Jaworski 2015a; Thurlow and Jaworski 2017a) and the widescale circulation of linguistic forms in a deregulated, neoliberal, market globalist arena (e.g. Shankar and Cavanaugh 2012). However, by that same token, scholars of language also undertake research into the ways there is value in uncertainty and vague linguistic forms. Urciuoli (2003), for example, examines the ways liberal arts education finds value in the strategic deployment of 'shifting' meaning - of intangibility, in the feel of language. Thurlow and Jaworski's (2017a) aforementioned notion of 'word-things' has deftly pointed this discussion toward matters of global inequality, arguing that the 'thingification of words' and the 'wordification of things' allows elite status (seemingly, its effortless attainment) to be promoted and packaged for consumption (following Lash and Lury 2007). In this book, in so many words, I advance this discussion by considering the ways that LGBTQ people find great value in the uptake of certain discourses of identity and equality - despite the fact that the underlying value of these forms is in their indeterminate or sloganized nature.

Overall, I adopt a holistic definition of mediatization, using the term to refer to institutionalized and commodity-driven processes of mediation and communication, which are increasingly prominent in the mass-mediated contemporary era. Though the ambiguity of the notion draws criticism from Deacon and Stanyer (2014), for whom it risks being a 'conceptual bandwagon', I follow Hjarvard (2013:1) in asserting that 'mediatization has proved useful to the understanding of how the media spread to, become intertwined with, and influence other fields or social institutions'. One of these social institutions is language itself; the ubiquity of media affects how we speak, are spoken to and converse across society. Thus, my holistic understanding links two senses of mediatization. Firstly, I take up media scholars' definition of mediatization, approaching it as a meta-process relating to the general expansion of the scope of media production and affordances of media. Secondly, in the vein of CDS and linguistic anthropology, I am also especially interested in examining how this 'accrual of power' affects which language forms are curated, encouraged, and circulated in mediatized contexts. This approach pays closer attention to late-capitalist processes of language commodification, and the concurrent increase in media forms' dissemination, recontextualization, and 'uptake' in everyday social interaction (Agha 2011b). I seek to explore how particular social worlds and personages become salient and attractive and how acts of intersubjective identity formation are affected by the representational choices of mediatized objects: e.g. advertising, news or social media (Agha 2011b). For linguistic anthropologists, mediatization is the 'ever-present backdrop' linking communication with commodification: in which an act of identification 'hails' a consumer, iteratively creating identities to dis/affiliate with, and along the way, sanctioning the social and political-economic contexts buttressed by such identity formulations (Agha 2011b:165; following Althusser 1971). Hence, mediatization is useful as a way to hone in on institutional and community 
practices with media: how do individuals and communities (re)inform and (re)inscribe the power relations seen in mediatized representations? In this book, it is therefore not a 'bandwagon' concept which understands 'the media' as a kind of external, malevolent technology (cf. Deacon and Stanyer 2014), but rather a concept which guides research into the uptake of certain linguistic forms: valuable for the media producer, and desirable for the consumer.

Mediatization is relevant to this book's analyses in two key respects. The first of these is found in the spatio-temporal orientation of LGBTQ subjects: their subtle conditioning to what I call an anticipatory chronotope; the mediatization of the future (following Park 2018). I outline this process in more detail in the following section. Secondly, with media central to habitus formation in late capitalism, I also see mediatization as impacting (i.e. disciplining) both how globalization is conceived by LGBTQ subjects, and how proud, queer identity is conceived by globalized LGBTQ subjects. These two impacts sit at the core of the larger discursive formation described in this book: the mediatization of equality.

A central claim of this book is that a mediatized (visual) language nowadays orients the audience of globalized media to particular social meanings about 'the globe' itself. How much, of course, will depend on individuals' own psychology and sociopolitical context. However, as Coupland and Kristiansen (2011) assert, it is 'inconceivable' for it to have no bearing at all (recall Frello's comments above: we are on the move whether we like it or not). Mediatization is not a technologically determinist concept (cf. McLuhan 1964). However, it does seek to capture media affordances; those allowing powerful institutions to rhetorically produce the world, as they see fit - e.g. as a landscape of globalization and global citizenship (cf. Bourdieu and Wacquant 2001). This framing accords with Boelstorff and Leap's (2004:5) understanding of globalization as a consequence of 'qualitative changes in technology and social relations that fundamentally transform the relationship between space and subjectivity'. Mediatization thus provides a way to describe how consumer media articulate the world as a whole, and how consumer subjects (re-)articulate themselves in the same terms. The implication with regard to globalizing discourses of LGBTQ rights is that media about LGBTQ identity and activism not only help inform subjects as to what LGBTQ identity/ies is/ are, under conditions of both disciplinary power and self-reflexive uptake, but also inform them of their rights as citizens, their cosmopolitan positioning, and how they may in turn help distant LGBTQ others to assert these rights. In fact, it establishes that very possibility in the first place.

Globalization is both real and rhetorical: manifest increases in the scope and intensity of transnational mobility run concurrent to symbolic justifications for the global liberalization of a capitalist marketplace (Bourdieu and Wacquant 2001). And, in the aestheticized economy of late modernity, it is 'inconceivable' that media institutions do not have a great deal of influence on how this rhetoric is taken up, invested in and (re-)circulated daily. The aforementioned cosmopolitan trope of the 'global village' coined by McLuhan 
(1964) can help outline this process in more detail. This term, as Chouliaraki (2006:27) summarizes, is 'a metaphor for the world being a place where all can be connected in a single community by means of the coordination of viewing action rather than the message of communication itself. It is an imagined 'we', united via processes of globalized mediation (e.g. television) as a communitarian whole, regardless of the message of any particular media. This is a simplistic view, given that McLuhan's assertion erases agency: that which is required for media technologies to do anything at all. However, scholars such as Chouliaraki (e.g. 2006, 2010, 2013) and Iqani (2016) provide a better-theorized account of the potential of media to encourage an ethical/communitarian perspective, 'in which human agency is invited into explicit dialogue with global inequalities and injustices, [in which] media discourses function to produce spaces in which cosmopolitan worldviews, and actions flowing therefrom, are more possible' (Iqani 2016:20). Within this context, the 'global village' can be considered not as a possible outcome or actuality, but rather according to its value as a semiotic resource, a textual artefact that may be invoked in media in order to bring something like a 'global village' into being.

In late modernity, the cosmopolitan content of Western media interpellates its viewers as cosmopolitan citizens: 'spectators' of globalized political and cultural upheaval, and 'grazers' on generalized forms of otherness (cf. Chouliaraki 2006, 2012, 2013; hooks 1992). It is in the course of an 'ordinary' life as a privileged, Western cosmopolite that globalized media grant legitimacy to a perspective on the world in which we are 'connected' to distant others - a 'village'. As Zygmunt Bauman has remarked (quoted in Ong 2009), this is why we now face a moral problem where our 'artificial eyes' enable us to see parts of the world we never could, without the 'artificial hands' to help change any part of the world. From some critical perspectives, globalized media legitimate the dominion of those with these 'artificial eyes' over those without them - through a teleological narrative of a world that necessarily progresses or advances in a certain way. Here my point is not particularly related to claims of hegemonic 'McDonaldization' of the world. Indeed, with regard to queer subjects, 'globalization appears to be making the world more different just as much as it is making the world more the same' (Boelstorff and Leap 2004:18). The starting point for this book's analysis is the simple fact that the mediascape from which people draw their relations to the world (and the semioscape through which the world is communicated) is nowadays a profound influence on the ethical and economic dimensions of individual habitus.

Many scholars of globalizing processes have advocated for thoroughgoing empirical accounts of how these processes take on the scale they do: not just in terms of GDP or migration flows, but as a powerful rhetoric, as an affecting, indelible part of people's pre-reflexive orientation to the world. Global studies needs accounts of how 'the globe' adheres to identity - how cosmopolitan mindsets are instilled. Through critical discourse-ethnographic methods in this book, undergirded by queer reflections on my own mobility, I hope that I can shed light on "how the media spread to, become intertwined with, and 
influence other fields or social institutions' (Hjarvard 2013:1). I also hope that my reflecting upon and 'troubling' of identity might pave the way for alternative ways to imagine LGBTQ identities and futures to those that are currently provided by media (Muñoz 2009). Ultimately, I am unsure that the 'language of love' through which I meet Chad and Scott (and feel bonded to their family) charts a way forward for queer lives. Despite my great respect for these men, I am unsure that an equitable future can be found in a media- and semioscape which heralds their travels as a vision of progress, and endears a global audience to strive for their social position: as full, authentic selves; as proud, mobile, and free.

The last step in describing the mediatization of social life is accounting for how it relates to a purported 'global gay' community (cf. Altman 1997), and the construction of an identity for that community: a lived habitus. I would argue that figures like Chad and Scott can be seen as 'paradigmatic personae', from which Western visions of equality are ongoingly (re)built (following Agha 2011a). Seeing 'love travel', seeing this loving family 'stay as they are', one cannot help but be oriented toward them. As a queer man, campaigns like \#LoveTravels condition me to want a life like Chad and Scott's, in all its intimacy, if not all of its lavish detail. If not their hotel suite, or Olivia's paper plane, or the children at all, then I am at least steered toward the potentiality of these mediatized tokens of global queer mobility; of freedom, wealth and love in motion. My argument here is that Chad and Scott and the other (mostly white, mostly male) Western LGBTQ subjects encountered in media function as marketable 'figures of personhood': representations of 'perceivable and performable behaviour' (including language) that emerge through semiotic processes, and 'actual persons oriented to [these representations] through such processes over specific demographic and spatiotemporal scales' (Agha 2007, 2011a:173). A figure of personhood can be the represented 'globally mobile queer' like Chad or Scott, and the actual figure who invokes that abstract representation - the 'I' whose love travels when they're riding in a Boeing, or soaking up Cape Town. According to Agha (2011a:173), once abstracted, a figure of personhood may be depicted through/as: 'a term of address ... a market segment ... [an object] of sexual desire ... [a bearer] of taste and refinement, or ... those who are prototypical icons of "cool", The mediatized depictions encountered in the course of this book exemplify all of the above. Agha (2011b:173) goes on to explain that such figures can be 'functionally effective as a normative ideal for some, [and] as a counter-model for others'. To be clear, there are many 'countermodels' to figures like Chad and Scott out there in globalized media - both mainstream and marginal forms of intersubjective 'communal imagining' that index alternatives to the globally mobile queer (Hall 2013). In this book, however, I focus my attention on the nature of mediatized figures as 'normative ideals', and specifically, on how icons of proud, mobile LGBTQ identity can serve performative functions: as semiotic resources for political ends that are both overwhelming, and simply not enough. Thus, my analysis 
apprehends mediatized figures like Chad and Scott not simply as stereotypes, but as legitimate representations of a desirable better world in-becoming, upheld as aspirational prototypes of progress. Queerly, the conclusions I draw rest precisely on taking matters of desire into account (cf. Thurlow 2016). The contemporary mediatization of LGBTQ habitus crafts a vision of equality that is not only politically powerful, or historically significant. It is also extremely alluring.

In the words of Iqani (2016:19), "without the rise of media in all their analogue and digital forms, without their form and the messaging that they were and are able to facilitate, arguably the world would not be nearly quite so global', and this is certainly true of the purported LGBTQ community. Media of/about mobility have been a fixture of the emergent gay scene since the mid20th century. For as long as they have been legible as a 'community', the media which describe queer cultures have assisted in embedding the view that they are a group of people defined by their movement away from or exteriority from home. As Warner (1992:xvii) further notes, their 'institutions of culture-building have been market-mediated: bars, discos, special services, newspapers, magazines, phone lines, resorts, urban commercial districts'. To some extent, it can be said that LGBTQ habitus has thus always been linked to capital, built through inchoate processes of mediatization (or at least susceptible to them). Arguably, because of that history, one could argue that it is particularly susceptible to the allure of neoliberalism as a totalizing rationality (cf. Dardot and Laval 2013) and thus susceptible to the critical definition of 'homonormativity' suggested by Duggan (2003). Regardless, within a 'world of flows' - 'a new global cultural economy ... a complex, overlapping, disjunctive order' (Appadurai 1996:32) perhaps all habitus is now linked to fast-paced, interdiscursive processes of identification, self-authentication, status-seeking, place-making and future-building. As Appadurai (1996:55) puts it, "where once improvisation was snatched out of the glacial undertow of habitus, habitus now has to be painstakingly reinforced in the face of lifeworlds that are frequently in flux'. To put it simply, however, in this world on the move, queer identities are among the shiftiest, most explicitly performative and intensely mediatized - and often willingly so. If only because seeing people like Chad and Scott in consumer advertising is still rare, mediatized representation (pure recognition, cf. Fraser 1995) is often celebrated as progressive, even revolutionary. To use Appadurai's (1996:55) words again, 'ordinary lives today are more often powered not by the givenness of things but by the possibilities that the media (either directly or indirectly) suggest are available'. In this respect, Chad and Scott are an emblematic statement of a successful future that could be - for me, or for any other non-heterosexual person.

With mediatization in mind as 'institutional practices that reflexively link processes of communication to processes of commoditization' (Agha 2011a:163), it is possible to provide a detailed account for the rhetorical production of both globalization, and certain dispositions of a 'global gaze' (cf. Altman 1997). In other words, in studies like this book, we can pinpoint how banal texts - e.g. '\#LoveTravels', or texts about 'diversity' or 'the true meaning of unconditional 
love' - hold value through their mediatized deployment as tools in the formation of globalized, individualized habitus. It is these texts' currency as a means of shaping the social world around us - and of cementing that shape of the world as the ideal one - that behoves us to apprehend them. This is because institutional media, whether in the form of advertising, tweets or outreach emails, are nowadays society's most significant and captivating storyteller about society itself (Hjarvard 2013). Media tell us who and where we are, and where we're going, and attention to mediatization thus offers a useful perspective for analysing how a cosmopolitan future is chronotopically constructed in a time of globalized neoliberalism (see Park 2018). As well, however, mediatization theory obliges critical scholars to take the covert details of a purportedly bright future into account, and grants them a responsibility to highlight what, or who, is absented in representations of a time and place free from heterosexism. I see mediatization as a heuristic meta-framework for understanding media, language, and other semiotic forms as powerful political-economic resources, and these resources as key to the ongoing legitimation of global inequality - even under the guise of 'equality' itself (Heller and McElhinny 2017).

In this discussion of the third pillar of my theoretical framework, I have summed up my perspective on the mediatized mobility of people, politics, and pride, and seeded caution about how media proliferations of commodified intimacy (e.g. \#LoveTravels) might have a negative impact on queer habitus; ultimately, placing homonormative limits on how future queer life can be imagined. I hope to have made clear that I see myself as an ideal object for these kinds of texts - I am allured by them. I am complicit. In the next section, I elaborate on how this book grants perspective on the many ways in which LGBTQ people have been and are 'enworlded', with particular reference to the capricious concepts of scale, chronotope, and genealogy.

\section{Scales, chronotopes, and anticipatory stances: A genealogy of queer 'enworlding'}

Discourses not only represent the world as it is (or rather is seen to be), they are also projective, imaginaries, representing possible worlds which are different from the actual world, and tied in to projects to change the world in particular directions.

(Fairclough 2003:124)

Queerness is now global. Whether in advertising, film, performance art, the internet, or the political discourse of human rights in emerging democracies, images of queer sexualities and cultures now circulate around the globe.

(Cruz-Malavé and Manalansan 2002:1)

These epigraphic quotes from key figures in discourse studies and queer studies are an ideal preface for the theoretical groundwork offered in this section. 
I write this book in the hope that media such as those listed by Cruz-Malavé and Manalansan might imagine proud, progressive queer lives differently against forms of 'fake futurity' (Muñoz 2009). At least, I write in the hope that current imaginings can be repurposed. Indeed, following Fairclough, both the discourses studied here and this book itself are 'tied in to projects to change the world'. Thus, I seek to supplement the extensive theory already covered with a focus on the 'projective' nature of discourses of global queer mobility: especially, the ways they 'enworld' queer people like Chad, Scott, and I to anticipate our belonging in the world to come, and our iterative crafting of that world. How do such discourses inspire 'us' to be a part of something bigger and more meaningful than the local, which may often be a space of pain and oppression? To do so, I outline three concepts (nowadays regularly deployed across the social sciences) which inform this book's study significantly - scale, chronotopes, and genealogy.

Scale is a discursive 'relational procedure that starts with comparison'; grounded in semiosis, and hence ideological (Gal 2016:110). It is not a priori or neutral, however, but is rather itself the product of processes of scale-making: 'institutionalizing projects, in which a particular way of seeing and being is socially enforced' (Carr and Lempert 2016:9; Goebel and Manns 2020). The dimensions drawn by scales, therefore, are organized around particular forms of normativity (Blommaert 2010). Such is the fundamental connection of scaling processes to social life; scale is the basic faculty of human beings, as social actors, to interpret taken-for-granted aspects of life, and ascribe values, dimensions and meanings to them. It is our basic human capacity for orientation, evaluation, and hierarchy, and it affects all aspects of globalized habitus. Indeed, scaling is the procedure that makes the 'global' possible as a spatio-temporal, ideological articulation of the world. In the context of this book, scalar processes constitute the guiding strategy (and moral rationale) for what I argue is a reductive, neoliberal conception of the future for LGBTQ lives. These articulations compel queer people to see their oppression as not simply unjust, but rather (or especially) as unproductive, illiberal, and outdated or backward (even ridiculous). In many respects, it is the lack of recognition of the benefits that justice provides (to individuals and institutions) that is the injustice, rather than oppressive structures and discourses themselves. It professes to correct inequitable outcomes 'without disturbing the underlying framework that generates inequality' (Fraser 1995:82). This, I ultimately argue, is the nature of mediatized LGBTQ enworlding in the current day: envisioning a better future becomes a matter of prompting better recognition of what LGBTQ people provide to a capital-driven lifeworld, rather than transforming society's relations with capital or other axes of inequality. Discourses of 'equality' are thus normativized and sloganized - a matter of marketing that 'opens up the world' to LGBTQ people (scaling their relation to it) rather than complex politicaleconomic debate.

In Carr and Lempert's terms, 'scaled hierarchies are the effects of efforts to sort, group, and categorize many things, people, and qualities in terms of 
relative degrees of elevation or centrality' (Carr and Lempert 2016:3). From this perspective, just as heteronormative orders are one attempt by social actors to hierarchize and elevate particular modes of intimate life, forms of 'proud' LGBTQ niche marketing and anti-homophobia campaigning are others. A belief that LGBTQ livelihoods are safer, more worthwhile or better in Western polities is inherently an act of scaling, because of the inherent value accorded to a life lived safely. Even more fundamentally, a perspective that non-heterosexuality is a legitimate lifestyle for a person to lead is also an act of scaling - for it to be legitimate, it is always scaled in relation to what is not. Of course, these scales are inarguable, and I am not arguing that a Western LGBTQ lifestyle is not worthwhile. Yet, as Carr and Lempert (2016:3) highlight, the "people and institutions that come out "on top" of scalar exercises often reinforce the distinctions that so ordained them'. This points to one of the most hard-to-apprehend aspects of scale-making: once a scale is made and enforced by the powerful, it can only be unmade, or reimagined, with great difficulty. And, because LGBTQ human rights have been scaled globally through institutions of market-led globalization, it is very difficult to de-scale them or reduce their expansiveness - to restrain them to the contexts they emerged in (Carr and Lempert 2016). Through time, and space, a better world and time has been foreseen and is now difficult to unforesee. A powerful chronotope has emerged, in which 'time ... thickens, take on flesh ... [and] space becomes charged and responsive to the movement of time' (Bakhtin 1981:85).

The discourses, discursive strategies, rhetorics, and word-things of contemporary LGBTQ enworlding identified in this book can be understood as 'scale-makers': 'those linguistic signs that point to shifts between chronotopes, comparisons between chronotopes, and/or the expansion of the meaning of, or the ability to interpret, chronotopes among a given population' (Goebel and Manns 2020:83). Scale, in short, is an (or the) apparatus by which chronotopes can be invoked, and reinforced. Many discourse scholars have directed attention at mediat(iz)ed discourses of future selves and future-orientedness, following Agha's (2007) insights on the role of mass mediation on the 'recombination' of subjectivity. According to Agha, following Bakhtin, time is not a 'semiotic isolate' and is understood through the forms of personhood we perceive for ourselves at particular times. Notably for this book, Park (2018) has shown how theories of mediatization are useful for investigating 'interdiscursive chains created between the (imagined) future and the present to induce neoliberal anticipation within subjects of today' (Park 2018:480). With media nowadays orienting peoples' conduct to a significant extent, there should be no doubt that the way people orient to and pre-empt the future in media can be a tool for legitimation - the process by which interlocutors accredit or give licence to social actions (van Leeuwen 2007; discussed in detail in Chapter 4). Hypothetical futures can themselves be operationalized to grant legitimacy to the present circumstances (Dunmire 2005; Reyes 2011). Indeed, as Dunmire (2005:484) notes, evocations of the future can 'prey upon ... the inherent 


\section{Introduction}

ambiguity and indeterminacy of the future in order to influence social perceptions'. While the political actors examined by Dunmire and Reyes 'prey' upon fear about the future, more positive, joyful discourses of affirmation in the future can also grant legitimacy. The institutions described in this book craft multimodally enacted, banally enworlding discourses in which LGBTQ people are not just free, but fulfilled, enriched, in charge. They legitimate a view of the world as limitless and full of possibility, with the implicit caveat that individuals must accede to certain normative perspectives (scales) on the world in order to surpass limitations, or reach possibilities.

As one example: Chapter 4's analysis shows evidence for the neoliberal lifeworld as one where everyone's life is conceived as a journey which rewards innovation, invention and the will to succeed above all else. At Pride and Prejudice (the event I examine) The Economist magazine presented their 'brand story' with a telling remark: 'The Economist provides quality journalism that people are willing to pay for, because once they've been introduced to our view of the world, they can't get enough of it'. The Economist position themselves as anti-ideological, while taking an offensive role in a "war of position" devoted to guarding the invisibility of capitalist interests', defining the parameters of what is common sense, and pivotally, what falls outside it (Cammaerts 2015:534). Pride and Prejudice is a powerful exemplar for the ways in which neoliberal institutions legitimate certain scales and forms of enworlding; recalibrating its ideology to 'make room' for LGBTQ people within, while in a deeper sense fixing them in place, and in time (Park 2018). In effect, the anticipatory stances encouraged by the mediatization of equality - the way it promises the world, in the world of tomorrow - scale the entire globe as a tolerant, liberatory space for LGBTQ people, but only if they surrender to neoliberal logics. The question, for critical and progressively minded scholars, becomes how to articulate these processes of governmentality, as a step in preventing them. Genealogical research - like this book - provides one answer (see also Martín Rojo and Del Percio 2019).

Enworlding in and of itself, like globalization, is neither innately malignant nor needless. There are countless sound arguments in favour of a view of social space which is scaled globally, above the local, through which dimensions validating individual action as part of transnational flows are sketched. All told however, echoing Heller and McElhinny's (2017) strident account of the intertwined histories of language scholarship, capitalism, and colonialism, 'we must create a new future'. The relation between 'mainstream', mediatized LGBTQ enworlding as the focus of my critique, and the queer enworlding I advocate for, is thus not a binary one, as this book's conclusion demonstrates. Regardless, it is certain that we must create altered modes of enworlding from those that exist now, and as part of that, I want to rewrite the story of LGBTQ equality - applying a new lens to how it is perceived at the beginning of the third decade of the 21st century. Ethically speaking, ecologically speaking, there simply is not much time left to do this rewriting. ${ }^{9}$ The time is now. Heller and McElhinny employ the Foucauldian ethos of analysis, genealogy, to provide structure to their 'walk backward into the future', and I wish to frame 
this book in similar terms, as textual analysis that disrupts notions that 'our present modes of being are timeless, essential, and could not have been otherwise' (Anaïs 2013:134; Foucault 1978). In short, Foucault's genealogies are 'histories of the present', a 'how did we get here?', and here I approach them like Heller and McElhinny $(2017: 10)$ as 'stories to be told about how and why ideas ... become important, contested, circulated, powerful, modified, marginalized, and erased'. How has equality (as word and deed, rhetoric, and material condition) become valued in the current day? What is its use?

Genealogies are analyses that disrupt the logic of late capitalism as a logic of anticipation; an anticipatory constriction of the future as a realm of potential (Heller and McElhinny 2017). Following Muñoz (2009), they can be seen as an 'interference of straight time and space', in line with queering as a research orientation. In this book, I argue against neoliberalism's 'governing through liberty', as it takes shape through the word-thing 'equality', and in many respects, this accords with Ahmed's (2010) genealogy of the logics of happiness in the current day. Ahmed's 'killjoy-like' claim is that happiness 'works as an idea or aspiration within everyday life, shaping the very terms through which individuals share their world with others, creating "scripts" for how to live well' (Ahmed 2010:58). Happiness has use; when deployed by powerful political actors, it can involve a 'demand for agreement': a coercion, a capitulation. In this book, I therefore question the 'happy future' envisioned through the mediazation of equality - that enworlds LGBTQ subjects - creating a moral and affective world which is undeniably promising, tempting, and happy. As a form of Ahmed's happiness scaled specifically as equality for queer lives, it creates 'a wishful politics, a politics that demands that others live according to a wish' (Ahmed 2010:2). And just as Ahmed's genealogy examines the 'unhappy history of happiness', I examine the 'unequal history of equality' in the present: the way queers are sold a cheapened, inferior form, oriented to capitulation, governed by the memory of our oppressed past and the promise of unlimited freedoms in a neoliberal world. If current-day queer enworlding scales the world of tomorrow inadequately, we must begin to reimagine it. That is what this genealogy of queer enworlding and queer mobility seeks to do.

\section{Crafting a critical discourse ethnography}

Theory and method blur into one in this book, and both bleed into my own life as someone who would like think of himself as cosmopolitan and progressive. As genealogical analysis, my investigations stem from a desire to recalibrate the mediatized scales drawn between the present and future, the now and then, for queer individuals: historically contingent scales of mobility as pride, identity as consumption, productivity as progress. To do so, I combine ethnographic methods with approaches from within multimodal critical discourse studies (MCDS) to pursue a critical discourse ethnography.

Critical discourse ethnography is a form of reflexive sociology (Bourdieu and Wacquant 1992), deeply committed to an examination of my own imbrication 
(if not complicity) in the operation of discursive formations; here, the mediatization of equality. It is a constant practice of undoing, stepping outside, and questioning of habitus - a sidestepping, that contests my own social fields and networked lifeworld. As ethnography, it builds on a foundation of 'examining social practice as it unfolds, while it happens' (Heller et al. 2018:8) but as I employ it here, it is also deeply personal. While not seeking to over-state my relationship with these men, or the relationship between geographically and socio-economically distant 'global gay' figures, my research is designed to explore the mediatized space between myself and iconized personhoods like Chad and Scott's: people I am compelled to consider like me, and people I am compelled to desire to be like. These figures embody the 'promise' of a world to come. My research is thus unapologetically queer: an autoethnographic, disruptive mode of sociolinguistics, that does not and cannot fit neatly into a rigid dataset or 'end' at the close of a chapter. Its object of analysis and critique is the overlap between the living of life and the discourses being studied: their positives, negatives, and 'mess', their affective-discursive resonance, their allure. In the vein of scholars like Thurlow (2016), then, my aim is to find ways of queering discourse studies; playing with and reshaping it in response to the complex, multi-sensorial and enchanting aspects of (neoliberal) ideological structures. Here I lay a foundation for what critical discourse ethnography entails: firstly, as a form of MCDS; and secondly, as an ethnographic expansion of it (cf. Krzyżanowski 2011) with particular focus on my experiences at two events with global(izing) significance. Finally, and especially, I wish to foreground this critical discourse ethnography as rooted in a reflexive positionality, what Milani (2014) calls the autoethnographic "I" on the scene' in my research.

Discourses are communicated through different kinds of semiotic resources, different modes, and realised through different genres. [At this level] ... many people most frequently experience these discourses as fun, as style, and simply as part of the taken for granted everyday world, even if on other more or less tangible levels they feel their power over them. All these different levels of communicative activity are infused by and shaped by, power relations and ideologies.

(Machin 2013:347, my emphasis)

The italicized elements of Machin's above explanation of MCDS ably summarize the principles grounding this book. Together, the utility of different semiotic resources (and modes, and genres) for the consolidation of power and ideology, as well as the taken-for-grantedness of this process, are core principles I adhere to here. In social constructionist and poststructuralist forms of critical inquiry (especially those following Foucault, e.g. 1972) discourses are the forms of knowledge about the world which emerge from the social contexts of lived reality. This differs from the generalized definition within linguistics of 'language in use'. As many have noted, however, these definitions are profoundly connected: 'practices that form the objects of which they speak 
(or write) are to a significant extent language dependent practices of definition, classification, explanation and justification' (Cameron and Kulick 2003:16). The intelligibility and meaning of language is always socially situated, and critical discourse studies (CDS) is the long-standing analytical toolkit for describing how language is thus a tool for coercion, legitimation, manipulation, quelling of opposition and reinforcement of the status quo.

In the introduction to their landmark account of the theory underlying CDS, Wodak and Meyer (2016) clearly surmise that it does not comprise a single, dogmatic 'school', but rather has manifold internal variations. In this book, I do not necessarily distinguish between these various forms of CDS. I instead align with a broad sweep of methods, concerned to understand how language as a social practice is profoundly linked to consolidations of power through its three essential functions, following Halliday: i.e. the ideational (representing ideas), interpersonal (establishing relationships) and textual (sending coherent messages to recipients) (Fairclough 2001, 2003). My empirically based account of how these functions embed certain sociopolitical standpoints in discourse is then loosely aligned to a three-step process of description, interpretation, and critique/explanation (cf. Fairclough 2001). Following Kress and van Leeuwen (2006) and Machin (2013), I am committed to using these tools for description, interpretation, and critique to draw out buried ideologies in communicative modes beside language. In other words, in MCDS, the focus is on how ideologies are embedded through the ideational, interpersonal, and textual functions of non-linguistic resources like images, music, and typography. It seeks to illustrate how identities, values, practices, and affects are highlighted, concealed, downplayed or legitimated through acts of deletion, addition, substitution, and/or evaluation. Attention to multimodality expands the definition of 'language' to a significant extent. However, more can still be done to adopt ethnographic methods in CDS and sociolinguistics, directing our gaze to the ways social life and its meanings unfold in particular times and spaces (cf. Heller et al. 2018; Krzyżanowski 2011). One claim made in this book is that a genealogy of the mediatized chronotopes of neoliberal governmentality (and queer enworlding) actually require us to vastly expand on our notions on what count as semiotic resources, and what count as texts, with ethnography as a starting point (Thurlow 2016).

In succinct terms from within linguistic anthropology, 'ethnography is the written description of the social organization, social activities, symbolic, and material resources, and interpretive practices characteristic of a particular group of people' (Duranti 1997:85). In this book, I uphold the principles of participant observation that undergird Duranti's definition, but there are two factors that differentiate my research design from 'traditional' ethnography. The first rises to the fore in Chapters 2 and 5, when I focus on my reflections and affects, autoethnographically, as the addressee of mediatized texts. In Chapters 3 and 4, while retaining these reflexive forms of textual analysis, I present an ethnographic investigation of two events organized and attended by the institutional producers of mediatized rhetorics like \#LoveTravels: Spectrum, 
the 2016 convention of the International Gay and Lesbian Travel Association (IGLTA), and The Economist's event Pride and Prejudice. ${ }^{10}$ The second difference is found in the fact that these events are much shorter than typical ethnographies, aimed at the 'thick description' of cultural 'webs of significance' (Geertz 1973). However, although my ethnography lacks prolonged participation, this is in fact a natural response to the temporary character of the phenomena I wish to understand (i.e. corporate events, leisurely networking trips). Emic perspective here derives from a short encounter that closely matches that of the people inhabiting the social world I wish to understand. ${ }^{11}$

As an attempt to understand the operation of discourse ethnographically, then, this book examines critically how metadiscourses and word-things of pride, profit, and their interrelation circulate through marketing, and within the exclusive contexts of marketeer meet-ups and corporate shindigs. And in its blend of method, I follow Thurlow's (2016) provocative call to find ways of queering and 'messing' with CDS; to expand our understanding of text, and open up to forms of meaning-making (and thus the operation of disciplinary power) that are beside words. The question I pose in my studies of these two events is essentially related to how the diverse materialities and sensorialities encountered there function as texts, and how the events are therefore scalable as complex, legitimating semiotic resources in and of themselves: tools of global capital, wielded by market globalist institutions. The critical discourse-ethnographic approach taken in this book thus retains an interest in the interplay of discourse and ideology and reaches 'towards more contextually-oriented and actor-related types of analysis' (Krzyzanowski 2011:231). One such method is event ethnography.

Until now, this term has lacked analytical clarity - details on how-to, and whatfor - but regardless, the ethnographic study of events is undoubtedly useful for "capturing the affective atmosphere or emotional "pulse" of an event, which people are often unable to verbalize during or after the event' (Koch 2018:2015). Comer (in preparation) provides a much fuller discussion of my discourse-oriented definition of an 'event', and a methodological framework for studying them as texts (see also Thurlow and Jaworski 2017b). In summary, by 'event' (e.g. conferences/conventions), I refer to a planned period of social interaction:

1. in which recognizable institutions, communities of practice and/or individuals are engaged in activities, through which they can be indexed by their presence and participation, and

2. for which a particular purpose has been identified, and

3. in which a complex of material-semiotic resources is employed to assist in highlighting (and construing) the presence of participants, the purpose of the event and/or the ongoing impact of what takes place (before, during, and/or after the fact).

In so many words, event ethnography is a research programme devoted to examining the way that presence, purpose, and impact cohere to create 
meaningful, significant events. Events cannot be randomly determined. Like the two studied in this book, they are often commercially oriented and institutionally driven. They may be spatio-temporally 'bound' and scaled in many ways - held once, annually, fortnightly, in one or multiple locations, etc. What is key is that their impact is not restricted to that particular timespace. To use the example of Spectrum, discussed in Chapter 3, we can see how it is defined via the presence of tourism professionals and others, with the purpose of establishing and strengthening business networks, with hashtags, marketing, digital media posts, and the on/off stage performances of participants all combining to highlight and magnify (re-scale) its impact (i.e. its significance within the world of LGBTQ tourism).

In the context of this book, events like those studied are complex materialsemiotic assemblages with global(izing) significance, and a heuristic focus for a genealogy of queer enworlding. Event ethnography, as a form of reflexive, ethnographic, and discourse-oriented work, is a means of collapsing the iteratively constructed boundary between text and context, or at least rethink their relationship (cf. Comer in preparation; Duranti and Goodwin 1992; Thurlow 2020a). As Thurlow and Jaworski (2017b:542) remark in one of a limited number of engagements with events within discourse studies, its analytical focus is to juxtapose 'the multimodal discourse of advertising/marketing materials with spatial, embodied, and interactional practices'. ${ }^{12}$ It is a process I liken to disrupting yourself, and fragmenting space; essentially, rethinking, and rearticulating the affective-discursive relations between yourself, the event, its happenings and its attendees. In this respect, for me (especially when covering the terrain this book does) it is a rather queer exercise.

In Browne and Nash's (2010:4) terms 'queer research' is that which '[highlights] the instability of taken-for-granted meanings and resulting power relations', and in many ways, queer linguistics bears a striking resemblance to CDS, through its challenge to normative authority in discourse (cf. Leap 2015). This is exemplified in recent thorough queer-inflected, empirically grounded analyses of homonationalism (e.g. Milani and Levon 2016, 2019; Lazar 2017). When combined with ethnographic insight, queer perspective's persistent critique can ably account for the ways in which sexual identities and normativities are taken-for-granted, contested, and earnestly upheld 'in specific and singular moments' (Heller et al. 2018:6). One of the taken-for-granted aspects of social life for a qualitative researcher is their objectivity; the neutrality with which they approach the topic of their investigation. However, as I have noted, it is not so easy to bracket out the ways our lives and our research projects intertwine (Adams et al. 2014). Ultimately all ethnography is fundamentally subjective in nature, producing theoretical statements, not 'facts'. The 'worldmaking' (indeed, enworlding) nature of all research means that no knowledge is disseminated apart from the conventions and conceptuality of the habitus of the person disseminating it. This inherent subjectivity raises questions for where 'I' sit, within critical discourse ethnography as a reflexive project. What can we say of times when the bodies of the researcher and researched intertwine, 
if not necessarily erotically, but in the sense of a shared encounter in space for example, on a free-wheeling, uninhibited dancefloor at a LGBTQ tourism convention? In ethnographic studies where the researcher moves through (and performs) the same places, at the same time, as the object/s of their research, it is especially important to recognize the positionality of the researcher. As Milani (2013:212) summarizes, 'engaging with the situatedness of data requires the researcher to make explicit the social, cultural, and institutional factors that have enabled him or her to collect a sample of tokens of discourse'. My research would be insufficient, were I to ignore the ways in which my queerness impacts on how move through an event in the service of queer mobility/ advocacy, attuned to how my particular body (and its political standing) also impacts on these movements and my welcoming into spaces. Undertaking an adequate critical discourse ethnography of queer mobility means my own body, mind, and feelings - my 'affective attachments' (Milani and Levon 2016) - become data. It must also be autoethnography.

To repeat the aforementioned statement by Cameron et al. (1999:141) 'even the most iconoclastic scholar is always in dialogue with those who went before'. This is, at once, a straightforward account of academic practice, and a warning to those who would mess with convention that there are consequences for doing so. And although the autoethnographic edges of this book perhaps indicate iconoclasm on my part, I do not want to recklessly tear down established practices here, but simply to slightly re-imagine them - in order to make them better reflect the 'messiness' of the texts I explore (cf. Law and Urry 2004). Which is to say, in some sense I feel relieved by Cameron and others' statement - even if things get messy, my descriptions of the social world always converse with those scholars who have come before. And this is true, even when acknowledging that there are meaningful aspects of social worlds, sitting beside discursive construction, which scholars in discourse studies have only recently begun to fully apprehend or articulate (cf. Thurlow 2016), and which autoethnography can help draw out. Affect is one such aspect.

For some theorists of affect, it is clearly distinguishable from 'emotion', in that 'emotions' are mediated/signified, and 'affects' are 'pre-personal and non-intentional ... unmediated and [escaping] signification' (Ahmed 2014:207, discussing Massumi 2002). Ahmed (2014) challenges this distinction between the emotions people name and have, and affects as an something floating above and through social life. As another scholar of affect, Margaret Wetherell, has remarked, 'the formulation of affect as an excess [i.e. something which always and interminably exceeds discourse] is unsustainable' (Wetherell 2013:349). I engage both their theorizations here (despite their differences), in a 'process of rapprochement' (Wetherell 2013:364) which approaches analytically the ways in which emotions circulate as discursive 'objects' in mediatized, globalized contexts, and how affect can be wielded as semiotic resources, as commodities and consequently, as wordthings. Like Ahmed (2014), I am not centring basic nameable emotions (e.g. 
'love', 'happiness'), but rather, focusing on how they are 'sticky': how affect does things to bodies and objects in the world through the language of emotions. I seek to consider the relation between feeling good and social goods, and how feelings are articulated as a way to make some things good, or into goods; 'how different emotions, once experienced, identified, and named as such, involve different orientations toward objects and others' (Ahmed 2010, 2014:210). To do so is to note that, following Wetherell (2012:14), 'there are no neat and easy dividing lines between physical affect and discourse ... [and] the unit of analysis for social and cultural research on affect [is therefore] affective-discursive practice, that bears on and formulates the conduct of activities' - including my own life and research.

My critical discourse ethnography thus incorporates forms of analytic autoethnography (Anderson 2006), as a way to pay heed to affects as resources; to study how affects circulate in a globalized economy and are deployed and practiced in contexts of queer mobility, seen through the lens of how I, as a scholar and queer man, encounter and practice them as emotions in a privileged body. These moves are 'grounded in self-experience but reach beyond it as well' (Anderson 2006:386), following a principle that accounting for yourself in research is most necessary, indeed integral, when it helps to elucidate the truth of how and what you researched. That is, when considering "the "I" on the scene' (Milani 2014), it can't be about you, but about an 'eye', your gaze and position and how you orient to and are oriented by the world.

In this book, critical discourse ethnography recognizes mediatized habitus as that which structures contemporary social life, but which does also leave room for reflexivity and the fostering of alternative viewpoints - recognizing that habitus is an enabling structure, through which critically convivial modes of being and progressive cosmopolitanism can be built on top of our current globalizing habitus (Mignolo 2000). It bridges the gap between the workings of media and the habitual living of life, and within the context of this queer, genealogical analysis, points toward the intersubjectively liberating and disciplinary aspects of LGBTQ identity formation in a time of neoliberal governmentality, as a way to move past them, in the present. In other words, it centres subjectivity as a resource for the description, critique, and changing of social worlds (Bourdieu 1990; Bourdieu and Wacquant 1992). The activist foundation of queer scholarship recognizes that 'everyday life is not a mere conglomeration of routines and clear tactics' (Manalansan 2015:567). And so, in concluding this account of critical discourse ethnography, I wish to avoid laying it down as a clear routine or set of tactics (although MCDS, autoethnography and event ethnography here form its backbone). Rather, it is a zigzagging, shapeshifting trajectory through globalized social life - reflexive and angry, active and reactive, emotive and objective, intimate and distant - a path (my path) toward 'another world'. For Muñoz (2009:189), being/doing/ thinking 'queer' is a 'resource for the political imagination', and so too is critical discourse ethnography. It is an insistence on somewhere else in time and place, and an analytical scaffold for that insistence. 


\section{Overview of this book}

In this book I examine the contingent nature of contemporary discourses of LGBTQ rights and equality, discussing (in turn): Cape Town, South Africa as a locus for the discourse and ideology of 'travel with pride'; discourses of LGBTQ advocacy as a business imperative; and, the vernacular, world-building project of LGBTQ advocacy. As recognition for open non-heterosexual lifestyles is achieved, and global queer mobilities are won, so too is how we conceive of 'equality' transformed. I ask, simply, if it is enough.

My first two chapters address physical, embodied mobility - the movement of people from place to place characterized by tourism. I contribute to critical debates regarding how (much) sexual minorities are imbricated in broader processes of material inequality and endemic injustice, pinpointing the place of LGBTQ tourism in these matters. As I will argue, inequality - a privileged life standing above, and apart from, the everyday - is inbuilt within LGBTQ tourism's founding mythologies and the self-aggrandizing rhetorics. As an empirical foundation for my analysis, I investigate the context of Cape Town, South Africa - a city marketed internationally as 'Africa's gay capital' since the end of the apartheid regime. Chapter 2's introductory analysis takes media used to advertise Cape Town to international visitors and identifies the recurrent linguistic and visual production of three rhetorics in a range of mediatized LGBTQ tourism marketing materials. I conclude by arguing that these rhetorics constitute site-specific examples of the type that circulate routinely to build up the discourse of 'travel with pride'.

My rationale for selecting Cape Town as a site was threefold. The first is practical: much critical literature already problematizes the idea of the city as a queer refuge, laying the foundation for my own study (e.g. Visser 2003, b; Elder 2004; Oswin 2005a, 2007; Rink 2008). Secondly, Cape Town provides a unique perspective for a broader commentary on how transnational social, economic, and cultural flows are discursively accomplished and unevenly distributed (see Özler 2007 for an overview). South Africa's geopolitical placement and longstanding (pre- and post-apartheid) inequality make it a 'country of two nations', according to its former President Thabo Mbeki (quoted in Milani and Lazar 2017). Cape Town exists in the 'global South', yet parts of it are exceedingly familiar to citizens of the 'global North', and it is regularly rhetorically constructed as a 'contact zone' between the two poles (Comaroff and Comaroff 2012). Many of its residents are also more affluent and mobile than most of the continent. With a Gini coefficient of 63.4 in 2016, South Africa has by some margin the lowest wealth distribution on earth; in simple terms, it is effectively the world's most unequal country (Özler 2007).$^{13}$ Thirdly, Cape Town's hosting of Spectrum, the 33rd IGLTA convention, presented an ideal opportunity to witness how touristic myths and rhetorics are enacted in/by Africa's unequal 'gay capital'.

Chapter 3 is thus an event-ethnographic analysis of the IGLTA convention and how the escapist discourse of 'travel with pride' surfaced there. Ultimately, 
I assert that in the world envisioned there, equality is accessible only to those with the individual means to tour the globe, and the convention thus emerges as a heterotopia: a contradictory 'enacted utopia' (cf. Foucault 1986). It invokes a paradoxically finite and infinite chronotope, as both here and now, and there and then (Muñoz 2009) - a site of transgression, 'love' and ersatz equality that juxtaposes a vision of another, better world for all LGBTQ people with a carnivalesque landscape of luxury.

My final two analysis chapters address the transnational movement of commercial and humanitarian discourses of global queer mobility, advocating for LGBTQ rights across the 'flows' of the modern globalized economy (Appadurai 1996). Chapter 4's study of another event (with self-assigned global significance) evidences how many of the world's most powerful corporations frame LGBTQ rights through particular appeals to the recognition of 'diversity'. Pride and Prejudice, established by the classical-liberal magazine, The Economist, is a conference aimed at establishing the 'business case' for LGBTQ inclusion. I attended the inaugural event in March 2016, in order to understand the conference's operation, in effect, as an advertisement for neoliberal citizenship as a path to LGBTQ freedom, and for what may be termed the nonperformativity of 'diversity': its way to not do things (Ahmed 2012). Alongside discussion of 'diversity' as a word-thing (cf. Urciuoli 2003, 2016; Thurlow and Jaworski 2017a), I identity affective legitimation as the discursive strategy through which The Economist and corporate partners use moral, rational, and mythopoetic arguments to posit the neoliberal habitus of market globalism as an ideal politics for LGBTQ people.

Chapter 5 takes the deep-rootedness of neoliberal logics in global civil society as a foundation for its analysis of discourse produced by the increasingly mediatized LGBTQ advocacy sector. In late modernity, organizations such as the six studied in Chapter 5 have a leading role in driving social change (Kaldor 2003). However, they increasingly operate within a competitive 'economy of scarcity', which 'inevitably tends to foster compliance with the rules of the Western donor market' (Chouliaraki 2013:6). Overall, through identification of three further discursive strategies - audience design, materialization, and mobilization and scalar work - my final analysis examines the imbrication of LGBTQ advocacy practice with the 'anti-ideological' logics of neoliberal market globalism (cf. Cammaerts 2015).

As the above summaries demonstrate, I distinguish between 'rhetorical tactics' and larger-scale 'discursive strategies' in this book. I also use 'discourses' in a broad sense to refer to vernacular, iterative formations such as 'travel with pride' or 'Africa's gay capital'. The over-arching formation covered across this entire book (extracted from the global queer semioscape as a whole) is referred to as 'the mediatization of equality'. Following de Certeau (1984; cf. Thurlow 2020b), this book characterizes rhetorical tactics (or simply 'rhetorics') as subordinate to discursive strategies. Rhetorics are free-floating, exemplified by vernacular proliferations of slogans, styles, and 'thingified' words: 'love', \#LoveTravels, 'love always wins'. Discursive 


\section{Introduction}

strategies are the ideologically grounded and situated forms of 'language work' that produce these (sloganized) rhetorics. In other words, where strategies are 'larger-scale, bottom-down or institutionalised ways in which [texts] are regulated and structured; tactics are those smaller, bottom-up or agentful ways in which [texts] may be engaged or resisted' (Thurlow 2020b:16). As this book progresses, I shift from describing these free-floating, bottom-up 'rhetorics' as they surface in the lifeworld of tourism and global commerce, to distinguishing four prominent and overlapping discursive strategies undertaken by corporate actors and LGBTQ rights organizations alike. I deem them 'strategies' rather than 'tactics' deliberately, because I believe they are strongly tied to authoritative subjects 'with will and power' and a place: 'the base from which relations with an exteriority composed of targets or threats ... can be managed' (de Certeau 1984:36): i.e. globalizing institutions such as the IGLTA and The Economist, based in the global North. Although this position of authority is contingent, it is nonetheless salient within the context of a globalized world which is continually (re-)scaled with the global North as its structuring centre. It fundamentally impacts the work that these institutions do, and how they conceive of it. ${ }^{14}$

Each analytical chapter examines the ways that practices of queer mobility, performativity and solidarity are constrained by a mediatized context of pervasive neoliberal governmentality. Chapter 6 concludes the book by summarizing the arguments of each of my analyses, and further problematizing the 'global gaze' upon which contemporary transnational LGBTQ rights discourses are founded (cf. Altman 1997). As queer linguistic work, my book closes with an embrace of the complex, 'rhizomatic' rough and tumble of discourse-driven life (Milani and Levon 2016), aspiring for a generative critique of power in the Foucauldian sense: the 'art of not being governed, or better, the art of not being governed like that' (Foucault 2007:44). Thus, in an open-ended manner, my conclusion forgoes neat analytical clarity in favour of describing the messiness of the discursive formation I have described. I so concede the ways in which currently commodified forms of 'equality' are enchanting: their interiority, the way they reach my deepest self (Lordon 2014). At the same time, this is a concession to how inequality can be made to seem virtuous and attractive (Thurlow 2016). Although I ultimately fall short of outlining a rigid agenda for change an archetypal 'queer failure' (following Halberstam 2011) - I do seek to offer a hopeful edict for collective wellbeing and 'queer alliance' (Butler 2015).

Through such an alliance:

it is pleasure and collective caretaking, love and the egalitarian circulation of money ... that will create the space for a progressive politics that might both imagine and create ... something worth living for.

(Duggan 2003:88)

In searching for a politics worth living for, a pride to be proud of, this book contributes to burgeoning discussion of the ways that inequalities arouse, seduce 
and satisfy, and the ways that discourses regarding their resolution function as modes of self-actualization, accumulation, and discipline. How they unveil the true self, and expand the horizon. Doesn't it feel good to do good? Doesn't it feel good to be authentic, creating another world in the here and now? Taking up a rhetoric employed through my analyses: why shouldn't equality pay off?

\section{Notes}

1 See http://lovetravelswithme.com.

2 Hyatt's dedicated website at http://hyatt.com/promo/world-pride has since been discontinued. However, the \#stayasyouare hashtag on social media is just one way in which the legacy of the campaign continues. See http://nickgreenberg.com/hyatt -pride, RE: \#DontGetARoom.

3 It is notable that Hyatt's campaign claimed theirs was 'a commitment that goes far beyond words'. The 'language of love' is never only language; this makes it even more critical that multimodal, multisensorial, affect-oriented approaches are used to examine it.

4 As Steger and James (2013) note, the imaginary they describe follows Taylor (2004), rather than more fully immaterial senses of the term.

5 See Green (2010) for a convincing amalgamation of both Foucault and Giddens' accounts of sexuality and identity (and their relation to power/knowledge), that serves as an astute description of how individuals construct them in contemporary life.

6 In this respect, queer theory finds parallels with broader epistemological reflections across the social sciences, as exemplified by 'Southern theory' and 'posthumanism' (cf. Milani and Lazar 2017; Appleby and Pennycook 2017).

7 Duggan (2003) referred to this as the 'new' homonormativity in her work. One might presume that by 'new', Duggan implied that the rather simpler process of normativity for sexual minorities to which Koller (2013) refers has been supplanted by an evolved form, profoundly imbricated within the market-friendly habitus of late modernity. Indeed, it is precisely this point that I wish to make. Duggan's work is not simply 'queer studies', but a sophisticated work of political science, which takes queer politics on board as part of her engagement in complex (ongoing) debates regarding the politics of recognition (cf. Fraser 1995).

8 In a personal communication, Erez Levon refers me to Cameron's (2011) argument, essentially (correctly) noting how in a heterosexist/patriarchal society, non-heterosexuality is always radical: 'gender and sexuality are not only inseparable from one another, they are also inseparable from the social facts of power' (Cameron 2011:101). A 'mainstream' enactment of queer identity, then, can never easily or solely be considered an apolitical 'mainstream' act, even if it exhibits homonormative politics. This is why I wish to underline here that the main object of my critique is not really any 'depoliticized' queer subject, but rather, the homonormative semioscape that depoliticizes their acts of identity - the game, not the players.

9 Although I do not mention it as often as I could, under the surface of every word of this book's critique lies the existential threat of climate change, and the complicity found in the refusal of the institutions I describe to create a new future in response. See Stibbe (2015) for just one of many recent, vital discussions of the interrelation of language, discourse, and ecology.

10 Since my research project was completed in 2018, IGLTA changed their name (tellingly) to the more inclusive International LGBTQ+ Travel Association, while retaining the original acronym.

11 This accords with Stillwagon and Ghaziani's (2019) recent call for a 'temporary turn' which better theorizes the relationship between ephemerality, placemaking, and queer intersubjectivity. 


\section{Introduction}

12 Although language scholars (broadly understood) have yet to engage with 'events' as a genre in great detail, there are some whose work informs mine. Seals (2017) has come closest to providing a systematic, ethnographically informed method for studying the linguistic landscape of mass-scale events. However, the events that Seals' method provides case studies for are the 'transitory linguistic landscapes' (Hanauer 2013) of large protests. Events such as these - citizens' politically motivated 'temporary representational occupation of a specific area' (Hanauer 2013:140) - have been explored in some (often logocentric) detail in sociolinguistic work. However, these kinds of events are quite different to the convention and conference I discuss; they are not mediatized nor necessarily produced in the same way; they are somewhat less legible as singular texts, produced by a singular producer (or cohort thereof). Thurlow and Jaworski (2017b) have presented a very helpful discourse-ethnographic analysis of a luxury travel fair - but they do not provide specific details for how to do an event ethnography. Comer (in preparation) is my response to this apparent gap in discourse-oriented literature: an attempt to build a programme and methodological framework for event ethnography in future analyses.

13 The Gini coefficient is a statistical tool which ranks nation-states between 0 and 100 , where 0 corresponds with perfect equality (where everyone has the same income) and 100 corresponds with perfect inequality (where one person has all the income).

14 It is important to note that in de Certeau's original distinction, tactics are not subordinate to the strategies of powerful institutions, but are in fact creative ways for the non-powerful to engage with and contest dominant structures. The rhetorical tactics I describe are used agentively, but still hierarchically 'controlled' by the strategies of globalizing actors. 


\section{Cape Town, April 2016}

Here I am, finally in Cape Town. I had been (and still am) nervous about making the most of this fieldwork. Distracted by the busyness of Spectrum, the event I am here to examine. Enticed by many of the fabulous destinations, resorts, and journeys under discussion there. And, I have to admit, attracted to many of the men here (and of course it's mostly men).

I wonder, in a moment of reflection, whether I can know what is it that is attractive about these men at any given moment - is it their well-dressed, well-groomed good looks, or their success, that allures? Is it their confidence, the way they express their pride, or is it their cosmopolitan life?

And now there is a handsome man on stage discussing the history of New York City's queer community, the city's pride in being the 'home' of Stonewall, and by extension queer liberation. He unveils a recent campaign produced by the organization he works for: New York's destination marketing organization (DMO), NYC \& Company.

'Join the rainbow pilgrimage', states the tastefully pastel-tinted message at top. 'VERY OPEN', says a neon sign in the illustration below. It beckons the viewer to the city, represented by landmarks like the Statue of Liberty and the Empire State Building. And below, there they are: the rainbow pilgrims. A vibrant mass of people - red, blue, green, violet - every colour of the rainbow streaming into a city famed worldwide as the home of liberation.

('Where pride began', or so a recent film claims - though queer scholars know better.) The notion of a 'rainbow pilgrimage' is a clever piece of marketing: at once, a tribute to queer history and the impacts of Stonewall, and a mediatized, shareable description of identities on the move. These identities are not fully voluntary, or chosen, but rather, always influenced by what has come before, an inherited fetish of movement to the big city.

There is something profound in the notion of pilgrimage, and of course, something profound in the journey towards authenticity that coming out performs into being - the realization of self. In one fell swoop, the ad indexes both the liberation of LGBTQ people, and the historical associations between tourism and pilgrimage to sites of the sublime, on which the former capitalizes.

The semiotic choices made for marketing purposes are always inherently, unavoidably ideological and political: uplifting particular social realities while devaluing others. In this ad, NYC \& Company implicitly devalues - or at least ignores - the lives of queer people 
who stay home, or stay away from New York - those who don't join the pilgrimage, either because they don't wish to, or just because they can't.

Some of this comes to mind, sure, as I'm sitting in the audience. I certainly reflected on it all later. But I was single at the time, and because I've been surrounded by successful, attractive men all day (and by topless hunks in the tourism media they produce), or just because paying attention is difficult, I keep on focusing back on the looks of the man speaking on stage. Not only that, but I'm thinking about his being at the club last night, a dimly lit space with muscular dancers on the bar showing off sexy torsos. Torsos worthy of a wet - and messy - 'bodyshot', a splash of creamy liqueur drunk out of the belly button.

Most of these shots ended up almost anywhere other than eager patrons' mouths, but none of them seemed to care when they were lost in the moment, in the spill. Did the man speaking on stage enjoy it there? The fact that the smudged club stamp is still sitting on his wrist might say so.

This uninhibited atmosphere is what makes gay capitals special; but at this point, are they all the same? While sitting in this audience in Cape Town, I feel transported to New York as the man on stage says it 'belongs to the world'. I've been there, I've drunk there, I've danced there, I've fucked there - and it did feel like it belonged to me. Can Cape Town belong to me? What am I looking for? Can I get the same things here as I can in New York? Should I be able to?

The man remarks anecdotally that the beauty of New York lies in how it places 'the billionaire next to the homeless man at the deli'. I see what he means. I know why he says it. And to some extent, I agree - that is charming. Certainly, one of the many intoxicating things about New York is its sheer diversity, its scale and the energy its diverse people bring to even banal encounters like a deli interaction.

But in a city like Cape Town, even with this largely transient and globe-trotting audience, is it just to find beauty in this? Is it right to find beauty in this 'sort-of' equality, this counterfeit fairness, this juxtaposition without equivalence? I mean, can't the world just have fewer homeless people?

From the way the man has enraptured the audience - their nods in agreeance, their knowing smirks, their love of travel (to New York, and elsewhere) - I am not so sure. 


\section{2 'Equality on the sea' \\ Interrogating LGBTQ privilege in the tourism discourse of 'Africa's gay capital'}

\section{Introduction: Setting the Cape Town scene}

Mobility and control over mobility both reflect and reinforce power. Mobility is a resource to which not everyone has an equal relationship.

(Skeggs 2004:49)

\section{Extract 2.1: GayTravel.com (n.d.)}

Cape Town is one of the few places in Africa where it's truly okay to be gay ... [it] has repeatedly been voted as one of the friendliest gay capitals in the world, and absolutely the gayest city on the African continent.

True to the fun-filled, borderless rhetoric of tourism, the power of mobility is notably absent in Figure 2.1 and Extract 2.1. Both refer to travel in a celebratory and even playful way: with reference to a series of mutually reinforcing 'gay capitals' (treating such cities as an exclusive cabal of destinations), and through the implicit claim that stepping on a flight with 'superior comfort' is an expression of pride. Both texts index the aforementioned 'enworlding' quality of tourism: its reliance on ideals of global togetherness. Entailing the flow of millions of people (and billions of dollars) a year, tourism subsists on ideals of cosmopolitanism and intercultural communication, achieved through (heavily mediatized) 'everyday representations and discursive accomplishments' (Thurlow and Jaworski 2010a:225; following Billig 1995). Like other tourism (and niche sub-sectors thereof), LGBTQ tourism is heavily dependent on utopian ideals of equality and globality, nested within these larger mythologies.

As Murray (2007:51) argues, LGBTQ tourism is a service produced in and through Euro-American capitalist economies, 'in which movement away from "home" and "the everyday self" is marketed through the desirability of difference and/or distance' (cf. Gogia 2006). Waitt and Markwell (2006) assert that travel is ubiquitous within contemporary Western gay culture, drawing a thread through the many journeys (both comings 'out', and '-and-goings') that typify Western queer narratives (alongside others who have investigated LGBTQ tourism with a scholarly/critical gaze, e.g. Puar 2002; Giorgi 2002; Murray 2007; Milani and Levon 2016). Both opening texts above hinge upon what Waitt and 

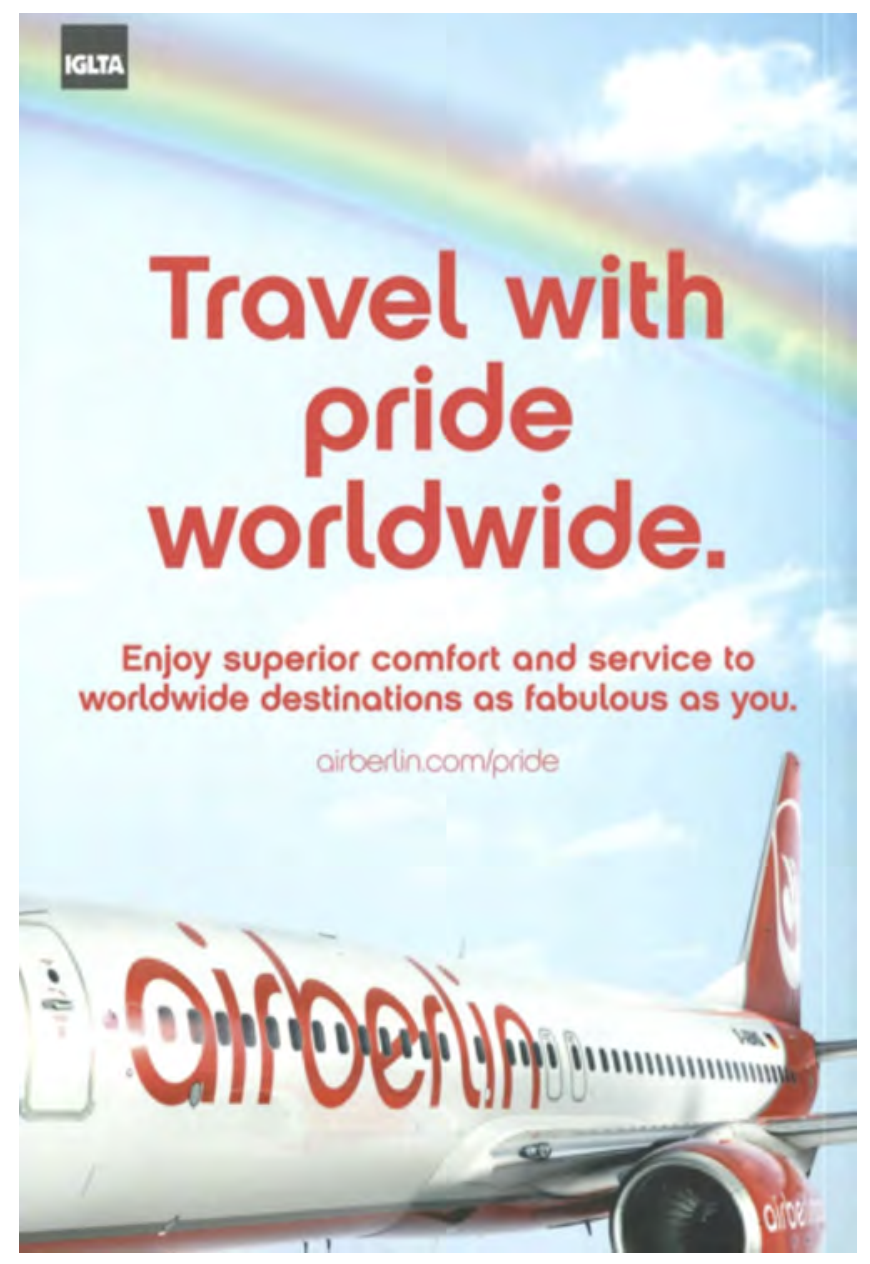

Figure 2.1 Back cover of Spartacus guide 2016, ad for Air Berlin.

Markwell describe as the 'quest for a utopia, a place where one can be apparently "free" of heterosexism' (2006:4). In the culture of Western sexual minorities, one does not just 'travel with pride', but travel is pride - an assertion of one's non-heterosexual identity in a heteronormative world. It is a search for that place 'somewhere over the rainbow' shown on the advertisement for Air Berlin, that 'fabulous' place where, in the words of GayTravel.com, it is 'truly okay to be gay'. Indeed, much of what brings LGBTQ tourists to Cape Town or any other 'gay capital' is cultural capital, generated via mediatized representation of these somewheres-over-the-rainbow - talk of somewhere that is often more equal than home. But even when tourism is fashioned as 'escape', attempts to do 
so are culturally coded and conventionally, rhetorically bound (Edensor 2001, 2007). In this way, rhetoric breeds reality: talk of a fabulous escape constructs that escape's fabulousness. Pink tourism is not queer people in love, on the move. It is love itself travelling. A welcoming world in creation. Thus, LGBTQ tourism's core product is discursively constituted, in the promise of photos from far-flung locales on social media, likes on social media posts and conversations with friends upon tourists' return: experiences of elsewhere, and their (re-)mediation. It is in this way that a core product of LGBTQ tourism in Cape Town can be seen as the story or, as I will suggest, the fable of Cape Town as one of the world's great 'gay capitals': a bastion of equality, a second San Francisco.

This chapter addresses the complex interrelation between discourses of tourism and sexuality, and the relationship between mobility and privilege. Building on critical research into the sociolinguistics of tourism (Thurlow and Jaworski 2010a; Heller et al. 2014), I examine how seemingly innocuous rhetorics of LGBTQ tourism obscure deep-seated inequalities under guises of cosmopolitan diversity, queer visibility, and global citizenship. I describe how the notion of 'travelling with pride' (exemplified in Figure 2.1 and Extract 2.1) manifests in utopian representations of Cape Town as a pink tourist destination. As I outline, however, its marketing as such clearly (and paradoxically) subsists on gendered, racialized, and classed division. Indeed, as Hennessy (2000:31) observes, 'in the complex circuits of late-capitalist consumption, the visibility of sexual identity is often a matter of commodification'. Following her critique, I mean to show how mediatized tourism texts commodify the notion of equality itself, so that it is produced and understood as a matter of individual attainment rather than any social condition. Overall, the mediatization of mobile queer bodies intertwines communication with commodification, orients LGBTQ subjects' construction of consumer identities and constructs neoliberal citizenship as the ideal form (Brown 2005). This is a central argument of this book, and my account for how this occurs begins with a journey to Cape Town.

I should again admit that I find myself deeply attracted to marketing material like Figure 2.1 and the movement toward 'Oz-like sites of concentrated fantasy' it offers (Waitt and Markwell 2006:3). As a queer white man, I am perhaps inevitably a person hailed by 'escape', beckoned to Cape Town. I am, importantly, wealthy enough to 'travel with pride'. I am welcome, and can easily envision myself, aboard that Air Berlin jet taking me to distant shores. Just as importantly, this 'motility' - potential, ability, and capacity for movement, assisted by capital (Kaufmann et al. 2004) - is patently unattainable to countless other queer people worldwide.

The UN World Tourism Organization's (UN WTO) first Global Report on LGBT Tourism (2012) states that the annual economic impact of queer travellers is over $\$ 65$ billion USD in the United States alone, and growing. The 'pink dollar' is a lucrative market for global tourism, and one that 'will continue to grow as society becomes more accepting and ... laws that promote equality are passed' (UN WTO 2012:9). Although reductionist discussion of the value of the global 'pink dollar' risks essentializing sexual and gender identities as static, and othering 
already-marginalized queer bodies, it is certain that some coherent, profitable global political economy of LGBTQ identity exists; however nascent, contingent or precarious it is. Furthermore, some scholars (e.g. Evans 1993; D'Emilio 1983) trace the materialist and economic foundations of queer liberation by arguing that capitalist consumption runs parallel to and is fundamentally entangled with sexual citizenship. Regardless of the role of the market in forming sexual identity and freeing them from oppression, it is clear that changes in social/legal tolerance enhance the value of queer consumers as a market segment. The South African LGBTQ tourism sector provides a clear example. As the UN WTO (2012:21) report proclaimed, it is 'a liberal country with a progressive constitution, where LGBT travellers are more than welcome'.

\section{The production of 'Africa's rainbow capital'}

How did Cape Town come to be considered 'absolutely the gayest city on the African continent'? Although they have of course always been present, 1994 marked a watershed year for South Africa's LGBTQ people, and their relationship with the world. The official, institutional transition from apartheid opened up the country to the rest of the globe as a newly established democratic and pluralistic nation; a 'beacon of hope' for the African continent, with a very progressive and robust constitution. The official transition from apartheid opened it up to the world as a democratic nation. The new constitution paved the way for the legalization of homosexuality, legislation protecting against discrimination on the grounds of sexual orientation and eventually, the legalization of same-sex marriage in 2006, becoming only the fifth country to do so (and the first in the global South) after the Netherlands, Belgium, Spain, and Canada. In Tucker's (2009:1) words, 'no other country changed its position towards queer individuals or the world's perception of itself in such a short period of time'. Importantly, however, this shift was, and continues to be, extremely contentious (Oswin 2007); by no means are all (or even most) South Africans content with the enfranchisement of queer people. Nonetheless, with progress, came tourists (though this relationship is not causal), and after this re-opening to the world, the city of Cape Town began to court the 'pink dollar' in order to generate income, assisted by savvy marketing (Rink 2013). As with similar trends in other places (Bell and Binnie 2004), being 'proud' was about pitching cities as 'gay capitals' of somewhere, and South Africa's 'Mother City' gained the reputation as Africa's own. Cape Town is now popularly represented, as in Extract 2.1, as immersed within wider transnational, cosmopolitan (or trans-metropolitan) networks of global gay culture - 'embedded spatially in the built environment of the gay village' (Tucker 2009:38; Bell and Binnie 2004). In these representations, 'cosmopolitan' is invoked by marketers to draw on the idea (or ideal) of tolerance: the world as one place.

De jure protection does not equate to de facto safety, however, and rhetoric does not always match reality. In South Africa, open harassment and 
violence towards LGBTQ people are common (Tucker 2009); rape of black and Coloured homosexual men, and so-called 'corrective rape' for lesbians, occur frequently. Patriarchal discourses circulate widely, suppressing female sexuality and rejecting same-sex attraction as 'un-African' or against religious teachings (Vincent and Howell 2014). Livermon (2012) has further described how this 'un-African' discourse will consistently racialize black queer bodies as white - 'the outside of blackness'. Beneath the seemingly liberated depiction of 'out' LGBTQ expression in South Africa lies an oppressive race-class-gender paradigm (Visser 2003a, b; Elder 2004; Oswin 2005, 2007; Tucker 2009; Rink 2008). Many have argued that even the purported 'gay village' of De Waterkant in Cape Town does not provide community; rather, it 'ultimately only welcomes the empowered white gay playboys, whilst at the same stroke marginalising the already disempowered of Cape Town' (Visser 2003b:124). It seems clear that the UN WTO's excited claim that 'South Africa is a liberal country with a progressive constitution, where LGBT travellers are more than welcome' belies a much more complex cultural politics, and an uneven political economy.

In this introductory analysis, I interrogate the LGBTQ tourist gaze in Cape Town, as part of the wider discursive formation of a homonormative global gay culture focused on recognition, mobility, achievement, and conspicuous consumption (following Duggan 2003). However, I do this with an awareness that South Africa is a place of refuge. No doubt, there is much to regard positively in the legal protection and increased visibility of queer individuals in Cape Town and South Africa. Even an act as mundane as holding hands with a same-sex partner at the famous 'gay beach' in Cape Town, Clifton 3rd, or while sitting at a De Waterkant café is a moment spent enjoying - savouring - something no other state in Africa affords in law. As such, the utopian discourse of Africa's 'gay capital' (cf. Rink 2008) is not so much a fabrication as it is a fable depicting the 'fabulous' life that is possible there. I am therefore arguing for a nuanced critique of this fable, which recognizes the safe space Cape Town offers to many locals and tourists alike, but which also recognizes how tourism discourses hail those who comply with a particular frame of queer identity, rendering invisible others who do not. Jasbir Puar (2002:936) sums this up well: 'while it is predictable that the claiming of queer space is lauded as the disruption of heterosexual space, rarely is that distribution interrogated also as a disruption of racialized, gendered, and classed spaces'. Puar's critique provides a clear account for the ways in which LGBTQ tourism is often blinkered and/or individualistic - like all tourism, often ignorant of or indifferent to the social and material inequities encompassed by one's ability to travel the world unimpeded, with or without pride.

\section{A queer multimodal discourse study of tourism}

As Thurlow and Jaworski (2010a) remind us, tourism is an intensely (or inherently) semiotic global cultural industry, subsisting on texts that mediate social 
relations at local and transnational scales. Within my broader critical discourseethnographic framework, this analysis uses tools from MCDS to understand how discourses of travelling with pride worldwide are produced and circulated through various semiotic resources: specifically, how language, image, colour, layout, and even more intangible forms of affect are imbricated in the realization of 'Africa's gay capital' (Thurlow 2016). In describing a sample of LGBTQ tourism texts about Cape Town, I wish to highlight ideological implications, not just for that city, but much further afield. Engaging in analyses like this chapter's assists in uncovering the means by which LGBTQ tourism discourse - indexing globality, mobility, and privilege - works to condition the lives of queer people in contexts of both leisure and business. Pride and profit.

Studies of language exploring the intersection of discursive practices, normative authority, and regulatory processes closely align with work undertaken within queer linguistics. To reiterate from Chapter 1, queer scholarship signifies not just an engagement with LGBTQ subjects, but also, an interest in how the identities to which this acronym refers have been (and continue to be) iteratively constructed as abnormal, and/or deviant. For Halperin (1995:62), queer is 'whatever is at odds with the normal, the legitimate, the dominant' - a purposeful floating signifier. Just as we can interrogate how heterosexuality is 'vigorously demanded and actively produced in specific sociocultural contexts and situated interactions' (Cameron and Kulick 2003:55), we can examine the ways that (especially mediatized) representations of same-sex attraction become normative (Motschenbacher and Stegu 2013). After all, queer is about 'creating disruptive commotion within the normative arrangements of bodies, things, spaces, and institutions', in Manalansan's (2015:567) terms. Thus, this chapter's analysis is not concerned with how LGBTQ subjects speak, but rather with how they are spoken to, and produced through mediatized texts. Furthermore, as 'a strand of inquiry that brings together a queer theoretical passion for deconstructing (sexual) identity categories with a linguistic attention to specific, real-life instances of language usage' (Milani 2013:209), queer linguistic studies recognize how identity and sexuality are profoundly interrelated and co-produced in/by discourse, but also commit (inasmuch as the approach constitutes a 'commitment' to anything, cf. Sicurella 2016) to examining all that contributes to sexuality besides language - i.e. desire, eroticism, pleasure, and the unconscious (Cameron and Kulick 2003:105). Through my own multimodal analysis of LGBTQ tourism discourse, I therefore strive to invoke the embodied, affective, ludic, and sexy ways in which meaning is assigned to the texts I examine.

I wish to ask how Cape Town is represented as a destination in pink touristic media: what key rhetorics are used to attract LGBTQ tourists to the Western Cape of South Africa? How is Cape Town called into communion with other 'gay capitals' like San Francisco, and why? What do these texts reveal about the underlying global cultural politics of LGBTQ tourism in Cape Town? What is the political-economic foundation? Along the way, I follow scholarship which dismantles some of the glossy, privileged rhetorics of frivolity and convivial 
globality associated with 'pink tourism' as an ideological construct (e.g. Puar 2002; Milani and Levon 2016), imbuing it with empirical substance. I describe in detail which rhetorical tactics construct the contradictory discourses of queer cosmopolitanism pervading representations of Africa's purported 'gay capital', and how they work semiotically. This theoretical and data-oriented underpinning allows the broader impact of discourses of 'destinations as fabulous as you' to be revealed.

The primary textual evidence used to support my analysis are materials drawn from digital texts (produced by tourism organizations and others) yielded via the first ten pages of a Google search using the terms 'gay tourism cape town', 'LGBT tourism cape town', 'queer tourism cape town', and 'lesbian tourism cape town'. These terms were chosen to correspond with those a typical Western tourist might rely on when planning a holiday in Cape Town. This research approach may be subject to what Pariser (2011) calls 'the filter bubble', that is, search engines directing users only to sites they have previously shown an interest in. In my case, however, this confirmation bias seemed acceptable precisely because it is truer to the experience of most prospective tourists. Of my five terms, the latter two were less fruitful. While 'gay' and 'LGBT' (or similar acronyms) are often used interchangeably, it is important to note that this is not innocuous; rather, it elevates 'one gendered section of the whole as the representative par excellence of that very group' (Milani and Levon 2016:75). In ways corresponding to the hyperbolic nature of discourse regarding Cape Town as a queer destination, as well, it should also be noted that there was far less material collected than had been anticipated (I elaborate on this and other disappointing aspects of Cape Town LGBTQ tourism discourse in Chapter 4). Accordingly, I also collected supplementary data for this analysis from brochures, travel guides, online apps, and other online media about 'Africa's gay capital'. Altogether, my data comprised a reasonably typical - and typically random - selection of marketing material specifically related to Cape Town as a destination for LGBTQ tourists from the period between February 2015 and April 2016.

Following the principles of queer and multimodal analysis laid out above and in Chapter 1, through the rest of this chapter I distinguish three multimodal rhetorical tactics (or simply 'rhetorics') with examples from a range of texts within my dataset. In the next section, I describe these rhetorics in broad perspective, providing data extracts as examples, and I then subsequently offer a closer, interpretive analysis of the website for Out2Africa, an emblematic text for the selling of Cape Town as Africa's 'gay capital'.

\section{Key rhetorics in Cape Town LGBTQ tourism discourse}

From across the range of tourism materials I examine, three salient rhetorical tactics emerged: a rhetoric of Africanness, a rhetoric of equality and an embodied rhetoric. As will be seen, none of the rhetorics is used in isolation; the discursive formation of Cape Town as 'Africa's gay capital' is dependent 
upon their co-constitutive character. Indeed, extracts drawn from a number of texts illustrate how these rhetorics work together to produce a discourse of Cape Town as a place on the edge of civilization (and a gateway to Africa); a vibrant, tolerant place with a welcoming 'out' community; a place of hedonistic, masculine, and overwhelmingly white bodies.

Within the dataset, Cape Town tends to be cast as a metonym for the entire African continent. Many local LGBTQ tourism operators use the continent's silhouette in their logos and marketing material - some produced by slick operations like Out2Africa, and others by much smaller, local tourism providers. Almost invariably, this silhouette is paired with either the rainbow colours of the gay pride flag, or pink, the conventionalized colour of nonnormative sexuality (Koller 2008). Since contemporary liberal discourses of LGBTQ identity emerged in the mid-20th century, both pink and the rainbow have been seen as de facto signifiers of LGBTQ rights globally; rhetorics of Africanness therefore rarely appear in the dataset without some reference to these rhetorics of equality. When they are paired together in this way, the 'Mother City' is represented as showcasing Africa - opening the continent up for visitors. It is also represented as somehow leading Africa, especially with regard to LGBTQ rights and its welcoming character, but more broadly in terms of its progressive 'global city' atmosphere. Paradoxically, undergirding Cape Town's metonymic role as a stand-in for Africa is its marked difference.

Alongside an optimistic rhetoric of Cape Town as a gateway to Africa, LGBTQ tourism operators actively construct its cultural distance from the rest of the continent. The following extracts (as well as Extract 2.1) exemplify how these rhetorics of Africanness frame Cape Town as, simultaneously, epitomizing Africa and (implicitly) standing apart by virtue of its vibrant, Western-adjacent, 'glam-to-the-max', 'magical' qualities. All in all, Cape Town stands apart, yet in a familiar way, as a utopian-sounding, 'must see' locale.

\section{Extract 2.2: UN WTO (2012)}

Feedback from LGBT travellers to South Africa cite the country's rapid urban development without losing its authentic 'Africanness' as a major attraction.

\section{Extract 2.3: Rough Guides (n.d.)}

The city has always had a vibrant gay culture, and is on its way to becoming an African Sydney, attracting gay travellers from across the country and the globe.

\section{Extract 2.4: Lonely Planet Cape Town and Garden Route (2012)}

Africa's pinkest city is a glam-to-the-max destination that any GLBT traveller should have on their bucket list. 


\section{Extract 2.5: GayCities (n.d.)}

Cape Town is magical. Think San Diego's beaches, San Francisco's boho culture, and New Orleans' resilience - all in a unique African context that is exotic and welcoming.

The visual and linguistic representation of Africa in the collected data is broadly positive, portraying it as a vibrant region with the capacity to embrace the rights of LGBTQ people. Other 'gay capitals' are directly evoked as far-flung, global parallels to Cape Town. In this respect, though Cape Town serves as a metonym for Africa, it is also removed from it - just as Tel Aviv has become both a metonym for and separated from Israel through LGBTQ marketing discourse (Milani and Levon 2016). The representation of Africa produced by these tourism organizations serves as a (re)inscription of both Africa's crosscontinental homogeneity and its essential difference from the rest of the planet within dominant discourses of globalism and Afro-pessimism (cf. Ferguson 2006; Awondo et al. 2012): a simplistic opposition between the tolerant, civilized West, encapsulated by liberal Cape Town, and the rest, a homogenous, homophobic Africa. Similarly to an image of Africa as the 'lost continent', a place of famine, war, and endemic poverty, an image of Africa draped in the colours of the rainbow flag inscribes a hopeful, but still ideologically constrained, universalizing and exoticizing message about Africa as a final frontier for progress, with Cape Town as its exceptional, standout 'gay capital'. The city is, paradoxically, only identifiable through its association with somewhere else more 'modern', more 'pink' - that is to say, more developed, more Western.

With that said, it is hard not to be swept up by the celebratory rhetoric of 'Africa's gay capital'. In addition to Extract 2.1, the following texts show the rhetorical tactic whereby an image of the city as a welcoming paradise - reborn from trauma - is presented as an incontestable truth.

\section{Extract 2.6: RhinoAfrica.com (n.d.)}

Cape Town is one of the gay capitals of the world! No wonder Elton John has a couple of favourite places to visit on our website (if you ask us nicely we'll tell you where!) - it is hard to imagine a more liberal, diverse and accepting society.

\section{Extract 2.7: GayCapeTown4U.com (n.d.)}

Cape Town [combines] a progressive and cosmopolitan spirit together with lessons from its darker past to create a scene that would rival that of similar seaside cities such as Sydney, San Francisco or Vancouver.

The imagery accompanying much of this soaring rhetoric indexes Africa via exotic fauna and extreme landscapes, with very little that indexes African culture or people. For the most part, the city is framed as a place that is visited, not one that is inhabited. To some extent, the representation of equality of 
LGBTQ tourism discourse displaces it from what is 'real' entirely. Cape Town is constructed in discourse as a utopian place; so much so, that 'it is hard to imagine' a more accepting destination. The 'lessons from its darker past' have been learned, and the city is now fully equal. As I suggested above, however, this is far from the case in reality. The hyperbolic nature of much of the 'gay capital' discourse surrounding Cape Town turns it into somewhere 'magical', almost otherworldly - the affective pull of which is discussed in more detail in the following analysis of Out2Africa. Overall, however, I am not concerned with whether the extracts above are truthful - it bears repeating that Cape Town affords queer individuals more security than most everywhere else on the continent, albeit through legal means rather than the assent of most South African people (Tucker 2009). Rather, I argue that this engaging discourse of 'African' equality obscures as much as it celebrates. The discursive formation of globalized and purportedly equal queer spaces such as Cape Town works to "create a "myth of community" - while also masking the lives of gay and lesbian people and the material inequalities of globalization' (Elder 2004:580). Even in the few instances where inequality is acknowledged within my data, it is mitigated, as in Extract 2.8.

\section{Extract 2.8: GayCities.com (n.d.)}

Partly because the vibe is casual, and partly because huge disparities remain between rich and poor, you'll feel most comfortable if you dress down ... so leave the fancy watch and glitzy brands at home.

This highly euphemistic reference to crime appears alongside Extract 2.5. Combined, they indicate that equality, in the discourse found on GayCities.com and elsewhere, is about being privileged enough to consume - not the alleviation of social inequality. In pink tourism, equality amounts to the right of individuals to travel - proudly, comfortably, and lavishly, in ways which accord with the theorization of touristic culture as an ongoing disciplining of grazing and gazing: the preparation of a lucky few to see the world and sample its delights, and the preparation of the world's places and people as objects to be seen (Franklin and Crang 2001). The rhetorics of equality I describe are the keystone of a marketable, reproducible model of 'gay capital', wherein Cape Town (if not its inhabitants) is packaged for prospective tourists as another - if not the foremost example - of a league of glam, seaside cities. These cities are framed as cosmopolitan bastions of liberal equality, with 'freedom' constituted through consumption and closeness to the 'global gay' scene typified by Elton John. Cape Town is uniquely African, yet distinctly un-African - as can be seen explicitly through repeated paeans to progress and 'vibrant gay culture' (i.e. Westernization, cf. Altman 1997). Implicitly as well, however, through the prevalence of whiteness, Cape Town is constructed as a place somehow outside Africa, or at least a place without African people. 
Scholars have previously noted how the global LGBTQ tourism industry heavily pivots toward white male consumers (Puar 2002; Murray 2007), and my dataset reflects this in its embodied rhetorics. Cape Town is iteratively constituted by shirtless, attractive people, engaged in (stereo-)typical activities of a seaside vacation. This is unsurprising, not just because global (especially pink) tourism subsists at least partly on the selling of hedonist fun, hence sex (Waitt and Markwell 2006). Given the exotic 'African' context highlighted so notably in my data, however, the racialized character of the bodies on show cannot be missed. Almost all are white, in stark contrast to the real demographics of Cape Town. Scholars have noted before how the global LGBTQ tourism industry, and even scholarship regarding it, is heavily geared toward male consumers (see Puar 2002). There is also, again unsurprisingly, a disproportionate number of male bodies when compared to female (across all texts examined), with numerous texts also exploiting the longstanding global middle-class male obsession with masculinity via the prominent representation of 'masculine' pursuits like surfing, well-built musculature and physical features like tattoos and dog tags. Not only does this elide female subjectivities, it marginalizes men who don't conform to the stereotypically masculine. The rarer (though still prominent) appearances of 'flamboyant' subjects reference particularly Western-centric signs of sexual liberation (e.g. Figure 2.3, cf. Tucker 2009), alongside almost ubiquitous white, muscular torsos.

\section{Extract 2.9: GayCities.com (n.d.)}

Bring your fat pants, though, because the food is great, and leave luggage room for sexy Baie Nice briefs to show off at one of the three gay beaches. ${ }^{1}$

These embodied rhetorics of Cape Town are predominantly visual, but also function linguistically. As Bucholtz and Hall (2016:173) have noted, 'bodies and embodiment are central to the production, perception, and social interpretation of language'. In Extract 2.8 and Extract 2.9, for example, we see how the body - its appearance, adornment, and 'affective attachments' (Milani and Levon 2016) - is central to the way prospective tourists to Cape Town interpret this destination and its people (inasmuch as it is inhabited at all, as was noted above). Much of the dataset contains regular appearances of innuendo: language such as 'a cocktail of sights and sounds that will leave you gagging for more' (Extract 2.10 below). Flirtatious language such as this elicits feeling, both in the sense of affect (the 'sexiness' of showing off briefs) and touch ('cocktail' and its metaphor). In these examples we see bodies interacting; in some sense, speaking, and often, arousing. We find masculinity, its subversion and embodied meaning (cf. Caldas-Coulthard 2008), which queer linguistic analyses allow us to draw out (Thurlow 2016). The embodied rhetorics outlined in this study cannot be touched, but they have a haptic quality - reflecting a desire to touch, and exceeding the rational and the visual (cf. Obrador-Pons 2007) - that renders them vital to larger strategic marketing of Cape Town as 
a 'gay capital'. This emerges via explicit (literal, material) bodily representation - i.e. scantily clad, buff bodies, and 'bits' of bodies - and more implicit (abstract, affective) references. Prospective tourists in Cape Town (framed as predominantly gay white men) are compelled, linguistically, and visually, to imagine themselves in both a tantalizing and privileged position. Embodied rhetorics are used alongside two others with which they directly contradict. A particularly 'African' vision of 'equality' is represented through the affective (desire-laden) representation of privileged, attractive men, with few women and almost no people of colour.

Following immediately from the sensuous/sensual appeal of these embodied rhetorics, and against the backdrop of the co-constitutive rhetorics of Africanness and equality, I now turn to an analysis of the website for Out2Africa. This text is not only a quintessential example of the three rhetorics in action, but also of the discursive production and privileging of the neoliberal subject in LGBTQ tourism discourse. It is the very essence of the purportedly progressive, cosmopolitan discourses of 'the gay capital of Africa' that not all are equally welcome. The fabulous ideologies undergirding notions of 'travel with pride' not only often subsist on normative understandings of what it is to be a queer person (or especially, a queer man). They also subsist on normative understandings of "who has what and who does not' (Iqani 2016); normative understandings of pride as an exclusive, fabulous product, a 'quest' that not all may undertake.

\section{Case study analysis: Affect and utopia in Out2Africa}

According to their website, Out2Africa is part of the Rhino Africa Safaris group of companies that in every year 2013-2016 was awarded the title of Africa's Leading Safari Company, and is 'a proud member of the International Gay and Lesbian Travel Association' (the subject of extensive discussion in the next chapter). Out2Africa focuses particularly on luxury gay travel in Southern Africa, presenting the starkest example within my dataset of tourism as a 'site of social categorisation and distinction' (Heller et al. 2014:430). More than any other LGBTQ tourism operator within/for Cape Town, Out2Africa stylizes its clients as elite, characterized by and through mobility. It is a privileged operation, but not exceptional, since Out2Africa's site is a quintessential example of how Cape Town's core LGBTQ tourism rhetorics function together. Furthermore, its representation of the bodies and identities of queer individuals illustrates how affective and embodied mediations play a role in selling Cape Town to pink consumers and producing the discourse of cosmopolitan diversity LGBTQ tourism operates within. I begin with an analysis of Out2Africa's website in order to elucidate the luxurious, privileged representation of equality it markets to tourists, and follow on with an examination of the interpersonal and affective work of a promotional video that features prominently on the site. 


\section{Out2Africa: A luxurious vision of equality}

Figure 2.2 shows the homepage of Out2Africa's website. Immediately, the contrast between the white background and pink text and hyperlinks is striking. The interrelation between white and pink in the site's dominant colour palette is, at first glance, the most salient marker of the website's genre (a luxury tourism advertisement) and of its target viewership. Pink is 'not just a colour', as Koller (2008) reminds us; it marks gender and sexuality, femininity, and passivity. The page is identifiable as catering to LGBTQ interests prior

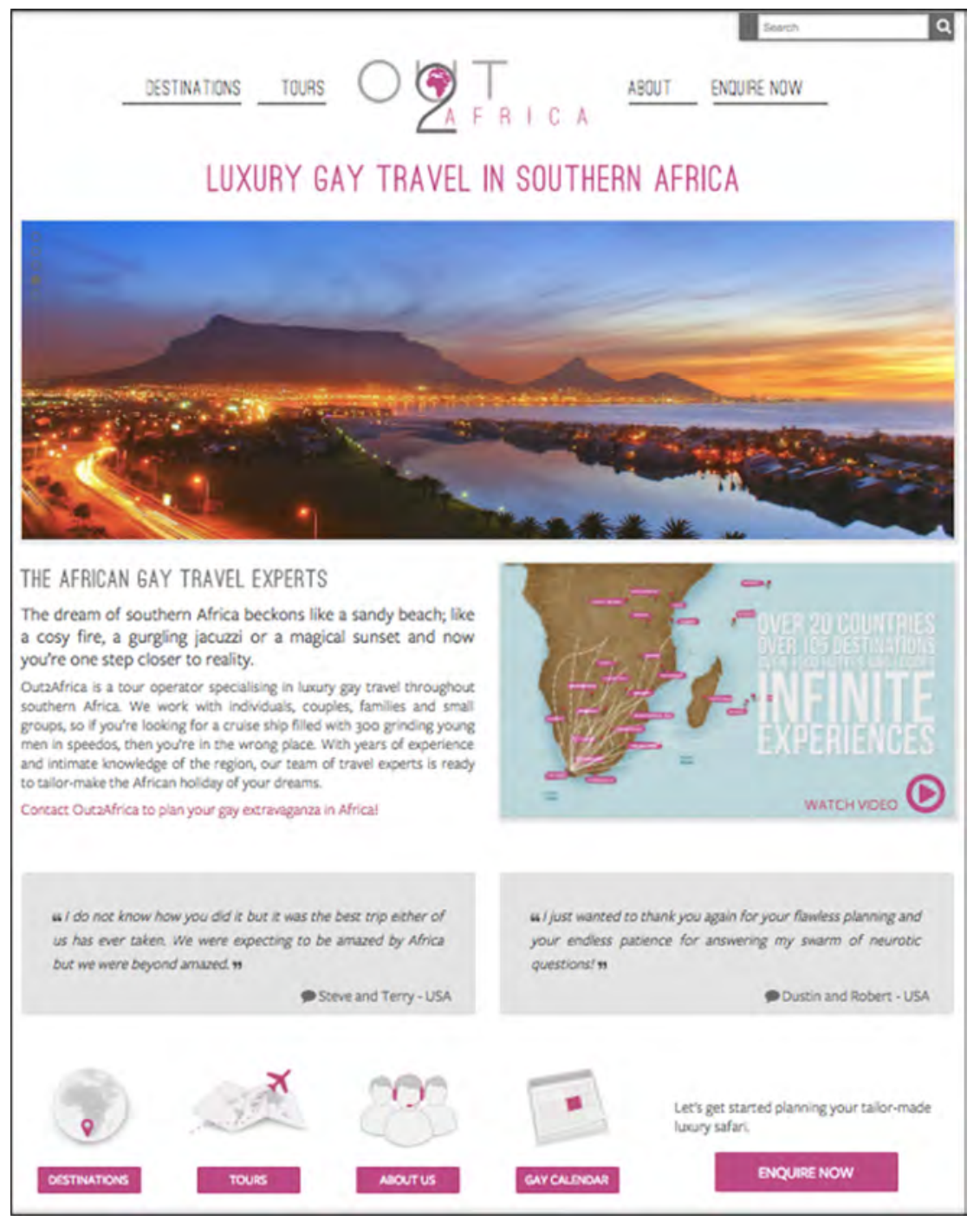

Figure 2.2 Excerpt from Out2Africa's homepage. 
to the reading of any linguistic material. Its lavish nature indexes splendour, like an expensive hotel suite; the political economy of producing such a site for a 'luxury gay traveller' is clearly high (cf. Thurlow 2016). 'Out', perhaps the most compositionally marked word on the page, indexes the exit of the figurative 'closet': a proxy for outgoing or prideful attitudes. Alongside the textspeak-like substitution of ' 2 ' for 'to' and addition of the pink globe, the company's name therefore evokes youthfulness and gay globality. However, in the words of the introduction, 'if you're looking for a cruise ship filled with 300 grinding young men in speedos, then you're in the wrong place'. The message is that Out2Africa markets something more than frivolity and sex/ uality. By implication, Out2Africa consciously refers to its clients as 'travellers': those who stand above the fray of mass tourism. Within this discerning category, Out2Africa invokes another type of tourist, one who seeks luxury as well as 'a gay extravaganza in Africa'. Four such travellers are given voice on the homepage - two male American couples, Steve and Terry, and Dustin and Robert. Out2Africa hails a narrowly defined subject, the affluent gay traveller, and encourages them to be 'amazed by Africa'. Here, the rhetoric of the metonymic continent features again, though contradicted by repeated referrals to and representations of only sub-Saharan/Southern Africa.

Djonov and Knox (2014) have argued that degrees of stasis on a webpage may be indicative of 'playfulness', and in this respect the website's banner images seem to provide a languid, leisurely showcase of 'the dream of Southern Africa'. Figure 2.3 presents a compiled selection of the banner images used across various pages on the site. Interspersing richly coloured panoramas with those of a surfer on the beach, the movement of the banner seems like an interpersonal invitation; a beckoning finger, or one idly scrolling between images of sunset and surf. Strengthening the frisson that this 'ideal' (Kress and van Leeuwen 2006) elicits in a would-be traveller, as well as serving as an 'offer image' inviting us to contemplate our own presence on the beach. The top two images, screenshots from the Cape Town page of the site, capture a sense of the utopian, during the transition from one banner image to another, following the gaze of the shirtless surfer toward the ocean, as the banner shifts his gaze that toward another man whose own gaze directs us in turn to the playful idyll of the beach. The choice of a (stock) image of a surfer is revealing, as it indexes more than opportunities to surf around Cape Town - there are profound interconnections between sensuality and the performance of masculinity in surfing culture (Evers 2009).

Queer, affect-oriented intervention in the 'carousel' transition of images underlines its evocative nature, slipping smoothly and sensually from being a conceptual representation to being a narrative representation - the unmaking of boundaries telling a tale of two lovers, perhaps? This interpretation is supported by the dreamlike aspects of the scene. As Milani and Levon (2016; cf. Thurlow and Jaworski 2010a) highlight, discussing a similar text, the image's emotive appeal manifests largely in the silence enfolding it, a silence punctuated by the viewer's imagining of the waves crashing against the shore, and potentially, the 

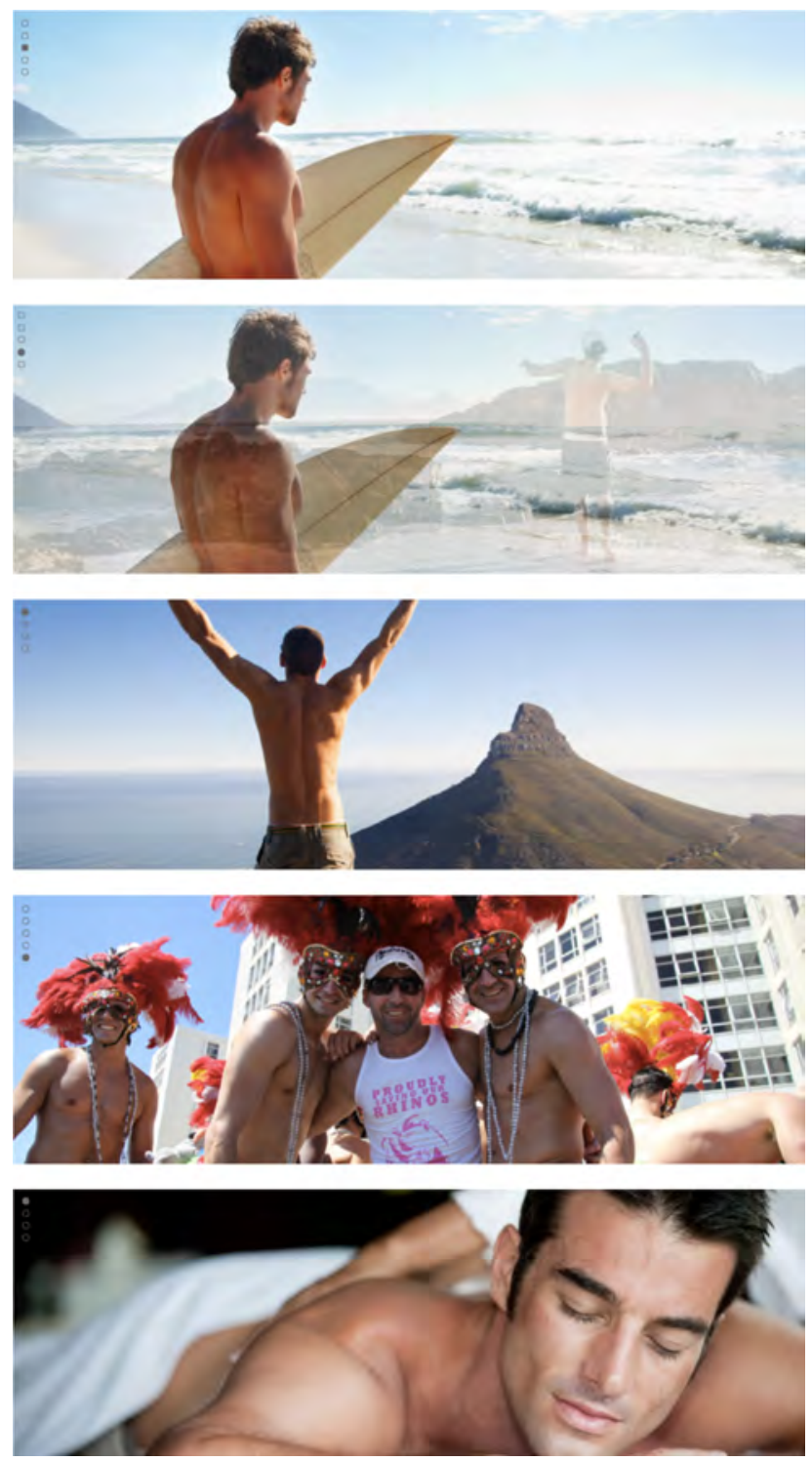

Figure 2.3 Excerpts from the Out2Africa website: sensuality, equality, luxury.

private moments in which these two men come together - unburdened by the heteronormative order. Exploring the possibilities for affective responses to the website's compositional and interpersonal meanings - their idyllic, sensual, sexy and utopian elements, their allure - makes Out2Africa's rhetorical framing of equality all the more salient. 
The montage of images in Figure 2.3 demonstrates the dominant representation of the white gay male on the Out2Africa site. Furthermore, contrary to the statement on the homepage, a brief survey of the website indexes, if not sex - 'grinding young men' - then bodies: attractive, muscular, young white men at play. Though Out2Africa (perhaps playfully) deny the sexualized aspects of their industry, the images on their site tell a different, contradictory story. Experiences of sunlight touching one's skin can in themselves be arousing, or sensual - 'sex with the sun' (Littlewood 2001:194, cf. Obrador-Pons 2007) - representations of the body bathed in sunlight are thus an especially sensual aspect of this montage. In addition to sunlight, the beach also features prominently on Out2Africa's site. Interestingly, this foregrounding of water is reflective of its recurrent presence in contemporary coming-out narratives (Mühlmann 2015). The beach inhibits an affective, sensual place in the discourses of (at least, male) queer subjects; it elicits utopia on the Out2Africa website, in the salience and visual privilege afforded to idealized images of men by the water. The central 'offer' image (Kress and van Leeuwen 2006), of the figure with arms spread wide, evokes all three of the multimodal rhetorics highlighted by this chapter, if obliquely. The attractive body, and the gaze from Africa across the ocean, toward distant shores and 'gay meccas' such as San Francisco - aspiring, dreaming, northward, westward - draw the website user into the idyll of the scene. One may seek to reflect upon the affective, intertextual nature of this figure - the trope of arms-outstretched, unbridled joy, recognizable through Leonardo DiCaprio's 'King of the world!' from the film Titanic. But the image also reflects elite, luxurious senses of the still and sublime (Thurlow and Jaworski 2010a): a sense of dominion on the part of the man pictured, whose downward gaze we are invited to share.

From the same page as the image of the surfer, Extract 2.10 contains a number of hyperbolic statements, through which representations of Cape Town as some kind of hedonistic gay utopia are presented as an uncontested/able truth.

\section{Extract 2.10: Out2Africa.com (n.d.)}

Whether it's a Manhattan you want or good old Sex on the Beach, Cape Town is a cocktail of sights and sounds that will leave you gagging for more. Luxury apartments and boutique hotels, glamorous sidewalk cafés and a feast of restaurants, bars and late night venues are all part of the cities [sic] vibrant gay culture. Consistently voted the best city in Africa and one of the world's favourite, Cape Town is a modern city with beaches, mountains, parks, and elegant winelands in its back yard; no surprises that it's the gay capital of Africa then.

The text's subtle reference to 'Sex on the Beach', 'cocktails', and less-subtle reference to 'gagging for more' index hedonistic lifestyles, through yet more camp, sexual innuendo. For the potential tourist, Cape Town is depicted as an enticing discovery, on the edge of, but very much part of, the modern, 
cosmopolitan 'global gay' scene - referenced in Figure 2.3 by the group of men whose costumes index pride parades worldwide. A minor but telling detail, the centred man's tank-top bears the bright pink statement 'Proudly saving our rhinos', highlighting the elitist, neo-colonial discourses of conservation, in which African wildlife needs to be saved from Africans, but not by Africans (Gardner 2017). The discrimination and threat of prosecution faced by black and other non-white LGBTQ communities in Africa are certainly not evident in this image, only Western-centric enactments of playful pride. As pleasing as these men's joyful, welcoming gazes may be, it is unclear who these men are - and who they are speaking for. It is unclear who these bodies belong to, but they are not bodies of the typical African. To be sure, despite the majorityblack population of (South) Africa, there are no black bodies represented on Out2Africa's site at all.

The underrepresentation of black or mixed-race bodies should not only be understood in terms of the normative whiteness of the gay tourist body (Puar 2002), but also in relation to the very privileged lifestyle being constructed in the discourse of the site, in its exoticization and idealization of 'the African holiday of your dreams'. Indeed, material conditions in South Africa are also largely elided from the website. As seen elsewhere in the data (see Extract 2.7), where these conditions are noted, it only serves to deepen the divide between an 'undeveloped' Africanness and the exceptional 'first-world' spaces Cape Town offers.

\section{Extract 2.11: Out2Africa.com (n.d.)}

Among the Garden Route's many many charms is the oppurtunity [sic] to enjoy a malaria-free safari in one of the five-star game lodges and private reserves in the interior, it's the cherry on a rather splendid cake.

Extract 2.11 extols luxury. The threat of disease for much of the continent is mentioned, but only to assure those contemplating a safari of its absence - for a few. Set alongside the archetypally anonymous, labouring hands massaging the immaculately groomed man at the bottom of Figure 2.3 (see Thurlow and Jaworski 2014a), this text serves to further obscure reality; to construct utopia and racialized elite difference. In the video featured in the next part of this analysis, we discover that 15,000 people travel to Africa per year. Who these people are remains a mystery, beyond their standard maleness. However, what is not unknown, what we can be assured of, is the privileged mobilities affording these people's journeys to Africa (Skeggs 2004).

\section{'Discover Out2Africa': Affect, infinitude, personalization}

Prominently positioned at centre-right on the homepage, the promotional video 'Discover Out2Africa' is 37 seconds of intense multimodality and playfulness (Djonov and Knox 2014). ${ }^{2}$ Compared to the elegant, 'silent' (Thurlow 
and Jaworski 2010b) composition of the website as discussed so far - the serene beach, the expanses of white - the video is a ludic onslaught of sound and colour (if mostly one colour in particular). Its music is infectious and irritatingly feel-good; an extremely upbeat tune plays, jazz-like rhythm interspersed with playful sound effects like shaken maracas. An image of Earth spins rapidly, the countries of the world delineated but monochrome; united as one bright pink landmass. A text advises viewers that 15,000 tourists come to Africa each year - wealthy states such as the USA, Canada, the UK, Germany, and Australia feature prominently on a pie chart formed from the Earth, which ultimately subsumes everything to become a simple pink globe. Vast distances are mitigated as the would-be tourist is told about a set of 'infinite experiences': over 20 countries, 105 destinations, and 1500 hotels and lodges (top, Figure 2.4). Each destination is reached from the nexus of Cape Town via an idly winding route - one of a countless number available. The viral-like spread of flight paths, itineraries, and infinite experiences across Southern Africa recalls the 'globalising genre' of airline route maps, as outlined by Thurlow and Jaworski (2003). Out2Africa mark themselves as a company with worldwide (particularly, Africa-wide) impact. As the video continues, the myriad journeys radiating out from Cape Town continue to obscure political boundaries. As in other linguistic and visual representations of Africa on the site, the borders and politics of the world's least-developed continent are at least diminished, and for the most part completely absent.

Each journey represented in the image at top in Figure 2.4 is 'tailor-made' by the (white) man in a suit seen in the image at bottom. Under the iconic (pink) shape of Table Mountain, he has a secret under his shirt - he's 'FAB', as the bright pink varsity lettering tells us. There is an intertextual resonance between his suit, tailoring, and silhouette, and other characters from fiction, such as James Bond. The way he reveals his closet 'fabness' is reminiscent of Clark Kent, Superman's alter-ego, an all-American height of masculine physical perfection. The way his manly exterior conceals a 'FAB' persona underneath recalls the troubling valorization of masculinity within gay male communities (Altman 1997). In sum, your own 'fabulous consultant' can ensure you book a safe, secure experience across all of a universalized Africa. The image of the man in Figure 2.4 encapsulates all that is present and absent in the discursive formation of 'Africa's gay capital', which is, in reality, a place of enduring inequality, yet it is here slickly presented as a model of cosmopolitan privilege. This is via its use of Table Mountain as a metonym for Cape Town, and hence Africa as whole; the icon of a white, professionally dressed body; and 'your own', the typical language of late-capitalist consumer media, promising preferential, individual treatment - synthetic personalization, in Fairclough's (1989) terms. It indexes hallmarks of Western gay identity - Altman's (1997) 'global gay', even in its use of the single word 'fabulous', which signals archetypally (Western) gay identity, and within touristic contexts is often considered a sign that users are 'friends of Dorothy' (cf. Barrett 2003). The use-value of words like 'fabulous' to construct and commodify LGBTQ identity, at once, provides 

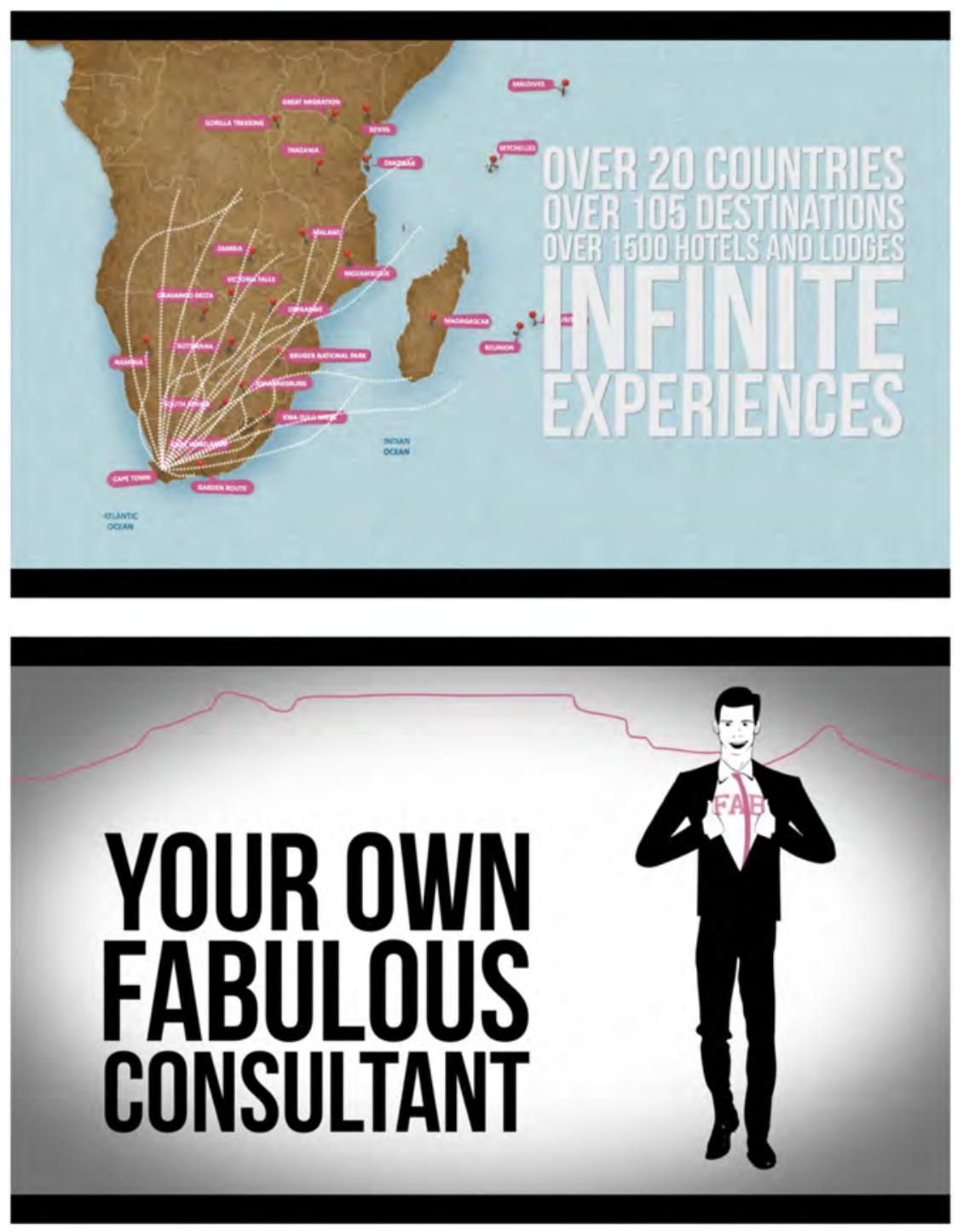

Figure 2.4 Excerpts from the Out2Africa website: infinite experiences, fabulous consultants.

support for my perspective that they are deliberately intangible word-things: naturalizing a necessary fabulosity for products (and destinations) geared to the LGBTQ community. ('Glam' is another example; 'sashay', 'yasss', 'fierce' are others, but there are simply too many such words with too many orders of indexicality across domains - many of them problematically racialized for me to list or discuss them fully here.) Just like the entire website, the 
video that Figure 2.4's screenshots come from erases female, black, and poor subjects. Generally, Cape Town is represented as a playground for privileged 'global gays' with athletic, sun-drenched bodies, a paradise and a portal to infinite extravaganzas, in a way that renders many - the immobile, discriminated, African queer, like the labouring masseuse - invisible.

As I previously noted, the discourse of 'Africa's gay capital' is, in some ways, a fable - a tale presenting the world as it could be, rather than is. Certainly, this particular fable is often a 'fabulous' one: evidenced in the ludic, hyperbolic character of the video my analysis concludes with. This dazzling, fabulous video arguably encourages viewers to intensify the erasures salient in other elements of the site. Out2Africa stands as one of the (if not the) finest displays of the rhetorics identified in this study, and more broadly, within the discourse of 'gay capitals' these rhetorics spring from. Across media depicting LGBTQ Cape Town, we find stark contrasts between those encouraged to 'travel with pride', and those whose lives in the 'gayest city on the African continent' and elsewhere remain insecure: altogether less than 'fabulous'. Indeed, the queer desire to travel - a 'quest for utopia' (Waitt and Markwell 2006), or 'pilgrimage' (Howe 2001) - is predicated on undeniably positive feeling yet inextricably tied to inequality and, as with all tourism, injustice (cf. Thurlow and Jaworski 2010a). I certainly do not regard this as the explicit or deliberate intention of Cape Town's tourism agents, such as those working for and with Out2Africa. Nonetheless, as I note further in this chapter's conclusion, mediatized representations of the identities and experiences of Cape Town's LGBTQ tourists are inevitably sequestered within the deeper logics of capitalism, and the commodification of sex/uality. They steer understandings not just of Cape Town as a 'glam-to-the-max' city to savour and be satiated by, but of the world 'on the plate' for mobile and often very affluent LGBTQ people, in which the privilege of global travel is something to take pride in.

\section{Concluding discussion: 'Travel with pride' and the utopian rhetorics of equality as privilege in LGBTQ tourism}

Through this analysis, I have used queer multimodal discourse-analytic methods to present a critical account for the discursive formation of an LGBTQ (or 'pink', or perhaps most accurately, 'gay') tourism industry in Cape Town, providing more recent evidence for the creation of what Visser (2003:186) has called 'a particular kind of homomasculine space'. In the description of three key rhetorics (Africanness, equality, and embodiment) and in my close reading of Out2Africa's website, I have argued that the mediatization of sexual identity results in global mobility and cosmopolitan privilege serving as metonyms for pride, and at the expense of any substantive challenge to material inequality or prejudice along axes of gender, race, and class. This mediatizing of the queer tourist worldwide must prompt further, sustained critique of seemingly positive texts like the Air Berlin advertisement I opened with, or the montage in Figure 2.5. The 'uptake' (Agha 2011) of a mediatized discourse of pride as an 
individualized and marketized pursuit, as found in Cape Town's pink tourism discourse and elsewhere, has profound implications for the future of queer liberation in an age of neoliberalism. In Pellegrini's (2002:138) words, we must ask, 'is it simply a case of tolerance winning the day, or does it suggest that capitalism can accommodate gay identity without fundamentally undermining its structuring inequalities?'

As a queer tourist and critical scholar, I am left wondering what it means to travel with pride to 'absolutely the gayest city on the African continent'. Is travelling with pride just about celebrating, and treating oneself - perhaps by buying briefs, as GayCities recommends? What political-economic circumstances allow for (or demand) a discourse of 'gay capitals' in the first place? Cape Town is, in many ways, a fabulous destination. After all, the rights of queer people are respected there by law; we are visible. Less can be said about almost every other place on the continent. However, it is not equal - contrary to Extract 2.6, it is not 'hard to imagine' a more diverse or accepting society. The producers of LGBTQ tourism discourse evidently obscure this fact. In their use of flamboyant, marketable word-things such as 'fabulous', and their valorization of white, muscular bodies and the global scene, they construct (and accede to) now globally circulating normative discourses of what queer identities are, and what a world that includes them looks like. In other words, they sanction a culture of mobility and conspicuous consumption, selling equality as a commodity to/for the global gays/gaze of the LGBTQ community (Altman 1997), while obfuscating the very real social problems that still plague Africa and much of the globe. Equality, in effect, becomes little more than a sellingpoint: a slogan, like GayCities' description of Cape Town as 'equality on the sea' (the heading above Extracts 2.5, 2.8, and 2.9). Pink tourism discourses of Cape Town find a parallel in Milani and Levon's (2016:77; following Puar 2007) discussion of homonationalist pinkwashing in Israel, which promotes 'Tel Aviv as a metonym of Israel, consumption practices as a metonym of freedom, and male same-sex identity and desire as a metonym of sexual nonnormativity more broadly'. Reflected empirically - enticingly, affectively through the three rhetorics discussed in this chapter, we see how mobility is a metonym for equality; travel is a metonym for pride.

The conclusions drawn in this chapter are derived from, and especially relevant for, the markedly unequal context of South Africa. However, the discourse of 'travel with pride' extends far further than just this one post-apartheid 'rainbow nation'. Indeed, echoing Figure 2.1, it extends to any destination 'as fabulous as you', worldwide, with 'you' constituted by any 'fabulous' figure with the wherewithal to go out and be 'out' in the world, their authentic, proud selves. The next chapter elaborates on the production and maintenance of this cyclic, self-reinforced discourse by tourism professionals, but reference to just one further tourism provider here can shed further light on this matter, by way of conclusion here.

In this chapter's introduction, I mentioned 'a welcoming world in creation' - in fact lifting this notion of the 'welcoming world' from the self-proclaimed 
'AirBnB for gay men', MisterBnB. Figure 2.5 compiles a selection of MisterBnB-produced media, with the purpose of illustrating how the dynamic discourse of 'travel with pride' undergirds their (budding) aims to connect the world's gay men - 'people like you' - allowing them to celebrate Valentine's Day, 'be extraordinary' ... and earn money. Another regular slogan used by MisterBnB encourages travellers to 'stay like a gay local'. In these claims, and

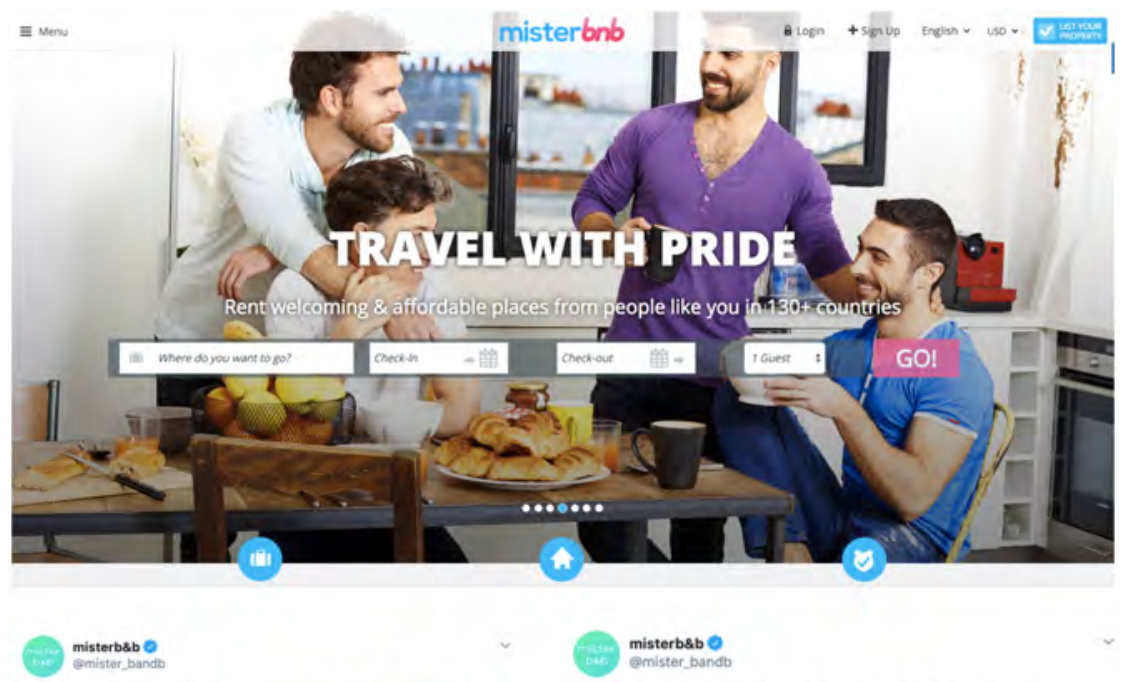

Be extraordinary when you \#travelwithpride check out this awesome listing bit.ly/20wvcGg

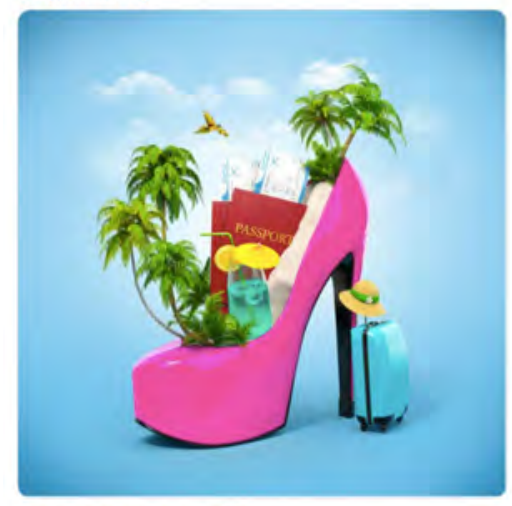

109 AM - Nov 6, 2015 - Twitter Web Client
Where are you taking your Valentine? Our 2nd choice...San Francisco! bit.ly/1Wfsfow \#travelwithpride
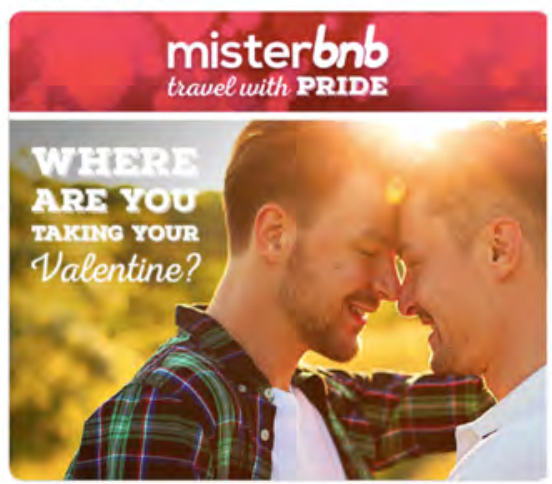

8:52 AM - Jan 25, 2016 - Hootsuite

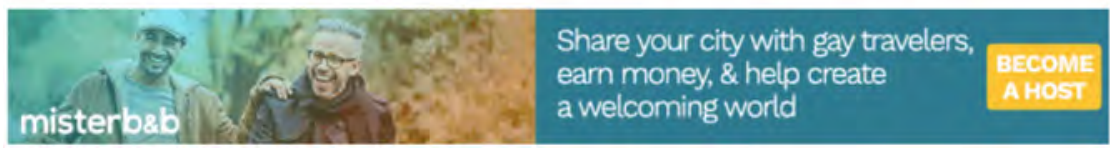

Figure 2.5 Montage of MisterBnB media: 'create a welcoming world'. 
the notion of 'helping create a welcoming world', there is evidence for the broader enworlding processes described in the introduction, through which both globalization and gay/queer identity are mutually and interdependently realized and scaled. Yet, as with the data examined in this chapter previously, there is reason to be concerned with who is being hailed here, how they are presented and the banal ways in which commerce is framed as a path to enrichment and enlightenment. Also concerning are the banal ways that 'travel with pride' correlates with a journey to San Francisco - or their first choice, Paris, the 'city of love' (MisterBnB is a French company). Pride is, again, mobility. Yet the immobile are not the only subjects left unrepresented. Cursory analysis of MisterBnB's email output, social media, and host/guest platforms indicate a rather insistent upholding of 'gayness' as the metonym for same-sex male activity and attraction, an erasure of other forms. (As a bisexual, perhaps I should be used to this.) Prospective hosts have the option of nominating as either 'gay' or 'gay-friendly'. Their testimonials about countless destinations from Tel Aviv to Toronto discuss the best place to get 'gay brunch', the best 'gay establishment for a bite to eat'. In these moments, LGBTQ tourism is clearly built up as a 'site of distinction' which distinguishes (and protects, and upholds) its niche market (Heller et al. 2014).

For the most part, MisterBnB's representation of people I am compelled to consider like me, and people I am compelled to desire to be like (echoing this book's introduction) consists to a great extent in fit, normatively attractive men, with Western-ness and whiteness as the structuring, constitutive centre to other forms of diversity (Lentin and Titley 2008). For MisterBnB, 'travel with pride' is thus indexed through a figure of the 'global gay' (Altman 1997): with pink stilettos, a cocktail, and the right passport, they can be the rainbow-coloured bird flying free (as seen in Figure 2.5). It is a self-maximizing, pleasureseeking principle: permission, if not encouragement, to 'be extraordinary'. Stepping out of my strident critique for a moment, one can say again that there is no doubt much to celebrate here. Amid the precarious and messy living of a queer life, the habitus that a company that MisterBnB produces is extremely welcome. There is no denying that. I myself stayed in a MisterBnB listing when I visited Cape Town for the convention described in the next chapter. With no claims to 'global' scale or comprehensiveness, I am arguing here that media play a significant role in encouraging queer people (especially privileged white men) to be enworlded: to see themselves in and across the world. To form the object of which a discourse of 'travel with pride' speaks. In the specific context of Cape Town, an extract from MisterBnB's website (indeed, an interview with my Cape Town host) evidences the winking rhetorics described in this chapter already: uniquely African 'liberal social attitudes' and 'eye candy'. 


\section{Extract 2.11: (Extract from MisterBnB website, n.d.)}

Cape Town's liberal social attitudes and health-conscious lifestyle make it a perfect gay destination. Stroll along the Promenade and you'll see same-sex couples holding hands and making the most of South Africa's LGBTI rights. We're also a popular destination for models on assignment, so there's no shortage of eye candy.

With recognition that MisterBnB are just one (rather young and relatively small) actor in a far broader network of tourism operators advocating for 'travel with pride', I now seek to close off my discussion of Cape Town in this chapter, using it as the foundation for chapters to come. ${ }^{3}$ As the next chapter outlines, the cosmopolitan, capitalist project of 'pink tourism' generates contradictory visions of queer utopia well beyond the South African context. Cape Town is simply a site where the contradiction is most stark - where the paradox of creating a 'welcoming world' for an elite few is easily revealed.

Tourism is a domain through which visual representation produces and (re-)mediates identities (Heller et al. 2014), and critiquing the representational character of pink tourism illuminates how the larger political economy of this industry subsists on commodifying material inequality as much as a utopian ideal. My analysis exposes how tourism is a powerful vehicle for globalizing rhetorics of LGBTQ identity that valorize white, wealthy, able-bodied, and predominantly male bodies: division between those encouraged to 'travel with pride' and those who are unable to. In Cape Town, we can see how these rhetorics work to erase queer people of colour and the profound inequality undergirding life in South Africa. Mediatized representations of beautiful bodies and landscapes, alongside hyperbolic descriptions of the city as a paradise, render Cape Town a fabulous but sanitized cosmopolitan playground.

In political and cultural terms, the discourse of 'Africa's gay capital' brings the city into further communion with others like San Francisco, while isolating it from the rest of the continent - and using this detachment as a selling point. Cosmopolitanism, 'as a way of achieving unspoken sophistication, is always classed and sexed' (Binnie and Skeggs 2004:52). Historically, the visibility of the LGBTQ (archetypally gay male) tourist, used to signify cosmopolitan values of equality, is only made possible through articulations of the free market, sexuality and liberal democracy: 'as in most marketing strategies, money, not liberation, is the bottom line' (Hennessy 2000:31). In the textual data presented in this chapter, we witness the ways in which non-heterosexuality, (global) liberal rights discourse and consumer-citizenship cohere, and how the identities, bodies, and practices of non-heterosexual people are increasingly hailed by, and subsumed within, seemingly progressive discourses of cosmopolitan diversity. And it is important to note at this chapter's conclusion that its implications reach far beyond Cape Town. Extracts 2.3, 2.5, and 2.7 all serve as illustrative examples of the ways in which select global cities increasingly seek to market themselves as tolerant destinations - 'gay capitals' - in order to boost 
their competitiveness, and attract tourists and economic capital (cf. Bell and Binnie 2004). A diverse set of places can thus then become a singular, desirable destination (a heterotopia; following Foucault 1986) - 'another world' - and one in which equality as privilege is assured.

As I outlined in Chapter 1, for Muñoz (2009:1), as well as myself, queerness is at once an agitation and dissatisfaction with what we have, an abstract longing for something else. It is the horizon, in sight but out of reach, 'essentially about the rejection of a here and now and an insistence on potentiality or concrete possibility for another world' (Muñoz 2009:1). While the contemporary world has become safer for some LGBTQ people, and some are becoming more mobile within it, many still gaze at and over the horizon toward somewhere more safe, more free. Within Cape Town's LGBTQ tourism discourse, gazes at the horizon manifest many times. The horizon indexes a vision, a dream, but one tempered by its placement within consumer media. Within a starkly unequal post-apartheid context, this utopian rhetoric sells a particular mediatized model of gay identity, and of equality, that relatively few are privileged enough to accord with, or afford. If Cape Town is 'one of the friendliest gay capitals in the world', then it represents a peculiar kind of equality - a place where white, male, privileged individuals are able to celebrate, desire, and elevate themselves, but at the expense and ignorance of others. As the mediatized discourse of 'Africa's gay capital' provides guidance on what equality and queer identity look like, we may be required to confront the truth that, in the end, 'inequality is just too attractive' (Thurlow 2016:513) to be overcome. The queer utopia represented there, and envisioned over the horizon - the 'dream of Southern Africa' - is currently, and simply, not one for all.

\section{Notes}

1 Baie Nice is a brand of underwear. The use of Afrikaans here (baie = 'very') has its own metapragmatic implications in the South African context.

2 Available at: https://youtu.be/ddkbi0EvK8g.

3 It is telling, I believe, that Out2Africa were discussed as a leading light for the burgeoning LGBTQ tourism market in Africa through the event Pride and Prejudice, discussed in Chapter 4. Such are the delicate interconnections between the mediatized discourses of equality described in this book. 


\section{Representing the Spectrum The discursive production of queer heterotopia at an LGBTQ tourism convention}

\section{Introduction: So-called 'pink' tourism, IGLTA, and its global convention}

'Travel with pride'. These words are familiar. In Chapter 2, I described the Air Berlin ad encouraging customers to 'travel with pride, to destinations as fabulous as you', and now I am looking at these same words once more appropriately enough, in a fabulous destination. Through Figure 3.1, I am also fixed - 'interpellated', to use Althusser's (1971) term - by the gaze of two handsome suited men, smiling back at me. In a way, they dare me to join them on whatever fabulous journey they are on. I am at the opening of the 33rd annual 'global convention' of the International Gay and Lesbian Travel Association (IGLTA): in their own words, 'the world's premier educational and networking event for LGBTQ tourism professionals'. And quite literally, I am in the entryway - the top of the stairwell leading into the lavish function room (with a magnificent view of Table Mountain) where the opening is being held. My first impression from the convention is therefore a simple one - I can and should travel with pride. Not coincidentally, I am attending the event precisely in order to understand slogans like these, and their enactment in the lavish space of the convention. ${ }^{1}$

This particular function is a fundraiser, organized by the IGLTA Foundation (the charitable arm of IGLTA) and the hotel group Preferred (specifically, their 'Preferred Pride' collection). Preferred Pride produced a leaflet for the convention with the same message, but a different couple, whose gazes are directed at each other rather than fixed on me (Figure 3.1). Taken together, these two texts complement one another as examples of 'demand' and 'offer' images (Kress and van Leeuwen 2006). One hails me as an addressee, and the other invites me into a voyeuristic, aspirational relationship with the represented participants; to contemplate my own desire for a moment of calm, with a handsome partner and glass of champagne. This is something Preferred Pride implicitly claim to provide: moments of joy, security, and togetherness. It would seem that the discourse of 'travel with pride', which I've already begun unpacking in Chapter 3, is prominent and voiced with conviction at the convention. 

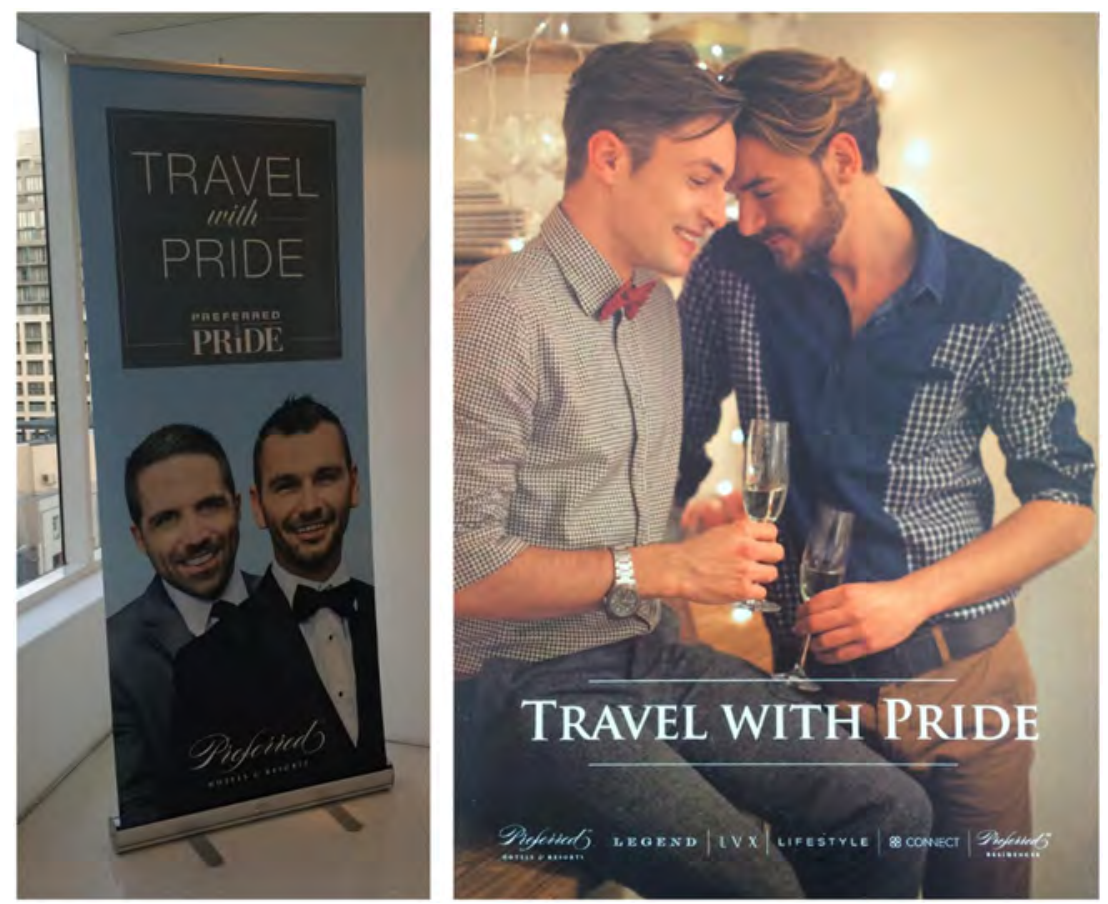

Figure 3.1 Preferred Pride media: 'travel with pride'.

However, this chapter's analysis does not begin with a naive, unquestioning belief that 'travel with pride' is straightforwardly attainable. Rather, my experiences at the convention revealed to me that there are many who do steadfastly believe that tourism is a force for positive change; particularly, for LGBTQ people, travel is both an assertion of ones' identity and a means of educating and inspiring others. As such, 'travel with pride' is not just an idea for some, but a materially, economically, and ideologically significant resource for sowing tolerance and opulence. The collated images in Figure 3.2 indicate how this idea materialized at/through the IGLTA convention (and was subsequently remediated on social media, cf. Thurlow and Jaworski 2014b). At top right, in the promotional video they produced for the event, IGLTA invoke a sense of intrepidness and dominion, showing a gay couple pridefully lay claim to the city of Cape Town. At centre, I am pictured engaging with some of the banal material texts that produced a 'carnivalesque' atmosphere at the event (Bakhtin 1968). At bottom right, we see a convention delegate doing what many were no doubt excited to do in Cape Town: to document the city and their sumptuous experiences, including the opening fundraiser's view. In tweets by convention delegates, the lush and idyllic setting for the convention is highlighted, as is a sense in which the South African LGBTQ community has laid claim to 

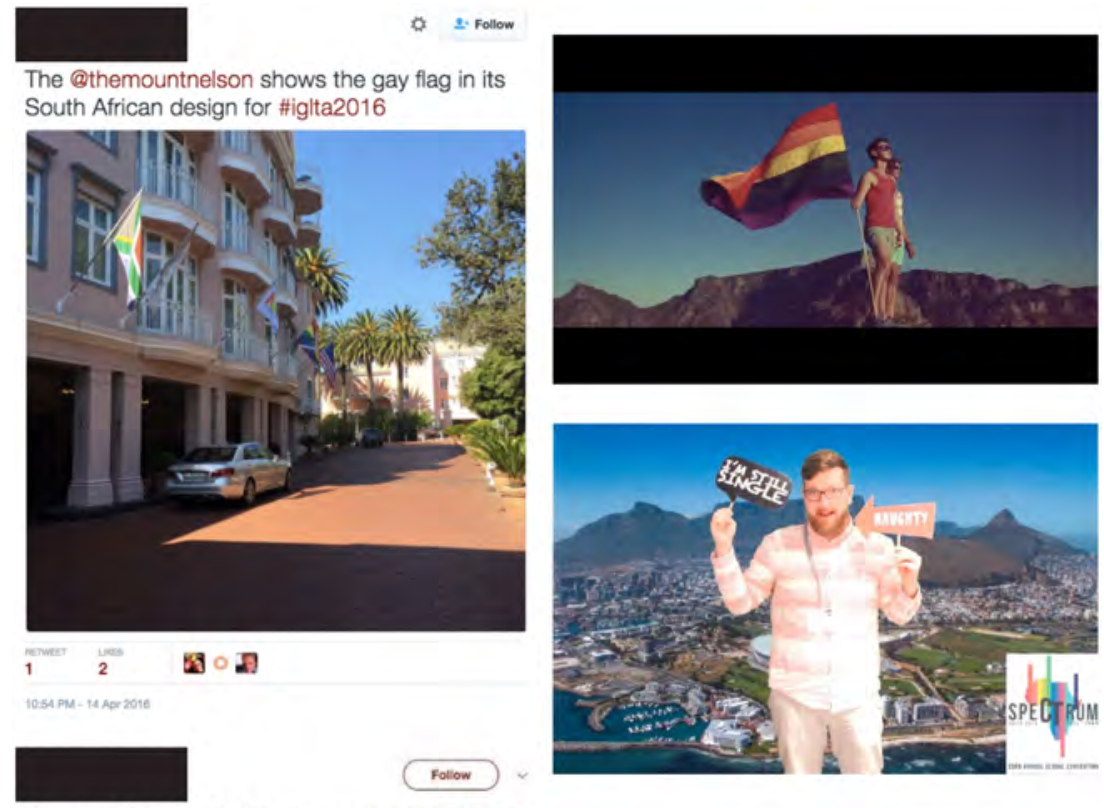

Ah, poolside lunch. Life is good. \#IGLTA2016 \#MeetSouthAfrica
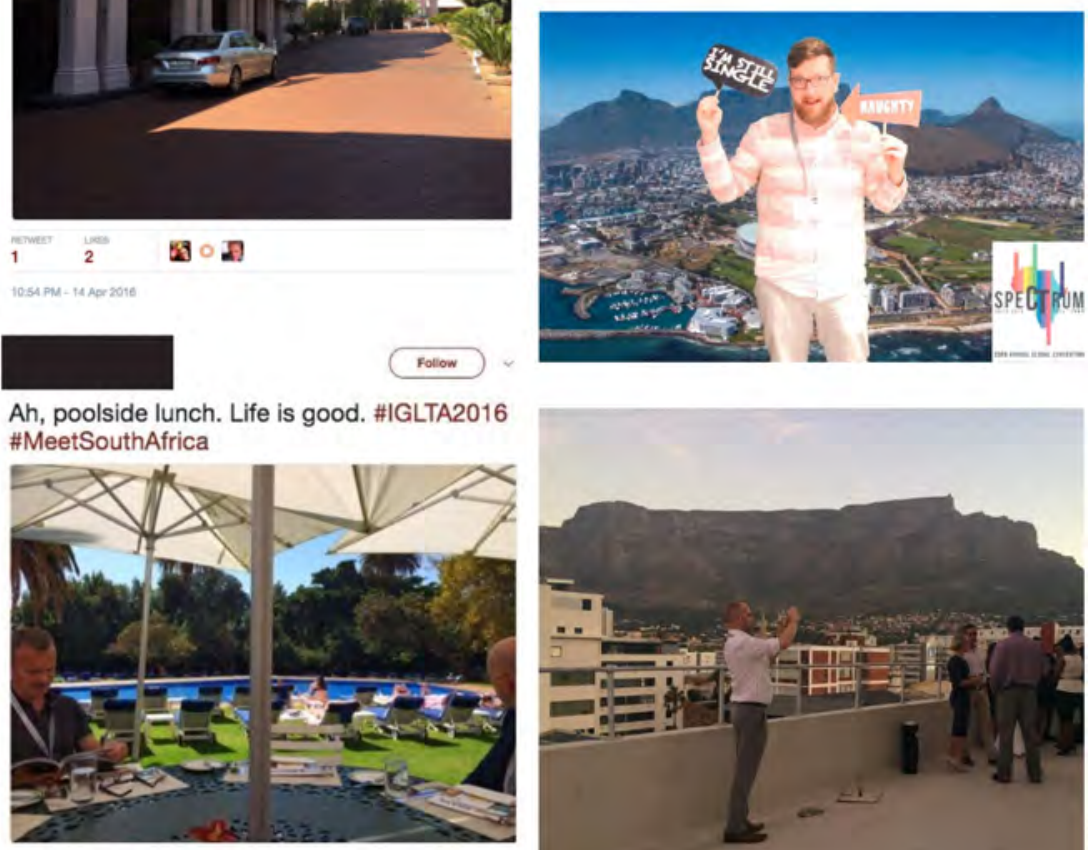

820 PM- 14 Agr 2016

$2 \operatorname{sins}$ of $D$

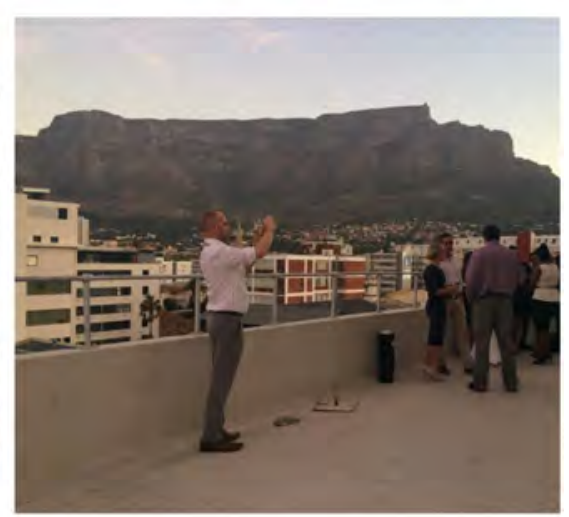

$\circ \quad 0=0$

Figure 3.2 Materializing 'travel with pride' at Spectrum.

the luxury hotel in which it was held. Through these tweets, the convention is spatialized as a lively, prideful site of both business and pleasure.

I elaborate on these materializations of pride, 'carnival', instafriendliness, and the 'good life' later in this chapter. For now, Figure 3.2 serves as tacit evidence for how life is good indeed, for some LGBTQ people. For some, life can be playful, prideful, and privileged at once. It indexes my over-arching concern in this book: how queer people come to see themselves as proud and 
cosmopolitan; the material circumstances that both index and inscribe these conditions; and the role of the market in articulating it all. These matters of the cultural, economic, and political are inseparable in purely business-oriented discourse of the so-called 'pink dollar'. Yet, as Sender (2004:240) has noted, 'a "business, not politics" refrain suggests ... that gays are just another identity or lifestyle group, like golfers' and denies that 'the gay market was constituted in part through the political marginalization of [LGBTQ] people'.

Travel to a gay capital is certainly not the same as a golfing vacation. LGBTQ people (including this author) are not solely or simply a market segment, but a community, formed through adversity. However, we are also a powerful 'bloc' in the global marketplace, and have been flexing our economic 'muscle' for some time (Chasin 2000). The world of proud, poolside tourism does not solely result from this economic power, but it is not entirely separate from it, either. As Weeks (2007:3) outlines, 'we are living ... in a world of transition, in the midst of a long, convoluted, messy, unfinished but profound revolution that has transformed the possibilities of living our sexual diversity and creating intimate lives'. While not fully safe from harm - our work is 'unfinished' - the world has changed immeasurably for queer people in recent decades. One might ask, is it any wonder that many at the IGLTA convention are convinced of the beneficial role of the industry they work in, seeing themselves as travelling and travel-loving individuals, but also as agents of change? As Chapter 2 argued, the everyday work of LGBTQ tourism naturally subsists on normative (market-segmented) understandings of LGBTQ identity, in which white gay men are too often the metonym for all other sexual minorities, and can all too easily embrace an ethos of individual expression and conspicuous consumption. However, I have found that this does not tell the whole story. I need to consider the production of texts such as those in Figure 3.1. To this end, in this chapter I use a queer-inflected, ethnographic approach to understand what tourism professionals think and feel about so-called 'pink tourism' and the future it offers - to provide a nuanced critique of their discursive practices.

The attendees of the IGLTA convention were friendly - indeed, 'fabulous' people, often reflective, who I must believe genuinely care about the livelihoods of the world's LGBTQ people. However (while recognizing my own complicity in these unequal discourses), the individuals and institutions at Spectrum 'take up' an unequal vision of pride in their rhetoric, and reinscribe it in media. The atmosphere of the event itself had a legitimating role in this process. It invited delegates to transport themselves to another place; perhaps, to imagine 'another world' (Muñoz 2009). This chapter, then, unpacks what it means for a LGBTQ tourism convention to 'enact' the real-looking but decidedly unreal, utopic vision of tourism it promotes (Foucault 1986), and what it means to juxtapose the stereotypical 'good life' with life as it is actually lived in a vastly unequal context like South Africa.

IGLTA was founded in 1983, in South Florida, as the International Gay Travel Association (the 'L' was added in 1997), with annual conventions held since 1984. IGLTA is a network of LGBTQ and LGBTQ-friendly tourism 
businesses and business associations, with members in more than 80 countries (of varying categories, e.g. airlines, travel agents, tour operators, and media organizations, accommodation providers, even somewhat enigmatic 'destinations'). On its website, IGLTA outlines its fundamental 'mission': 'to provide information and resources for LGBTQ travellers and expand LGBTQ tourism globally by demonstrating its significant social and economic impact'. As the world's foremost collective of organizations committed to the viability and visibility of 'gay travel' (i.e. the discourse of 'travel with pride') the organization has a self-ascribed transnational leadership, trend-setting, and future-forecasting role. IGLTA collects information about emergent markets, forthcoming developments in travel and the needs of the LGBTQ tourist, and communicates these to members. IGLTA's purported mission demonstrates how social and economic considerations are intertwined in organizational rhetoric - and thus, due to its prominence, how the organization shapes the broader 'lifeworld' (and value) of LGBTQ tourism as a driver for social-as-economic (and economicas-social) change. IGLTA's 'mission' indicates how LGBTQ tourism subsists on the larger mythologies of interculturality and cosmopolitanism that all tourism does, but also indicates how generalized logics of capitalism can support the foundations of queer liberation. Pink tourism is just, and it is profitable.

In a document produced for IGLTA's 30th anniversary in 2013, IGLTA proclaimed that the community had been 'seeking out welcoming spots in cities from Berlin to New York' long before the organization existed. In their words, 'as global rights and recognition have expanded, so has the visibility of gay travel ... We can all agree our industry has a bright future!' Their metropolitan focus here reflects the urban, cosmopolitan rhetorics, and myths undergirding contemporary Western queer culture (cf. Bell and Binnie 2004, Waitt and Markwell 2006). It's telling too, that the 'bright future' envisioned in this text is focused on 'recognition', rather than 'transformation'. Following these initial remarks on IGLTA's own genealogy, I now turn my attention to providing my own outline of how the 33rd IGLTA convention held in Cape Town was constructed as an enactment of progress: the building of a 'bright future' in the latest of a long list of hard-fought 'welcoming spots'.

\section{'Spectrum': Emplacing and enacting pink tourism discourse}

Between the 14th and 16th of April 2016, IGLTA hosted its 33rd annual convention, with 320 delegates in attendance from all over the world, including many (luxury) tourism operators in sub-Saharan Africa. The sliding-scale cost of attendance began at $\$ 395$ USD and topped out at $\$ 1,795$. IGLTA's post-event review claimed that the event generated 2.36 million ZAR for the Cape Town economy - it was a large, exclusive, money-making event. The front cover of this review indicates well how the event was performed. ${ }^{3}$ With the city of Cape Town (and the initials 'CT') again standing metonymically in place of Africa as a whole, and vice versa (see Chapter 2), the word 
'spectrum' is juxtaposed with a literal spectrum of colour - tones of the rainbow flag encompassing but also surpassing the bounds of the continent. (The event logo appears in the bottom right of my selfie in Figure 3.2.) Images of safari animals and the famous (and highly affluent) Atlantic coastline of Cape Town index historically salient images of Southern Africa as a destination. This underlines how significant the presence of the convention in Cape Town was, in the eyes of IGLTA and other tourism practitioners. This was truly seen as an African event: an opening (or enlightening) of Africa to the world of pink tourists. Indeed, South Africa was also seen as uniquely and appropriately suited to host the event, because of its storied dismantling of apartheid institutions and rebirth as the 'rainbow nation'. As a name and theme for the convention, Spectrum therefore indexes multiple ideas: the rich diversity emblematic of post-apartheid South Africa; the varied means by which LGBTQ people can identify themselves; and the diverse backgrounds, interests, and needs of IGLTA's clients. Since 2016, subsequent conventions have been identified/ defined by a uniting theme like 'Spectrum': in 2017, 'Shine'; in 2018, 'Together', and in 2019, 'Unite!'. ${ }^{4}$ In each case, an evocative sense of queer community, visibility, and pride is indexed.

All of the convention took place in the expansive grounds of the host hotel, the luxury Belmond Mount Nelson, with the exception of the Foundation party and the opening cocktail reception (which both took place at highend function spaces in the city centre). Since 1899, this hotel been serving well-to-do guests in the surrounds of a colonial-era garden estate, offering 'timeless indulgence in the shade of Table Mountain' in the words of its website. For the course of the convention, the hotel entrance was topped with the flag of IGLTA and a blended version of the South African and rainbow LGBTQ pride flag, in addition to the standard South African, American, and British flags. This 'banal transnationalism' (cf. Billig 1995) was an overt signal of LGBTQ people being welcomed by the hotel, just as citizens of a select few nation-states typically are at the entrance of four- and five-star hotels worldwide (see tweet in Figure 3.2).

The Belmond Mount Nelson exemplifies the 'imperial elite' mode of distinction and luxury travel Thurlow and Jaworski (2012) have identified, hearkening back to a 'lost' age of Out-of-Africa adventure and glamour. Its semiotic landscape was rich with neo-colonial fantasy: immaculate grounds, chandeliers, friezes detailed with emblems of bygone territories like the Cape Colony, and the 'immaterial bodies' and invisible labour of silent black staff. The artwork at top left in Figure 3.3 exemplifies those used to decorate much of the hotel's reception and function space - featuring an ahistorical caricature of the joyful other. These permanently emplaced (mis)representations can be contrasted with the elaborate yet temporary set-ups of participants in the convention (Figure 3.3, top right). Here, as in the tourism discourse analysed in Chapter 2 , we see white, male bodies foregrounded and valorized under the broad umbrella of an appreciation for 'diversity', and feelings of 'pride' - as indexed by Spectrum's name. Generally, a great deal of the convention's staging rested 

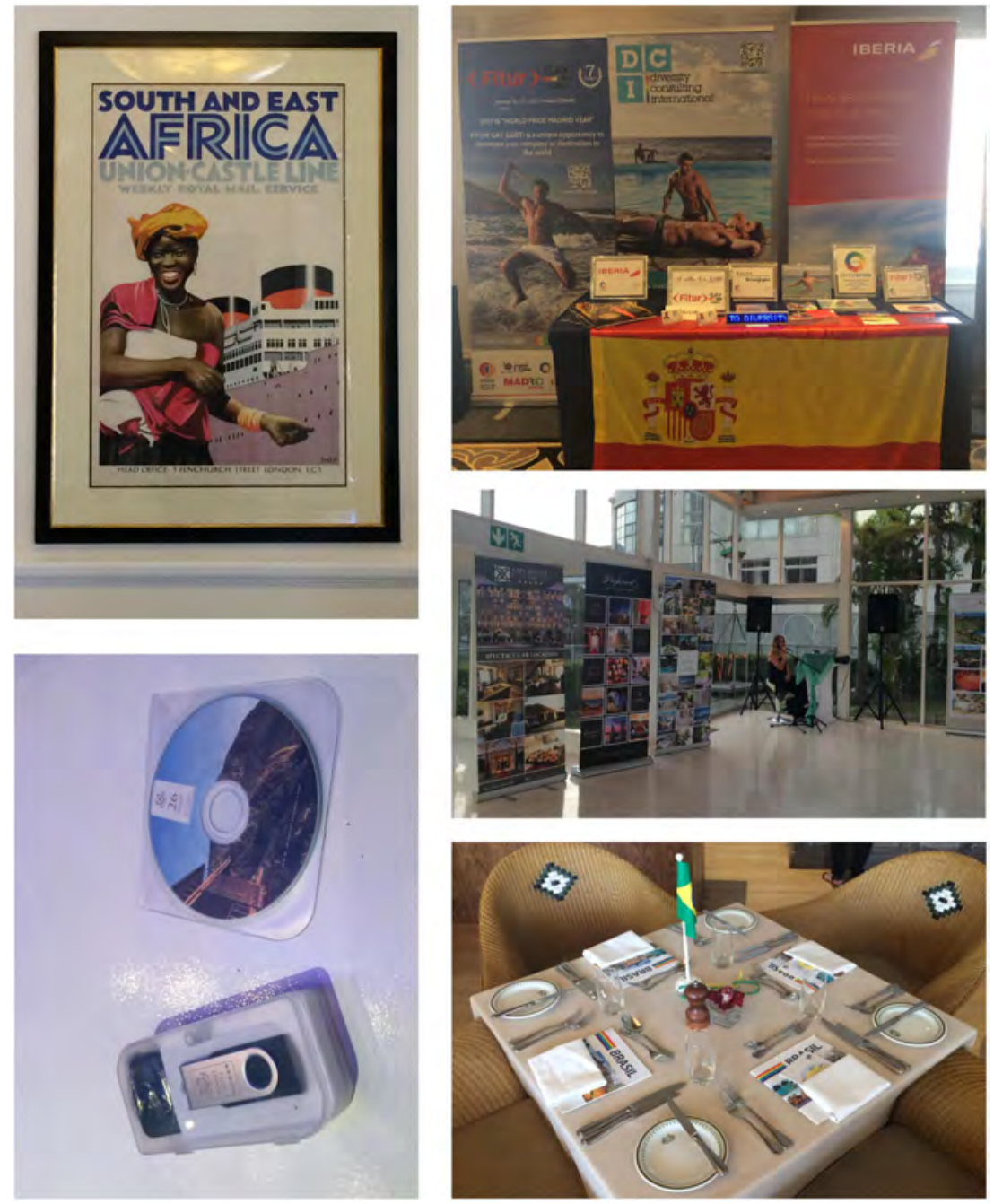

Figure 3.3 Situated, aural, gustatory, and high-end resources at Spectrum.

on elaborate assemblages such as these: stands and exhibits advertising particular resorts, destinations, organizations, and airlines. There were, however, fewer of these kinds of stands than I had expected before attending the IGLTA convention, and they were generally left unattended by staff, for delegates to browse at their leisure. As in Thurlow and Jaworski (2017), the event was additionally enacted via aural and gustatory resources - at the Foundation party, the vibrant stands, and rich marketing material were accompanied by high-end canapés and easy-listening cabaret music (centre, Figure 3.3). 
Unlike in Thurlow and Jaworski (2017), however, the IGLTA convention wasn't aimed at moulding the dispositions and habitus of pink travel to the broader public - would-be travellers - but rather, reinforcing the dispositions of the tourism professionals who shape that habitus, at once scaffolding their own rhetorics and exhibiting their rhetorical skill. For the most part, the convention did not have a 'mercantile' atmosphere so much as one of austere, refined conviviality; centred on education about tourism trends, and affirmation of tourism's importance to the world. Where explicit promotional work was done, it was often striking for the measured manner in which it was done, as seen in the sophisticated presentation/promotion of Brazil as a destination at lunch. Alternatively, it was simply impressive for its high-end economy, seen in the individual USB sticks and mini-discs used to promote a luxury hotel in Llandudno, Cape Town, an elite seaside suburb (Figure 3.3).

The extent to which the IGLTA convention glamorized the positive outcomes of tourism cannot be overstated. As an enacted, three-dimensional assemblage, it is a resource allowing the LGBTQ tourism industry to communicate and imagine itself, on-stage and off: at once a site of commerce, 'awareness'raising, and cultural production. There were also numerous ways in which the convention could (and did) transport itself, in banal fragments, across vast distances and timeframes. There were countless pieces of marketing material, like the USB or Preferred Pride leaflet, designed to be taken away - used, consumed, discarded, away from where they've come. Likewise, the website for the convention could be accessed from anywhere in the world, remediating a wealth of text and talk from the conference. Furthermore, through the official conference hashtag, \#IGLTA2016, any attendee or would-be attendee could manifest 'ambient affiliation' with the values expressed by the organization, as well as track, contribute to and search through conversations about the event and its staging (see Zappavigna 2011). Overall, Spectrum was a complex, 'messy' array of texts, combined, and constructed into one.

The best way to apprehend the convention's complexity as an assemblage was to employ a discourse-analytic and ethnographic approach (Krzyżanowski 2011), event ethnography, as outlined in Chapter 1; attuned to the (relatively) static meaning-making potential of mediatized resources, but also engaged with material relations between people and contextually grounded social meanings.

\section{Event ethnography at the IGLTA convention}

Event ethnography is my attempt to design a framework which takes mobility, materiality, and affect into account equally, oriented to both text and context (see Comer, in preparation, for a much more thorough account of this methodology).

I entered the context of Spectrum with the following statement of exploratory aims and goals (following Seals 2017): I aim to determine as much as I can about the social, cultural, and economic worlds of LGBTQ tourism, as they are enacted and materialized at IGLTA convention, and I aim to do so with 
a queer openness to non-binary thinking and immaterial realms of affect. My diverse 'dataset' from the IGLTA convention took the form of: presentations/ speeches on stage; digital texts, social media, and tweets using the hashtag \#IGLTA2016; magazines and marketing material; the built environment of the venues; informal conversations with other delegates; and other ethnographic insights and (queer) affective responses to what happened there. My participation in the IGLTA convention took place across four days, beginning with the IGLTA Foundation benefit and continuing to the closing reception. I attended general sessions, 'educational breakout sessions' and networking events alongside as many other delegates as possible, recording my impressions of the presentations, and unobtrusively observing interactions between attendees. In the course of the three days of events, I sat in on 14 presentation and discussion segments, of varying length, with titles such as '15 Mistakes to Avoid on Social Media When Promoting LGBTQ Travel', and 'How to Make LGBTQ Travel Matter to Millennials' (at all times, I took note of the demographics of the space I was in). The IGLTA convention was a space of commerce and communication, but it was also celebratory. I attended a number of receptions - venues for (boozy) networking and conviviality, at which atmospheres of camp, pride, and sexual freedom reigned. I occasionally eavesdropped, seeking to get the best sense of how the event was interpreted by others, capturing sassy or snide remarks about it (or, indeed, its attendees, who I also occasionally flirted or joked with, in response to the atmosphere).

It was important for me to fit in at the IGLTA convention, and I followed the dress code for the event, 'business casual', as outlined in the delegate handbook ('cocktail attire' was encouraged for the opening reception). Like other delegates I was required to wear a name badge at all times, which identified me as an academic from the University of Bern, Switzerland, and I participated only in parts of the convention which were open to non-businesspeople (which meant a 'buyer-seller marketplace', structured like a speed-dating event, could not be examined). Given I was not there to do business, was not a tourism professional and had not attended before, the obvious question is: how did I present my attendance at this event as legitimate? It is important to comment upon the ethics of my event ethnography at the IGLTA convention. Writing about ethnographic work, Duranti (1997:102) has noted how that 'while it is not ethically appropriate and practically feasible to completely hide one's presence, at the same time it is very limiting to collect data solely on participants' response to our presence on the scene'. Although some members of the convention expressed interest in how a sociolinguist or communication scholar would view Spectrum, most did not. In this respect, responses to my presence were limited. At the same time, it was of course still important for me to find a 'blind spot', to be as unobtrusive as possible - empathetic yet detached from the goings-on. While I was usually covert and silent, when I engaged in conversation, I would always explain that I was an academic participant, interested in 'how the discourses of LGBT mobility - people's freedom to travel, and their right to express who they are - circulate the globe'. When first registering 
for the convention, I noted my interest simply as 'LGBTQ tourism', but was always identifiable as a 'PhD student in Language and Communication'. In many respects, throughout my ethnographic investigation I felt close to how Thornton (1999) describes herself in her ethnographic study of a corporate setting, as an 'Alice in Adland'; out-of-place, yet still invited into a world I was not familiar with, and welcomed. Because of the risk of encountering hostility to my critical perspective, I kept this aspect of my research clandestine, but importantly, was never dishonest with any of the attendees I spoke with. As is noted later, many people I spoke to were themselves critical of aspects of the convention and the discourses which flowed there. Ultimately, I believe event ethnography, involving a balancing act of insider/outsider perspective and involvement, sits well within the ethical standards of social-scientific research. No individuals I spoke with will be personally identified in the analysis which follows.

Quite appropriately, the binary-resistant nature of event ethnography lends itself well to the concept of heterotopia (Foucault 1986). Compared to the sheer unreality of utopias (like those discussed in the last chapter), for Foucault (1986:25), these are places that are:

something like counter-sites, a kind of effectively enacted utopia in which the real sites ... are simultaneously represented, contested, and inverted. Places of this kind are outside of all places, even though it may be possible to indicate their location in reality.

Many sociolinguists have adopted the Foucauldian concept of heterotopia, including, notably, Milani and Levon (2019), to describe the experiences of queer Arab men in relation to the oppressive yet 'liberal' Israeli state (see also, e.g. Lou 2007, Thurlow and Jaworski 2012). The term is notoriously polysemous (Johnson 2013), yet undoubtedly useful when engaging in critical studies of space and social order (as mediated by discourse). As Johnson (2013:800) explains:

The idea [of heterotopia] ... encourages sites to be used as a starting point for research as both a conceptual method and object; it helps disrupt established thought, practice and human subjectivities; it resists the settling of binary thinking; and it assists in formulating new relationships and alliances.

Rather than adopt the concept too-literally here (following Johnson 2013), I wish to focus on its relational aspects; the incremental and discursively-tied moments and enactments when spaces become heterotopic. Here I use it to describe the ways Spectrum justified a landscape of excess for some, inaccessible to others; sketching 'another world' that is far and near, material and immaterial, accessible and impossible. The IGLTA convention indexed unity and separation because it is, however paradoxically, more than one place at once. 


\section{Analysis: Elite escapes and enacted utopias at the IGLTA convention}

As a lavish celebration and fixture of the LGBTQ tourism industry, the IGLTA convention is uniquely placed to convey the sector's self-articulations and selfrepresentations - the mythologies which sustain the discourse of 'travel with pride'. I now present a selection of insights from my event ethnography at the convention, following three organizing principles. With reference to extracts from some of the speeches at the convention, textual/visual extracts, as well as ethnographic insights on my experience, I will outline two broadly conceived rhetorical tactics: pink tourism as a force for good, and as an escape. To these I add a third 'meta-rhetoric': my consideration of the IGLTA convention itself as an escapist enactment of good, a site where the two other rhetorics are enacted for additional rhetorical ends.

Through 'force for good', I aim to invoke the same longstanding paeans to cosmopolitan tolerance used to frame Cape Town as 'Africa's gay capital'. I also refer to the means by which global tourism is understood by many proponents as both a hallmark of globalization, and evidence of its positive outcomes - rightly or wrongly, a tool for sustainable development (see Mowforth and Munt 2009; Thurlow and Jaworski 2010a). We see again here that 'globalization', with regard to tourism, is as much a discursive formation as a material process: a tool for 'talking about, and justifying, material realities, and inequalities of global capitalism' (Thurlow and Jaworski 2010a:4). In this first rhetoric, LGBTQ tourism is framed as a source of prosperity, poverty reduction and the liberalization of prejudicial views on same-sex attraction. Through 'escape', I again invoke Waitt and Markwell's (2006) discussion of LGBTQ tourism as a 'quest for utopia'; a way to leave prejudice and peril behind at home, embracing fully the conventionalized, capital-driven mythologies of LGBTQ (gay) tourism. Here, I examine a wide range of material indexing a broad suite of specific and indeterminate locations, well beyond Cape Town. In this notion of 'escape', I seek to capture the ways that transnational queer identity and pride are intertwined in the mobile workings of market globalism.

Although it is not the sole site of 'escape' my analysis focuses on, Cape Town is still my research site: the backdrop to the previous two rhetorics' enactment. This in itself informs the third principle, building upon the previous two - a meta-rhetorical framing of the event as an 'escapist enactment of good'. The IGLTA convention is a dramaturgical action - a performance. My meta-rhetorical examination of the convention centres around how the delegates at Spectrum iteratively performed the convention - as both a tourism event, and their own touristic encounter with Cape Town - into a fabulous, pride-filled space. I wish to underline how I see the IGLTA convention as a meeting-point of multiple rhetorical tactics - including, at times, those outlined in Chapter 2. The staging of the IGLTA convention is a (mobile, but annually resituated) marketing strategy. As I characterize it, the convention is a device whose rhetorical functions include its own reproduction and justification - sustaining the 
larger discourse of 'travel with pride' - but in ways which do not easily cohere or settle. For this reason, I see it as an often incoherent landscape: a heterotopia. I conclude with a discussion that expands on the notion of heterotopia to account for how this powerful tourism organization performs progress into being - in both Butler's (1990) and Goffman's (1959) senses (cf. Gregson and Rose 2000). The convention represents progress, at times contests it, and at times inverts it (Foucault 1986); at all times, juxtaposing the real and the possible, the material and the more-than, the economic and the affective.

\section{Pink tourism as 'a force for good'}

I am at a keynote speech by the CEO of the World Travel and Tourism Council (WTTC), David Scowsill, which opened the IGLTA convention. Scowsill's presentation was interspersed with textbook examples of the visual representation of tourism: pristine, unpopulated beaches, buzzing cityscapes, and images of tourists (literally and figuratively) on high, offering their triumphant gaze upon the world (Kress and Van Leeuwen 2006). But also, like at the Foundation benefit, I am being met with a direct gaze, staring at me from Scowsill's presentation on screen. In contrast to the gazes of the two men at the start of this chapter, however, this is the longing gaze of a child - demanding feelings of pity and compassion, rather than joy. Although, at one level, this is a quintessential touristic representation - children of colour - the girl is also an archetypal example of the 'spectatorship of suffering' whereby media promote sympathy for passive, distant suffering without enlivening struggle to resolve that suffering (Chouliaraki 2006, 2010; Vestergaard 2013). The girl invoked an anonymous, displaced sense of helplessness. The absence of context rendered her a representation of humanity as a whole (Vestergaard 2013). The text alongside explicitly pointed to both the cosmopolitan ideals of tourism as 'a force for good', and neoliberal ideals of individualism:

\section{Travel \& Tourism promotes self-respect self-confidence self-sufficiency}

The implicit claim here, broadly, is that tourism is a way to alleviate global poverty; to bring the world closer; to reduce prejudice. In this section, I outline just some ways this rhetoric emerged at Spectrum, beginning with Scowsill's speech.

In its own words, the WTTC represent perhaps the likeliest salve for the pains of the world: existing to 'promote awareness among governments and wider society of the enormous contribution made by Travel \& Tourism [sic] to the economic, social, and cultural well-being of our planet' ${ }^{5}$ Likewise, the content of Scowsill's speech also strongly indexed principles of self-sufficiency and entrepreneurialism, in addition to espousing the social and economic 
impact of global tourism (avoiding any mention of its environmental costs). This equating of economic prosperity with broad-scale social progress is perhaps the core tenet of neoliberal theory and has long been the subject of (fierce) critique from (post-)development and political theorists such as Escobar (1995). Scowsill made a point of highlighting how tourism accounted for nearly $10 \%$ of global GDP, claiming that the sector supports 284 million jobs (or 1 in 11 jobs on the planet). In his speech, Scowsill presented tourism as 'a force for good in the world', 'a family lifted out of poverty' and, with particular resonance for the crowd at the IGLTA convention - 'a driver of social inclusion and personal mobility'. For him, this is the 'human' side of tourism: employment, growth, job creation; economic solutions to large-scale social problems.

Perhaps this economic focus is all unsurprising; Scowsill is, after all, a businessman, and tourism is, after all, big business. According to the UN WTO (2017), international tourist arrivals reached 1,235 million people in $2016 .{ }^{6}$ There is a great deal in the discourse of tourism as an economic force, however, which seemed to compel its operators to truly believe in the transformative power of 'personal mobility' in a borderless world. Scowsill sounded like a televangelist, constructing the staging of the IGLTA convention as a progressive act, and its cause as a moral one. As he performed his role advancing the industry's agenda, the international delegates at Spectrum performed commitment to it: nodding along, murmuring agreement, visibly moved by his call to imagine a world over the horizon (cf. Muñoz 2009). In so doing, attendees reinforced the dispositions being expressed by Scowsill, and his aspirational speech mediated 'the relationship between the psychic and the social' (Ahmed 2004:119), aligning all who listened with common, rationalized purpose. This is adherence (to an affect, and a cause) as coherence - a 'sticking together' (Ahmed 2004, 2014) that legitimates a habitus enshrining tourism as a force for good, in which the actions of tourism professionals enact change. Often, glimpses of mistreated or oppressed sexual minorities would emerge - to provoke similar 'spectator-like' feelings of pity like those for the child above.

In closing his speech, Scowsill appealed to his audience's sense of leadership, as rationally and morally legitimated 'stewards of the world's natural resources', breaking barriers, and ensuring (mutually constitutive) 'social and economic advancement'. He invoked a bright 'hypothetical future', in Reyes' (2011) terms. Overall, Scowsill's speech drew its political power through a gentle, positive set of 'sticky' affective strategies - unlike in Reyes (2011), championing inclusion, rather than eliciting fear - yet still, undoubtedly, used these strategies for politically motivated ends. This political argumentation is undoubtedly deceitful, seeing as GDP growth is an unsustainable measure of social and economic wellbeing (see Hickel and Khan 2012). Furthermore, the disingenuous claim of 'stewardship' over natural resources matches that of environmentally harmful discourses/practices in other areas such as the oil industry, where metaphors often frame the natural world as something 'wild' in need of human control (Breeze 2012). Scowsill (and countless other speakers at Spectrum) repeatedly invoked a 'we' (but with a far less clearly defined 
'them', cf. van Leeuwen 2007; Reyes 2011). In an immediate sense, 'we' refers to those involved in global tourism, but as in the strategic use of the child's face, more broadly, all of humanity is being spoken of - a common future for all of us. A common freedom. In sum, and as he noted himself when he began speaking, Scowsill was dedicated to discussing 'the freedom to travel', explicitly orienting to a larger campaign of the same title which WTTC ran during 2016. Freedom to travel, in his words, was 'principally the ability to travel freely and to enjoy the holiday of your choice, whenever you like and with whoever you choose', and it was through this issue that he saw WTTC as being able to help what he called 'the LGBT sector' (a lifestyle group, cf. Sender 2004).

Evocative rhetoric about the 'freedom to travel' at the IGLTA convention was certainly not limited to any one mode. After Scowsill's speech, the audience was shown a video rich with the poetic, euphoric rhetorics of contemporary marketing (Thurlow 2016). Entitled 'I Am Travel', this WTTC-produced video was designed to 'enworld' its audience at Spectrum, and all of the world's inhabitants, as objects of touristic practice (see Figure 3.4). ${ }^{7}$ Narrating this dazzling spectacle, accompanied by a simple piano score, the booming voice of a British-accented man recited an adapted version of Robert Louis Stevenson's poem 'Travel' (1885). Images of cityscapes, deserts, and nature intersperse with images of orientalized figures - a Buddhist monk, an Asian child bathing, a central Asian man fixing the viewer with his gaze. As the video drew to a close, the booming voice declares:

\section{I wander until I find my Eden, As we all have the right for travel freedom And no more delay with hours of haggle, I am the world ... I am travel.}

The video's well-travelled majority-white and majority-gay male audience applauded loudly when the video ended, uplifted and celebrated by its message. It was a fervent almost-hymn, an act of self-belief: an evocative, mythopoetic (narrative) act of (self-)legitimation (van Leeuwen 2007). In its final four lines, the adapted poem subtly shifts from the voice of Stevenson's seeker
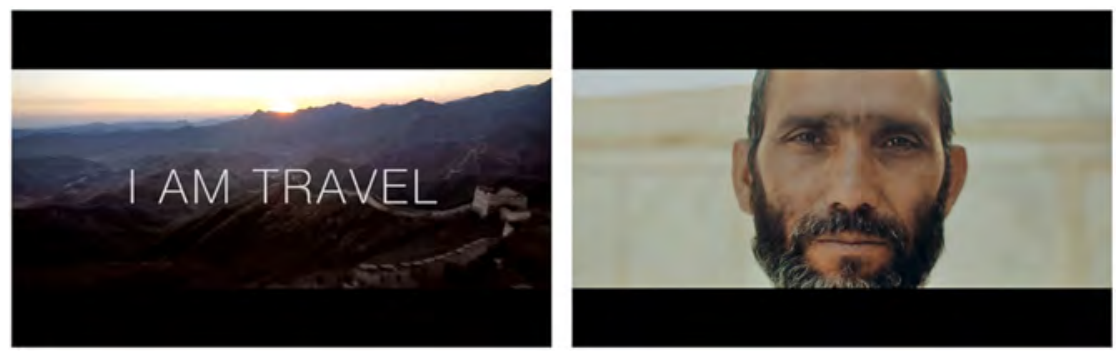

Figure 3.4 WTTC: 'I am travel'. 
of the sublime to one somewhat like Scowsill's, a corporate advocate for the free movement of people (with the right passport, and requisite finance). This heteroglossic text balances business interests while pointing to something else, beyond it. This text thus presages the complex, heterotopic quality of the convention as a whole, punctuated with acts of enworlding like this video, that promote the 'freedom to travel' as a noble 'quest for Eden' that is also implicitly neo-colonial and neoliberal.

Importantly, the 'we' speaking in the final few lines can once again be broadly understood as referring to all of humanity. However, the very fact that they are being highlighted in the video indicates that the people it featured (peoples of colour, indexed as humble and exotic) are part of the allure of travel, part of the destination: immobile. An implicit admission that that tourism is dependent on forms of inequality. This was the first of Spectrum's many reminders that the queer/cosmopolitan 'idealization of movement, or transformation of movement into a fetish, depends upon the exclusion of others who are already positioned as not free in the same way' (Ahmed 2014:152; Puar 2007; her emphasis). The cosmopolitan project of tourism is thus paradoxically linked to a project of staying-put for certain subjects, waiting for the grace of Western visitors to come. The South African context made this especially salient. In a welcome message in the event booklet, the then-Tourism Minister Derek Hanekom expressed his hope 'that this convention will advance and promote the right to freedom and equality even further, and that its message spreads across our continent and around the world'.

Even across banal texts like the event booklet, the 'globalizing habitus' of LGBTQ tourism as an enworlding, prosperity-seeding project is formed (Jaworski and Thurlow 2010). On another page of the booklet, an ad for MGM Resorts touts its credentials as an equitable employer and asserts that the world is at its best when 'we are at our most inclusive'. The reader is invited to delight in this creation of a better world: 'Creating opportunities for all. Now that's inspiring'. The convention booklet scales the event and its indexical relations as enworlded (Carr and Lempert 2016), and articulates them as incremental actions: steps toward a better life for Africans, through the 'right to freedom and equality'. It also imbeds a sense of inevitability and rationality to that scaling. Thus, it should be expected that economic growth, framed as 'opportunity', is an essential precursor to LGBTQ-friendly social relations. This globalizing habitus is one in which travel is pride, and is a 'force for good', in which the rhetoric of unbound mercantilism begets equality. Here, rhetorics of prosperity, authenticity, and neoliberal citizenship cohere in a way that explicitly asserts that tourism is a force for good, with 'good' defined through rational, moral and intersubjectively 'productive' terms.

In his own opening speech following Scowsill's, Hanekom declared that Spectrum was 'the making of the South African success story': 


\section{Extract 3.1:}

Many of the early chapters of this story are completed, some are still being written, and people like yourselves, who come here from all over the world, are helping us write future chapters about the success of tourism in our country ... This convention will help brand South Africa as a country that welcomes LGBT travellers.

Hanekom opened by immediately providing support to the IGLTA's own rhetoric (e.g. Figure 4.6) about the ground-breaking nature of the event. Hanekom explicitly asserts that the convention will improve South Africa's 'brand' within the tourism marketplace (line 4), and attract 'pink dollar' consumers. LGBTQ people are, in short, useful as tools for profit. Hanekom was jailed from 1983 to 1986 for anti-apartheid activism, and has a statesmanlike demeanour that lent his speech an air of gravitas. As I listened, I was moved by its message. Hanekom's speech provided IGLTA delegates with a moving account of South Africa's post-apartheid re-shaping as a 'democratic, caring society'. Drawing on the trope of the 'rainbow nation', he remarked that 'perhaps we are better described as the kaleidoscope nation ... where things are constantly changing and shifting, and sometimes even colliding'. This reference to 'collision' followed Hanekom's description of some of the many challenges South Africa faces through the 'stories still being written' (line 5, above).

Hanekom's speech highlighted the common rhetoric invoking South Africa as a stepping stone to progress for Africa as a whole; an exemplar for other countries to follow, guided by the growth in GDP that springs from tourism and other development. South Africa was repeatedly metaphorically referred as a light, a lighthouse, a beacon. With regard to LGBTQ rights, Hanekom (unsurprisingly) drew upon the country's famous constitution to note that while such rights are enshrined there, he could not promise delegates that they would be accepted by everyone, anywhere they went (though of course such a promise could not be made anywhere). Rather, he drew on notions of a uniquely African hospitality, promising them 'a wealth and a depth of human belonging that you are unlikely to find anywhere else on the planet'. Hanekom outlined the humanist philosophical concept of 'ubuntu' (from the Nguni Bantu term for 'humanity'), rooting it in Southern Africa and claiming that it is 'embedded in the soil and it lives in the heart of every South African'. He drew reference to Africa as a 'collective home' for humanity, the 'cradle of humankind'. These rhetorical actions subtly reflect the metonymic role which Cape Town and South Africa serve for the entire continent. As moving as Hanekom's words were, the contradictions inherent in rhetorically claiming that ubuntu lives in the heart of every South African, that Africa is all humanity's home, while acknowledging that queer people will not be welcomed everywhere there, cannot be ignored. Hanekom's appeals to ubuntu strongly imply - troublingly - that LGBTQ tourism is a sector through which a welcoming, open philosophy can be spread. 


\section{Extract 3.2:}

What I can say without any shadow of a doubt is that, as a country, we need you and want you here. Not because of who we are, but because of who you are ... We need you because, in many instances, you bring a new way of looking at things - a new and exciting way of living which has always been part of our South African life, but frequently ignored, or disparaged, or violently rejected. We want you here to be a light to the millions of LGBT people in our country, so that wherever they are, they might know that they are not alone ... Whether you are lesbian, or gay, or bisexual, black or white or any shade of colour, this incredible continent of Africa is your home. This is where we all come from, whatever journey we have travelled and wherever we find ourselves today. This continent is our collective home. Let us celebrate our belonging to the family of humankind, and let us rejoice that I am who I am through you. And you are who you are, because of others. Let us celebrate this wonderful thing called 'ubuntu' ... On behalf of the people of South Africa, I welcome you. I cherish you. I value you. I look for the things you can teach me about being human.

As this speech extract shows, Hanekom spoke in the third-person - adopting the voice of a generalized (South) African - multiple times, in order to express how much the country/continent requires the presence of these delegates, and by extension queer tourists, in order to 'be a light' (line 8) to millions of queer people, to 'teach' them to be unafraid (lines 13,11). Toward the end of his speech (line 16-17), Hanekom shifted from the repeated use of 'we' into a more heteroglossic stance in which even one sentence (composed of two imperative clauses) carries a multivalent, shifting number of subjects and arguments: 'our belonging', 'the family of humankind', 'I am who I am through you'. All index subject potentials, as an audience member, pointing to my/ our/your shared belonging, a shared 'cherishing' (line 20) of the other. It is a polyphonic, authoritative, and affective (again, almost hymnal) summation of ubuntu. Here a spirit of ubuntu, appropriately, stands in for a far more explicitly prejudicial (and inaccurate) perspective of Africa as a homogenously homophobic place, in need of Western instruction (cf. Awondo et al. 2012). However, the message that is ultimately sent to delegates is the same either way; that it is mobility, of Western ideals, returning 'home', that can lead by example ('be a light') and teach South Africans how to embrace sexual minorities, so that they can then enlighten Africans elsewhere. Not only are tourists an economic boost to South Africa, they are also a tool for belonging.

Hanekom's speech was met with a standing ovation in the packed conference room, and scores of delegates were quick to affirm its uplifting message via the conference hashtag, alongside pride flag, loveheart and same-sex couple emojis. Given that Scowsill and Hanekom were featured prominently in the agenda as the two opening keynote speakers, they warrant particular attention. 
The two key messages from each of their presentations reverberated throughout the remainder of the convention's sessions: firstly, that the freedom to travel is a fundamental human right which also generates significant income, and secondly, that Spectrum's staging in Cape Town was itself a sure sign of progress and a bright future for LGBTQ travel in Africa and elsewhere. LGBTQ tourism was repeatedly referred to as 'building bridges', as a force for change; but the moral 'worth' of such change was continually rationalized through its currency in a global marketplace. In a Q\&A session, when Hanekom was asked how South Africa could influence the rest of the continent's criminalization of homosexuality, he said: 'what we have to do with the rest of Africa is to lead by example, to show that there is nothing to fear, and much to gain'. The convention swelled with banal tokens of neoliberal ideology, e.g.:

\section{'Not only is it the right thing to do, it's the right thing to do for the economy ...' 'We [LGBTQ people] would constitute the 19th largest economy on the planet...' 'Inclusion is good for business ...'}

The convention was framed as a means of connecting with the local and transnational community, and more broadly, planting seeds for future prosperity. One afternoon of the convention was devoted to volunteer outreach; delegates were given the option of visiting a local LGBTQ shelter, engaging in a township tour or meeting HIV+ children at a daycare centre. In these moments, the convention's atmosphere shifted, profoundly, to one of hope: including hope in the power of (LGBTQ) tourism to change the world. Perhaps the most stirring moment of Spectrum came when Ndumie Funda, the founder of the lesbian welfare NGO Luleki Sizwe, was presented with the 'IGLTA Community Honour award'. She began her thank you speech with a moving rendition of 'We Shall Overcome', a song made famous through the civil rights movement; many people, including Funda, wept as she told the audience of growing up in poverty, of losing loved ones to AIDS, and violently, through so-called 'corrective rape'. At a key moment in her talk, she made this striking point: 'You can't feed poor LGBT people with LGBT rights, they want food'. Suffice to say, there were a wealth of moments at the IGLTA convention when the inspirational rhetorics of tourism fell away, and a more conflicted perspective rose to the fore. In these moments, I was even further convinced of the majority of these tourism professionals' belief in its and their progressive potential, but also exposed to a deeper awareness of the extent of the material challenges faced in (South) Africa.

During one session, delegates discussed two opposing perspectives on how exactly tourism can lead to socioeconomic change; never questioning this view, but asking whether change occurs as a result of tourists' mobility, or through the 'preparation' of places to be visited and seen (Franklin and Crang 2001). As one delegate put it, there is a tension between two propositions: 
'Let's create better places to live so people will come' vs. 'People have to come to make it a better place'. No one presented either of those options as an easy, matter-of-fact option. However, in acknowledging that Africa could or should become a 'better place', it seems as if this proposal remained one focused on the needs of clientele - a certain market segment - rather than the 'humanity' indexed by ubuntu philosophy. This raises questions about what it means for the convention to be held in Africa, and fed into questions of what 'Africa' and 'Africanness' can mean, as an identity, experience and unique selling point. What was discussed, in simple terms, was the easiest way for 'Africa' rhetorics to be woven into a borderless world of privileged mobility.

The continent was always framed in relation to an unspoken, unacknowledged centre in the global North - the source of tourists who will provide wealth, in return for a slice of its mythical, pre-modern landscape and character. At Spectrum's 'Developing LGBTQ Travel Business in Africa' session, a delegate asked, 'how can we make Africa less price prohibitive for backpacker tourism?' In that moment, I wondered whose lives would be most changed by opening Africa up for backpackers, as with for LGBTQ tourists - the visiting, or the visited? I thought of Massey's (1994) vivid description of the people the 'mighty 747' flies over: the inherently, involuntarily immobile (Carling 2002), those left in the wake of mobility. The freedom to travel espoused so passionately at Spectrum is framed as a way to change the world for the better, to unite and celebrate humanity. But, ultimately, perhaps its change-making potential as a 'force for good' is restricted to those who are on the move, not those who wait for those on the move to arrive.

All in all, the seemingly most powerful rhetoric at the convention related to the actualization of self. 'Forces for good' did arise at the convention both as a rhetoric of the global tourism industry, and through the belief of its delegates in this principle (which I don't doubt). However, the much stronger feel of the convention was of a mixer, a party, and an escapist celebration. Accordingly, in the remainder of this chapter's analysis, I wish to examine how this actualization of self (the 'real you') emerged at Spectrum. In my discussion of the convention itself as a meta-rhetoric, I underline Africa's 'good life' character for those globally mobile professionals themselves.

\section{Pink tourism as 'escape'}

One way to tease out the differential mobilities of queer subjects is to foreground the relationship of tourism and travel to constructions of home. The ambivalence of the notion of home plays out in several ways. For example, home that is not a refuge for queers needs to be escaped.

(Puar 2002b:114)

A number of imperatives greet me from a complimentary passport cover provided to Spectrum's delegates by a then newly developed (and since discontinued) LGBTQ travel app. 


\section{Let's go! \\ Go meet people again.}

I am immediately attracted by the prospect; the frisson of a new city, new friends, and of discovering 'gay places worldwide', as in the app's tagline. Perhaps unsurprisingly. As outlined in previous chapters, many scholars have argued that mobility plays a significant role in the formation of queer identity. Some claim the two are now perpetually linked, and perhaps fundamentally, if one follows D'Emilio's (1983) argument that it was post-war migration to big cities that allowed notions of gay identity to form in the first place (see also Weston 1995; Howe 2001).

Jasbir Puar, as quoted above, has written in some detail about the nature of LGBTQ tourism as an imperative for queer people, noting how queer people have long travelled for recreation and to escape intolerance (Puar 2002a, b). In Chapter 2, I invoked this quasi-mythology of 'escape' with reference to the 'quest for utopia' it indexes (Waitt and Markwell 2006). In this section, I seek to examine how a rhetoric of escape emerges in text and talk at the IGLTA convention, with the aim of highlighting how interpersonal meanings grant this rhetoric considerable power, even to a familiar audience. In other words, I hint at some of the ways which quite banal LGBTQ tourism discourse sustains the story of escape which feeds the industry's growth (ergo, its purported power to change the world).

A celebratory tone of LGBTQ visibility politics persists in LGBTQ tourism. As Puar (2002a:935) states, many queers now seem 'proud to be travelling and especially proud to be viable consumers in global, international travel'. 'Pink' tourism professionals are proud to promote this consumption, as evidenced by the last section. There is a more than simply economic value to the industry, however. In many ways, tourism is seen as a way to be visible, and free - it invites LGBTQ people to

\section{come as you are, and come OUT to play!}

Representing these words this way indexes the multimodal rhetorics of authentic, out-of-closet rebirth (if not transcendence) seen frequently in the 'escape' data discussed below. I want to highlight their reliance on fixtures of globalized queer semioscaping: the rainbow, pink and a ubiquitous, unquestioned 'out'. Both of these specific sloganized statements of pride feature prominently in the examples in Guaracino's (2007) 'best practices' guide to gay and lesbian tourism marketing, indicating their communicative currency. Written as a guide for tourism marketers, Guaracino's (2007:69) book provides valuable insight into how this niche sector is perceived; one where 'humour goes a long way' and 'a picture is worth a thousand words', that should 'be attractive, upscale, gay-specific ... [but] avoid stereotyping'. Inasmuch as stereotypes should be avoided, however, the data collected at Spectrum repeatedly indexes purportedly universal elements of Western queer culture - including the ritualized 
'coming out' narrative, which in Butler's (1990) critique constrains sexuality and does not challenge gender binaries or hierarchies. From my experience at Spectrum, it is certain that there is a political-economic value in references to 'coming out' - which, as scholars have pointed out, is always life-long and 'processual' (Sedgwick 1990; Liang 1997). The metaphor of 'the closet' has a significant role in the politics of lesbian and gay movements, and according to many, it is 'the most momentous act in the life of any lesbian and or gay [i.e. queer] person' (Plummer 1995:82). To state the point clearly in the context of this chapter, 'coming out of the closet' is the ultimate 'escape'.

Since the Stonewall era, 'the closet' has been a publicly intelligible signifier for various kinds of LGBTQ epistemologies, but as Sedgwick (1990) tells us, this is only because of the associated politics oriented toward coming out of the closet. In this way, queer modes of being and knowing are centred around quite narrow, fixed frames of outness - escape, and visibility. The practice of coming out serves as a tool through which LGBTQ people imagine their sexual alterity and imagine their belonging to a coherent whole (notwithstanding unwieldy acronyms). For this reason, Liang (1997) defines the act of coming out in terms of its performativity. Coming out calls attention to and asserts identity, while performing it into existence: it is a speech act that not only describes a state of affairs, namely a speaker's gayness, but also brings 'a new gay self, into being' (Liang 1997:293; see also Chirrey 2003). Moreover, it has been argued that the perlocutionary force of the speech act of coming out extends beyond the speaker, to any hearer/s, and the broader social context they speak within (Liang 1997). The perlocution (effect) of coming out is dynamic, unfixed, unpredictable and not immune to prejudice (Chirrey 2003). In the discourse of 'travel with pride' seen at Spectrum, however, it seems immune. Part of coming out's (that is, escaping's) effect is to act as a barrier from harm. Of course, this has profound implications for the immobile: those who cannot (afford to) escape. Oftentimes, as well, coming out as 'escape' is combined with connotations of connection: sexual rendezvous, but also, long-lasting love. Overall, in this section I argue that at Spectrum, a rhetoric of 'escape' intertwines with a ritual/fetish of (at once) movement, mobility, going/ coming out and the affective performativity of space/s as freedom. I show how IGLTA members' representations of LGBTQ tourism practice are both materially entangled with global political economy, and evocatively entangled with embodied desire, hope for freedom to be.

As presented in this section, 'escape' is a heavily mediatized rhetoric, and a number of the texts I discuss come from magazines/brochures I received at the event's marketing stands and during the media networking segment. All are explicitly oriented toward gay travel. I consider takeaway texts like these an important element of event-ethnographic analysis. Following scholars like Milani and Levon (2016), it is important for research of semiosis and/in space to rethink the ways that 'netscapes' and mediatized representations of space both merge with material spaces, and constitute powerful performances of space in and of themselves (Lefebvre 1991). However, delegates' and presenters' off-hand 
comments, conversations and discussions certainly reflected and reinforced what is invoked in the texts below, and in the meta-rhetorical discussion later in this chapter, I underline how the convention space manifested a sense of 'escape'. Suffice to say, as the current chapter makes clear, virtual representations of 'escape' to far-flung locations are a powerful tool for a globalizing habitus of LGBTQ mobility: 'travel with pride'. They were a fixture of the semiotic landscape at Spectrum - featuring in every magazine, and serving as the backdrop to countless presentations. And, as one might expect, this was in itself a backdrop to mentions of New York, Sydney or other gay capitals in many eavesdropped conversations. Escapes - to the city, or to paradise - were a hot topic during work meetings over lunch, networking drinks before dinner and catch-ups in the corridor. The ink that inscribes the discourse of 'travel with pride', in true mediatized fashion, bled from the page into the quotidian 'circulation of meaningful images and interpretations of the world around us' (Park 2018:480).

'Escape' was indexed at Spectrum via appeals to freedom, authenticity, and visibility, with regular (often ribald) claims to the sexual/spiritual release they provide. It had a markedly metropolitan focus, as well as a male one. A German advert for Fort Lauderdale indicated that one can have an Urlaub mit Selbstbewusstsein ('holiday with self-confidence') in 'Florida's gay hotspot'. In a discussion about Fort Lauderdale's lauded destination marketing organization (DMO) LGBTQ micro-site, delegates were given the order: 'Go luxe. Go fab. Go all OUT'. An advert for Vancouver interdiscursively appropriated the look of a mobile dating app, indicating that the Canadian city is 'seeking' all members of the LGBTQ spectrum - and as a green dot indicated, it is always online, always there. 'More than just a pretty face' and 'Looking for a lasting relationship', the 'culturally rich, deliciously urban' city is described as 'the best date you'll ever have'. However, movement to any urban destination, according to a GayCities stall at the media marketing event, allows travellers to discover their 'happy place' - indexed by the inside of a packed club, bathed in an ethereal light. Although to some extent there is much in these extracts which is quintessential to all tourism discourse (e.g. Thurlow and Jaworski 2010a), the multimodal communication of authentic individuality, a 'lasting relationship' with a city and sunny, convivial hedonism takes on a special resonance when directed at LGBTQ people. Place, as a material 'product' in the niche market of LGBTQ tourism, comes to be associated with symbolic values (Heller et al. 2014). In indexing 'outness' and escape', these texts necessarily point to some abstracted, yet intrinsic, sense of confinement - a lack of sexual expression, confidence and/or fulfilment. They point to a constructed 'home' which, following Puar's (2002b) epigraph above, needs to be escaped. Yet, as Puar goes on to note, 'home' can often become a mobile, fluidly defined place - a queer 'homeland' can be something that is sought out, not acquired (cf. Howe 2001). As a result, LGBTQ tourism marketers claim that you can find 'your way' in Greece, or find 'more than just a pretty face' in Vancouver. Thus, movement always offers more-than; entire countries and metropolitan centres can be dates - fabulous 
destinations offering the promise of muscular men, brooding alone, or as part of a frivolous group. Here, both linguistic choices such as a ubiquitous 'out', and the direct address of a synthetically personalized (implicitly alienated) 'you', and visual choices such as horizons and infinity pools, imply that tourism is not just a force for change for the outside world, but for oneself. It indexes a limitless freedom that the everyday of a heterosexist world cannot - an ersatz vision of LGBTQ equality premised on the (marketized) value of being authentic and self-confident.

The dominant presence of (presumably) gay male subjects in the data here is notable: reflective of the bias toward them within the industry (Puar 2002b). According to a boutique marketing consultancy attending Spectrum, much of this presumably stems from men being seen as a quantifiably bigger market share or being more likely to be urban-oriented, less family-driven 'bigger spenders'. Men comprised a far greater share of the conference delegation, in my impression.

Examples in Figure 3.5, from collected marketing for St. Petersburg, Florida (the 2017 host), and Toronto, Canada (the 2018 host), provide further evidence for how LGBTQ tourism presents authenticity as a taken for granted, inand-of-itself positive value, and the inherent outcome of the all-powerful (re-) iterative coming out process. One case in point is the claim that St. Petersburg is 'where the real you shines through'. Whereas tourism is typically understood as a never-ending search for an 'authentic' other (MacCannell 1976), the texts discussed here show how, in LGBTQ tourism landscapes, an authentic self is what is on offer - the chance to be seen (and made visible) as the 'real' you (Giorgi 2002; Holt and Griffin 2003). What is being sold at Spectrum, and in the texts I collected there, is the claiming/forming of identity itself (Plummer 1995; Baker 2005; Trilling 1972).

According to the DMO representative who introduced St. Petersburg as the next host city to Spectrum's delegates, it prides itself on its connection to the LGBTQ community. The top images in Figure 3.5 reproduce ads for the city encountered at Spectrum. They feature messages which, through use of a typical synthetically personalized endearment or imperative, promise St. Petersburg as a locale 'where the real you shines through', where you can 'step outside' and 'glow inside'. In keeping with the 2017 convention theme, Shine, the city's marketing repeatedly indexes a sense of enlightenment, implying that 'out' and proud tourism is a path toward an authentically realized, (literally) bright future. Their marketing anticipates (and sells) the fact that St. Petersburg offers an enlightened exterior space, that crafts a 'glowing' interior; an authenticated, actualized self. But this promised 'brightening' is not limited to St. Petersburg - rather, movement to any city crafts a 'happy place', to echo GayCities above. In texts like these, a chronotope emerges that links LGBTQ futures, space, and authenticity to practices of individual consumption, sexual citizenship and mobility. That is, the 'happy place' GayCities refers to is fixed to a 'there and then' which is not yet here or now (Muñoz 2009). A happy, shining (secure, liberated) time awaits the queer traveller. Figure 3.5's bottom images also point to the 'shining' future awaiting visitors to Toronto. The 

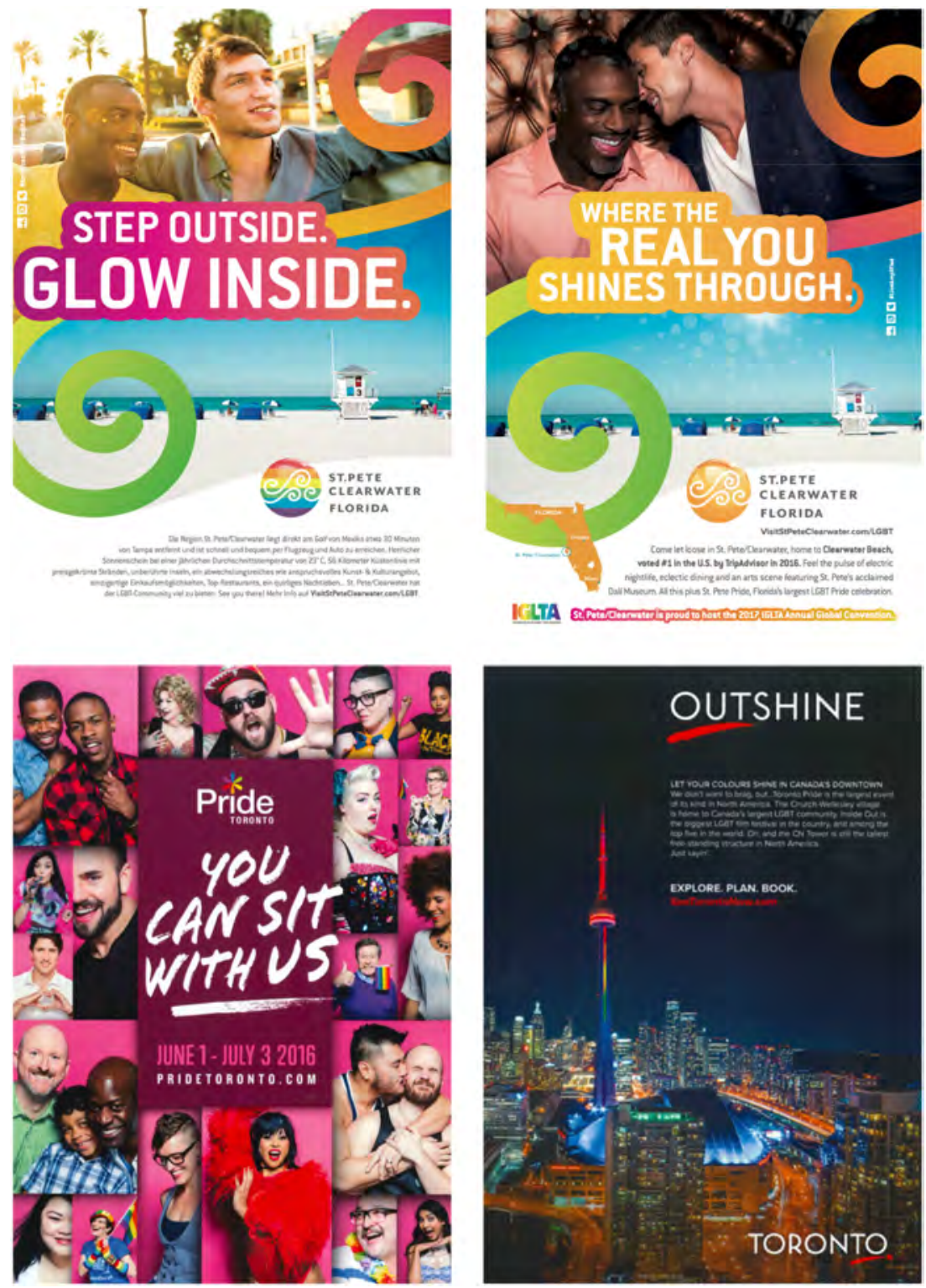

Figure 3.5 The multimodal representation of 'escape' (2016). 
Canadian city is framed as a place where you can 'let your colours shine', where 'you can sit with us' - a humorous intertextual reference to the film Mean Girls (on a bright pink ad for the city's pride celebration). Humour is also salient in Extract 3.3, in which the voice of the city repeatedly alludes to the size of its attractions.

Extract 3.3: Toronto DMO leaflet, 'Outshine' (Figure 3.5, n.d.) LET YOUR COLOURS SHINE IN CANADA'S DOWNTOWN We don't want to brag, but ... Toronto Pride is the largest event of its kind in North America. The Church-Wellesley village is home to Canada's largest LGBT community. Inside Out is the biggest LGBT film festival in the country, and among the top five in the world. Oh, and the CN Tower is still the tallest free-standing structure in North America. Just sayin'.

The 'us' and 'we' here represents a voice for the entire city, represented as a diverse crowd of welcoming faces (it also elides the lingering presence of prejudice in Toronto). The 'you' who visits is shown as a normatively attractive white man (not pictured), shown in a quasi-baptismal position, as if to say he has been reborn by the city. The leaflet's repeated superlatives can be seen as another banal sexed sign (Milani 2015) which replicates stereotypically gay male fixations on penis size, and affectively performs a camp attitude of braggadocio. In calling itself 'Canada's downtown', Toronto's DMO points to the importance of metropolitan downtowns to queer mythologies; such mythologies also sustain the common equation of LGBTQ space with a general city-wide inclusivity (Bell and Binnie 2004; Florida 2002). In sum, short texts like 'outshine', 'you can sit with us' and even the tongue-in-cheek 'just sayin' evocatively signal - and iteratively perform - the value of an authentic identity, of inclusion and of the power of cities like Toronto to bring this value into the world.

The search for somewhere better, freer than home was always salient at the convention, across presentations about topics as varied as social media, responsible travel, millennials, and demographic trends. In this section I have described how these rhetorics of 'escape' emerged in the IGLTA convention and its takeaway material - to provide empirical weight to this foregone conclusion that pink tourism is about being free, and authentic. A great deal of the convention's segments and presentations were devoted to metadiscursive commentary on how this rhetoric could be effectively wielded for profit, and how reaching out (being community-oriented) could become outreach (a model for growth). In doing their job, paradoxically, the tourism professionals at Spectrum continually enshrined the affective, more-than-a-market-segment nature of LGBTQ tourism with that very market segmentation - quantifying the community, and providing raw numbers on who/what they (i.e. we) are.

Overall, much of this discussion echoes what was described with regard to Cape Town's 'Africa's gay capital' discourse in Chapter 3. I see the discourse 
of Cape Town as a gay capital as one strain of a much larger discursive formation in which equality is both sloganized, and materialized in the staging of the IGLTA convention. Within this formation, for some, equality comes to fruition in the escapes represented here, and is called into being in the operation of global LGBTQ tourism's premier event - especially so, when it is held in Africa. In the final part of this analysis, I wish to focus on perhaps the most immediately salient way in which 'escape' was invoked at Spectrum: this first African IGLTA convention itself. It was abundantly clear that for many/most delegates, this business trip involved a great deal of leisure. This prompts me to question how these conventions can serve as escapes in themselves, and to interrogate an important, if under-researched (cf. Cresswell 2010) aspect of transnational mobility: how it feels.

\section{Spectrum: An escapist enactment of good}

\section{It's a sun drenched, gulf kissed, breeze cooled, cabana chillin world.}

Or so says the banner advertising St. Petersburg, standing behind a handsome guitarist, on the night of the convention's closing reception. In this section, I analyse the ways in which a 'sun drenched', 'breeze cooled', 'cabana chillin [sic] world' as ideology, as marketing - manifested in the actions of delegates. I want to know how the event itself was an escape, and I can begin with reference to the guitarist himself. As he played easy-listening acoustic, I overheard some men comment on his looks (indeed, I was myself momentarily struck by them). This would not be worth commenting on, had the St. Petersburg's DMO spokesman (and reception emcee) not made explicit in his presentation just prior that the musician (his straight nephew) had been flown to Cape Town precisely because he could provide entertainment and 'eye candy'. Although this comment is undoubtedly at least partly tongue-in-cheek, in other ways it reveals the unconventional manner in which the convention was constituted. The guitarist was here used at Spectrum in order to make St. Petersburg (and Shine) seem that bit more sexy, and indeed, to make the convention sexier also. In other words, St. Petersburg was spatialized at Spectrum as an attractive destination: a 'sun-drenched' landscape of handsome, sophisticated men. In the corner of this foyer, the guitarist and the stand behind him together rhetorically framed both Shine and Spectrum as uninhibited events; events where there were men to admire, and where it was okay to admire. Events that were escapes from a heteronormative world.

The line between business and pleasure at Spectrum was distinctly blurred. Many delegates were, both officially (e.g. as travel writers) and unofficially (as tourism professionals seeing the city for the first time), in Cape Town to soak up the sights, and enjoy themselves. The way that the convention operated points to how the enactment of delegates' own 'escape', amid an immersive landscape of luxury and fabulousness, brought to bear a self-centred 'force for good' in which structural inequalities remained largely unchallenged. In addition to being heralded as a landmark for Africa, the event was often - proudly 
- described as a party, and often resembled one. It was, however, certainly not a party at which all were welcome. Indeed, for all its talk of inclusion and equality, the enacted and envisioned world of Spectrum was decidedly unequal: the exclusive 'good life' of Figure 3.2's poolside lunch.

One could well argue that Spectrum stood out from many other environments with which it might be compared, through its willingness to play with sexual (and corporate) norms, as well as through the alluring environment it offered delegates. That it not to say that other business events are not sumptuous, or privileged, but rather that the indulgent, free-spirited elements of Spectrum assisted in performing the convention into being as a text. I have already touched upon how the convention's staging in Cape Town was framed by many attendees as an enactment of change itself - an example of tourism being good for the world. Here, in addition to this point, I wish to focus on how the queer performativity of the convention seemed to entice delegates (Milani forthcoming); justifying their individual consumption (as tourism professionals, and as tourists) and celebrating self in place of and as community. From what I experienced at this convention, it seems apparent that a large part of why LGBTQ tourism is seen as such a change-making practice by its attendees comes not just from its economic outcomes, but through their wondrous enjoyment of Spectrum: its typically touristic 'corporeal movement and forms of pleasure' (Urry 2002:152). I say this not to imply that the delegates are all unthinking, eager consumers and consumers alone, but because I know how attractive the sun-drenched vision of queer life it offered was. How it felt. When I took the photograph of the view of Table Mountain in Figure 3.2, like the man in the picture, I was engrossed. I had been in Cape Town for just over 24 hours; slightly jet-lagged, almost overwhelmed by the city's natural beauty. I can only assume that many delegates' breath was taken away by this view just as mine was. From the first evening's cocktail party, to the daily lunches, to the closing reception, the spaces of the convention were (performed as) glamorous and 'VIP', but were also playful: an exuberant escape.

I examine three aspects of Spectrum to build this point before my concluding remarks about its production of a prideful heterotopia (Foucault 1986). Firstly, I examine the video used by IGLTA to advertise the event, which I watched pre-arrival. Secondly, I describe the many ways in which a camp, convivial, and 'carnivalesque' atmosphere was invoked during the day-to-day performance of the event itself (Bakhtin 1968; Harvey 2000). Lastly, I focus particularly on the queer, celebratory atmosphere which came to light at the event's end (perhaps, its climax), the aforementioned closing reception.

The promotional video simply titled 'IGLTA $2016^{8}$ opens with some of the visual rhetorics of escape I discussed in the last section: dappled, ethereal light, and a lone man gazing at the infinitude of the horizon (top left, Figure 3.6). The man is soon joined by another man, and together, they enjoy some of the city's sights. Over an upbeat tune by the popstar Ellie Goulding, these men - a picture-perfect couple - are shown frolicking on the beach, drinking wine, dancing, jogging, and smiling, as well as shopping for colourful briefs. 

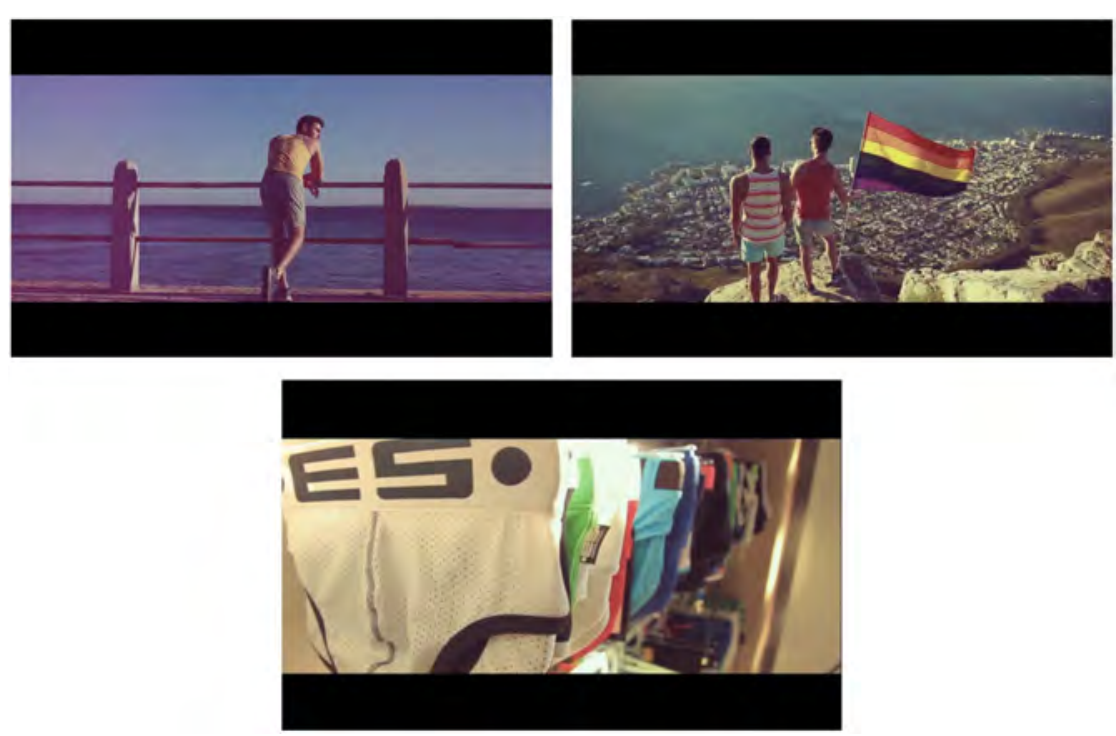

Figure 3.6 Excerpts from the Spectrum promotional video.

The close-up shot of the underwear in Figure 3.6 is just one of many implicit references to Western gay consumer culture in the text. Like with Extract 2.9's referencing of 'baie nice briefs', the underwear is shown 'as if the viewer is engaged with it' (Kress and van Leeuwen 2006:127): invited to consider wearing them, and to touch them, or consider them inhabited by a beautiful man. These young, clean-cut and muscular men (mirroring many of Spectrum's delegates) are shown striding down the street, holding hands without fear of reprisal. Halfway through the video, we meet a lesbian couple - close to the archetype of femme 'lipstick lesbians'. They embrace, do shots at a bar, dance provocatively, and live without fear; as has been noted, this is far from the everyday reality for South African queer women (Tucker 2009). Further along, we see the text's first black South African subjects, dressed in stylish, hipster clothing, indexing a black middle class. As the video ends, we return to the original couple, climbing Table Mountain in the setting sun. They hold hands and raise the rainbow flag, gazing over the horizon and the 'gay capital', flying a symbol of pride, perhaps also as a symbol of the 'right to travel freedom' (echoing Scowsill). The video closes with Spectrum's rainbow silhouette logo of the African continent.

The video does not make explicit whether it presents us with locals or tourists. However, the style/sophistication of its subjects indicates, at least, a lack (indeed, erasure) of material inequalities. Overall, the video offers the same utopian vision of Cape Town I flagged in Chapter 2. It sells the city, though not to tourists, so much as those that sell tourism. The fact that it advertises the 


\section{2}

convention itself raises an interesting question; to what extent is this business event also an excuse for leisure, a way for attendees to soak up (a glimpse of) 'another world' (Muñoz 2009)??' In many ways, this video could be an ad for any other gay capital - Toronto, or St. Petersburg. Many Spectrum attendees travel for a living, and Cape Town is just one of a litany of places they may seek to visit, review, advertise, and build networks in. I don't wish to interrogate this (self-evident) fact, but I do wish to highlight the ways in the upward mobility and consumption shown in this video preface the ideological working of the convention as a whole, and how it is enacted for participants as a joyful retreat from a prejudicial world. It should be noted that very little in the video links it to Spectrum, save for occasional moments where a sticker of the logo resurfaces: floating in the ocean, stuck to a signpost. As well, this video has fewer than 1,200 views up to June 2021 - for its material lavishness (inherent in licencing Ellie Goulding's song alone), it seems to have a very small audience. Presumably, Cape Town's DMO contributed to the video's costs, and it will serve as advertising for the city for as long as it is hosted online. All in all, it is a multi-purpose digital vision of Cape Town as a 'gay capital', and the convention as a chance to let loose. To escape.

The montage of images in Figure 3.7 illustrates how a carnivalesque performance of party, play, and social transgression emerged at Spectrum; an inversion of established or expected norms, which offered a kind of 'second life' outside of the ordinary: 'the suspension of all hierarchical rank, privileges, norms, and prohibitions' (Bakhtin 1968:10). In the first instance, the grounds of the hotel - poolside life - offered a typically touristic setting for leisure. There is no question that the delegates loved indulging in the Belmond Mount Nelson's amenities. Its rooms were extremely luxurious. Each day of the convention, delegates staying at the host hotel were provided with a gift bag containing locally produced wine and preserves. After the volunteer outreach afternoon, I observed many delegates swimming and drinking by the pool - literally and figuratively putting the townships, orphanages, and shelters they had visited behind them. In their actions, and the actions of the convention organizers and sponsors in pampering them, the convention is realized as a space of prestige and progress.

A fancy-free suspension of order is exemplified in the sassy signs and carnival masks, located next to a photobooth (a now-commonplace set-up at festivals and celebrations). The photobooth offered a way for delegates to receive a metonymic memento of both the city and convention at once; the Spectrum logo came printed on the resulting photograph (see my selfie in Figure 3.2). The photobooth was located directly next to the hall hosting plenary sessions of the conference - the business and education sessions were therefore spatially linked to much less 'serious' aspects of the event, in which delegates' own leisure was foregrounded. The 'I'm still single' sign points to an element of the convention which was always salient, if only addressed through sassy asides and flirty remarks: the opportunity for delegates to hook up. These are literal banal sexed signs (Milani 2015), and the performances they allow for are especially 

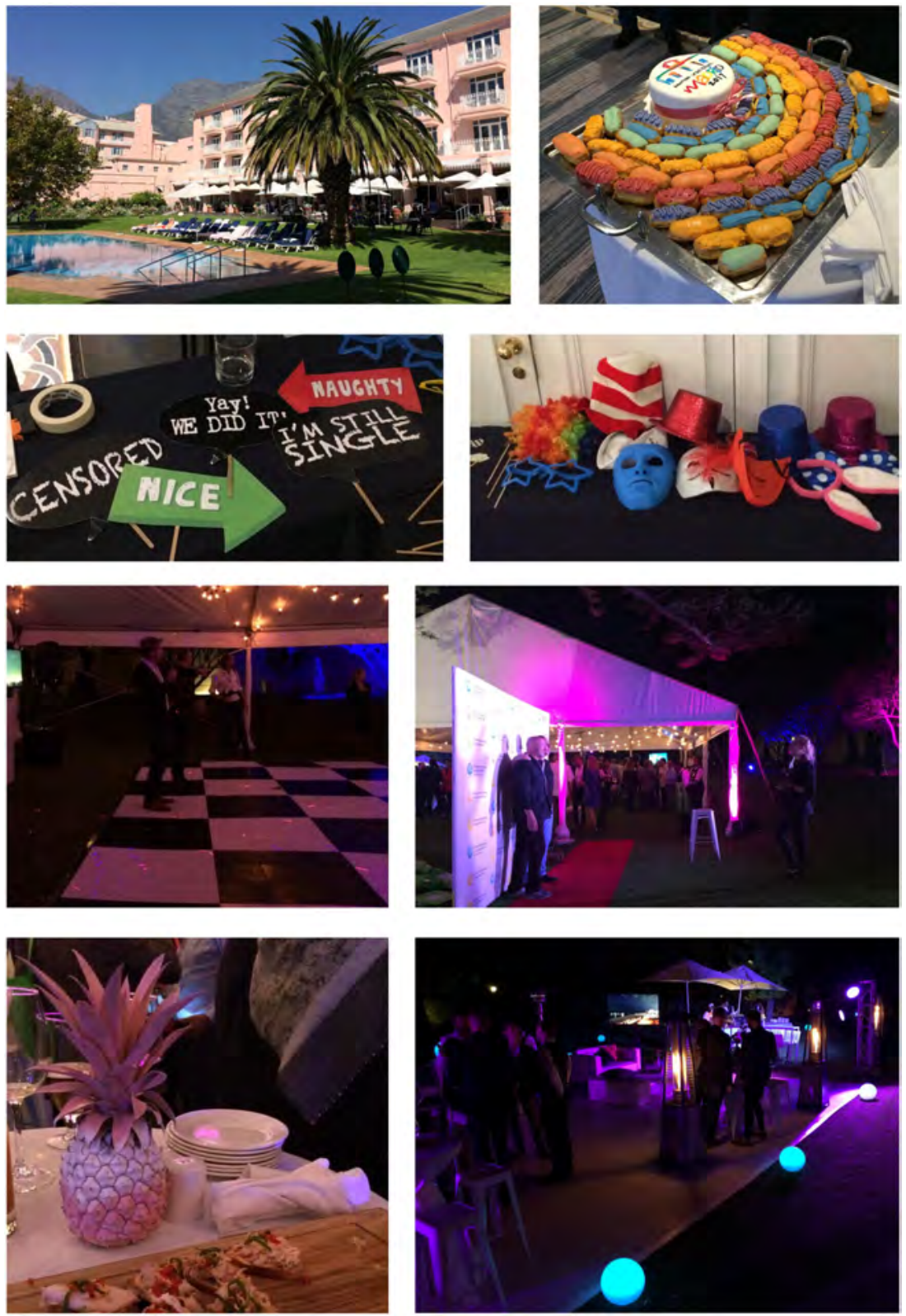

Figure 3.7 Montage of carnivalesque aspects of Spectrum's staging. 


\section{Representing the Spectrum}

significant at a corporate event, characterizing the space as somehow transgressive; indeed, 'naughty'.

A morning tea with coffee and cakes became an opportunity to market the 2017 WorldPride in Madrid, but also to perform a modest affect of pride, indexed by an arrangement of rainbow icing. Simple semiotics of LGBTQ pride emerged in Spectrum's day to day, with a dual function of earnest, liberated queer celebration and camp performativity. The affordances of the event space meant that these doubled meaning potentials were truly immersive expressed through talk, text, object, and abstract, as well as vibe. While eating one of the profiteroles from the rainbow, the founder of the aforementioned app (p. 102) and I spoke casually about his 'lifestyle platform'. I could not help but sense he was flirting with me. Just beforehand, spokespeople for Madrid had given a wink-heavy presentation about how 'hot' and 'fabulous' the city was (their stand offered fans for delegates to take away - another index of the city's 'hotness'). At other points, a male presenter spoke camply of his love of the colour pink: 'that's just the kind of girl I am' (cf. Harvey 2000). The emcee at the opening party lavished praise on the cocktail dresses of many attendees: 'too chic ... dressin' up for y'all'. During a prominently scheduled 'CEO chat' with the heads of the DMOs for New York City, Washington DC, Brazil, and Cape Town, the lively moderator effusively praised the men, and ordered that their water be replaced with champagne - indexing both elite status, and flamboyant excess. As she later tweeted, performative flourishes like 'just the rt [right] amount of bubbly' are the 'secret to success' to moderating a panel the 'rt leaders'. On his wrist, one of the CEOs still had a trace of a club stamp from the night before; a transitory skinscape (Peck and Stroud 2015), indexing the seedy 'atmospheres' of a club, and emblematic of the mood of the convention. (Each night of the convention, for many, ended at gay bars in De Waterkant.) He made a point of acting unsure about the prospect of champagne 'the morning after', to knowing chuckles from the audience.

Suffice to say, at no point was the convention ever fully work-like, or fully free-wheeling, but always both - a place of stylized camp, but also, no doubt, where camp emerged naturally as a consequence of the liberated atmosphere, including across talk (Harvey 2000). Spectrum's enactment, in other words, involved both performance - a doing of queer liberation - and performativity - a folding of these performers of queer liberation into the reproduction and subversion of 'travel with pride' discourse (Gregson and Rose 2000). Carnivalesque sites are generally understood as places of resistance and counter-hegemony, and scholars have previously characterized sites of pride this way as well (e.g. Markwell and Waitt 2009; Bennett 2017). However, I wish to assert that the 'carnival' mood at Spectrum - a 'carnival time' when life is 'subject only to ... the laws of its own freedom' (Bakhtin 1968:7) - is in fact testament to how the convention was deeply imbricated within a deeper paradigm of mobility for some, and immobility for others. As a period freed from normative/hierarchical moorings, Spectrum's 'carnival time' is analogous to the concept of 'queer time' (Halberstam 2005) - a mode of temporality 
attuned to queer subculture. However, whether it is seen as 'carnival' or 'queer', the emancipatory spirit enshrined in many aspects of Spectum's staging in fact disguises how it is a 'site of ordered disorder', encouraging a 'controlled de-control' (in ways typical for tourism; Edensor 2001). Spectrum evidences how landscapes of LGBTQ tourism, in which norms are transgressed and toyed with, can also become sites of discipline - through which modes of liberation are bound to projects of individualist consumption.

I came to understand the dramaturgical, carnivalesque spirit of the convention most fully through its closing reception, and its dancefloor. St. Petersburg's representative made clear in his welcome speech how he viewed the city's get-together in very simple terms, disavowing how it was represented in the event booklet: 'It's not a “closing reception", it's a party, c'mon!'. Indeed, as the lower four images in Figure 3.7 indicate, the closing reception was framed not only as a party, but an exclusive one - down to the red carpet and professional photographer set up at its entrance on the hotel's pristine lawn. It was well-catered, and alcohol-fuelled, with a fully stocked cocktail bar. Certainly, the emcee representing St. Petersburg made clear that they wished to treat delegates well, indicating that his 'fabulous' city had a lot to live up to, after Spectrum. It seemed the IGLTA convention is always constructed not only as an opportunity to do business, but an annual chance to mingle with others, form bonds, and celebrate community. The entrance declared: 'It's not goodbye, only farewell till next year!' Pastel pink lighting, spray-painted pink pineapples as table decoration and a central checkerboard dancefloor all pointed to the party as a camp celebration of pride.

On this dancefloor, I felt deeply connected to other delegates. It is also where I intuited the innate tensions between what the convention offers and what it envisions most profoundly; contradictions between a gestalt-like affirmation of place, history, and identity, of equality, and a clearly defined boundary between those that celebrate, and those that are silent, absent or uninvited. The soundtrack repeatedly called upon disco and early house classics: a style of music which for many queers (and especially gay males) is 'about performing imagined histories of community belonging and the spectatorial enjoyment of the enactment of that performance' (Currid 1995:180). Over the course of the evening's festivities, I heard iconic tracks by Gloria Gaynor, Donna Summer and the Pointer Sisters, ABBA, Madonna and a personal favourite, as well: CeCe Peniston's 'Finally' (a strong intertextual relation exists between this song and the cult queer Australian film, Priscilla: Queen of the Desert). Overwhelmingly, this is music made by divas, whose 'fast and heavy beat, colourfully synthesized sounds, and comforting sentiments' have historically enabled the queer celebration of "family" in spaces that are physical, yet transcendent' (Brett et al. 1994:370). Some scholars have argued in relation to diva worship that gay men engage divas as 'imaginary figures of therapeutic escapism' (Farmer 2005:169). In this perspective, when the crowd of delegates sang along to 'We Are Family', by Sister Sledge, they sought to transcend normative materiality, and reconstruct, 'at least in fantasy, a more capacious, kinder, queerer 
world' (Farmer 2005:170). The sight of a conga line forming on the dancefloor perhaps underlined most the extent to which the staging of the convention played with formal norms of corporate space. It was fun. Through these playful moments, senses of the carnivalesque and a transcendent (perhaps utopic) more-than-materiality were foregrounded. In carnivalesque actions, 'the individual body ceases to a certain extent to be itself; it is possible, so to say, to exchange bodies, to be renewed. At the same time the people become aware of their sensual, material bodily unity and community' (Bakhtin 1968:255). Lyrical/linguistic and material/embodied practices like 'we are family' and a conga line established a unity between participants, allowing for the transgression and renegotiation of societal bounds and the boundaries between bodies. They capture sensual and sexualized affects which often lie under the surface, unrealized. The convention, my body and the affective discourse of 'travel with pride' here all begin blending into one. Once the party ended, however, I witnessed the black (majority female) African catering staff cleaning up the mess that had been created by an overwhelmingly white, wealthy and male crowd. I was reminded of just how much remained unchallenged in LGBTQ tourism discourses/practices. How can something that makes my heart, and life, so full be so reliant on others staying bereft?

The transgressive atmosphere of pride at the closing party and the convention as a whole is necessarily compliant with transnational inequalities along axes of race, gender, mobility, and class. However, I have not yet adequately described the end-point of this seeming contradiction: the affective legitimation of 'travel with pride'. I now turn to summing up the points made here, and to highlighting how, in its juxtaposition of sex and sales, pride and profit, carnival and compliance, the landscape of the event became a heterotopia.

\section{Concluding discussion: The 'good life' and self-actualization as neoliberal citizenship}

Through this analysis, I have presented a critical account for the discursive formation of 'travel with pride'. I already began exploring this discursive formation in Chapter 2, following scholars like Waitt and Markwell (2006) and Puar (2002a, b) in describing how travel is framed for Western queers as a 'quest for utopia', away from heterosexism. In this chapter, I sought to understand the processes of production underlying these discourses, to understand why they are so effective, and why so many tourism professionals believe in them so steadfastly. As I said above, the landscape of the IGLTA convention invites its transitory audience members to imagine, and inhabit, 'another world', echoing Muñoz (2009). In this concluding discussion, I want to describe how the event crafts a heterotopia, following Foucault (1986), which 'contrasts and mirrors its past, its contemporary, and its opposition' (Lou 2007:191), and enacts what has not (yet) happened, or cannot happen, in the world we have.

I have argued that the lavish staging of the convention and its presentations, assorted marketing and performative atmosphere (cf. Gregson and Rose 
2000) altogether work to create a landscape that is both vastly unequal and the 'picture' of equality. I thus expand upon the critiques of LGBTQ tourism discourse in Chapter 2 to highlight the capillarity of 'travel with pride', extending its reach worldwide from metropole to metropole, to note how tourism professionals are enmeshed by/with its camp, carnivalesque materialization. What seems unquestionably positive is in fact a contingent set of representations, practices and indeed, emotions. The convention beckons its delegates to soak up the story of tourism as a force for development, of their individual role as a 'light' for Africa, of tourism as an authentic pursuit, and to enjoy the annual party which celebrates the industry. Spectrum's landscape is heavy with indexical reference to the archetypal 'coming out' narrative within Western culture, in which 'visibility politics supplies much of the force of certain forms of gay and lesbian travel' (Puar 2002b:102). These politics subsist on a mythology of the 'other world' tourism creates, and the transcendent way in which liberation is supposedly called into being through the visibility of travel. Under the sway of global capitalism, however, these politics are profoundly entangled with legacies of colonial exploitation and contradictory understandings of LGBTQ people as a market segment, as well as much more - a community. The IGLTA convention is thus made possible through an 'unfinished but profound revolution' (Weeks' 2007:3), and within this revolution, the gay tourist emerges as a persona 'that combines travel, social progress, and politics in new ways' (Giorgi 2002:57). Through my evocative experience at Spectrum, I witnessed how the rhetorical skill of tourism marketers, at once, sells tourism as a 'force for good', asserts tourism's value as an 'escape' from heteronorms and transforms a corporate event into a playful, self-aggrandizing form of 'escape'. All told, the convention is a skilful legitimation of privilege - of global tourism as a vehicle for progress, self-actualization as progress for others and parties as progress. This is, I believe, precisely what McDermott (2011:76; Weeks 2007) warns of when she speaks to the consequences of ignoring our 'unfinished revolution': 'the danger is that the world will only be "won" by the socially privileged'.

The inherent contradictions between socially progressive politics and conspicuously consumptive practices, between 'the world we have won' and the injustices still impacting that world, and between individual recognition and collective transformation, lead me to characterize the convention as a heterotopia. It is a location where neoliberalism is distinctly desired, for its ability to secure tolerance, queer sublimity and global mobility for seemingly all LGBTQ people, despite the fact that an entrepreneurial neoliberal citizen is by definition disinvested in the needs or desires of others (Ludwig 2016; Brown 2005).

Heterotopias, as 'effectively enacted utopias', are capable of welcoming subjects into a world that is both materially situated and bound, but also elsewhere; dislocated from that material environment in order to produce an alternative, immaterial space which both challenges and sustains the original (Lefebvre 1991). As a heterotopia, the IGLTA convention is produced 'simultaneously 
in space and in time, often in multiply imagined spaces and time frames' (Blommaert 2010:42). It thus highlights the real, 2016 manifestation of Cape Town, and its inequalities, but also brings calls forth an alternate imagining of the city untethered from geographic, historical, and racialized divides - however incongruous this might be. Heterotopias open up spaces 'of rest, refuge, and play ... of, and for, the imagination' (Johnson 2013:798), and can distort the conventional experience of time. The heartfelt renditions of decades-old diva songs index this quality in part, but most of all, I see this aspect of heterotopia enacted at Spectrum via the consistent indexing of queer futurity (Muñoz 2009). In rhetorics like 'your happy place', we find evidence for 'the intrinsic connectedness of spatial and temporal relationships' (Bakhtin 1981:84) - where the promise of a free space is always, likewise, a promise of a transcendent, secure time. Carnivalesque spaces like the convention itself also offer the promise of a life subject to only its own laws (Bakhtin 1968). They signal 'queer time' - the turn away from the narrative coherence of adolescence, adulthood, matrimony and child-rearing (Halberstam 2005). However, rather than being radical or progressive, the queer times indexed at Spectrum seem more tied to luxury and (stylized) camp performativity, than to a rejection of normative boundaries (or economic orthodoxy). Movement to the space-times available through travel is regularly framed as exclusive, deluxe or enterprising; the product of one's discovery of an authentic self (MacCannell 1976), and often a form of queer pilgrimage (Howe 2001). When exposed to the discourses of 'travel with pride' - by studying them, producing them, glamorizing them and living it up themselves - the audience at the IGLTA convention is compelled further to both desire this life for themselves (quite reasonably) and believe in its capacity to enact another world. This world - this heterotopia - is enacted for them at the event. This shows, to paraphrase Pellegrini (2002), that capitalism can easily accommodate gay identity without fundamentally undermining its structuring inequalities. It just needs to show it a good time.

Ultimately, while rhetoric of 'the human side' of tourism, delivered by charismatic marketing professionals, is alluring, the truth is that these performers and storytellers of/about travel ('with pride') as a force for good are in fact just very good at selling travel. One should also acknowledge the fact that these tourism leaders' audience is in fact one with an exceedingly large number of global customers: a 'second order' audience oriented outwards into the world, guided by actively curated marketing, but also unsteered, crafting myriad models of transnational mobility, individualism, and authentic identity (and one as the other). Through them begins an iterative process, through which the fable of a happy place - a gay capital like Cape Town - can be posted online, retold again and again, compelling tourists' desire for an explicitly self-actualized site of safety, carnival, and cosmopolitan freedom.

Even positive fables of African hospitality and common humanity like those seen at Spectrum - ubuntu - are folded into the logics of neoliberal capital, whereby they become slogans, selling points, and boosts to GDP. Echoing Extract 2.6, one might wonder whether for some subjects it really is "hard to 
imagine' a project to change the world that is not limited to the ersatz equality I saw at Spectrum. However, many delegates at Spectrum voiced critiques or concerns with the staging and character of the event: one who described his discomfort with the massive white and gold deluxe coach that drove him through local slums; another who decried how he 'pranced' as a tourist through an LGBTQ shelter on the outreach afternoon; another who works to forecast the 'bright future' of LGBTQ travel for IGLTA and the UN WTO, but like me expressed doubts in its cosmopolitan rhetoric. Overall, however, the heterotopia at Spectrum enacts a world in which LGBTQ rights are respected and celebrated, but which also desires an economic system which exploits or disregards the extension of those rights to those that cannot afford them, or those whose citizenship denies them. This necessarily has profound impacts for how the discourse of 'travel with pride' ripples and circulates outward from the convention, into how LGBTQ people perceive of themselves, their own mobility and social movements for equality in the current day. It shows how standard mythologies of tourism as intercultural, globalizing exchange take on new valence in the context of the growing global LGBTQ rights movement. In my interpretation, there is no question that the texts examined here - including Spectrum as a whole - at least valorize identities that are premised around transnational and mobile forms of consumption. They perhaps also inspire a neglect for other forms of injustice. Here, I follow on from other queer/feminist scholars such as Gill and Kanai (2018:319) who underline the importance of research that '[takes] neoliberalism seriously via its affective and psychic registers, as an increasingly central means of governing and producing people's desires, attachments, and modes of "getting by". Thus, I have pointed to the ways in which actors at Spectrum foreground the entrepreneurial self, calling forth 'a hedonistic "emboldened" attitude' rather than transformative social, economic or political change (Gill and Kanai 2018).

At the heterotopic IGLTA convention, forms of affective legitimation are used to equate economic prosperity with wellbeing, favour 'diversity' over solidarity, tie self-determination and self-responsibility to the pursuit and 'promise of happiness' (Ahmed 2010) and offer 'the promise of being able to be one's true self, which is framed as the ultimate freedom' (Ludwig 2016:421). By legitimating actions on an affective basis, through forms of 'sticking together' (Ahmed 2004, 2014), inspiration, positivity, the archetypal 'good life' and the value of being one's 'true self (and its attendant entrepreneurialism), these institutions don't just govern over sexual minorities, they prompt them to govern themselves. The confident voice of a representative at Spectrum exemplified this ethos: 'Not only is it the right thing to do, it's the right thing to do for the economy'. As their presentation boasted, 'equality pays off. This desire to claim - and flaunt - one's 'true self', of course, corresponds with historical coming out narratives (Plummer 1995). This 'ultimate freedom' of being yourself is always seen as preferable to the alternatives - being tired or afraid (Baker 2005). Thus, adopting an LGBTQ identity assists in crafting the 'model neoliberal citizen', a person whose sense of self mediates their relation to 
others; 'one who strategizes for her- or himself among various social, political, and economic options, not one who strives with others to alter or organize these options' (Brown 2005:43).

In this way, sexual citizenship becomes tied, economically and affectively, to neoliberal citizenship, and acts of travel iteratively mediate and reinforce their co-dependence. In this way, travel becomes a way to celebrate one's pride, forever, and to bring a bright, cosmopolitan future into being. Affirmation is framed as transformation. It may be, however, that in this frame, that staying home, or staying 'in', may be to languish in oppression - to not escape. Perhaps, it is a submission to an unchanged, otherwise unequal world.

\section{Notes}

1 Notably, both images in Figure 3.1 come from series of stock photographs available from iStock, by Getty Images, the world-leading image bank. Figure 2.5 also featured the men on the right. Image banks like Getty nowadays provide 'ideologically pre-structured worlds' (Machin 2004:335) which stylize and harmonize audiences' expectations for how the world is represented, shaping forms of 'difference' and 'diversity' along ideological lines, in the service of capital. Machin's (2004) and Aiello and Woodhouse's (2016) studies demonstrate why we must be wary of how a mediatized queer semioscape, however banal, may inscribe norms on how LGBTQ couples should look, behave and feel.

2 Available at: https://www.iglta.org/media/1364771/iglta-timeline.pdf.

3 Available at: https://www.iglta.org/media/1364108/2016-convention-review.pdf.

4 Information about previous conventions is available from IGLTA's website; at the time of writing, more detail is available for those held since 2013. Prior to being held in South Africa, the event had been held primarily in mainland North America, in Europe on five occasions, and in San Juan, Puerto Rico (1985), Sydney, Australia (1996) and Florianopolis, Brazil (2012).

5 See: http://www.cloud-europamundo.com/files/2016_11/WTTC_Convencion_An ual_Euro pamundo_Parma.pdf.

6 Though, as I noted in the introduction, and as Thurlow and Jaworski (2010a) have highlighted, these numbers are generally comprised of the same people travelling on multiple occasions, for business, leisure or otherwise - true 'tourists', not 'vagabonds', in Bauman's (1998) terms.

7 Available at: https://vimeo.com/146898154.

8 Available at: https://youtu.be/Ks0mHPIBIG8.

9 One may also question to what extent it is an excuse for $m e$ to do research in a beautiful setting - how does the city's appeal influence my decision to study it? I am reflective of - and extremely grateful for - the social position that allows me to venture to Cape Town. 


\section{London, June 2016}

It's about when I get my third or fourth kiss on the cheek that I realise how much fun I'm having - but also that I might want to take a break before cracking open my next beer. Standing at the sidelines, blowing kisses to the parade - the drag queens on floats, the elders of the community, the doms, the subs, the furries and puppies, and all the cute little normie homos marching along with their friends and colleagues. The London Pride Parade in 2016 is a scene of joy, and revelry, as well as defiance, in light of events in Orlando the week beforehand. It is a shifting sea of sexual alterities, united in an action that is personal, political and perhaps most of all, celebratory. A party.

From where I'm standing (dancing, drinking, feeling myself), Regent Street is a huge fucking party.

I'm with my mate Steve, along with Citibank, and Marks \& Spencer (and Starbucks, Barclays and all the other companies using colourful frames as social mediafriendly props). With their help, the message is sent: 'live and love', 'be yourself', with \#NOFILTER. We're encouraged to frame those selves, to uphold them; to sassily push our authenticity out there, to remediate and share that fact. And we (or at least I) am happy to oblige. It's all part of the fun of the day.

As many have noted, the rapturous atmosphere of London Pride is nowadays as much a site of commerce as of protest (like many other pride parades worldwide). There is no point denying the fact that a company like Citibank stands to benefit financially from being seen 'on the right side of history': supportive of LGBTQ employees and customers. Perhaps it is much more interesting to question how I stand to benefit, materially and emotionally, from this embrace by a corporate entity.

In other words, perhaps the better critique of so-called 'rainbow capitalism' and 'pinkwashing' is not one that focuses on what's in it for the corporate agents plugging their queer credentials, but what's in it for me - how does someone like me stand to gain from the commodification of pride? How might the very possibility of pride-as-product rest on how the affective rhetorics of corporate inclusion feel to individuals; the psychic consequences of being supported, encouraged, even 'loved' by the forces of capital?

One might describe a pride parade as a 'transitory semiotic landscape' (Hanauer 2013). It is a complex array of diverse communicative resources, materialized in diverse forms, in constant motion and often fleeting - even as fleeting as the short life of a bubble, blown by a marching Tesco employee, or me, or anyone else who 'bursts' with pride. 

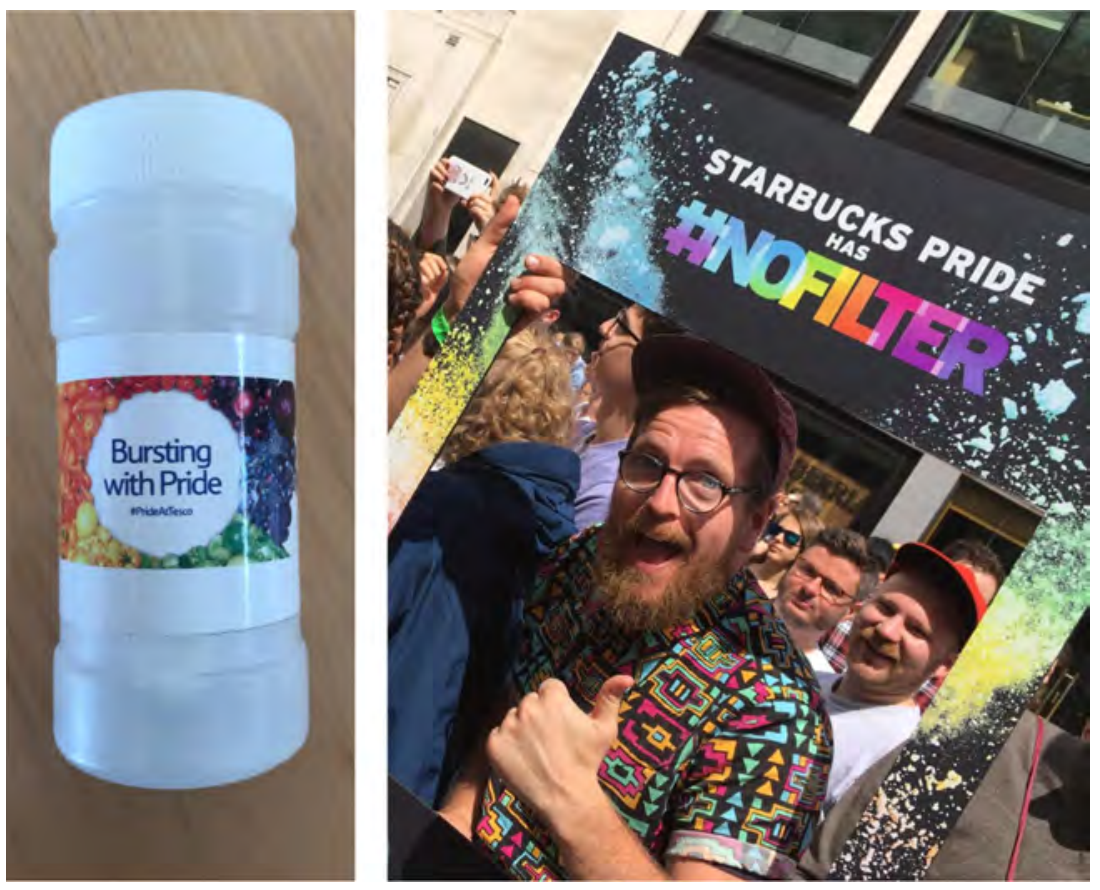

In reality, however, this landscape is rather something more like a wave, a flow, a force. An 'atmosphere'. A queerscape, in which material-affective-semiotic processes like the 'bursting' of pride are key resources, instilling a transitory 'affective regime' (Wee 2016). I'm so happy to be at London Pride, and so happy to drunkenly dance to all these artists, all these songs. All this celebration - of self and community - is making me feel absolutely fabulous.

I'm so happy, I could burst with pride. And thanks to Tesco, thanks to Citibank and thanks to all the forces of the market, I am free to keep on bursting. To live, to love. No filter. 


\title{
4 Counting 'the cost of discrimination'
}

\author{
Managing LGBTQ diversity at The \\ Economist's Pride and Prejudice
}

\section{Introduction: The Economist's Pride and Prejudice}

In this chapter, I expand my scope from tourism to the workings of contemporary global capitalism writ large - 'the capitalist present', in Blommaert's (2010:1) words. Global capitalism undergirds both the embodied mobility of people and the rhetorics of 'travel with pride' described in previous chapters. It is the latter, I argue, which render the former as legitimate and desirable: examples of the rhetorics invoked by governments and other powerful institutions 'to justify their voluntary surrender to the financial markets' (Bourdieu and Wacquant 2001:4). Globalizing processes signal 'new freedom for some ... [and an] uninvited and cruel fate for many others', setting in place inequities between 'global, extraterritorial elites and the ever more "localized" [immobile] rest' (Bauman 1998:2). Understanding the power of this rhetoric behoves the examination of globalization's discursive basis: how one's 'cruel fate' becomes another's 'pot of gold'. To this end, the rest of this book is devoted not simply to understanding the mobility of queer people, but rather to reflecting further on the semiotic resources (and situated practices) which help constitute their identities, worldviews and the broader circumstances of their movement - exemplified in Figure 4.1.

These types of resources flow through (and constitute) the global semioscape (Thurlow and Aiello 2007): the circulation of meaning-making practices which bring unified forms of globalized habitus to the fore, and bind together people, technologies, financial resources, information, media images, individuals, nation-states and commonly conceived cultural and political ideologies. As it is described in this book, the 'rainbow' in Figure 4.1 (its name and visual representation) can perhaps be seen as the sine qua non signifier of LGBTQ identity within this global semioscape. The rainbow is a fixture of media which refer to queer people (see Chapter 2 and 3), and its correlating indexicality of a cohesive, affirmed diversity - inclusive of an 'identificatory positivity' (Fraser 1995:83) - is a fundamental part of the burgeoning 'queer semioscape' this book accounts for.

This semioscape is complicated by the process of mediatization, whereby society is increasingly dependent on logics of the media, and often, the logic 


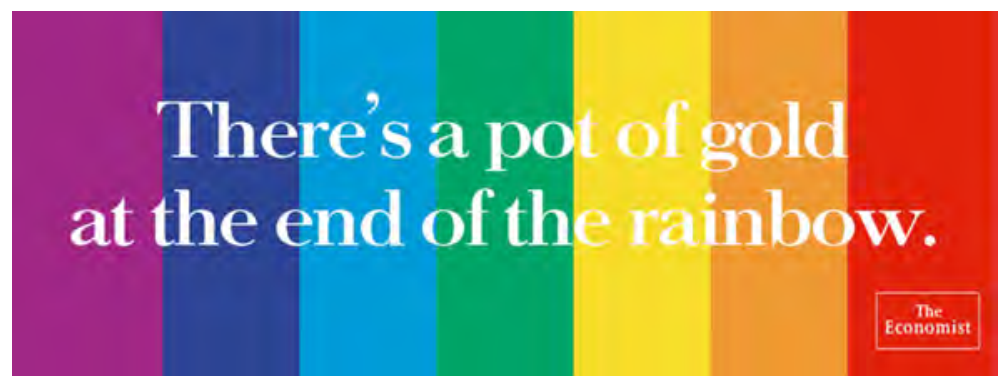

Figure 4.1 The Economist's claims to prosperity and/as equality.

of institutions with editorial lines, vested interests, and (however much they deny them) geographic and national ties, such as The Economist, the producer of Figure 4.1. Although he does not identify it as such, we can see mediatization in the way Zevin (2019) describes The Economist, in his extended analysis of the magazine's relation to the globe. In his words, 'what truly sets the Economist apart is the way it has shaped the very world its readers inhabit, by virtue of three close relationships: to liberalism, to finance, and to state power' (Zevin 2019:5). As a powerful player across the global mediascape, with a proudly classical liberal stance, The Economist plays a significant role in proliferating the rhetoric of globalization that Bourdieu and Wacquant (2001) have critically remarked upon, as: the vital integration of markets; apolitical; inevitable; unsteered and apolitical; beneficial to all; and democratic and democratizing (Steger 2008, 2009). In this chapter, I begin examining what mediatized (and emplaced) discourses of and about sexual others (like Figure 4.1) perform in the hands of institutions like The Economist: how they follow logics and imagine futures which 'fold them into life', but at a significant, and covert, cost (cf. Puar 2007). I point not only to the rhetorical emergence of neoliberal ideals in seemingly progressive or celebratory texts, but also describe how these ideals strategically enshrine the model 'neoliberal citizen' (Brown 2005). This model of citizenship constrains the possibility of alternatives, limits conditions of possibility and sets bounds on how the world is imagined. Chapter 3's event ethnography examined the ongoing development of one facet of neoliberal citizenship. This chapter's study uses event ethnography to examine another facet, at another event: the powerful discourse of 'diversity' arising at The Economist's 2016 conference Pride and Prejudice: 'a global LGBT conference and initiative that will catalyse fresh debate on the economic and human costs of discrimination against the LGBT community'. ${ }^{1}$

In line with The Economist's self-definition as a 'lodestar of liberalism' (Zevin 2019:7), the social media banner image in Figure 4.1 is thus meant to radiate an affective, yet rationally marketized, message of hope: 'there's a pot of gold at the end of the rainbow'. The rainbow invokes the prideful queer semioscape, but this text also indexes the ideo-, finance-, and mediascapes market-friendly 
globalism that The Economist inhabits. An intertextual link to The Economist occurs through the crisp white Milo Serif font being used, drawing a recognisable link between Figure 4.1's expression of classically liberal values, and the magazine itself. As Zevin (2019:2) remarks, 'slick marketing' - right down to font choice - is how the magazine '[tugs] at the insecurities of striving readers'. The text, in short, it is about profit - cleverly, succinctly stating to its audience that a multimodal discourse of sexual diversity is valuable in economic terms, as well as, if not more than, in terms of social good. It is part of a recent groundswell of support within the corporate sector for LGBTQ diversity, inclusion and 'pride at work'. The push for the recognition of diversity along lines of sexual orientation and gender identity (often marked via the unwieldy acronym, SOGI) follows from older initiatives which have as their focus ethnic and racial diversity, or tackling the 'glass ceiling' for women. Importantly, however, following Ahmed's feminist critiques of the language of 'diversity', diversity 'has been attributed with a problematic genealogy, as having dubious origins, and uncertain and potentially damaging effects' (Ahmed 2007:236). Explication on what diversity actually is, what it includes and thereby what/who it necessarily excludes, remains muffled by the evocative sounds of celebration - the frisson of affirmation. As Ahmed (2007, 2012) and others have noted, however, that may be precisely its purpose: to foreground a fuzzy agreeability and unarguability - to look good, rather than do good.

Figure 4.1 at once indexes, realizes and justifies late-capitalist global political economy - it advertises the seemingly endless possibilities of the liberal values The Economist espouses, despite it being unclear whose pot of gold is being referenced, who the rainbow represents or where it springs from. Figure 4.1 exemplifies the politics of recognition (Fraser 1995). Again following the work of Sara Ahmed $(2004,2014)$, however, there is also an affective economy in play here - shared emotional dispositions, values and visions of a better world, presumably for all. As this chapter will demonstrate, otherwise rational, managerial discourse can often be shot through with sly winks, appeals to love and other emotions, further mediating - and entangling - the relationship between the market, the state, the individual and the collective. Affect arises in the movement of mediatized texts such as Figure 4.1, and the more they circulate, 'the more affective they become' (Ahmed 2004:45). In this chapter, I will outline how this also makes them more effective at enshrining a moral framework which aligns with and legitimates the rhetorics of global neoliberalism.

The event's name (as the same webpage explained) referred to how what The Economist called the 'LGBT world' is dividing into two sharply opposed camps: Pride, where 'in many developed countries particularly, the mood is one of celebration', and Prejudice, where 'elsewhere the situation ranges from mild intolerance to hostile rejection and violence'. In The Economist's estimation, these camps essentially equate to the 'ever more gay-friendly West' and 'the [then] 77 countries that still outlaw homosexual acts between consenting adults'. Although there is a concentration of homophobic legislation in Africa and the Islamic world, and The Economist notes that much also still needs to be done in the West, this description is biased and inaccurate (Awondo 
et al. 2012). Importantly, it contributes to an evolutionary narrative - 'we were like them, but have developed, they are like we were and have yet to develop' (Hoad 2000:148) - which many have derided as narrow, ethnocentric teleology. After all, while the specific notion of 'gay identity' may follow from capitalism's weakening of the material foundation of familial living (cf. D'Emilio 1983), there is no reason to assume that homosexual practices and diverse sexual identities do, as well. Even the assertion of an 'LGBT world' subtly reinforces Western epistemologies of sex/uality, despite how scholars in queer linguistics alone have documented same-sex sexual practices/identity formation in the non-West (e.g. Livia and Hall 1997). While The Economist does not explicitly deny that these practices exist outside of the West, Pride and Prejudice's agenda nonetheless exemplifies how it contributes to a spatial (and temporal) imaginary 'whereby non-Western places are imagined as contemporary re-enactments of Western pasts' (Rao 2014:174). This imaginary is deeply entangled with the broader imaginaries of Western-style development as a 'global faith' (Rist 2008) that The Economist devotedly follows. ${ }^{2}$

I intend my study of Pride and Prejudice to serve as a warning about who we allow to direct the course of global politics, and how 'diversity' talk that appears to bring forth positive change may be better understood as a way not to make change at all. As a progressive act of solidarity and 'global citizenship' on behalf of The Economist, Pride and Prejudice sits on shaky foundations. In contrast to Spectrum, the landscape at Pride and Prejudice was camp only in brief moments, blithely professional and overall not particularly - or at least only momentarily queer. It was a positive, safe space, certainly, and there is no doubt something to celebrate in the mere fact it took place (and has continued to take place since). However, in my reading of the event, the 'affective regime' (Wee 2016) that arose there was less likely to invoke a sense of hope, or freedom, than the thrill of success: the allure of prosperity. In this, there is no contradiction; the event's affective regime matched perfectly with the corporate context it was enacted in, one where diversity served as a 'mechanism of asserting the superiority of one form of politics over others' (Ahmed 2012:151). An ideal case study for complex interrelations of the corporate world, media, social actors and affects within discourses of diversity, Pride and Prejudice is arguably the most significant push for so-called SOGI diversity in the business sector that the world has seen. At the very least, it is designated as such by The Economist itself.

Although delegates earnestly sought to represent the prideful face of global commerce, ultimately the event hinged on a single narrative of liberalization and marketization. This narrative is exemplified in the branding seen in Figure 4.2 , which displays the aestheticized representations of diversity that extended to the event booklet and other material. The underlying objective of the conference was clear: 'the business and economic case for LGBT diversity and inclusion'. In this chapter, I am not simply identifying the neoliberal ethos in which diversity and the recognition of rights must have a 'business case'; rather, I want to unpack how this profit- and affect-driven business case is legitimated. Although I am critical of this business case, I should acknowledge 


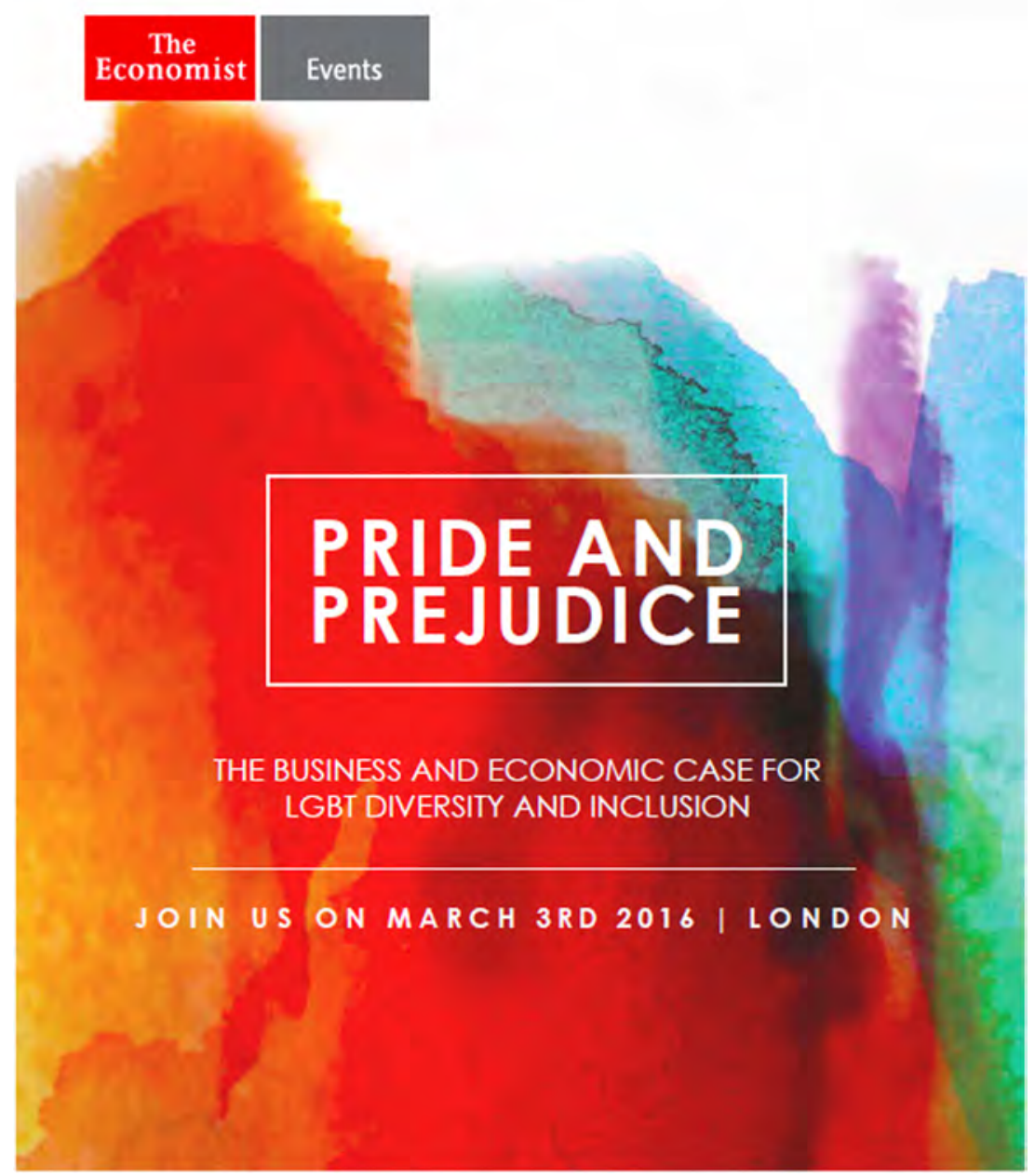

Figure 4.2 Pride and Prejudice: a sophisticated presentation of 'the business case'.

the (limited) positives of the global business community asking the following questions (from the event homepage), even if their underpinning in priorities of economic value problematizes the event's 'unbiased' framing:

What is the outlook for LGBT rights in different parts of the world? Can legislation shift public opinion, or should policy follow social change? What are the economic, business, social, and human costs of discrimination? Why should LGBT rights matter for business? Where is the next front in the battle for LGBT acceptance? 
The fact that it was held across three 'global cities' and financial centres, 'spanning three continents' helps to rhetorically construct the event's 'global' nature. It took place over the duration of March 3rd, 2016, beginning at 8:00am in Hong Kong, before moving to London, and concluding in New York, with an eight-hour schedule for each venue. In combination (jointly reproducing a page from the event booklet), Figure 4.3 and Extract 4.1 provide some sense of the spatializing/globalizing character of the event, as well as underlining its rhetorics of leadership and innovation.

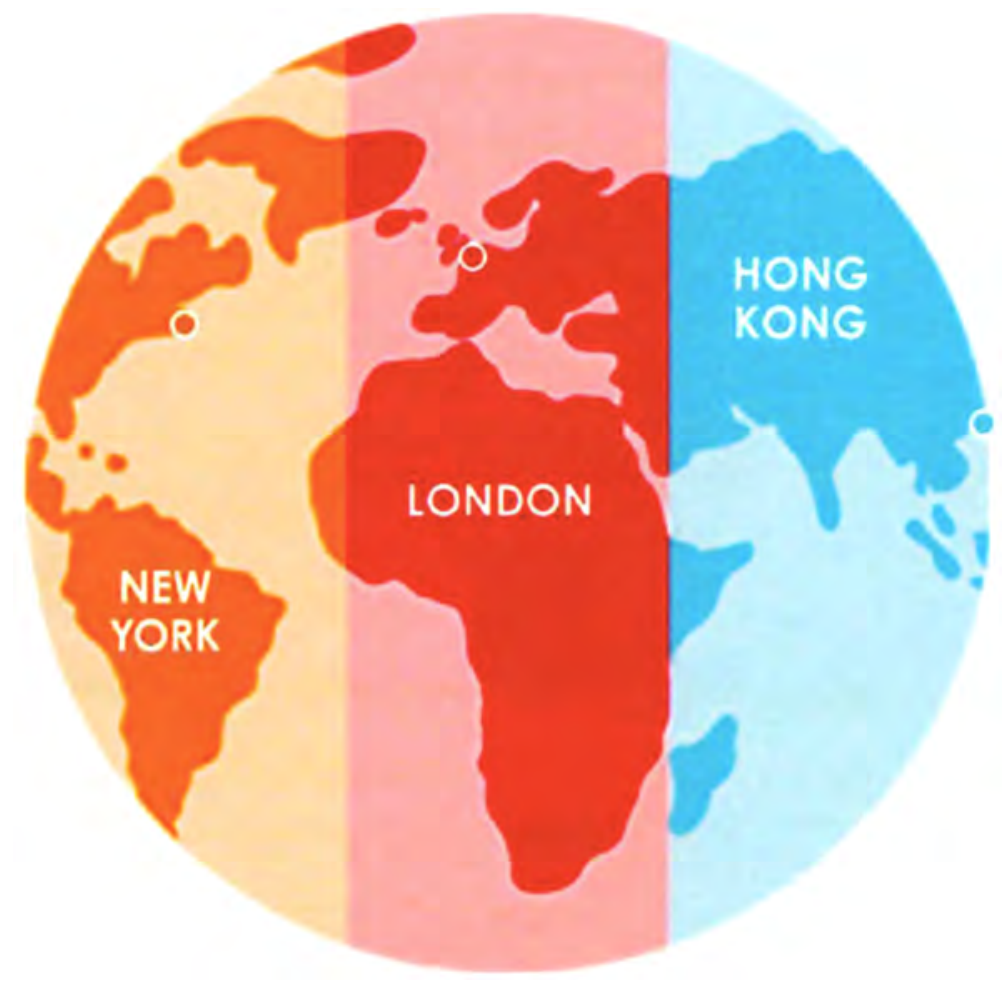

Figure 4.3 Excerpt from the Pride and Prejudice event booklet.

\section{Extract 4.1: Event booklet excerpt}

Pride and Prejudice, a 24-hour event spanning three cities - starting in HONG KONG and moving on to LONDON and NEW YORK - will encourage fresh thinking among policymakers and industry leaders on the LGBT movement and its impact on business around the world.

The speaker lineup features some of the most influential business decisionmakers, government policymakers, and innovative thinkers from across the globe as they discuss a content-driven and business-oriented agenda.

Pride and Prejudice will tackle the tough issues pertinent to each region, with one common question in mind: what is the cost of LGBT discrimination? 
Figure 4.3's representation of a globe defined and labelled by these three financial centres is telling. Each of these cities is seen to dominate their section of the world: Hong Kong metonymically defines Asia (with the Pacific left unseen), London defines Europe, the Middle East, and Africa (and is fixed in/on the latter, in the dead centre of the globe) and New York is the locus of the Americas. Thus 'global' is indexed through an event's presence in just three cities, themselves home to both highly mobile cosmopolitan elites and an immobile, often impoverished underclass. The latter group goes unmentioned.

The global credentials of Pride and Prejudice are boosted by the fact that the event was livestreamed, and viewable to anyone (with a viable internet connection) via its website. Through the use of a dedicated hashtag, \#EconPride, the event was framed as conversational; aligning with conceptualizations of Twitter as a source of voice and visibility through its affordances of 'ambient affiliation' (Zappavigna 2011). The organizers of Pride and Prejudice were presumably keen to present an image of democratic broadcasting, enabling onlookers to personalize messages and speak about - and against - the discourses of diversity in circulation there (see Thurlow 2013, on commercial social media's forms of 'faking it'). The creation of hashtags presupposes an invested community of listeners who might actively follow this keyword or search for it - they presuppose affiliation (Zappavigna 2011). However, Page (2012) adds that while hashtags do have the capacity to perform affiliative work for a public Twitter user, the network's non-reciprocal nature means that the use of hashtags, retweets, and other communicative practices is not always dialogic. Corporate Twitter profiles are rather best understood as using hashtags as 'strategies of amplification' (Page 2012), to promote commodities and shore up their brand value. In the case of praeter hoc hashtags such as \#EconPride (created in anticipation of an event, rather than in response, cf. Bruns and Steiglitz 2012), this seems especially pertinent. Tweets using the hashtag are effectively (effective) marketing tools. For this reason, the 'participatory' culture of the event, indexed through repeated invitations to 'join the discussion', can be seen as sleights of hand. Overall, under scrutiny, the discursive practices that \#EconPride affords more closely resemble illusory forms of 'synthetic collectivization' used by powerful agents to accrue capital (Page 2012, 2019; cf. Fairclough 1989), rather than genuine forms of social positioning or position-taking.

This is not to say that the dominant discourses of the event, or its elite status, were not contested at times; dominant discourses always contain fissures (Gal 1989). Many Twitter users employed \#EconPride to criticize the prohibitive cost and claims to diversity of the event and its follow-ups, and the liberal, market-minded principles of The Economist itself. Yet this risk of contestation and criticism was clearly not deemed a threat to The Economist and others' interests. For the powerful firms in attendance at Pride and Prejudice, the risk of speaking out in support of LGBTQ rights is less significant than the reward.

In London, Pride and Prejudice was held at a lavish convention centre in the heart of the city's financial district. The standard cost of registration was $£ 1,195$ GBP. With even the reduced rate for academics, NGO workers and 
government costing $\mathcal{E}^{8} 836.50$, there is no question that the event was organized for an elite (or at least well-funded) contingent of businesspeople, 'policy makers' and 'innovative thinkers'; access was out of reach for the great majority of the world's grassroots activists. Within this exclusive context, The Economist and other powerful, affluent stakeholders it speaks for discursively construct their global significance, influence, and vital importance for the future of LGBTQ diversity and inclusion. To this end, there are many ways in which the stakeholders of the event adopted a self-congratulatory stance in relation to the event. The event was framed as honourable, its delegates as honour-bound and its outcomes as undoubtedly positive - a heightened dramaturgy that lent it a pervasive atmosphere of altruistic legitimacy. This dauntless 'benevolence' is invoked through the closing words of the 2016 homepage: 'Bringing about meaningful change requires a mix of strategies - litigation, the championing of anti-discrimination laws, diplomatic pressure and a long process of social and cultural adjustment. And courage'.

The event felt like - was produced to feel like - the beginning of something big. And there was something unnerving about being included here (cf. Ahmed 2012). I was challenged by the autoethnographic perspective I brought to the event, reminded of my out-of-placeness there, as perhaps the wrong type of queer; as a critical scholar, a non-businessperson, lower-middle class. I wondered what relevance the discussion had for workers on low wages, such as those silently clearing the dirty dishes left after the 'networking breakfast' which began the day. What relevance does this discussion have for those negatively impacted by the unsustainable actions of the polluting, exploitative, and/ or rent-seeking corporations represented there? What, exactly, is courageous about seeking to build business for the already powerful? How, and why, is diversity made important only "when those who are important say diversity is important' (Ahmed 2012:59)?

At Pride and Prejudice, I conclude, this multimodal legitimation of a 'drive for diversity' is ultimate an affective, 'sticky' capitulation to a neoliberal ethos (Ahmed 2014). It was articulated through evocative linguistic, spatial/material, and sensory resources and experiences: all told, forms of affective legitimation which blur boundaries between moral, rational, and historicized forms of legitimacy.

\section{'Diversity discourse', neoliberal media, and affective economies}

As Makoni (2014:81) has presciently summarized, it is 'the powerful who celebrate the notion of diversity; those of us from other parts of the world feel the idea of diversity is a careful concealment of power differences'. These critiques resonate with those of 'multiculturalism' that emerged decades ago and continue in the current day (e.g. hooks 1992). But diversity is 'in vogue', in both the academy and the public sphere, and this dualist approach to the concept present challenges: it is difficult to unpack or problematize 'diversity' while public institutions voice support for it so regularly, normatively, and 
instrumentally (Vertovec 2015). My critical perspective here posits that the public push for diversity and the development of scholarship regarding it have risen in line with the proliferation of affirmative politics, promoting equality of access and recognition within a narrow political arena, rather than the transformation of politics, and the arena itself (Fraser 1995; Ward 2008).

Although Pride and Prejudice was presented as a significant 'new' beginning, it represents by no means the first or only way that gays and lesbians have 'gone to market' or when the market has embraced the discourse of diversity (cf. Chasin 2000). Another powerful liberal media brand, the Financial Times, produces an annual supplement called 'Executive Diversity', devoted to discussing the impact of sociocultural differences on corporate culture and how they must be appreciated - and managed. Just as feminists use the language of 'the glass ceiling', it discussed smashing out of 'the glass closet' on the cover of its 2014 edition. Recently, a coalition of companies called Open for Business has begun making the case 'that inclusive, diverse societies are better for business and better for economic growth'. ${ }^{3}$

Within scholarship following 'diversity' as a key object of research, as Del Percio and Sokolovska (2016:1) have outlined, the central question is, 'what do discourses of diversity achieve and what do they stand for?' Answers to this question have been explored through analyses of regimes of so-called 'diversity management', 'corporate citizenship' or 'corporate social responsibility' (e.g. Pride and Prejudice), diversity in higher education discourse, diversity in advertising and the utility of diversity with regard to processes of gentrification (e.g. Ahmed 2007, 2012; Berrey 2015; Lees 2003; Lentin and Titley 2008; Modan 2007; Shankar 2015; Urciuoli 2003, 2016). Ward (2008) has specifically examined diversity culture in LGBTQ activist organizations. Some concerns about the uses of 'diversity' have emerged within business management literature itself (e.g. Lorbiecki and Jack 2000; Benschop 2001). Echoing scholars like Binnie and Skeggs (2004), much of this work shows how diversity can be commodified to convey Bourdieusian distinction; used to market cities, neighbourhoods, brands and universities as vibrant and cosmopolitan. Within critical sociolinguistics a number of scholars have described how linguistic diversity and variation function in a globalized marketplace, and contexts of language commodification and normative stylization (e.g. Cameron 2000; Heller 2003; Duchêne and Heller 2012; Park 2013, 2016). Diversity has also manifested in theories of 'superdiversity', describing a kind of incalculable 'diversity within diversity' in globalized landscapes (Blommaert 2013). Overall, however, many scholars of language that look at 'diversity' have until recently seemed to focus rather strictly on linguistic diversity, rather than discourses of diversity, and have lacked attention to semiotic modes besides language. Where discourses of other forms of diversity have been taken up, they seem to accord with that promoted by state and economic institutions, so that diversity is taken-forgranted, rather than problematized in and of itself. Contributions to special issues by Del Percio and Sokolovska (2016), Faudree and Schulthies (2015) and Aiello and Pauwels (2014) avoid an over-enamoured treatment of diversity. 
They also, importantly, address the political economy of diversity: 'the ways and conditions under which diversity is invested in, enacted, disciplined, and sometimes contested by actors and institutions occupying differently valued positions in social structure' (Del Percio and Sokolovska 2016:2). Like them, in this chapter, I wish to underline the 'problematic genealogy' of diversity, with particular attention to appeals to diversity centred on sexual orientation and gender identity (cf. Ward 2008). The folding of SOGI considerations into diversity management has been studied within management literature (e.g. Colgan 2011), but it has not yet been subject to similar sociolinguistic analysis as that of Park (2013).

Diversity management 'not only benefits [a] company by enhancing its public image, but also allows companies to maximally utilize their employees' potential by harnessing the wide-ranging skills, knowledge and experience represented by their varying cultural and social backgrounds' (Park 2013:559). Thus, what is important to note here is how 'diversity discourse' is tied to a culture and ideological construct of boundless enterprise, and that diversity management - the texts thereof, and the word 'diversity' itself - is a critical tool in the legitimation of that discourse. This exemplifies what Fairclough (2003:114; following Bourdieu and Wacquant 2001) has identified as one of the significant features of the texts of new capitalism, or neoliberalism: 'their "performative power" in bringing into being what they purport to (merely) describe'. Overall, diversity management functions as a 'metadiscursive regime', through which forms of difference are acknowledged, conditioned and evaluated into 'diversity'; the market-friendly face of social differentiation (cf. Park 2013).

The prominence of managerialism (aka 'corporate speak') in transnational news media such as The Economist is troubling, because of how it takes commonplace neoliberal rhetorics and treats them as common sense (Chun 2016). Mediatized discourses of diversity management strengthen the neoliberal politics they are founded upon, providing 'a post-materialist identity politics which fuses positivity and a feeling of non-conformity with a studious avoidance of structural inequalities', as Lentin and Titley (2008:21) state, echoing Fraser (1995). Diversity management locates its value in the individual's human capital, not in their belonging to diverse social groups, reframing diversity as 'an ahistorical notion detached from deep-rooted structures of inequality' (Park 2013:560). As a result, those who seek social justice and redistributive progress are now challenged by a situation in which the resources which provide the global public with guidance for 'good life' and 'good citizenship' - including the rhetorics placing value in 'diversity' - valorize livelihoods that are unsustainable, or entrench material inequality. Part of the challenge lies in the fact that the very effectiveness of the mediatized expression of 'diversity' lies in its ambiguousness; its 'shiftiness' (Urciuoli 2003). But the challenge also lies in the affective workings of what diversity indexes; how that index mediates 'between the psychic and the social, the individual and the collective' (Ahmed 2014:119), aligning interested subjects with social dispositions of entrepreneurialism and neoliberal selfhood. 
Diversity management entails ideological stances towards the way we communicate (and thus manage) differences in the workplace and the varied ways we can think and talk about those differences. Under neoliberalism, management of an employee transfers to management of their entire self and sense of citizenship, and in this way, diversity serves as a means of tempering and quelling any threat to managerial practices. 'Diversity' is collaborative, where 'equality' is confrontational, seeming 'to evoke some sort of politics of critique or complaint about institutions' (Ahmed 2012:65), rather than focusing on what such institutions are recognizing, affirming, and valuing. As Ahmed (2012:81) continues, 'to speak the language of diversity is to participate in the creation of a world' - a feel-good world, fusing positivity with the right amount of non-conformity and kinds of digestible difference (cf. Hooks 1992).

Many studies of diversity discourse have focused upon the semantic flexibility of the term - and how it indexes a broad positivity about whatever it can index in context. Lentin and Titley (2008) call diversity an 'ambiguous transnational signifier', and Urciuoli (2003) refers to it as a 'strategically deployable signifier' - a term that appears referentially stable but whose meaning and conceptual content shift across contexts and users. As Lees (2003:622) has noted, although a wide range of uses threatens to make the term incoherent, it is actually 'key to the appeal and power of diversity ... Like motherhood and apple pie, diversity is difficult to disagree with. Janus-like, it promises different things to different people'. Importantly, as Lentin and Titley (2008:10) note, 'despite diversity's suggestions of diffusion and de-centredness, it always has a constitutive centre, unquestioned and assumed'. Its aim is thus always to symbolically reconstitute minorities as part of the whole, but never to reorient the whole so that the privileges afforded to the affluent, powerful or privileged can be contested. At the same time, diversity discourse does a great deal of ideological work in legitimating the socio-economic underpinnings of the whole, in which there is no axis of inequality other than the cultural or ideational. It is these acts of erasure which are most troubling about diversity discourse, not its social ambition. In the uncertain world of 2020 and 2021, the 'promises' and reassuring outlook that the recognition of diversity offers are no doubt welcome. It performs hope; it feels like incremental progress.

To appropriate Butler (1997a:44), the language of diversity

not only signifies [conditions in which all differences are appreciated], but that this signification will also be the enactment of the thing ... the meaning of a performative act is to be found in the apparent coincidence of signifying and acting.

To speak of diversity is to be doing diversity - to call its feel-good positivity into being, and 'produce the effect that it names' (Butler 1993:2). Adding to this theoretical framing, however, Ahmed (2012) discusses how circulating the language of diversity can also be conceived as a way not to enact change - it is a non-performative speech act, a way not to do things with words. In these 
instances, 'the failure of the speech act to do what it says is not a failure of intent or even circumstance, but is actually what the speech act is doing' (Ahmed 2012:117, her emphasis). Non-performativity yields a result when it does not do anything: 'if we take saying diversity as if it is doing diversity, then saying diversity can be a way of not doing diversity'.

It is easy to overstate what diversity discourse distracts from, and how this distraction plays out in practice. In the trenchant critique some of scholars, the trouble with diversity is that it distracts from materialist concerns and obscures the injustices of class. As Ahmed (2012) notes, citing Butler (1997b:33), this reflects a tendency of many leftist commentators 'to relegate new social movements to the sphere of the cultural, and indeed to dismiss them for being preoccupied with what is called "merely" cultural'. These issues also arise in sociolinguistics, in otherwise comprehensive analyses of political economy in/ and late capitalism (e.g. Block et al. 2012; Block 2018). ${ }^{4}$ However, there is simply no denying that sexual identity and political economy are profoundly interlinked. As Butler (1997b:42) notes, 'the economic, tied to the productive, is necessarily linked to the reproduction of heterosexuality' (cf. D'Emilio 1983), and the disciplining of non-heterosexuality is innately tied to the need to maintain capitalist modes of production. Given that critical politics of identity are also increasingly intersectional (Crenshaw 1991), accounting for views of class as a way identity gets articulated, there can be no separation of the two concerns in contemporary life. The relationship between the material and symbolic/cultural is not binaristic, and we should therefore not propose binaristic frameworks for solving problems that intersect the two. This includes the dismissal of affirmative politics off-hand. Diversity discourse is by no means perfect, but it does something. It makes many people feel secure, successful and happy.

In examining Pride and Prejudice, I am examining networks of firms with thousands of employees, millions of customers and untold global influence. I must acknowledge that through that influence, LGBTQ diversity discourse works; it employs, pays, feeds, as well as supports, delights, excites, and emboldens countless queer subjects and allies worldwide. In this respect, I want to highlight how Ahmed's $(2004,2014)$ concept of 'affective economies' undergirds this chapter's analysis (while also guided by thinking on affective-discursive practices, following Wetherell 2012, 2013). Pride and Prejudice belongs to an affective economy in which emotions function as a form of capital, sitting alongside - acting as a bulwark for - the globalized neoliberal economy it emerged from. In Ahmed's (2014) description, affect is relational; traded and shared by individuals and institutions over time, accruing value and building attachments between them as this occurs:

Affect does not reside positively in the sign or commodity, but is produced only as an effect of its circulation... Affect does not reside in an object or sign, but is an effect of the circulation between objects and signs ... Some signs, that is, increase in affective value as an effect of the movement 
between signs: the more they circulate, the more affective they become, and the more they appear to 'contain' affect.

(Ahmed 2014:120)

The mutually constitutive nature of the social and the affective is highlighted here; it is exemplified in Figure 4.1's juxtaposition of the 'pot of gold' (equality as a commodity), and 'the rainbow' (equality as affect: joy, defiance). Outcomes are stuck to affects, and affects stuck to other affects - to pride, profit, and the frisson of potential. Affective economies provide collective bonding and belonging, defining the shape that sense of belonging takes, and therefore defining what we foresee as legitimate linkages between certain emotions.

The theorization of affective economies is therefore helpful for describing how semioticized affects of LGBTQ pride intermingle with affects of enticement and self-interest at Pride and Prejudice - how one was used to justify the other, how a purportedly moral cause becomes rationalized and marketized. This chapter thus aims to unpack diversity discourse's broadly positive registers; 'excitable speech' (Butler 1997a), but reflective of a more distant, 'Januslike' engagement, to use Lees' (2003) description. The rhetorics that I examine retain a definitive 'stickiness' (Ahmed 2004) - bonding individuals and institutions together through desires, enticements, a drive for progress - but they do so in such a way as to always uphold the legitimacy of the market-driven rationales. This ambiguous potential of diversity management as a metadiscursive regime - its sticky promises of many different things at once to many different people - makes it a vital object of investigation. It teaches us about how discursive forms of legitimation respond to the totalizing habitus of contemporary neoliberalism.

\section{Legitimation in discourse}

Neoliberal habitus is always in the process of legitimating itself; providing market-oriented answers to spoken or unspoken 'why' questions - 'Why should we do this?' or 'Why should we do this in this way?' (following van Leeuwen 2007:94). There is evidence for this in how the question of 'why' LGBTQ diversity and inclusion are important is so often answered with regard to the business case - its profit-boosting capacity. In the process, a worldview in which economic interests are prioritized and valued above all else is also legitimated, in subtle yet powerful ways. This event ethnography therefore relates to discourse analyses focusing on practices of legitimation (e.g. van Leeuwen 2007; Reyes 2011; Breeze 2012).

Legitimation refers to 'defensive or justificatory practices of an institutional nature, used to bolster and defend the legitimacy of the actions of an entity or collective body' (Breeze 2012:4), and in this respect, Pride and Prejudice can quite clearly be seen as entirely constituting a complex discursive and metadiscursive practice of legitimation, enshrining a neoliberal ethos and the role of diversity and inclusion within it. The corporate rhetorics in use at Pride 
and Prejudice can be so powerful that they succeed in making neoliberal ideology seem natural or inevitable, like 'common sense' for the audience; those that are not immediately taken in by the idea of economic growth as a key to progress will at least see its potential, as reasonable and sensible. As Cammaerts (2015:523) notes, 'neoliberalism as an ideology has managed to position itself as quintessentially anti-ideological, as a natural state of affairs, as invisible'. Legitimation is the process through which this invisibilization occurs.

I orient to prior theorization of legitimation especially to highlight the role of emotions within this process (van Leeuwen 2007; Reyes 2011). I do this so that I can point to how powerful neoliberal institutions increasingly rely on positive affect and outcomes, rather than negative (e.g. fear), to perform the legitimacy of their actions into being. Studies of legitimation, where they have focused on emotions and affect, have tended to highlight how political discourses are often motivated by/through negative feeling: fear, prejudice, nationalist resentment, xenophobia, etc. (cf. van Leeuwen and Wodak 1999; Reyes 2011). The extent to which positive affects - such as pride, comfort, desire or feelings of authenticity - can be employed by institutional actors to justify perhaps still unjust practices has so far not been studied in sufficient detail within critical discourse studies (cf. Thurlow 2016). This chapter thus expands upon the study of legitimation in globalized corporate discourse (e.g. Breeze 2012) - an important step, given that so much of the world's society and economy is now affected and directed by the actions of globalized firms (Mosco 2005) - and does so with specific attention to how such discourse renders neoliberal governmentality feel-good, desirable, and pleasurable (cf. Ludwig 2016).

With the above theoretical framework in place, the following research questions guide this chapter's analysis. Again taking cues from Ahmed (2007:237), I asked, 'Does the repetition of the term give it currency?' And if it does, what does it mean for diversity to 'have' currency? Further, given Pride and Prejudice is specifically marketed via 'the business case' for inclusion, in light of theorization of non-performativity, I wished to know how a foregrounding of LGBTQ diversity might occlude action along other axes of discrimination and injustice. Simply put, where or what is discrimination in the discourse of Pride and Prejudice? A supplementary question related to my own subjective relation to these discourses: how am I imbricated, hailed or interpellated, and affected by these mediatized discourses of LGBTQ inclusion and diversity? Can opening myself up to these considerations shed light on their effectiveness and increased ubiquity?

Tying together a critical perspective on neoliberalism with an acknowledgement of its positive affects and outcomes, I am distinguishing my research from the rigidly Marxist approaches to neoliberal political economy of scholars like Block et al. (2012), and re-working the critical approach to diversity management of Park (2013). Ultimately, I want to provide a critical description of how LGBTQ diversity is represented, stylized and, ultimately, valued in the elite lifeworld of the 'C-suite' seen at Pride and Prejudice. 


\section{Multi-sited event ethnography at Pride and Prejudice}

Although this chapter's event ethnography takes a different shape to that of the last chapter, in response to the differences between Spectrum and Pride and Prejudice, my analysis remains fundamentally queer and discourse-ethnographic. Here that includes recognizing how multisensorial the discourse in circulation at Pride and Prejudice is, indexed across modes; through speeches on stage, free marketing material and even the chic crockery and muted lighting used during breakfast and lunch. Pride and Prejudice 'took place' in multiple ways across multiple scales and spanned multiple time-zones. There were therefore many ways in which a researcher could participate in the event and track its discursive formations. Attending to the mutating nature of ideological objects in the context of a live, lavish event like Pride and Prejudice requires a researcher to take heed of linguistic (spoken/written), visual, material, spatial and digital modes, and their varied affordances. It also behoves me to attend to more ephemeral aspects of the event - vibe, atmosphere - which will often be highly significant for performing the event into being as a discursive practice and a conceived, perceived, and lived space (cf. Lefebvre 1991).

Legible as single complex texts, events like Pride and Prejudice are held together through participants' communication of presence, purpose and impact. The event seemed primarily devoted to expressing its own legitimacy: interpellating sexual minorities as neoliberal citizens, and touting the benefits of 'diversity' across the global marketplace. In other words, delegates' presence, the event's purpose, and its purported impact are all intricately bound to the service of neoliberal ideology. Appropriately, this event-ethnographic study, then, follows Chun's (2016:356, following Shankar and Cavanaugh 2012) recommendation that research be conducted 'into local sites in which neoliberal practices have taken hold to see how people are employing language use shaped by company policies'. Not only was the event distributed across three sites, but technology allowed Pride and Prejudice's rhetorics (more so than at Spectrum) to ripple not just worldwide, but also across timeframes: through the use of its hashtag, its dedicated app and its website, featuring dozens of articles published in advance of the event and afterward. This was a strategic move by its marketeers in order to index globality and innovation. It is also, seemingly, an obstacle to studying the event. Marcus (1995), however, has helpfully outlined 'multi-sited ethnography' as a way to approach contemporary transnational, globalizing processes without regard for particular sitedness. 'Events' as I have conceived them (cf. Comer in preparation) are not assumed to have a static existence in a single location. Event ethnography is inherently multi-sited, rootless, untied to place: 'tracing a cultural formation across and within multiple sites of activity' (Marcus 1995:96).

When I spoke with delegates, I told them I was a 'PhD student in Language and Communication', interested in how LGBTQ identity is framed in corporate and other media. However, very few people seemed very interested in me - I often detected a furrowed brow when someone glanced at my nametag. Perhaps, some wondered how I managed to afford the attendance fee. 
The general disinterest I encountered at Pride and Prejudice (my insignificance within the world of transnational commerce) indexes my peripheral standing in relation to the dominant discourses in circulation there, and provides passive approval for a covert, 'fly on the wall' approach. Altogether, the 'dataset' for my account of Pride and Prejudice includes: The Economist's event website as a whole; 64 articles posted on the event website between late 2015 and March 2017; marketing material and social media pages for The Economist and others in the run-up to the event, where the event is mentioned/indexed; tweets written before, during and after the event, using the hashtag \#EconPride; recorded segments of the parallel events in London, New York and Hong Kong; the built and interior environment of the venues for the event, and promotional stands set up there; data collected from the app created for the event; and my ethnographic reading of the event in London itself, including my insights and (often queer) affective responses to what happened there.

In the following analysis, I describe two salient rhetorics of cost (of discrimination as expensive), and opportunity (of progress as profitable) that emerged through my study. These rhetorics are premised upon an amoral, 'rationalized' and 'naturalized' legitimation of inclusive practices by reference to their profitability and boosts to productivity (van Leeuwen 2007). I then account for rhetorics which upheld and affirmed the purported leadership and courage of The Economist and businesses in attendance at Pride and Prejudice: the tools used to enshrine the event's elite delegates as arbiters of progress. I conclude by accounting for how the conference assembled a vision of sexual and neoliberal citizenship where one collapses into the other - a world where return-on-investment justifies inclusion. In such a world, to be different is to embrace 'diversity', and in such a world, the word 'diversity' and its associated discourse are built up as a commodity, just like the diverse LGBTQ others that it purports to value.

\section{Analysis: Enterprise, authenticity, and legitimacy in LGBTQ diversity management}

The rhetorics of cost, opportunity, and leadership in circulation at Pride and Prejudice tend not to circulate alone. Rather, they are intermingled and mutually reinforcing. Figure 4.4, which shows an excerpt from an advert for the event, is evidence of this. In the tagline, the cost to the global economy of LGBTQ discrimination and prejudice is made abundantly clear. In the sub-headings, a list of statistics asserts that the sizeable populations of queer people worldwide present a clear opportunity to the business world through their 'purchasing power'. This is an example of what can be seen as 'authoritative speech', the use of in-group jargon or discipline-specific 'narrative detail' to establish credibility as an expert (van Leeuwen 2007; Tannen 1989). The Economist definitely regards itself as an authority and leading force for 'the liberal credo' of freedom and free markets. The language typical of corporate space, and the candid discussion of LGBTQ individuals as economic units (if not agents) immediately act to persuade readers of The Economist's leadership - both those powerful 


\section{DISCRIMINATION IS EXPENSIVE}

The purchasing power of the LGBT community worldwide amounts to \$3 TRILLION annually 2.8 8ItLION people live in countries that criminalise gay people. The estimated annual cost of homophobia to India's economy is $\$ 30.8$ BILLION.

Figure 4.4 Pride and Prejudice: 'discrimination is expensive'.

enough to attend Pride and Prejudice, and the magazine's vernacular audience. In other words, The Economist, in this single ad, legitimates itself as authorized to speak on a social issue - discrimination - in solely economic terms, by drawing links between these disparate statistics to craft a message of undue expense. The cost is not to the billions worldwide whose sexual lives are criminalized, but to the (largely developing) economies in which they live. Unsurprisingly, at the bottom of this ad The Economist makes clear that not only are LGBTQ people an opportunity for profit, but this event is as well; advertising sponsorship opportunities with a snappy message - 'progress needs a push' (apparently, a network of wealthy firms is leading the way by giving it one).

\section{Rhetorics of cost}

Overall, the rhetorics of cost emerge at Pride and Prejudice in two respects; firstly, with regard to the cost of ignorance on the part of the business community about how 'discrimination is expensive' and secondly, with regard to the social cost of discrimination against the LGBTQ community. These concerns for the social cost can more accurately be seen as a concern to maintain a productive, profitable workforce. In all but the most affecting (and to some extent queer) moments of the event, like when a frontline activist or NGO worker spoke, the latter 'cost' of discrimination was framed matter-of-factly, as a neutral foundation for growth - a leak to plug. Human costs were absented or summarily dismissed. In a segment of the event entitled 'Why it matters: Defining the business case' (as if it does not matter beyond this business case), 'commercially-minded CFOs and investors' discussed whether it is 'a compelling business issue, or a secondary concern'. At other times, human costs were abstracted, so that their politicaleconomic consequences became most prominent. This was the case on another advert/registration document where, under the heading of 'Why now?', came the explanation 'Persecution drives people to seek asylum'. In such a formulation, the hatred and violence that causes asylum claims is not necessarily the issue, but rather, the implied, eventual burden for Western states which have to 
address such claims. The aforementioned 'glass closet' is granted equivalent status in the list of reasons to act, just below the point about prosecution. Hence, the cost of persecution is equated with the 'powerful force' which prevents LGBTQ employees from reaching their full, valuable potential. Although this economic model of sexual citizenship has historically been a tactic of activist groups, 'flexing economic muscle' (Chasin 2000), the degree to which LGBTQ individuals are framed solely as economic actors is still eye-opening.

In Figure 4.5 (at top), an excerpt from an infographic from the event app (full of coolly quantitative, numbers-driven analysis) states that only one in six executives believes that 'LGBT advancement can boost the bottom line'. In matter-of-factly decrying this lack of perspective on the part of business leaders, Figure 4.5 evinces much of the discourse at Pride and Prejudice, in the repetitive manner in which the LGBTQ community is overwhelmingly regarded less as a culture or marginalized group, than as a market segment (with significant purchasing power). 'LGBT advancement' exists in relation to the bottom line; the 'costs' associated with it are found in the lack of insight of the other five executives. In keeping with its 'brand identity', Pride and Prejudice uses bright bursts of highly differentiated and highly saturated colour (Figure 4.5 , bottom). The affordances of these bursts of colour index the legacies of 21st-century gay liberation and the rainbow flag, but also "become signifiers of "adventurousness", with differentiation standing for the absence of monotony and routine' (Kress and van Leeuwen 2006:236). This dynamic brand identity therefore seems to invoke the adventurousness and courage of the executive who recognizes the true economic costs of discrimination - celebrating the unrestrained, innovative thinking which reduces those costs, with the added benefit of affirming LGBTQ identity: a 'secondary concern'.

Professor Lee Badgett, the economist who provided the 30.8 billion figure in Figure 4.4, was interviewed at the event in Hong Kong, during a session called 'the dollars and cents of discrimination'. Extract 4.2 is her response to the question: what do you think the cost to the broader economy is for LGBT discrimination?

\section{Extract 4.2:}

I think it's potentially very large. I think we don't often think about such a small group of people, relatively speaking, LGBT people might be anywhere between 3 to 5 percent of a nation's population, and yet, uh, because of the impact of stigma and discrimination on those individuals, it hurts them as individuals but it also reduces what they're able to contribute to the larger economy. Can we put a number on it? That's the big bottom line I guess [laughing] ... and I think it is possible to do that.

One may say it is entirely reasonable to argue in support of LGBTQ inclusion, as Badgett later does, through reference to the lower levels of education 

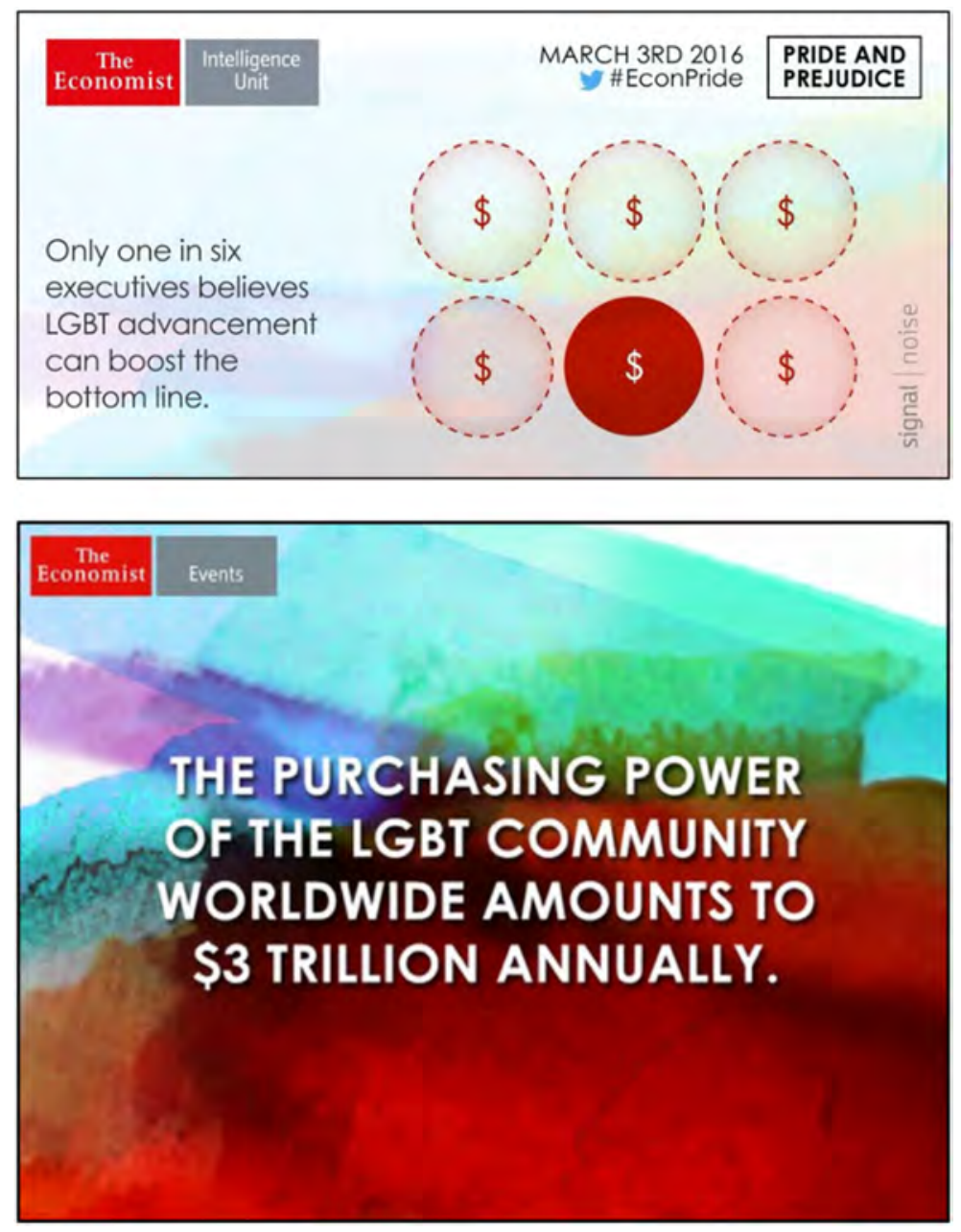

Figure 4.5 Pride and Prejudice: the cost of homophobia.

of LGBTQ people; gaps in education leading to low employability; and issues such as homelessness leading to a 'global gay wage gap' of 10 percent (see Badgett et al. 2014). But why is it so reasonable to consider individuals in terms of their contribution toward the larger economy (line 6)? We should be hesitant of descriptions of the world which assume a cost-oriented, rational subject, as such descriptions call that subject into being. It is often not a lack of reason which breeds unrest and violence, but obstinate certainty in how reason can be universally conceived and applied. There are consequences of 
too strictly enforcing a utilitarian market rationality in considerations of human wellbeing - putting 'a number on it' (line 6). This concern for the economic costs of discrimination erases concern for moral action, and, for that matter, has drastic, alarming implications for how to conceive of the young, old, mentally ill or those who are not able-bodied. In response to a question her interviewer took from Twitter, asking whether Badgett thinks LGBTQ inclusion 'needs an economic argument' - 'shouldn't it just be a moral issue?' - she asserted that the two are complementary, perhaps the 'micro-' (on the ground) and 'macro-' (sum total, globally) sides of a scale of 'impact'. To place the social on the same plane as the economic, however, and then to foreground discussion of the latter, is effectively to build a schema whereby these micro-issues can be forgotten, and ignored, if addressing them ceases to be a financial imperative.

The potential for such sentiments is demonstrated in the statement in Extract 4.3, from the openly gay CEO of Qantas, Alan Joyce. Despite there being a clear necessity for Joyce to speak the language of the 'moneymen' in the audience (and anecdotally, I know he is a prominent LGBTQ diversity advocate in Australia), the mercantile voice he uses is alarming. Discrimination is presented as an impediment to progress; but rather than this being due to the ethical, human or social cost of being hated, hating oneself or killing oneself, it is presented as a barrier to 'productivity' (line 4). Joyce provides a figure which notes that an 'open, inclusive environment' boosts productivity by 30 percent (line 6).

\section{Extract 4.3:}

In Australia, again, I think the stats show that LGBT people are 3 times more likely to be depressed. The suicide rates for young gay men are 7 times the national average. Now that does have an impact on productivity. And again, if you try measure that back to what that means in sick days and health issues and productivity, some studies have come out and said you could get from a completely open, inclusive environment, you can get 30 percent improvement to productivity, which could be worth for an economy like Australia's, hundreds of millions of dollars ... and companies like Qantas millions if not tens of millions of dollars to the bottom line.

Again inclusiveness is valuable not due its social value, but as an opportunity. As an example of a corporate in-group 'neoliberal keyword' (Block et al. 2012) repeated several times in this extract (lines 3, 5, 7), 'productivity' is clearly a valued premise for the organizers and delegates of Pride and Prejudice. It indexes the infinite economic growth which neoliberalism sees as a moral virtue in and of itself, and appears very frequently at Pride and Prejudice, alongside words like 'talent', 'entrepreneurship', 'innovation', 'creativity', and 'opportunity'. All of these terms are used to index the benefits of diversity's digestible difference - a chorus of heterogenous perspectives which encourage the 'maximization of the self, and the maximization of corporate profit, in one voice. The cost of discrimination, therefore, is one that comes about through lack of foresight of the 'pot of gold', rather than prejudice - irrationality, not persecution. In 
short, the material 'return' on equality is not in fact equality for the LGBTQ individual, but the profit that comes from opportunities to use these individuals as cogs in a corporate machine. This follows the standard disposition induced by neoliberalism: a world of competition and the ceaseless maximization of oneself above others. Safe to say, this disposition, nested within the context of the capitalist habitus of globalization, has profound implications for the narratives of 'coming out', self-actualization, and authenticity so valued in LGBTQ media. I will now elaborate on these narratives, through my discussion on the rhetorics of opportunity at work at Pride and Prejudice.

\section{Rhetorics of opportunity}

The rhetorics of opportunity emerge through the aforementioned representation of self-maximization, productivity and LGBTQ progress as mutually constitutive - interdependent and sequential. In shrewdly rational presentations and other texts, multiple actors at Pride and Prejudice legitimated the limited frame of progress possible within the affirmative politics of diversity: different lives, different histories, different backgrounds, but the same commitment to a politics of aspiration. Under this framework, diversity, and productivity are cohesive and benevolent; everybody wins. In this respect, the directive of Figure 4.6, which was used on social media ahead of the event (like Figure 4.1), seems eminently reasonable - why not 'open opportunity'?

Why can't social progress be profitable? Supposing they are employed, educated and able to work at the kinds of firms Joyce mentioned, the suicidal gay men he referred to (presumably) stand to benefit from a corporate culture of openness, even if their wellbeing is not the end-goal, but simply a utilitarian step toward it. The profitability of progress is described not simply in terms of its fundamental boost to productivity, as with the 30 percent figure that Joyce provided, but also via diversity's utility as a means of attracting the best possible employees to a business - often signified through the keywords of 'talent', 'creativity', and 'innovation'. According to many speakers and institutions represented at Pride and Prejudice, the skills, knowledge, and creativity of LGBTQ people are stifled in a workplace where they aren't 'appreciated', or

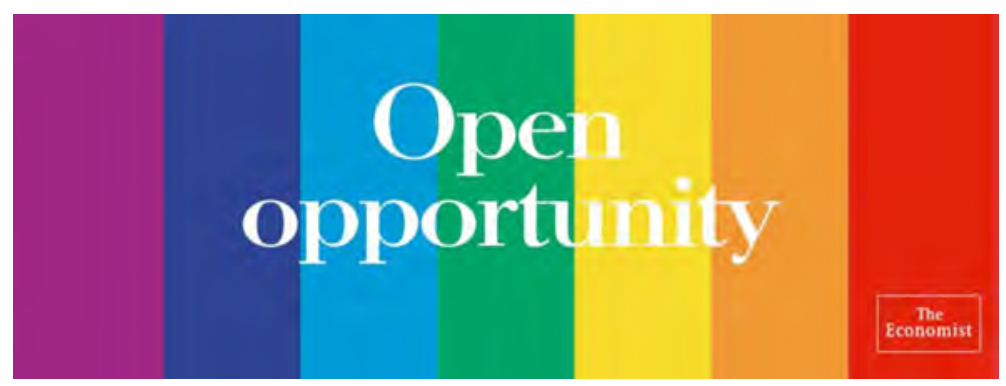

Figure 4.6 The Economist's claims to boundless prospects for prosperity. 


\section{4}

where they can't be 'authentic'. 'The case for diversity' is made through an appeal to heterogeneity/heteroglossia - the inherent value of multiple voices in a corporate suite or meeting room, presenting (purportedly) a diverse set of ideas. Diversity is framed as a path to productive forms of creativity, and especially, 'talent', with the presumptive HR representative or businessperson always seeking creativity and authenticity in workers, and always seeking to maximize them. Telling a global audience of the positive outcomes of diversity (to the bottom line and individuals), the sage, authoritative voices of 'business leaders' give voice to neoliberal thinking with a wise, considerate persona: a desire to appreciate everyone. Over time, as this 'desire' is performed, this voice's rhetorical effect is to make its politics seem common sense and desirable to the audience, even kind - leading to its uptake in the 'talent base', a met expectation that diverse employees give all of themselves to the employers that value them so highly.

Appeals like this, to the value of many voices, are reflective of metadiscursive regimes as the 'specific orders that condition the way we talk about language [and communicative practices] ... which can function as a mechanism of control in the workplace' (Park 2013:558). In the case of how diversity is discussed at Pride and Prejudice, it is self-evident that what is outwardly framed as a liberatory process is in fact devoted to constraining and conditioning the broader ideological framework in which diverse individuals' talk - in the service of corporate profit - is produced. It also serves to ever more deeply subsume the cultural lives of 'diverse' personnel under 'the purview of the organization, [seeking] to secure their commitment, initiative, and accountability' (Park 2013:560). In other words, what is framed as the celebration of diverse interests, talents, and perspectives actually serves as manifold forms of capitalization - so that whatever experiences and potentials LGBTQ people have can become tools in the enrichment of the institution, and the exploitation of the worker. This exploitation is, in effect, voluntary. These firms do not enforce 'diversity' so much as persuade employees of its (i.e. their) worth in the marketplace: to become 'self-steering' selves (Rose 1999). As I assert in this chapter, this voluntary disposition of sexual minorities as workers within the global marketplace makes great use of the affective drive for authenticity so profoundly valued within contingent 'global gay' cultural politics.

An advertisement for IBM from the London event booklet (Extract 4.4) exemplifies the rhetorics of opportunity; produced by a multinational, professing evocative yet strategically hollow messages about 'diversity of people, diversity of thought' as a smarter way to innovate, and a way to impact the world. This resembles a kind of feel-good coercion - a way to claim diversity breaks with 'mono' mindsets, despite the implicit ways in which 'the people you bring together' will always align with neoliberal thinking.

The opportunities that diverse ideas and thought provide - 'a smarter way to innovate' - are valued because of their impact on a world of clients. Rhetorics of opportunity construct a persuasive argument whereby the diverse lives of sexual minorities are subsumed within the purview of the corporate entities 
they are employed by (at one end of the scale), and by the boundless, globalizing habitus of the neoliberal marketplace (at the other).

\section{Extract 4.4:}

\section{IBM is proud to be a Global Advocate sponsor of Pride and Prejudice.}

IBM recognizes the unique value and skills every individual brings to the workplace. We believe that innovation comes from seeking out and inspiring diversity in all its dimensions.

Consciously building diverse teams and encouraging diversity of ideas helps us make the greatest impact for our clients, our colleagues, and the world.

\section{Diversity of people. Diversity of thought. A smarter way to innovate every day.}

This ad was topped with a hopeful message: 'your future made with IBM'. In the chronotopic future envisioned by firms like IBM, employees' diversity is an asset which must be strategically constrained, nurtured, and conditioned. This is so that they can become happier, more productive workers - bringing their 'authentic selves' and the 'innovative' ideas to the table. In directly addressing audiences at Pride and Prejudice with a synthetically personalized 'you' (Fairclough 1989), IBM invokes this neoliberal chronotope as each delegate's own future. They craft an all-encompassing regime of positivity, premised on the value of authenticity, self-actualization, and creativity. This authenticity is inevitably tied to a schema of rational, capitalist individualism, as has been explored elsewhere with regard to urban development (Bell and Binnie 2004), and material culture and food discourse (Cavanaugh and Shankar 2014; Mapes 2018). A spirit of selfmaximization in a world of competition is framed, in sum, as the best outcome for both employer and employee, in a world where the potential of the former relies on the potential of the latter, and vice versa; a neoliberal synergy of individual bright futures and competitive, market opportunism.

Numerous speakers on stage at Pride and Prejudice were lesbian, gay, transgender or bisexual, and many drew upon their own stories as part of their legitimation of LGBTQ pride as a force for profit. The event was full of mythopoetic realizations of the value of inclusion - stories of profit, inclusion, selfhood, support - mythologizing the workplace as a space of self-actualization. Rounding off my discussion of the rhetorics of opportunity, I now examine how a prominently scheduled speaker, Vivienne Ming, legitimated the aforementioned synergy (of individual and corporate competitiveness) through narratives of her own life as a transgender tech entrepreneur, lending an emotive air to what, in other respects, was a strikingly rational discussion. Ming talked in London about her transition to living freely as a woman, and what she calls 'the tax on being different': how growth, innovation, and entrepreneurship are limited by prejudice, and often, individuals' migration away from discriminatory 
environments. Extract 4.5 provides an edited recount of the closing section of her speech about this 'tax'.

\section{Extract 4.5:}

We think we can do better [at improving hiring decisions in the moment]. And not because the goal is helping disenfranchised people. The help is for us. We're the ones that need it ... I'm focused, as a data scientist, as a neuroscientist, as an entrepreneur, on building the kind of tools which will allow us to value every human life appropriately. I want to build that world. I want my kids to live in that world, where every single human life is fully valued for what it is. I build glasses. That's what I do in my work, I build glasses that we can all wear, so that we can see the world for what it truly is. I don't think that discrimination is done by villains, it's done by us. And there is some business world out there in which we build an economy based on the talent pool of 7 billion, rather than the talent pool of a few hundred million people, because they happened to be born into a life that was fully valued. So, I want to move beyond social justice and into self-interest. I want to think of this in a greedy, rational way ... Really taking hard numbers to drive this decision-making. And someday create a world in which we can all benefit from the human potential of everyone around us.

Ming is an impressive, affable presenter, and there were a number of moments where I was amused and affected by her stirring rhetoric of 'human value'. When she pointedly referred to her thinking in a 'greedy, rational way' (line 15), she clearly did so with an ironic, winking stance, and I have no reason to believe that she isn't interested in helping disenfranchised people (line 2). I also don't think discrimination is always done by villains (line 10), but know that 'villainy' can emerge in incremental ways - including through a discourse which speaks about human lives as valuable only in economic terms. As much as I enjoyed her story of self-discovery, I also shifted uncomfortably in my seat when I envisioned the world she referred to creating (line 18). Rao (2015:41) has aptly encapsulated the key reason: 'There is something profoundly troubling about a strategy which makes respect for personhood contingent on the promise of that person's productivity were their personhood to be fully recognised'.

Ming's mythopoetic narratives iteratively build the foundations that sustain them: the common-sense understandings of homophobia as merely cultural, and economic growth as a salve for social injustice. Ming's affective and markedly informal storytelling practices draw a direct link between her own history and period of self-realization, self-maximization, and self-actualization, and the maximization of what her and others can offer business. What they offer is a vision in which human lives are reducible to what they offer business. To instrumentalize an LGBTQ life in an intolerant society because of its potential, rather than its simply being a life, worth living, is here framed as a common-sense strategy. It seems clear from her talk and the event as a whole that no diversity in how or why people are 'valued' is possible. Ming sees herself 
as 'building glasses' which reveal people's true value (line 7). These glasses, however, simply reveal how hiring decisions can be improved, and where all employees are regarded equally, rather than all people.

Often, the metadiscourse of diversity management in circulation at Pride and Prejudice presupposed the idea that previously, diverse groups were universally regarded as 'messy and dysfunctional', unpleasant or undesirable - a 'headache'. When diversity is universally underlined as an asset, with diverse mindsets being a valuable way to beat out competition in the marketplace, it is a repudiation of this 'headache' idea - but it upholds the notion that being different is somehow innately messy, a cultural (i.e. irrational) concern. The simple statement Ming makes toward the end of her presentation - 'I want to move beyond social justice and into self-interest' (line 13) - captures the essential ethos of the event, whereby 'diversity' is tiresome and dysfunctional, unless/until it generates income. It envisions a world where, to borrow the words of Banet-Weiser and Lapansky (2008:1255), 'profitability is the moral framework'. The opportunities that LGBTQ inclusion presents are manifestly business-oriented - again, unrelated to it being ethically or morally right. Rather, its market-friendliness, where its market-friendless makes it a moral imperative. In this respect, one may say that the discourse of diversity management in operation at Pride and Prejudice represents a blurring of the categories of legitimation van Leeuwen (2007) and Reyes (2011) have identified; not just their working in combination, but their melding together and working as one. What is market-friendly and rational is moral; what is moral is restricted to what is authorized by the powerful; affective stories of finding one's authentic self, and indeed that legitimate selfhood, are tools in the maintenance and strengthening of a vigilantly rational neoliberal system, presented as caring.

In the totalizing lifeworld of neoliberalism, self-appointed voices of expertise (cf. Reyes 2011) effectively guide us to align our emotions with market-oriented rationality and uphold the leadership of The Economist and the corporate sector in social change. Through the next section, I now turn to the third of my rhetorics, sketching how this leadership (including these leaders' meta-rhetorical production of the rhetorics of cost and opportunity) is itself legitimated.

\section{Rhetorics of leadership}

Extending the analysis of legitimation to corporate discourse is an important next step in its application, given how 'large corporations are extremely powerful players on the world stage, holding vaster resources and greater influence in world politics than many states' (Breeze 2012:5). Much of the power granted to large corporations has come about via post-war Washington Consensus politics, that uphold the supposed neutrality of the free market, and the supposed moral leadership role that corporations can take across global society. In his analysis of discourses of 'leadership' in political and corporate spheres, Kerr (2008) has identified a 'militarization' of corporate discourse, which distinguishes 'managers' 
from 'leaders', enshrining the latter as guiding lights in a state of permanent crisis. In this context, 'leaders' can more easily win the trust and support of the public. Because of this trust and support of the public, that is both legitimately 'earned' (granted) and rhetorically 'produced' (claimed), large corporations, and media institutions like The Economist can always found their discursive, disciplinary practices in an air of legitimacy. The assertion and upholding of legitimacy are a precursor to any effective economic arguments based on cost and opportunity.

The strategic framework Pride and Prejudice operates in, affective legitimation, blurs the resources and tactics used to build legitimacy (e.g. moral, rational, etc.) into one, often in evocative, intangible ways. Here I follow Kerr in noting that 'leadership' is 'a part of constructed social reality ... a "vision of the world", a representation that becomes performative in constructing (producing, reproducing, legitimating) perceptions, representations, and practices of the powerful as leaders' (Kerr 2008:204, cf. Bourdieu 1991). Leadership is dramaturgical, in short, enacted 'on stage'. A 'vision of the world' which centres corporate leadership (Breeze 2012) is dependent on forms of legitimation, creating ideological space for institutions to build compliance through advertising and promotion; in the case of Pride and Prejudice, pride parades and other LGBTQ advocacy contexts, companies sell their products and brands as socially responsible and caring, as not only liberal, in the sense of The Economist's steering ideology, but liberating.

Pride and Prejudice was from beginning to end legitimated as a high-end, exclusive event, driven by a rational agenda of rigorous analysis and coolheaded discussion - the behaviour of leaders. As Figure 4.7 shows (at top), the event was not open to just anybody - a cabal of PR personnel, administrative staff and other employees of The Economist were on hand to make sure that all delegates were welcomed, that all media representatives were given their information package and importantly, that no unregistered person could enter. Upon arriving in the morning, I was greeted by a generous 'networking breakfast' (centre left) which subtly communicated the status of the event. Because I was one of the first delegates to enter, I was able to see the table in a pristine, orderly state - a banal index of the work of the largely 'invisible labour' of catering staff, a signal of luxury (cf. Thurlow and Jaworski 2014a). The materiality of the food, the bunch of lavender in the centre and the material semiosis of the delicately arranged crockery, bathed in purple light, all contribute to the performativity of the space. During the networking dinner, the austere wording of the labels also stood out as a marker of prestige, through over-lexicalized references to gnocchi with 'crispy sage', beef bourguignon with 'Lisbon onion maris piper purée' and sea bass with 'citrus spelt grain' (see Jurafsky 2014). My upside-down cheesecake for dessert came decorated with an edible purple flower - matching the overall purple colour scheme of the event, with lighting which worked to grant banal objects like the sterile white-tiled floor or line-up of water bottles a regal, distinguished air. Following Kress and van Leeuwen's (2006) description of the textual affordances of colour cohesion and coordination, the use of purple overall grants the event a homogenous brand. The subdued tone of the purple may be a marker of a lowered intensity of feeling, 

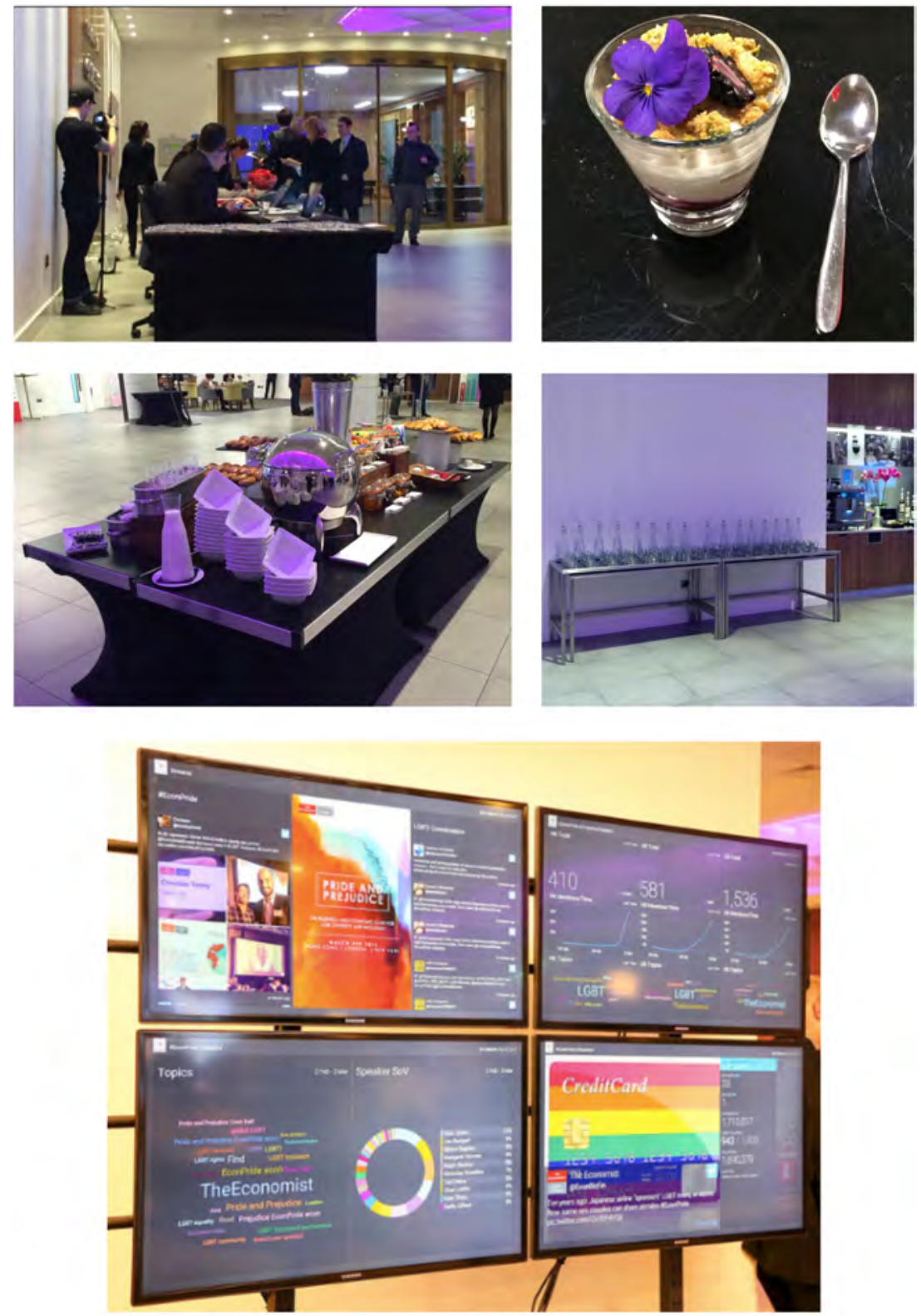

Figure 4.7 Montage of performed slick, luxury, and cool branding at Pride and Prejudice. 
or 'neutralization' (Kress and van Leeuwen 2006) - a signal to the delegates of the austere (rather than celebratory) and rational (rather than emotional) nature of the day's discussion.

Once delegates arrived, they milled about busily, preparing for a day in which the event would be almost perpetually in motion. Overlooking busy delegates at all times, an array of screens chronicled activity online, following the \#EconPride hashtag, and providing a somewhat intoxicating quantified summary of what was being discussed across the three locations. This backdrop is a 'corporate slick' performance of leadership: the use of exact numbers and complex information terminology has been noted as an authorizing practice which frames powerful actors as 'voices of expertise' (Reyes 2011; Breeze 2012).

Data-driven and technologized performances on screen (continuing in the event app) are evidence of Tannen's (1989) 'narrative detail', a kind of 'statistical thrill' (rather than panic, cf. Woodward 1999) whereby excessive, quantitative detail is used to perform a sense of the superlative. Participants' actions and tweets, in being framed as a critical mass, served to grant Pride and Prejudice legitimacy, indexing synthetic collectivization, and a frisson of pride, profit and progress within a context of 'data fetishism' and a 'society of the statistic', where social action is plotted according to calculated regimes of risk and probability (Page 2019; Morozov 2013; Woodward 1999). Through conversations, and further social media activity, delegates further mediated this grand, impactful scale, and performed the event's impact into being. Attendees were meant to be wowed by the scale of the event, its innovative energy. As one delegate quipped as we gazed at the moving tweets, word maps and data visualizations, it was 'kind of overwhelming'; it did, however, serve as good advertising for the company advertising analytics products at a stand nearby. It is clear that Pride and Prejudice's sponsors and producers equated 'the business case' with a kind of data-driven, statistical legitimacy, lending its analysis a credibility that also further distorts (or distracts from) the human fundament of any discussion of LGBTQ lives. In these statistics, 'LGBT rights', 'LGBT diversity' and even 'LGBT employees' are so abstracted as to seem entirely removed from the precarious, subjective reality of LGBTQ identity. This focus on measurement and calculation, however paradoxically, seems to stand in opposition to the more affect-driven rhetorics I discuss here however, both, eventually, can act to persuade either a sceptical CEO or a young gay employee of the value of the corporate world's leadership role in LGBTQ advocacy.

Indeed, leadership was regularly invoked at the level of the individual employee at Pride and Prejudice - at the level of 'out leaders', whose 'coming out' experiences grant them an expertise and passion which allows them to flourish, and for them to encourage others to. Extract 4.6 is an extract from an article entitled 'Bringing your authentic self to work', written by Tony Tonicela, IBM's 'Global Thought Leader of Diversity, Inclusion, and Talent Management'. 


\section{Extract 4.6:}

Leadership is another area where LGBT employees can contribute in a significant way ... Leadership and coming out both entail a level of risk taking, since, in both situations, we are publicly taking responsibility for something for which others judge us positively or negatively. The coming out experience can impact the way we operate as leaders in that it provides a lens through which we view and address a variety of leadership responsibilities ... As out leaders, we benefit from the lessons of our coming out experience which ultimately shapes our leadership style. We have, in essence, embraced our authentic self in the workplace.

Tonicela declares that this 'embrace of an authentic self grants LGBTQ people exceptional skills with regard to the leadership role market globalism plays in enacting LGBTQ inclusion. This points to the way in which, particularly with regard to SOGI diversity, diversity is repeatedly spoken about as something more than just good business, and a driver of innovation - in addition, it is also a recognition of authentic selfhood. Like the 'escapes' discussed in Chapter 2, diversity management is a means for queer people to find and actualize their 'real' (or authentic) selves - but of course, one may note that, like 'escapes', diversity is premised upon a journey to the 'real' that exists in a constrained economic system and is surely not accessible to all. In telling his own story of becoming a 'diversity leader', Tomicela mythopoetically draws on the legacy of the archetypal coming out story - or its 'authority of tradition', and 'conformity' (van Leeuwen 2007) in order to fold 'authentic' LGBTQ lives easily and comfortably into the neoliberal workplace. In this view, the heralded potential to be yourself that authenticity brings can also build a passionate, productive, risk-taking leader.

The affective rhetorics of pride and profit circulating at the event sometimes got under my skin (cf. Thurlow 2016). The last form of affective legitimation I discuss is such a moment. Upon arriving at the London venue, I noticed a stand being set up by Pride and Prejudice's 'regional ally', Avanade, skirted by two bright orange placards declaring that:

\section{'We act with integrity and respect' 'We innovate with passion and purpose'}

These evocative declarations seem to refer to grandiose aims with a typically deliberate vagueness. As I approached the stand, I noticed that a table was covered in small jars of jellybeans and featured a vibrant bowl of jellybeans in the centre, next to an advertisement for the company's 'corporate citizenship' initiatives (Figure 4.8). 

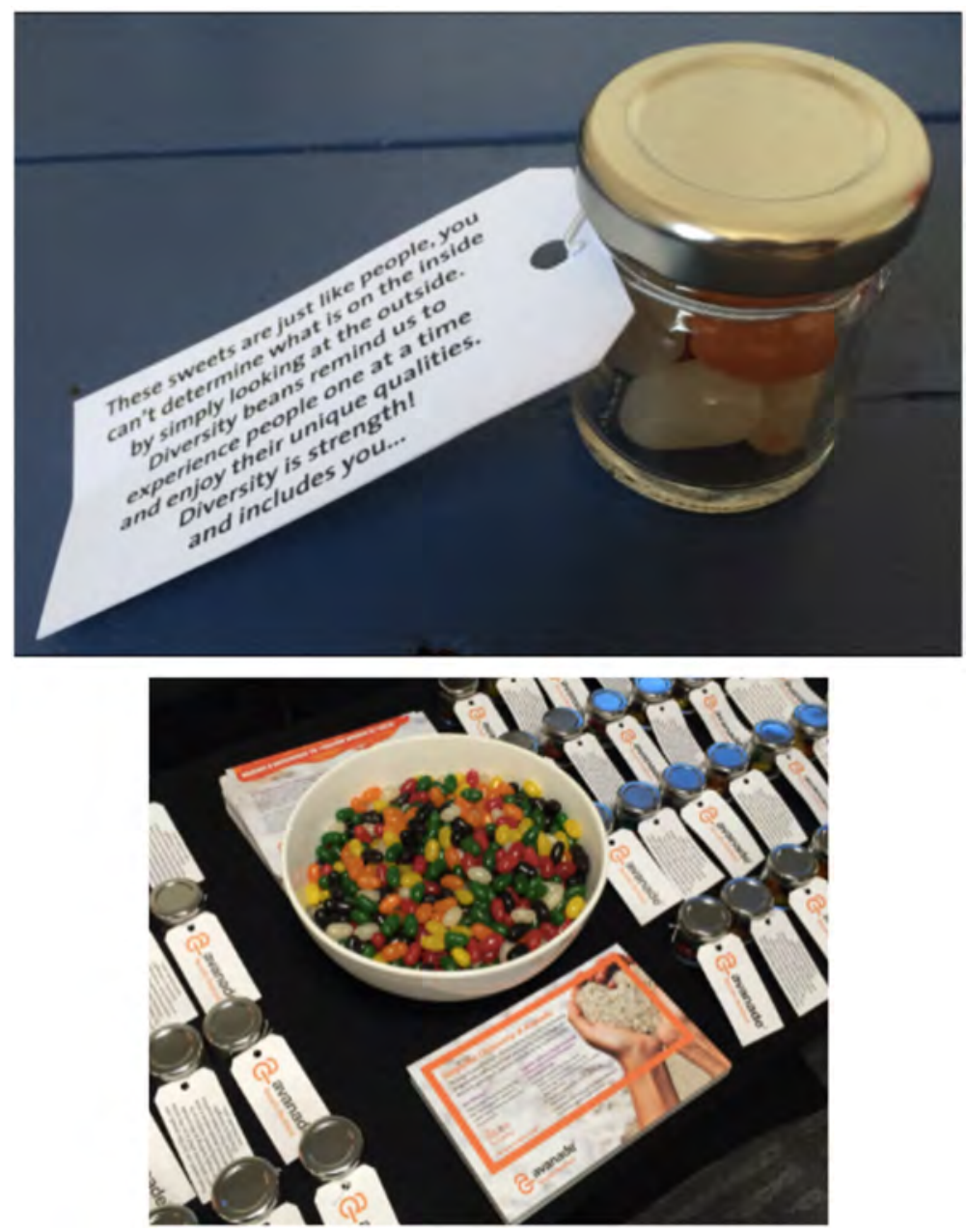

Figure 4.8 'Diversity beans' with an uplifting message.

\section{Diversity beans remind us to experience people one at a time and enjoy their unique qualities. Diversity is strength! And includes you...}

A gustatory, material-semiotic representation of 'diversity' further demonstrates how the notion is a form of (literally) digestible difference. As Ahmed (2012:69) remarks, however: 'if diversity is digestible difference, then other forms of difference become indigestible, as that which the organizational body 
can't stomach'. Within the confines of Pride and Prejudice, and with the particularly uplifting message these beans have (personalized, en masse, for me and the other delegates), this sweetening of diversity serves as both limiting and welcoming; an affirmation, and enclosure.

I was greeted warmly by a woman who told me to try a jellybean, while she coyly said 'They're designed not to be what you expect!' When I hesitantly took a green one into my mouth, expecting a green apple or perhaps lime flavour, I was surprised by the taste of cinnamon. When I tried a black one, expecting the distinct taste of liquorice, it tasted just as distinctly of banana. It was true - the woman hadn't lied, and nor had the beans - they are just like people, and you can't tell what's on the inside by simply looking at the outside. In any other context, a rainbow jar of jellybeans that don't taste how you'd expect may not carry as profound and uplifting a message, nor be as genuinely heartening, as these beans were at Pride and Prejudice. Nor might there be a marketing professional on hand to encourage you to literally taste the message for yourself (and to smile and say, 'tweet it!' as I moved away, beans in hand). At Pride and Prejudice, however, there was. In these beans, I found evidence for how 'inexpensive tat [can be] made magical through a kind of multimodal - or rather synaesthetic - alchemy' (Thurlow 2016:500). As such, the portability of the 'diversity beans' and their flavourful 'punch' carry an exciting, evocative message about the ease with which diversity can be appreciated and instituted: a quick fix, just like taking a magic pill, à la Alice in Wonderland. The moral-cum-rational message of these beans is that 'diversity is strength' and includes me; I have the obligation and opportunity to lead the way: to appreciate people's 'unique qualities', to ensure their (and my) imbrication in a totalizing global marketplace of 'talent', 'innovative thinking' and above all, growth. These beans serve as a singular expression of the affective power of the event's legitimation of individual achievement and enterprise.

Overall, Pride and Prejudice was hinged upon a complex web of affective rhetoric, offering a pathway to authentic selfhood and a better world. As Avanade proposed in an ad in the event booklet, remediating, and affirming the message the beans send, it is up to business, and myself as an imagined or real employee, to 'change things for the better' and 'create change for a living'. Compared to the emotions wielded in Reyes' (2011) study of legitimation through emotion, those deployed by The Economist still aim 'to construct, impose, debate or legitimize certain perceptions of reality' (Reyes 2011:788) but are perhaps even more powerful, by virtue of their boundless positivity. They legitimate a politics of a totalizing market globalism, employing effervescent, all-adherent economies of aspiration, togetherness, hope, success, and (the force of) love in order to do so. These are politics centred around enterprising, authentic individuals as venerable moral-rational agents. In them, the virtue of simple humanness is replaced by the virtuous and loving "figure of the enterprise' (Dardot and Laval 2013:259). In them, whether queer is an identity, desire or subjectivity, the value of any 'diverse' queer being in and of itself is 
replaced by the value of queer's potential: for growth, for profit, for a productive 'better' world.

\section{Concluding discussion: Affective legitimation in the discourse of the 'glass closet'}

Central to [corporate LGBTQ advocacy initiatives] is a common sense understanding of homophobia as a cultural disposition that might be disincentivized through the deployment of economic carrots (the promise of growth) and sticks (the withdrawal of capital) ... viewing homophobia as 'merely cultural' enables international financial institutions (IFIs) to obscure the material conditions that incubate homophobic moral panics, and their own culpability in co-producing those conditions.

(Rao 2015:38)

In this chapter, with the support of a theoretical framework strongly underpinned by the queer, feminist scholarship of Sara Ahmed, I have attempted to provide empirical detail to the 'problematic genealogy' of diversity Ahmed (2012) has identified, using principles of event-ethnographic analysis and the immersive, multi-sited context of Pride and Prejudice to do so. In this respect, I have described the three rhetorics of cost, opportunity and leadership in this chapter, in order to sum up the means by which affective legitimation has come to make equality a business decision; the way that a 'business case for LGBTQ diversity' is made rational, moral, and inspirational at once. Affective legitimation is a discursive strategy which reaches into - and mashes up - the innermost subjectivities, rationalities, emotions, desires, and tastes of LGBTQ advocates and allies in the corporate sphere. What appears to be a profound, progressive step for the global marketplace to take is just another way in which it consumes its critiques (and alterities) as sources of renewal for neoliberal governmentality. All in all, the opportunity to 'create change for a living' that Avanade espouses can more accurately be seen as an opportunity to withhold change: to prevent any 'progress' which does not adhere to the logics of neoliberalism as a totalizing rationality and moral compass (cf. Dardot and Laval 2013).

Echoing the above sentiments of Rao (2015), Ahmed (2012:69) herself has presciently asked: 'Does [the language of] diversity "stick" because it is not associated with sticks?' And appropriately enough, during his segment Alan Joyce also professed to being 'more of a carrot than a stick person', committed to exposing the economic power of the pink dollar rather than focusing on decrying the inherent injustice of forms of discrimination. The opportunity that diversity and inclusion present to the world of business at the purportedly 'global' event of Pride and Prejudice was the focus of its discussion. In large part, it was widely disconnected from either national or transnational assertions of LGBTQ rights, or the moral case for equality - or rather, the moral case was subsumed within the economic case, and the two were rhetorically framed as one. 
The 'pot of gold at the end of the rainbow' I began this chapter with can be seen, therefore, alongside this theoretical and empirical background, as a very direct, effective and affective 'carrot'. It is a mediatized foregrounding of economic aims, indexed in part through the allure of 'enrichment', but with the added benefit (to the powerful of market globalism) of obscuring the material foundations of the rainbow in the first place: the historical marginalization and deprivation of LGBTQ people. The objective of actions like Pride and Prejudice, ultimately, is to deny the possibility of solutions to homophobia that also address material injustice; to assert that there is no alternative to a free market-based resolution to this 'merely cultural' issue (cf. Butler 1997b). In order to meet this objective, I have argued, The Economist and other institutional actors employ forms of affective legitimation: (what I define as) instances of legitimation in which the various strategies used to justify a particular institutional order blend into one, so that the authority of tradition is perceived through rationalized frameworks, which in turn are treated as moral axioms, and in which those rational-cum-moral axioms may be expounded through evocative narratives, and so on. In decidedly neoliberal contexts, such as Pride and Prejudice, affective legitimation is the discursive process through which otherwise financial, bureaucratic or political-economic concerns can be imbued with pathos and emotional appeal; as 'something more-than'. Indeed, Pride and Prejudice provides evidence for affective legitimation as a discursive strategy in which ethos, logos, and pathos are one-and-the-same appeal, always steering support to the same thing: power, as that which imbues authority, gleans credibility, provides guidance on moral action, rewards aspiration and provides fulfilment through the affirmation of authentic selfhood in oneself and others. In the contemporary world, this power is held by the same profit-seeking firms that attended Pride and Prejudice, who (in their words) act as catalysts for 'change'. Ultimately, I argue that it is through attention to processes of affective legitimation that we can come to understand how corporate regimes of diversity management so effectively and powerfully fold LGBTQ individuals into the architecture of neoliberal market globalism.

The rhetorics of affective legitimation I am describing at Pride and Prejudice could also be referred to as affirmative legitimation. They are, essentially, forms of legitimation aimed at promoting politics in which ideological conflict 'can be redressed through a shared commitment to civility, consensus building, openness and diversity' (Hickel and Khan 2012:220; my emphasis). This focus on consensus and representativeness is typical of the kinds of affirmative politics that Fraser $(1995,2000)$ has decried. In other words, we can note that diversity management, as an affirmative metadiscursive regime, is therefore profoundly linked to a kind of affective quelling of LGBTQ politics - the folding of sexual minorities into the fabric of a violent economic system (cf. Wee 2016). That this quelling is engaged in so willingly is, once more, emblematic of how neoliberal ideology is increasingly interpreted as 'anti-ideological', self-evident, and apolitical by the broader public, a result of the increasing invisibilization of capitalist interests in mediatized discourse (Cammaerts 2015). Rather than 
being straightforwardly manipulative (cf. van Dijk 2006), affective legitimation operates by strategically framing a single institutional order as the source of universal morally, rationally, and mythopoetically justified principles, and thus works to draw sexual others into this order willingly. The role of positive emotions is key in the formation of such will. At Pride and Prejudice, rhetorical signals of pride, satisfaction, and success (as a boost to profit, thus GDP, thus social wellbeing), and the allure of authenticity were all employed for the purposes of legitimating (and constraining) LGBTQ identity under neoliberal globalization. As well, multimodal resources such as rainbows, bright colours, and even the unexpected taste of a jellybean can be employed to enshrine institutions and their discursive practices with an 'anti-ideological' legitimacy.

In this chapter I have provided an empirical account of the commitments of the business world to LGBTQ diversity, thus outlining the implications of diversity's 'currency' in the neoliberal workplace (cf. Ahmed 2012); the utility of 'diversity'. Ultimately, these implications are twofold. Firstly, I argue that the actors at Pride and Prejudice frame neoliberal citizenship as the most legitimate form of authentic LGBTQ citizenship, through forms of affective legitimation within the metadiscursive regime of diversity management (cf. Park 2013). Ahmed writes how, through the context of diversity management, "diversity becomes a means of constituting a "we" that is predicated on solidarity with others. Yet this solidarity becomes a mechanism of asserting the superiority of one form of politics over others' (Ahmed 2012:151). In other words, we must be included - or else: to be excluded from solidarity is to abandon its prospect, and the prospect of transformative change. When I see multinational corporations such as IBM and Avanade inviting me to 'create change' by asserting my authentic sexual citizenship, it places an inherent limit on how that citizenship is constituted. I see a homonormative politics - an affirmative and assimilationist politics - deploying aspirational and prideful aspects of a transnational affective economy in service of an unjust political economy. I see myself and other queers interpellated by the promise of another world, but unable to reach it, unless we assert the superiority of market logics in a neoliberal future; that is, unless we exert a self-maximizing, entrepreneurial spirit, asserting our individually held, rigidly defined, 'authentic' identities. The attainment of such identities is, according to the discourse at Pride and Prejudice, a moral and rational pathway to a hypothetical future of success, leadership, and boundless opportunity. In sum, Pride and Prejudice evinces a seamless bringing-together of neoliberalism's mediatized pursuit of authenticity (cf. Trilling 1972; Cavanaugh and Shankar 2014; Mapes 2018) with the pursuit of an essential authenticity that is typical to historical discourses of sexual identity (cf. Sedgwick 1990). The neoliberal citizen 'does not begrudgingly participate in work, but displays initiative, responsibility, and flexibility, willingly taking risks and engaging in projects of endless self-improvement' (Park 2013:559; cf. Brown 2005). For them, solidarity with others is only possible as a joint foundation for the antiideological premise of self-improvement; i.e. as a foundation for reflexivity in a world perceived as a competitive market (cf. Chun 2016). I discussed in the 
last chapter how the lifeworlds of LGBTQ tourism premise consumptive and self-actualizing 'escape' as a fundament of LGBTQ identity. In texts and affective practices such as those by Avanade, there is evidence for how this framing of 'authentic' sexual citizenship and/as individualist neoliberal citizenship is a characteristic of all corporate discourses of LGBTQ identity. This reminds us, powerfully, that those in power rule by both force and consent - the forces of neoliberalism increasingly find strength in subjects' willingness (indeed, desire) to be taken in by it (cf. Ludwig 2016).

Secondly, I wish to highlight the non-performativity of 'diversity', as a strategically deployable signifier (Ahmed 2012; Urciuoli 2003), with the aim of speaking back to the 'business case' that Pride and Prejudice purportedly highlighted. It may be the case that what this business case is meant to advertise is not the opportunity that sexual diversity presents to the corporate sphere, or the costs of ignoring it, but rather, the very non-performativity of the term itself. In the mediatized discourses produced by and at Pride and Prejudice, rhetorics of cost and opportunity abound, but always operate in an economic framework. Discrimination against sexual minorities as diverse 'others' is not rejected in and on itself as a social injustice, or 'cost', but rather as an impediment to the capitalization (and/or exploitation) of that 'diversity'. Diversity is always something which the corporation can amass, through framing diversity both as something digestible and as non-threatening; in essence, its compatibility with the valuable 'anti-ideological' and affirmative mindsets of neoliberalism (Cammaerts 2015; Fraser 1995). In this sense, the 'business case for LGBT diversity and inclusion' that The Economist professes to make with Pride and Prejudice (with a significant amount of self-aggrandisement), rather than relating directly to sexually diverse people, rather seems to relate directly to 'diversity' as a strategically deployable signifier (cf. Urciuoli 2003, 2016). In other words, and following Thurlow and Jaworski (2017b), at Pride and Prejudice 'diversity' can be framed as a 'word-thing' - feel-good and accessible, 'unmeasurable, but deliberately intangible' (Thurlow and Jaworski 2017b:192). This has implications for how the event as a whole is considered. As with other events of its type, Pride and Prejudice can be described as a dramaturgical action, a strategic performance. Rather than being performative, however, we can see it as wholly non-performative, following the arguments of Ahmed (2007, 2012) again: a metadiscursive marketing of how 'naming can be a way of not bringing something into effect' (Ahmed 2012:117). As well as selling the LGBTQ community through their potentiality as neoliberal citizens, the event is committed to selling the feel-good non-performativity of the sign 'diversity'. In this way, the event itself acts as marketing for metadiscursive regimes of diversity management as a product; how saying a lot about 'diversity' is seen as doing diversity, how 'diversity' leaves political-economic orders untroubled and how diverse others can be involved in the production of this discourse.

Pride and Prejudice exemplifies how social, cultural, and symbolic capital can be reshuffled by powerful media organizations like The Economist to meet ideological ends: how language, affect, and even the senses are operationalized 
within the habitus of market globalism. As Del Percio and Sokolovska (2016:3) note, discourses of diversity 'represent a powerful means to create a climate of tolerance, harmony, and freedom', but, as this chapter has shown, they are also increasingly wielded by global corporate/media actors to facilitate the exchange and accumulation of capital - in ways which does not necessarily diminish the material inequality or prejudice experienced by those who are 'diverse'. In fact, I argue that non-performativity is precisely what 'diversity' discourse is designed to achieve within the context of corporate citizenship. In effect, it is simply designed to sell diversity as boundless 'pure potential' (cf. Park 2016): a way to get ahead, a way to attract talent and a way to quell alternate views with regard to the future of LGBTQ rights. The many genuine people working to and for discourses of 'diversity' at Pride and Prejudice, therefore, accede to a vision of a 'better world' whose internal logics impede that world from actually existing, at least not equally. In privileging their own and others' recognition and success within the neoliberal workplace, they iteratively undermine the possibility of transformation: finding alternatives to the unjust governmentality of neoliberalism. In their hailing through the metadiscourse of 'diversity', and by virtue of the currency of their 'authentic selves', they are included - welcomed, valued, and secure. Of course, however, 'inclusion', like 'diversity', is not equality - to quote Ahmed once more, 'things might appear fluid if you are going the way things are flowing' (Ahmed 2012:186). If you are digestibly different, authentic, and self-interested, you may be both consumed and enriched by the habitus of market globalism.

I have identified affective legitimation as the discursive strategy through which moral, rational, and otherwise evocative arguments are employed by The Economist, and its global corporate partners, in order to posit the neoliberal habitus of market globalism as the natural and ideal politics for LGBTQ people - a 'global homocapitalism' (Rao 2015). This process accords with The Economist's broader promise (and brand) of liberalism (Liberalism ${ }^{\mathrm{TM}}$ ), in which it is the selflegitimating ideology of a globally mobile, powerful ruling class (Zevin 2019). But a postscript is required here. In 2017 and 2018, the by-line through which Pride and Prejudice was understood evolved. The 2016 event's focus, 'the business and economic case for diversity and inclusion' became 'business as a catalyst for change' in 2017, and 'the path to advocacy' in 2018. Although there is no denying the event's corporate foundation is still intact, there is ample evidence in the videos, presentations, and social media produced for these more recent events that The Economist has transitioned Pride and Prejudice to a social justice-oriented framework - or so they claim. In 2018, one of the keynote interviews was promoted as follows: 'in this session we will broaden the mission to capture the expectation that good business isn't just about revenue and reputation, it's about people'. Although this is somewhat heartening, it retains an essential commitment to neoliberal frameworks of citizenship, whereby the entirety of an individual's self is subject to influence, recognition, and management by their employer. In this respect, the event retains a binaristic vision of a hypothetical future in which to be included is to be a proud tool in an 
unjust, unsustainable system; to be excluded is to be aggrieved and insecure. With, ultimately, no challenge to ideologies of neoliberal political economy at all, I am left to wonder how the discourses of diversity I've examined at Pride and Prejudice might be repurposed (cf. Ferguson 2010). Queer futurity, after all, may rely on 'uneasy and unpredictable alliances' in the struggle for justice, as Butler (2015:70) tells us. An equitable future, no doubt, is seriously 'jeopardised by a world in which key economic, political, social, and cultural decisions are set by global networks of firms, many of which dwarf in wealth and power most of the world's nations' (Mosco 2005:59). However, despite my critical orientation to the venal nature of 'diversity discourse', I also can't deny its poetic appeal. After all, who am I to deny the truth in a rhetoric like 'difference is what we all have in common' (as in the Twitter banner below), if it might - might - shed light on the true 'cost' of discrimination?

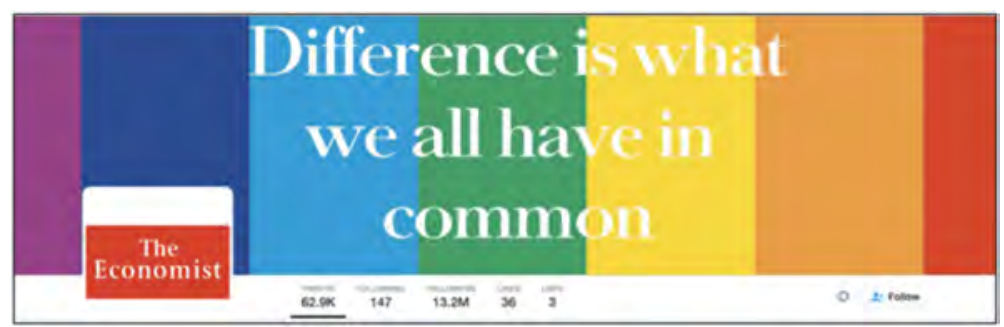

\section{Notes}

1 Unless otherwise indicated, textual excerpts regarding Pride and Prejudice are taken from the website for the event: https://prideandprejudice.economist.com/.

2 This spatio-temporal imaginary Hoad (2000) points to is of course also salient in the chronotopic visions of present and future seen at Spectrum in Chapter 4.

3 See https://www.open-for-business.org/.

4 These scholars do not entirely disavow the importance of identity politics and 'merely' cultural matters. However, they arguably fail to recognise how matters of recognition and redistribution, to use Fraser's (1995) terms, are co-dependent, co-morbid.Addressing either properly fundamentally requires that attention be paid to both (cf. Duggan 2003; Butler 1997b; Rao 2015). 


\title{
5 Sloganizing and 'materializing' equality
}

\author{
Scales of solidarity in the discourse of \\ transnational LGBTQ advocacy
}

\section{Introduction: The 'post-gay' scapes of transnational LGBTQ rights}

Figure 5.1 presents screenshots of two videos uploaded to YouTube by the organizations OutRight International and UN Free \& Equal, in advance of Human Rights Day (December 10th), 2015. ${ }^{1}$ Each is devoted to discussing the 'price' and/or 'cost' of exclusion, and thus serve as an ideal bridge between the topic of the last chapter and this one. The rhetorics of cost (both literal and metaphoric), as examined in the last chapter, evidently have sway outside of the vehemently classically liberal context of Pride and Prejudice. LGBTQ advocacy discourse, although generally focused on broadly humanitarian, rightsbased aims, therefore has parallels with the affectively legitimated discourse of diversity management. In short, this chapter is about exploring those parallels. Partly, this involves identifying ways in which transnational LGBTQ rights communications resemble those of global commerce, adopting their internal rationale: the pursuit of growth, the omnipotence of the marketplace. Furthermore, however, it also involves identifying how these communications often adopt a teleological perspective - a kind of chronotopic 'faith' with regard to the banal enactment of globalization (Rist 2008). Notions of global development, global queer futurity and globalized queer identity are all iteratively accomplished by those who produce media in support of this faith. Overall, this chapter explores the terrain of advocacy discourse in order to reveal its complex interrelation with the transnational habitus of the increasingly 'anti-ideological' logics of neoliberalism (cf. Cammaerts 2015).

The mediatized styling, campaigning, mobilizing, and scaling of advocacy discourse allow us to conceive of the world as a cosmopolitan 'planetary conviviality' (Mignolo 2002), and establish the possibility of a future-world without LGBTQ exclusion - a 'post-gay' globe (Ghaziani 2011). Although by no means am I decrying this discourse absolutely; in this chapter I wish to problematize it: to speak back to the semiotic production of a world without discrimination, to see what, and who, it also erases, and the alternatives it does not present.

In the landscape of advocacy discourse, the value of equality can often be foregrounded. Economic outcomes are given moral weight, and thus 


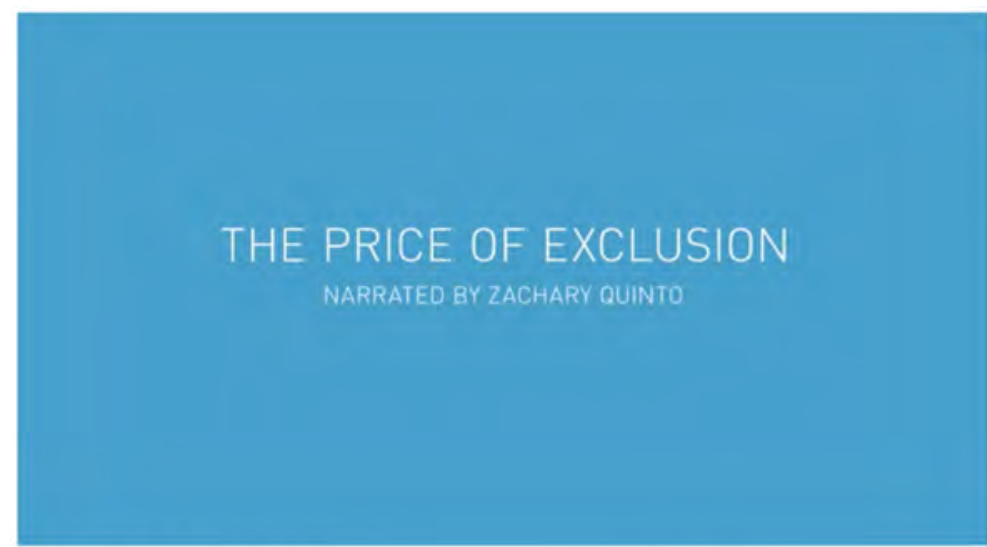

UN Free \& Equal - The Price of Exclusion

108,126 views.

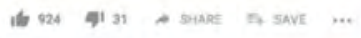

(U) UN Human Rights

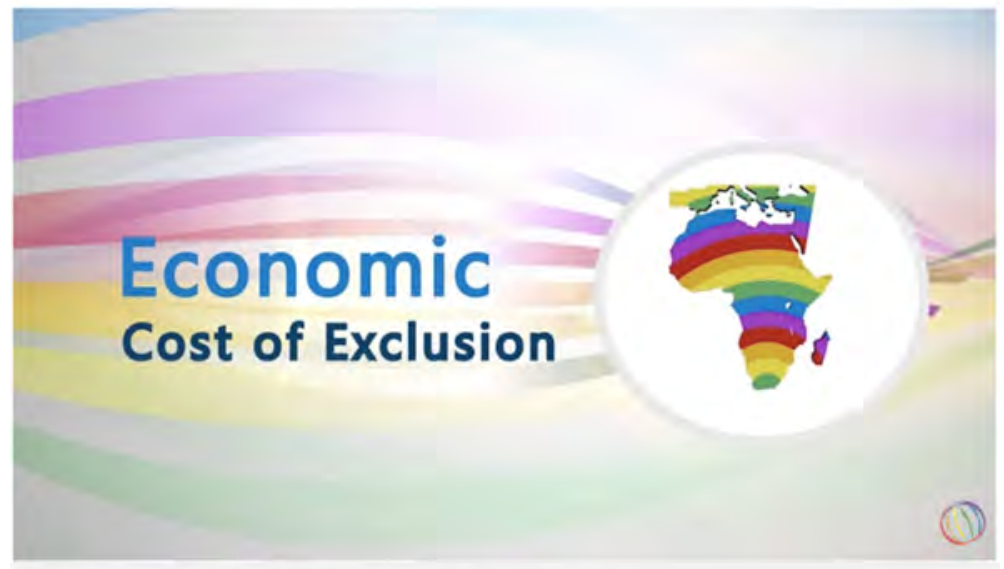

"Don't Waste Our Talents" - The Economic Cost of Exclusion

(a) OutRight Action International

Figure 5.1 OutRight and UNFE: 'the price/cost of exclusion'.

the inherent divide between them is blurred. The process I term affective legitimation is thus evidenced in Figure 5.1 via appeals to logos via the 'cost' of exclusion that are also appeals to pathos, because of 'wasted talents', the evocative 'opportunity' of inclusion, entrepreneurialism, and 'causumerism'. Affective legitimation is just one of the discursive strategies I identify in this final substantive chapter. Against a theoretical backdrop 
identifying 'positive thinking' as a crucial value in the contemporary consumerist world, and consumer citizenship as fundamental to the articulation of sexual politics (Richardson 2005, 2015, 2017), I interrogate the seemingly positive nature of LGBTQ rights discourse. I follow other scholars who wish to understand (and critique) how socio-historically marginalized groups respond to and resist unjust power structures - although the discourse of transnational LGBTQ rights has received relatively little attention from sociolinguists until recently. Overall, I seek to provide a nuanced perspective on the laudable work that LGBTQ rights organizations do, while recognizing their imbrication with unjust or amoral discourses and ideologies, ultimately criticizing them for following flawed political-economic strategies. In essence, they advocate for a world in which both success and abjection for LGBTQ people hinge on individual action, and individual identity, scaled at society-wide dimensions; where my own actions as a consumer citizen and 'equality champion' are scaled as the path to prosperity for my (purported) community, within a consumptive, market-oriented future.

As I will argue, the end result of the 'scale jumps' of transnational LGBTQ advocacy is that movements for equality now seem to align with something akin to a self-centred post-feminist sensibility (cf. Gill 2007, 2009; Lazar 2014), with regard to the neoliberal sexual politics of affirmation and recognition. This is what some call a 'post-gay' or 'post-queer' sensibility, in a context of contemporary (homonormative) politics (cf. Ghaziani 2011; Ng 2013; Green 2002). The theorization of a post-gay mindset serves as the foundation for my study of transnational LGBTQ advocacy discourse, and the dimensions at which this civil society sector is scaled. I do so from a perspective attuned to arguments from scholars (e.g. Rao 2014, 2015; Ní Mhaoileoin 2017), who are sceptical of how the largest and most powerful advocates for LGBTQ rights frame progress and non-heterosexual identity. Rao, for example, has provocatively claimed that the global imaginary undergirding transnational LGBTQ advocacy relies on false consensus on how progress is constituted. The scalar/ spatial comparisons between the West and non-West that sustain the discourse of LGBTQ rights, he argues, in fact 'masquerade as gestures of solidarity in a shared struggle' (Rao 2014:174). At least to some extent, Rao seems correct here, if one recognizes how often and how significantly the end-goal of LGBTQ advocacy discourse seems largely fixed on me. My identity and my relation with the world are affirmed through my support of these organizations. My solidarity with a community of empowered selves is vital - not our solidarity in a shared struggle for transformative change. My thinking here follows on from Chouliaraki's description of 'post-humanitarianism' (e.g. 2011, 2012, 2013). Although a post-gay sensibility, in the context of LGBTQ rights, is by no means 'post-homophobia' (claiming that discrimination itself is no longer an issue), it does successfully elide any material/economic causes for homophobia from discussion, in favour of seeing it as 'merely cultural' (Butler 1997b; Rao 2015). 
There are (at least) two ways to interpret a claim such as Cruz-Malavé and Manalansan's (2002), that 'queerness is now global' (as discussed with regard to 'enworlding' in the introduction). The first relates to the globally mediatized aspects of queer identity construction, and the second relates to the universalizing discourse of human rights regarding sexual orientation and gender identity. The two are ideologically entangled and interdependent: adopting a gay identity is now seen as a human right, and being a gay man is increasingly reliant on the crafting of intertextual links between oneself and other 'types' of gay man portrayed in media. So far in this book, I have already touched upon lines of theory examining the teleological and epistemological foundations of globalized sexual politics. The literature on the topic is extensive and well-worn (e.g. Altman 1996, 1997; Binnie 2004; Hoad 2000; Povinelli and Chauncey 1999; Manalansan 1995; Cruz-Malavé and Manalansan 2002; Rao 2014, 2015). Alongside growing acceptance of LGBTQ practices in the global North and South, a number of perspectives on 'global queering' have emerged, which variously assert the monolithic spread of Western-style gay liberation to the global periphery, or the dynamic and localized expression of multiple forms of non-heterosexuality, both before and after colonialism. This 'transnational turn' considers the effects of 'increasing transnational mobility of people, media, commodities, discourses, and capital on local, regional and national modes of sexual desire, embodiment and subjectivity' (Povinelli and Chauncey 1999:439), and considers how they provide conditions for change.

In the confines of this book, it isn't possible to address the true complexities of this transnational turn, amidst polemical debates regarding homonormativity, homonationalism, 'the gay international' and even 'gay imperialism' (cf. Duggan 2003; Puar 2007; Massad 2002; Haritaworn et al. 2008). However, there can be no doubt that some kind of transnational queer public exists, in both representational and material form. It is imagined, but not imaginary: a transnational public sphere that has 'enabled the creation of forms of solidarity and identity that do not rest on an appropriation of space where contiguity and face-to-face contact are paramount' (Gupta and Ferguson 1992:9). A queer public now actively forges mediatized connections with/in itself across borders, allowing for solidarity and community where one was not possible previously, to be taken up and (re-)produced in all aspects of our everyday lives. Without in-depth ethnographic research alongside Southern LGBTQ activists, I cannot comment on the 'uptake' of mediatized discourses of LGBTQ rights in the parts of the world that are most dangerous for these kinds of subjects. As Lazar (2017:440) presciently notes in her examination of the strategic adoption of normative/nationalist frameworks by queer activists in Singapore, "what and how any activism ends up looking in any place cannot be determined a priori nor assumed to be a foregone conclusion'. I cannot speak on behalf of Southern or peripheral actors or activists. What I can and do examine is how I (and others like me) relate to the mediatized imagining of queer futurity and in/security, to ask: how is my collectivity with the world's queers conceived? How is a 'post-gay' world of queer subjects envisioned? 
Importantly, like 'post-feminism' before it, post-gay provides a theoretical framework for describing social dispositions, more so than a real-world disposition in itself (Gill 2007). It is a distinctly new response to the sexually liberated world around it: late modernity's world of free-flowing scapes, consumer culture, and endless flows of symbolic capital. A post-gay era is paradoxically characterized by twin impulses of assimilation into the mainstream, and the inner diversification of LGBTQ communities (Ghaziani 2011). It is both 'queer' and decidedly not-queer. It describes current-day processes of identification and disidentification; how forms of collective sexual identity can nowadays be perceived as resources to be picked up or dismissed at will.

In this chapter, I use the term 'post-gay' for convenience, and to follow on from prior commentary from Ghaziani (2011), and Ng (2013), among others. (Its metonymic use of 'gay' remains problematic.) Indeed, ironically, that is in fact the precise problem with the post-gay cultural sensibility that Ghaziani and others point to: 'to be post-gay means to define oneself by more than sexuality, to disentangle gayness with militancy and struggle, and to enjoy sexually mixed company' (Ghaziani 2011:102). In such a sensibility, 'gay' loses currency (it evolves as a resource), so that it no longer signifies an especially transgressive position. Rather, a post-gay sensibility privileges an individual form of subjectification and reduces focus on the external political forces or societal relations which ground the subject. For Green (2002:523, 2010), this has the unintended effect of eliding the historically contingent 'institutional organization of sexuality [and] complex developmental processes attendant to sexual identification'; it essentially obscures the fact, outlined in Chapter 1, that sexuality both precedes and emerges in processes of subjectification (cf. Bucholtz and Hall 2004). Expressed differently, one could say that although a 'post-gay' sensibility maintains the use of recognizable tokens of queer struggle, such as 'pride' and 'out(ness)', the political undercurrent of forced 'closeting' and defiant 'coming out' processes is quelled within it (as prominently seen via tourism texts in Chapters 2 and 3). Even in queer forms of political organization, activism and advocacy, the focus will be on affirming 'diversity' (see Chapter 4), and increasingly, following Ward (2008), on professionalizing, instrumentalizing and commodifying diversity for strategic ends.

Importantly, 'post-' is not intended to suggest an end to discriminatory practices, but their de-emphasis, in so many words; as Ghaziani (2011:101) puts it, 'activists today are motivated less by drawing boundaries against members of the dominant group and more by building bridges toward them'. Appeasement, not conflict. Suffice to say, I do not subscribe to a post-gay sensibility. When Ghaziani (2011:120) notes that 'post-gay could entail a multiculturalist blurring of modernist boundaries and a move toward expanded tolerance and freedom [or] entail a neoliberal, class- and racially inflected, and surface blurring that redefines the contours of hetero- and homonormativity', I believe that the latter is true. In other words, although Ghaziani (2011) is right to highlight the trend toward post-gay sensibilities - to be clear, they are definitely salient in much of the discourse examined in previous chapters - any 
narrative which claims that we are 'post-gay' is as inaccurate (and offensive) as a claim that the world is 'colour-blind', and racism is no longer a problem. Post-gay is a falsehood. I thus align with Thurlow (2016) who has highlighted (with regard to elite discourse) that "there is no "post" in reality [and] what is real ... is the ever-expanding mythology of "post". That is, the narratives which tell society that the discourses, spaces, and institutions of the powerful and privileged have now been opened up are in fact a way to strengthen and reinforce those unequal power relations.

Indeed, there would be few people that claim that homophobia is not an issue in the world today (that is, to prove my point, so long as they see homophobia as a problem at all). However, there is nowadays a tendency to frame LGBTQ equality as on the horizon; not yet arrived, but not unforeseen (cf. Muñoz 2009). In the contemporary era, humanity can see a home for LGBTQ people, under a rainbow flag and other indexicalities of hope, progress and love - the foundation of a dynamic global queer semioscape. Classical liberal values, configured as neoliberal governmentality, are envisioned as a path to prosperity for a previously demobilized constituency. It is mediatized texts which offer this hope, this neoliberal mode of anticipation, a vision of the 'interdiscursive chains' between the future and present, that I analyse here (Park 2018). I have touched upon these topics in earlier chapters, with regard to tourism and diversity management. In this chapter, I take on board the challenge of describing transnational LGBTQ rights as a global institution, and challenging the outcomes of their global articulation.

This analysis thus hinges on a belief that the heavily mediatized projects of transnational LGBTQ advocacy do not just represent social life, but guide it in certain directions. Queerness is now global, but some queernesses are more globally legible than others. The cultural hegemony of the West makes this so. For an individual of some non-heterosexual identity, whether or not they follow the archetypal narrative of 'coming out' when claiming such an identity, they will still be representable as somehow L, G, T, B or Q or +, somehow on the spectrum created through being outside the norm, affirmed in the media of liberation. These most basic tools of liberation - identifying oneself as somehow otherwise - immediately perform other scales of identity into being. The legibility of non-heteronormative social action is made possible through a spatiotemporal imaginary, and evolutionary narrative, in which the West (and a metonymic gay identity) is dominant (Rao 2014; Hoad 2000). However laudable they are despite this, this leads to forms of marketized (i.e. mediatized) queerness being the objects 'through which queers constitute their identities in our contemporary consumer-oriented globalized world' (Cruz-Malavé and Manalansan 2002:1). As I eventually contend, this creates a double-bind which restricts how queer futures are envisioned.

LGBTQ rights are now seen as a global issue, and the number of civil society actors mobilizing for them has increased and diversified a great deal since the founding of the International Lesbian and Gay Association in 1978 (Paternotte and Seckinelgin 2015). These organizations particularly advocate 
for LGBTQ rights as human rights, following on from transnational movements for the recognition of such rights that began post-1945. LGBTQ organizations did not focus their work around a human rights strategy until the early 1990s. Despite this, a universalist human rights framing of LGBTQ politics is now dominant - the multilateral Declaration of Montreal and the Yogyakarta Principles in 2006 further served to accelerate and intensify the struggles of LGBTQ movements as human rights movements (Kollman and Waites 2009). All of the strategic communication I study in this chapter broadly commits to this human rights framework (Ciszek 2017). This framework has however received significant criticism for representing a professionalization of advocacy 'that denies local and potentially divergent ways to emancipation in favour of a single and globalized mode of activism' (Paternotte and Seckinelgin 2015:221). These critiques extend to a criticism of human rights frameworks generally, given they inevitably establish norms of human subjectivity, and reify state authority to recognize and legitimate particular subjects (Thoreson 2011).

The construction of a discourse of LGBTQ rights and a politics of global LGBTQ solidarity has been empowering for many. Nevertheless, it is imperative that queer scholars and queer people keep track of the extent to which activist movements and/or advocacy organizations adopt neoliberal models of citizenship, and the consequences of this for future activism. Within the context of a burgeoning post-gay sensibility and all-encompassing market globalism, we can follow Richardson (2015:263) in stating that 'lesbian and gay movements and activism, as well as individual subjectivities, have been profoundly shaped by neoliberal policies, discourses, and practices' (e.g. Figure 5.1). Under such a normative framework, the discourse of human rights is perhaps inevitably a tool for making particular perspectives on identity and citizenship seem universal, even 'anti-ideological' (Cammaerts 2015). It is right to ask what kind of sexual subject is crafted through media produced by and within contexts of neoliberal citizenship, as well as what models of liberation.

A generative approach to critical discourse analysis offers a way to unpack the operation of affirmative discourses in media, establishing their impact and questioning how they could be made better (cf. Macgilchrist 2016). That is what this chapter offers. Suffice to say, in many ways, any discursive centring of the Western, neoliberal, and (stereotypically) gay male subject may seriously undermine the relevance and efficacy of international anti-homophobia campaigns (cf. Thoreson 2013, 2014). By invoking this Western subject, LGBTQ advocacy risks articulating the particular kind of solidarity evident in much humanitarian discourse: a 'narcissistic disposition of voyeuristic altruism' (Chouliaraki 2010, 2012:1, 2013) whereby subjects' relation to the Western spectator results in aid and empathy, rather than subjects' needs alone. Yet, as I argue here, this is precisely what LGBTQ advocacy institutions tend to do. While 'you' (the Western advocate) can 'power more wins for love', and bask in an ersatz equality yourself, transformative change for the world's poor and marginalized queers is not yet here. In advocacy texts like those I explore in this chapter, 'equality' is thingified and commodified, as in the preceding 
chapters (cf. Thurlow and Jaworski 2017). In the process, love, hope, and other affiliative, performative affects are (re-)semiotized into the moving, materialized product of an altruistic, allied, and global lifestyle for the centred Western subject.

My analysis is structured around three discursive strategies which I identify as strongly guiding the operations of the LGBTQ advocacy organizations I have studied. These strategies are subsumed under heuristics of audience design, materialization, and mobilization, and scalar work. To aid my analysis of these strategies, I provide further comment on audience design, stance, and word-things in the following section.

\section{Audience design, stance, and word-things}

The notion of audience design derives from Bell's (1984, 2001) framework for understanding how, as Cameron (2000:325) aptly summarizes, 'stylistic choices are primarily motivated by the speaker's assessment of the effect certain ways of speaking will have on particular addressees'. Here, I wish to examine its strategic deployment in social media and digital outreach, as a way to construct (and reinforce) affiliation between advocacy organizations and their audiences: moments of 'interpellation' (cf. Althusser 1990) where linguistic styles and other resources such as 'camp talk' (Harvey 2000) are used in order to invoke an intimate relationship or 'allyship' between organization and addressee. This is reliant upon broader societal 'association[s] of linguistic features with particular social groups' (Bell 2001:142), including by those groups themselves - the recognition of queer people, writ large, as a single community of practice, indexed by/through a uniting queer semioscape. Bell (1984, 2001) distinguishes a responsive and initiative axis along which style shifts can occur; respectively, where the shift responds to a given situation, and when it serves to alter the key of an interaction itself. Responsive and initiative style shifts must be seen as 'two complementary and coexistent dimensions of style' (Bell 2001:165). Because the style shifts I discuss here are strategically deployed to both reinforce community boundaries and mobilize agents for community activism, they represent both axes in action. External, indirect addressees - either indifferent to or active participants in a heteronormative or oppressive society - become the referees to which stylistic variants are directed, while these variants also work to affirm direct addressees' identities. In short, audience design in advocacy discourse indexes the celebratory and defiant attitudes (purportedly) required to bring about change. It distinguishes an in-group community of queer people and their allies from those who they seek to dis-identify with and dismiss.

Many texts exemplifying forms of audience design adopt forms of stancetaking, through which these organizations attribute agency to themselves as 'queer' agents. Stances indicate 'what kind of people we think we are, and what we think about the people we are speaking with or imagine we are speaking with' (Jaworski and Thurlow 2017:277, 2009; Jaffe 2009). Stance 
is the discursive operation through which social actors evaluate social objects and align themselves with regard to those objects and other subjects (Du Bois 2007). As Jaffe (2009:9) notes, it 'saturates talk about others', and manifests practices of categorization, evaluation, intentionality, affect, epistemics, and identity formation. Acts of stancetaking are thus inherently scale-making; expressly ideological and habitus-forming (cf. Jaworski and Thurlow 2009, 2017). In the context of advocacy discourse, the ludic stance and style shifts of much of organizations' strategic communication stand out for how they ascribe negative value to homophobic ideologies in place around the globe, while enshrining affects of cool defiance and hope as the best way to achieve change. By virtue of the fact these styles/stances are adopted by institutions or individuals acting on behalf of institutions, to address individual members and supporters, they can also, lastly, be characterized further as forms of synthetic personalization/collectivization (Fairclough 1989; Page 2012, 2019). Like already-discussed hashtags like \#EconPride, a great deal of advocacy discourse subsists on scaling individuals as part of, if not the driving force behind, an organized, all-encompassing collective: the figurative right side of history. ${ }^{2}$

These ludic stances prompt the adoption of styles seen to manifest a LGBTQ positionality, given that style can be seen the discursive enactment of identity (Fairclough 2003). However, none of what contributes to a salient stance (e.g. style, intertextually meaningful phrases, entextualized personae, single words) exists outside of the ongoing commodification of language. As Heller (2010:102) informs us, meaning-making practices are nowadays easily co-opted into the marketplace as signs of authenticity and a mode of distinction in niche markets. The queer semioscape that styles and stances help constitute - at both local and global scales - thus responds to the mediatized expression of everyday queer life in the West, and initiates relationships between and among those living those lives. This includes the use of shifter-like 'wordthings' to both signal, and construct, queer enworlding: a welcoming world in becoming. Advocacy discourse is not immune: presenting itself as authentic through styles and stances seen as authentic through their mediatized uptake within the aforementioned in-group community. Advocacy actors talk the way 'we' talk, and defy prejudice by acting the way 'we' act, as self-authenticated, 'out' individuals. Authenticity is thus a tool to flatten social hierarchies and build bonds in ways which elide privilege (cf. Mapes 2018). And at times, even the smallest rhetorical constructions, word choices and associated performances of attitude can be seen as invaluably authentic - as well as very valuable in the market. As this analysis will show, LGBTQ advocacy is rich with wordthings (and 'language objects' like t-shirts) pointing to the way words can be materialized, and objects can be semioticized (Thurlow and Jaworski 2017; Jaworski 2015). Through this process, word and deed are replaced by ersatz substitutes. Following Ahmed (2012), as with 'diversity', the end result is that the use of a word is scaled as a shift in the world. Wearing the word 'love' is a doing of authentic love. An 'equality' bumper sticker is equality in motion. Thus, word-things are speech-act-like, in that they are seen as manifesting 
some material quality or process - actual change - despite being for the most part deliberately vague or purely evocative. In this book, I characterize wordthings as the smallest element of the much larger process I (incompletely) describe: the mediatization of equality.

\section{A queer, multimodal, critical (yet positive?) discourse study}

In this chapter, I examine the means by which multimodal semiotic resources realize particular ideologies regarding global LGBTQ advocacy. I wish to understand how such ideologies realize particularly affective notions of futurity, wellbeing and security - alongside a queer (linguistic) investment in the troubling of how sexual orders are fixed and upheld by discursive practices. LGBTQ advocacy encompasses a wide breadth of institutional actors, representing a wide variety of communities and subjects with often very different agendas and political positions - rights-based, activist, radical or somewhere in between, distributed across the globe. It operates at a considerable, worldwide scale, or perhaps more accurately, at dynamic scales that are stratified and hierarchized, which often work to occlude the very distinction between such scales: e.g. local/glocal, 'G'/LGBTQ, etc. (Blommaert 2010; Carr and Lempert 2016).

Given my own subjectivity as a queer man from the global North, this study is again invested with the being, thinking and doing aspects of queer scholarship (cf. Thurlow 2016). And in this respect, I of course have to acknowledge how valuable it is to remind underprivileged, marginalized queer people that they are worthy and loved. However, although such a positive perspective is significant, it does not preclude me from pointing to negative aspects of advocacy discourse. I can, and should, be both deconstructive and constructive.

One could say I adopt the generative principles of so-called positive discourse analysis here (PDA, e.g. Martin 2004; Macgilchrist 2016). PDA emerged through scholars questioning the normative underpinnings of critical discourse studies itself, and its focus on problems rather than solutions. It seeks to understand 'how change happens, for the better, across a range of sites' (Martin’s 2004:9). Macgilchrist (2016), although supportive of movements toward 'positive' or what she calls 'generative' critique, has rightly noted that critique is by no means (and has never been) limited to 'negative' critique alone. To this, I would add that critique in and of itself can and should often be recognized as a transformative intervention, especially when and if it uncovers possible injustice in discourse that is otherwise taken-for-granted as 'positive'. Although there are clear linkages between pink tourism, diversity management and the world of LGBTQ advocacy, perhaps the starkest link is that these three phenomena are vernacularly understood as a good thing by (classically) liberally minded people. They index enlightenment values: liberty, individuality, openness. Advocacy discourse presents as perhaps the most innocuous of the three: objective, altruistic, not profit-minded (or at least usually not, cf. 
Figure 5.1). Echoing Lentin and Titley (2008:12), one may say that there are plenty of reasons to "welcome the "broad discursive space"" provided by diversity politics, pink tourism, and mainstream LGBTQ politics, to be 'almost automatically grateful' for the space they create. However, in this chapter, and this book, I am not performing PDA. I am not interested in the benign actions of benevolent institutions. I am interested in the benign-like actions of benevolent-seeming institutions: in neoliberalism's mode of 'governing through liberty', through apparent freedoms, apparent positives (Dardot and Laval 2013). No doubt, this requires me to 'go beyond seeing neoliberalism as an evil essence or an automatic unity' (Ferguson 2010:183). It requires me to understand that the injustices of neoliberalism are not perpetrated by evildoers, but often through well-meaning people, like and including myself. All in all, this chapter's analytical framework compels me to remark upon the good things that advocacy texts can do, while generating a critique of the material conditions undergirding that 'good', and suggesting - indeed, demanding - that they improve. The conclusions I reach in this chapter and book follow on from this insistent demand: for better, for enough, for all.

My first aim with this chapter is to draw critical sociolinguistic research closer to sociological and queer theoretical discussion on the globalization of LGBTQ rights. Following Machin's (2004) identification of 'positive thinking' as a crucial value in the contemporary consumerist world, I seek to interrogate the seemingly positive nature of this discourse, following nascent sociolinguistic engagement with how it operates (e.g. Lazar 2017; Bennett 2017; Jones 2015; Gal et al. 2016). My second aim is to bridge LGBTQ advocacy with critical perspectives on the heavily mediatized world of humanitarian communication (Chouliaraki 2010, 2012, 2013; Vestergaard 2008, 2013, 2014). Such critiques contend that we have entered an age of 'post-humanitarianism', whereby humanitarian appeals skirt closely to self-oriented forms of consumer citizenship or 'causumerism' (see also Banet-Weiser and Lapansky 2008; Richey and Ponte 2011). Following this point, thirdly, I aim to unpack the ways in which sexual minorities are subsumed into a neoliberal ethos of individual achievement and conspicuous consumption. Building on Rao's (2015) provocation regarding a 'global homocapitalism', I aim to demonstrate how the affective - and effective - anti-homophobia campaigns of transnational actors may obscure dimensions of inequality which are as unjust as homophobia (if not to blame for how such prejudice emerges). As in Chapter 2, where I questioned the notion of 'fabulous destinations', here I unpack the notion of 'a fabulous life', as implicitly and explicitly indexed in the texts produced by LGBTQ rights organizations. When faced with such slogans of resistance and progress, one should ask who is seen as progressive, and how some worldviews are framed as progressive. What, exactly, is 'a fabulous life'? How is LGBTQ advocacy entangled with discursive frameworks in which, in Chouliaraki's (2013:178) words, care for vulnerable or distant others is 'part of the multitasking of everyday desk life' ... where solidarity is embedded in cultures of consumption and 'an ethos of mutual benefit with minimal effort'? 
My empirical evidence is drawn from the websites, social media, and other digital outreach of six trans-/international LGBTQ rights organizations: All Out, OutRight Action International (formerly IGLHRC); UN Free \& Equal (UNFE), Stonewall, It Gets Better (IGB) and Human Rights Campaign (HRC). Each can be identified according to their self-characterization as movements for change: equality, and/or for the elimination of discriminatory practices against queer people, in a broad sense. I have already mentioned how varied the organizations working toward LGBTQ rights can be (Paternotte and Seckinelgin 2015). Although all of these organizations listed have some degree of investment/interest in global advocacy, HRC is generally focused on American policy-making, or on providing an American 'voice' for LGBTQ rights worldwide. IGB began with an American focus on youth suicide prevention and has since expanded its outreach and campaigning globally. Stonewall is the largest LGBTQ rights organization in Europe and primarily orients toward British activism - somewhat ironically, taking its name from the United States riots often considered the most important event in the gay liberation movement (Kollman and Waites 2009). OutRight has consultative status with the United Nations, and UNFE is the United Nations' own campaign against homophobia and transphobia. Some organizations (e.g. HRC) focus on lobbying government, some (e.g. All Out, IGB) on rallying membership and/ or funnelling funds to grassroots community groups across the world. They are diverse economic agents: some accept funding from state/s and corporate actors, while some are exclusively member-funded. Some operate in languages other than English - to some extent tokenistically - while some are essentially Anglophone. ${ }^{3}$

All can safely be called Northern non-government organizations (NNGOs), which as Kaldor (2003:94) has written, increasingly serve as an 'expression of the blurred boundaries between state and non-state, public and private ... organized around humanistic missions'. In other words, NNGOs are symptomatic of neoliberal modes of governance in late modern civil society, in that nonstate (i.e. flexible, 'low-cost') actors are increasingly prominent in driving policy and social change (see Paternotte 2015, for further discussion of the 'NGOization' of LGBTQ activism). NNGOs like those I examine increasingly operate through competitive governance models in an 'economy of scarcity' (Chouliaraki 2013:6); in effect, this tends to influence these organizations' alignment with the capitalist principles of the mainstream Western political system. For my purposes, these NNGOs' self-characterization as belonging to and representing a presupposed 'global LGBTQ community' brings them into the purview of my research; by definition, they drive home particular notions of what global queer identity and mobility look like or could look like. The 'brokerage' relationships between these NNGOs' employees and Southern actors (and their transnational 'members') are historically contingent, complicated by brokers' own doubts about their actions, and by no means one-way (Thoreson 2013; Lazar 2017). Overall, these NNGOs seek legitimacy with broader publics of the West/global North through articulations of 
cosmopolitan solidarity: 'a communicative structure that disseminates moral discourses of care and responsibility’ (Chouliaraki (2013:27).

Between December 2015 and March 2018, I studied the websites for each of these organizations and acquainted myself with the social media outreach of these organizations (Facebook, Twitter, Instagram and YouTube), where possible, building up a dataset made up of screenshots, videos and still pictures lifted from the organizations' public marketing. This represents a typical (if not comprehensive) 'broad sweep' of their messaging. Over that same period, I signed up to organizational mailing lists of seven of the ten organizations to keep a record of their public communication. Inevitably, there are aspects of my research design which blur the boundary between my position as a supporter of these organizations, and as a researcher. Overall, however, this chapter's data comprised a reasonably typical, extensive account of how advocacy work was communicated by this large group of the world's largest LGBTQ rights organizations, during the period from late 2015 to early $2018 .^{4}$

\section{A 'fabulous life'? Discursive strategies in transnational LGBTQ advocacy discourse}

I do not see the three strategies described here as operating independently, or at all times. The relationship between these strategies is generally non-hierarchical and contingent, and overall, I see them as emerging organically - guided from a base in the global North - according to organizations' missions of activist strategic communication for social change (cf. Ciszek 2017). I make no claims to universality about whether my interpretation reflects how organizations' strategic communication impacts audiences on the whole. I simply provide an empirically oriented sociolinguistic analysis of the common meaning potentials of the texts they produce.

As will become clear, I see forms of scalar work as the structuring centre of LGBTQ advocacy discursive strategies. I expand upon this relational, comparative work later, and in this chapter's conclusion, but begin here by discussing the intersubjective identity construction achieved through audience design.

\section{Audience design: Building a convivial collective}

Audience design emerges in my data in banal textual practices such as the use of 'fabulous', which I have already foregrounded (and critiqued) as an in-group, stereotypical marker of gay male identity. Although it is important not to overread the use of this word, its appearance in advocacy discourse is significant. As Barrett (2003) notes, quoting a satirical phrasebook titled How to Say Faaabulous! in 8 Different Languages; 'if a man uses this word, "it's a tip off he's acquainted with Dorothy", The word serves as a root for many terms in the historical gay cant, Polari (Baker 2005), and is also used across 'iconic' popular media. The significance of this word as a routine index of gay male identity (alongside other 

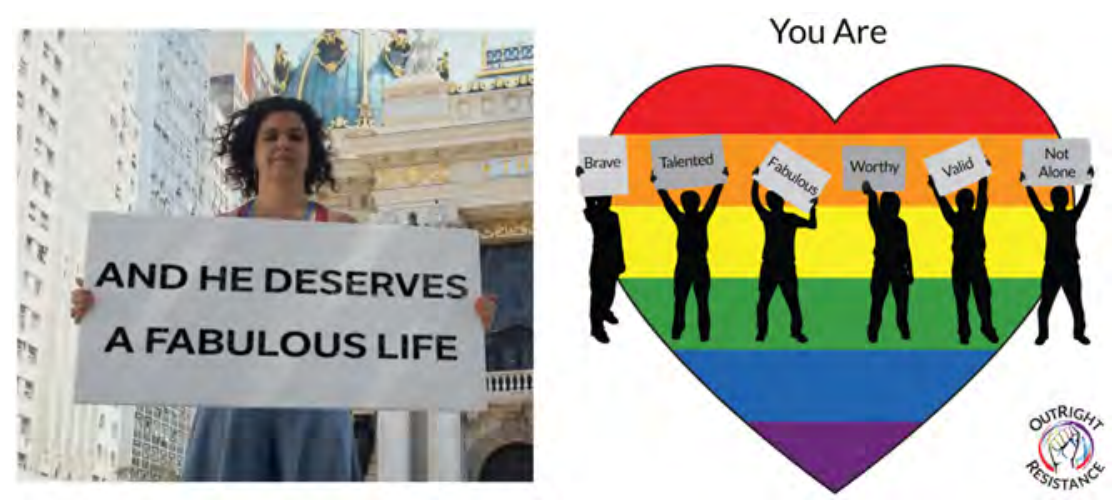

Figure 5.2 A 'fabulous' life.

semiotic material, e.g. pink, cf. Koller 2008) is still under-researched. However, the fact that it is linked to some kind of 'out' gay identity cannot be questioned. I interpret 'fabulous' as being used to index both linguistic style and to enact a stance toward the very end-goal of advocacy texts itself.

At left in Figure 5.2 is a screenshot from a video produced by All Out in which diverse people (young and old, male and female, of many races) hold placards declaring their hope for the future, positioned in various cities around the globe (also seen in Figure 5.8). ${ }^{5}$ In the preceding scene a woman in Barcelona holds a sign which reads 'my son might be gay'. Figure 5.2's woman in Rio de Janeiro says: 'and he deserves a fabulous life'. At right, an image from an email from OutRight proclaims not only that the recipient of the email is worthy, brave and 'talented' (echoing the valorization of 'talent' seen in diversity management), but that they are 'fabulous'. As I already noted, 'fabulous' jointly indexes something like 'marvellous' but also something 'fable-like', fairytale-esque and invented. In his discussion of diva worship among the gay community, Farmer (2005) writes that divas' fabulousness extends to devotees 'untold possibilities for the production of equally fabulous modes of empowered selfhood'. In this respect, the appeal to a 'fabulous life' can be interpreted as an appeal (like divas') to a kind of sublime (self-) discovery; a fabulous life is one in which an authentic selfhood has unfolded from the inside-out, and a discriminatory lifeworld is out of sight, out of mind. A 'fabulous life' is thus one in which a post-gay mindset thrives - that is, where gay identity does not matter, but where it can be adopted, expressed, and even worn (i.e. materialized and mobilized) with pride by 'self-steering selves' (Rose 1999).

'Fabulous' functions as a banal floating signifier, a word-thing, that as it comes to iteratively perform identity, I would argue also becomes increasingly commodified; intertwined with archetypal 'coming out' narratives and authentic 'outness' to serves the interests of Western capital's drive for individualist 


\section{Sloganizing and 'materializing' equality}

self-actualization (cf. Sedgwick 1990; Plummer 1995). However, 'fabulous' is just one example of many ways in which advocacy texts stylize alignment building a close relation between organizations and addressees/viewers/recipients (Fairclough 2001). Many texts exemplifying forms of audience design adopt forms of ludic or camp stancetaking, through which these organizations attribute agency to themselves as 'queer' agents. Even on banal landing sites for updating email preferences, and innocuous reminder emails, intertextual references to classic gay anthems, iconic artists, and 'divas' project sensations of love, sass and transgressive (if still normative) forms of community. In moments such as these, a convivial and profoundly affecting sense of community rises to the fore. The kind of audience design I am describing also emerges in organizations framing their members as 'family', through a ubiquitous 'you', and through direct terms of address - emails which begin with 'Friend...', or which use personalized subject lines: e.g. 'We $\bullet$ Joseph'. HRC's end-of-year email in 2016 (certainly, a tumultuous year) stated centrally, in clear and reassuring terms:

\section{With you by our side \\ LOVE WILL WIN}

What is also very clear, however, is the strategic intent of the organizations engaging in this discourse. In the rhetoric of these organizations, love itself is under threat because of the actions of prejudiced, bigoted, and/or ignorant individuals. This is a generalized, liquid 'love' that neither challenges or affirms the heteronormative order (cf. Bauman 2003). This is yet another way in which a post-gay future is obliquely indexed through forms of appeal positing that the best future is one where queer identity does not matter. The resolution to homophobia is framed through the reduction of historically contingent sociopolitical concerns regarding LGBTQ rights to a simple question: should love win?

Love's victory is also framed as something easy: a simple consequence of 'giving now'. The following extract exhibits this dynamic, which Chouliaraki (2010, 2013) calls the 'technologization of action' and which underlines the 'enormous challenge' of humanitarian campaigning in this context (Vestergaard 2008). This challenge can be distilled down to the inherent logics of consumer marketing - addressees must feel their values reflected in every email from an NGO like HRC, and this, in turn, makes it difficult to rationalize the email's cause as about much outside the addressee's desires and capabilities (as a consumer). To 'give, now', is to show love, now; to love is to click now (cf. Morozov 2013).

\section{Extract 5.1: HRC email (31/12/2016)}

You have my word that the Human Rights Campaign will do everything it takes to protect and advance our rights. But we can't do it without you ... Please give now - help defend equality and defeat bigotry. 
To thank you for your donation, we'll send you two of our classic HRC equality logo stickers. By displaying them, you'll send a powerful message that - whether lesbian, gay, bisexual, transgender, queer or an ally - not one of us is in this alone. (If you're like me, it still makes you feel good every time you see one!)

Framing each email as an interpersonal encounter (signed off personally by a member of HRC's staff) contributes to a humanitarian habitus in which equality is incremental and individually conceived - the outcome of every click or display of a sticker. Surely, the truth is more complex. Regardless, here support for 'equality' for queer people is increasingly regarded as an individualized commodity for the altruistic consumer. I am not arguing that 'the simulation of interpersonal meaning' (Fairclough 1992:216) in Extract 5.1 is entirely fake; that is, I do not believe it is cynical or insincere. It is perhaps 'quasi-interpersonal'. However, like Chouliaraki (2010) and Vestergaard (2008), I believe there is some reason to be concerned by the effective scaling of LGBTQ equality at an individualized, technologized level: as an achievement made possible by the construction of an intimate relationship with a distributed yet intimate audience, 'with you by our side'.

Figure 5.3 presents a selection of excerpted images from All Out's emails. Together they exemplify how the path to equality is shown as the outcome of individual, technologized action, '[breaking] with pity in favour of a potentially effective activism of effortless immediacy' (Chouliaraki 2010:109). In them, a convivial, transnational sensibility is brought into being, and each and every supporter of All Out is conceived as an 'equality champion'. Each participant in the video discussed in Figure 5.2 is an 'equality champion'; each viewer of that video, donor, and recipient of an email are praised for being 'more powerful than any hate group'. Overall, All Out's strategy for fundraising and subsequent transnational advocacy work rests on describing each person who supports that work as a defiant opponent to 'homophobes', 'bigots', and 'haters'. When they campaign to send affirmational postcards to two teenage girls imprisoned for kissing in public in Morocco, or advocate for a ban on 'gay tests' in Tunisia, any empathetic spectator who wishes they could do something to help is presented with that possibility of active, intimate aid. You are 'not alone' with the girls via some effortless clicks. A click can 'ban [gay tests] now'. This click can be 'more powerful than any hate group' - courageous, and indeed, at 'home' next to images of protest and activist voice-raising.

Importantly, this courage is understood as belonging to a convivial collective; a cosmopolitan mass whose victory is inevitable ('Love always wins', cf. Figure 5.6), whose togetherness is inherent and borderless, and whose 'champions' are everyday people, battling cultural beliefs, rather than structural issues. This collectivity can be understood as a kind of 'pseudo-sociality' (Thurlow 2013), for humanitarian ends. Although the quotidian donations and actions of supporters have a real impact, the significance of that impact is staged, and these supporters are in fact condescended to (following Bourdieu 1991); they 

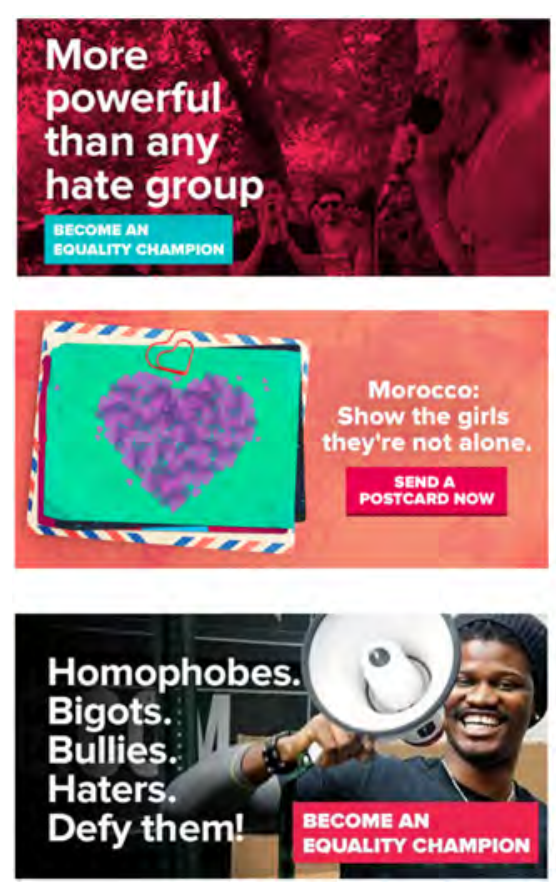
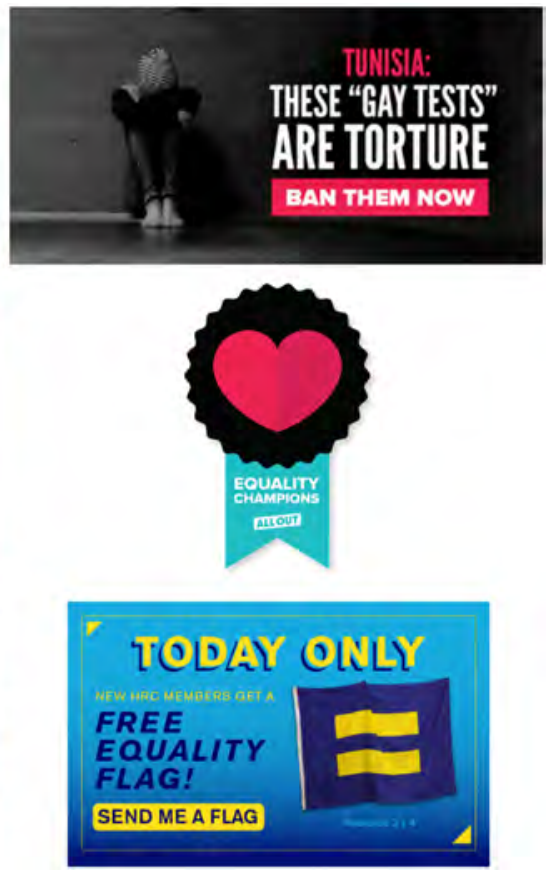

Figure 5.3 'Become an equality champion': the technologization of action.

are told that they are more meaningful than they could possibly be, and given overt praise for being so meaningful. For their efforts, simply for reading an email, each purported champion is provided with a stylized ribbon, formed from a loveheart - a semiotic trophy, and another 'thingified' token of a banal, positively charged affect. If an email recipient clicks on 'Become an equality champion', they are directed to a webpage to donate or sign a petition. If not quite as 'slacktivism', here the enactment of equality is rendered as instantaneous, focused more on the bravery of the clicker than the pain of the abstract LGBTQ other. Action is scaled, at the very least, as a kind of self-expression that one can be proud of.

The discourse produced by these transactional organizations is often granted an incredulous, indignant quality through the use of simple terminology and 'sassy' language: indexing youthful disobedience and what could be termed a defiantly blasé stance, alongside elements of 'ludicrism' and parody (Harvey 2000). Jaffe (2009:9) describes stance alignment as a continual social project which seeks to 'naturalize' other social-relational stances. We can hence see any instance of this ludic indignance as banal political expression: formed through globalist appeals to the inevitability of LGBTQ equality, incredulity 
at those who impede it and an ironic detachment from the anonymous victims of prejudice (cf. Chouliaraki 2013). In these stances, 'resistance and defiance come positively charged, but remain locked into the individual - indeed the psychological - requiring self-belief and sass but not, crucially, social transformation' (Gill and Kanai 2018:324). In fact, what is highlighted most of all is self-satisfaction and the evocative thrill of being a 'nuisance'. Here I follow Gill and Kanai's (2018) arguments of how positive, youthful defiance has become a way to restrict the shape of resistance, upholding sassy forms of neoliberal citizenship. Figure 5.4 provides an example.

This comic from an All Out email in May 2016 is in many ways an outlying example because of how juvenile its approach seems. In other respects, however, it provides a quintessential example of what I mean by 'self-satisfaction'. The comic in Figure 5.4, and especially its closing panel, essentially asks (or demands, cf. Kress and van Leeuwen 2006) the viewer to 'keep annoying decision makers' - but also indicates that this is enough. Admittedly, I cannot be certain how a recipient of this an email feels when they see the text. At the same time, I feel it is right for this analysis to be dissatisfied with its sassy demeanour and for a character like 'Alex' to be called out for its silly narcissism, and its simplification of the 'battle' for LGBTQ equality.

I am an All Out member, and thus part of the convivial collective invoked in the panels of the comic in Figure 5.4. I support 'Alex'. However, one can't help but note how childish, if not patronizing, this comic feels (despite how measured and strategic its production must be). Indeed, as a synthetic character, Alex appears decidedly young, in addition to having a markedly Western (and gender-neutral) name for a character of clear South Asian descent. The subject lines for the emails advertising this comic (and asking for monthly donations) were 'Be annoying!' and 'You're a real pain in the butt'. These choices rest on a notion that enough youthful pestering will stop homophobic legislators in the global South. This is an idea that is perhaps not entirely meritless, given long histories of civil disobedience and playful protest. It is, however, simplistic to suggest that the purpose of activist altruism is for thugs to find you 'seriously $\mathrm{f}^{* * *}$ ing annoying'. Doing so centres the interests of the small-scale donor, and solidifies a disinvested, somewhat impatient stance that is dislocated from the significant structural barriers to change.

Elsewhere in my data (and especially in the work of All Out), this ludic stance is re-enacted and re-semiotized in multiple, interdiscursive ways. Examples from my large corpus of All Out's regular email outreach show how Australia's marriage equality plebiscite was called 'the most stupid vote in the world'; the 'vile anti-LGBT bill' spoken about in Figure 5.4 was challenged in an email subject line with a sarcastic 'Seriously, Georgia?'; in an online poll, Donald Trump was voted the 'homophobe of the year'. Overall, the iterative re-enactment of this kind of markedly cheerful, synthetically personalized stance presupposes both that banal, participatory anti-homophobia action is fun, and that homophobic/transphobic legislation or violence is not only wrong, but ridiculous. In other words, it naturalizes post-gay perspectives 

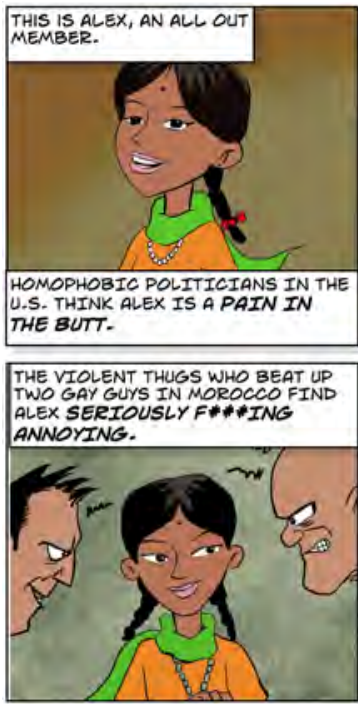

ALEX IS A REAL NUISANCE FOR LEADERS OF THE CATHOLIC CHURCH.

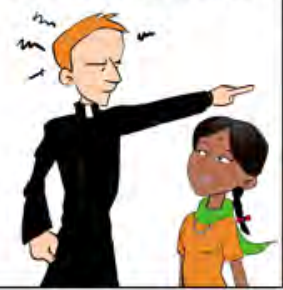

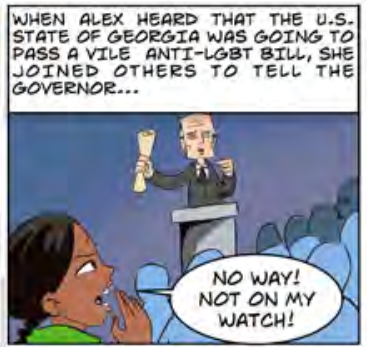

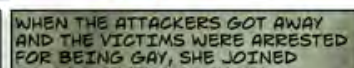
AND THE VICTIMS WERE ARRESTED
FOR BEING GAY, SHE JOINED 80,000 OTHERS TO SHOUT..
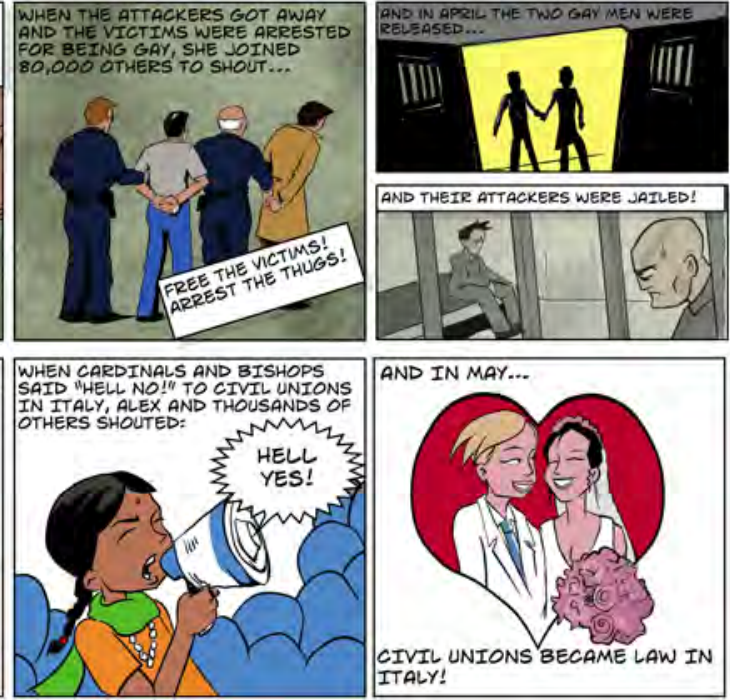
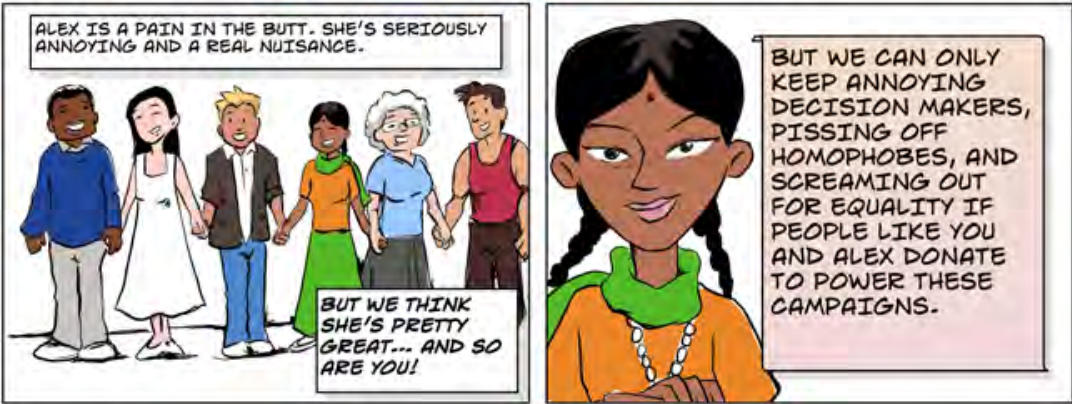

Figure 5.4 All Out: 'Be like Alex!'

on struggle and liberation as things that are almost here; Alex and others like 'you' just need to help them progress. It is Alex (a singular member of the convivial collective shown in the bottom left of the comic) who says 'not on my watch', and her (i.e. 'you') who can feel satisfied with being a 'pain in the butt'. Perhaps unsurprisingly, though certainly problematically, victims of 
oppression (from a monolithic, unquestioned form of global homophobia) are largely framed as the object of Alex's help. They do not help themselves.

In the next section, I describe how some of the stances and styles I've described here are materialized in supporters' bodies and material objects (e.g. wearable items, tote bags, and bumper stickers), and the ways that advocacy organizations focus on the communicative affordances of movement. My object of analysis is thus moments like Extract 5.1 stating, regarding the display of a sticker, that 'it still makes you feel good every time you see one!'. These moments craft a mobile form of affective-discursive practice which is both heart-warming and (troublingly) 'cool' (cf. McGuigan 2009). The items they discuss are seen as actually materializing and manifesting change itself, and mobilizing support, through the movement of individually expressive subjects and 'virtuous commodities' (Žižek 2009). In moments of 'wearing' progress on your sleeve, the potential for progress seems to blur with its tangible arrival - and the individual on display as proud and progressive, again, seems central.

\section{Materialization and mobilization: Cool activism and consumer culture}

While audience design emerges in a number of different shifts in style and stance with regard to the identity of supporters and oppressed others, the strategy discussed in this section works rather simply. Figure 5.5's examples of \#wordswewear (following Jaworski and Lou 2020) exemplify ludic stances, which can be seen as a stylized and synthetically personalized performance of a blasé attitude and 'cool' sophistication. This final example of stancetaking, however, also serves as a materialization of that stance - an expression of indifference to gender norms in 'cool activist' products (cf. Chouliaraki 2013; McGuigan 2009). At left is an ad for a sassy item produced by IGB, the 'whichever' hat, decorated with a rainbow, blended male/female pictograph, as if to ask: 'Who cares?'

IGB are youth-oriented so it makes sense that they use youthful language. It is also perfectly sensible for it to produce marketable goods as a form of fundraising. However, this 'whichever hat' is still striking for how it combines an indifferent stance toward the gender binary with the materialization of that stance in the form of a commodity and wearable text. It's also notable that a number of organizations which produce 'official merchandise' (in Stonewall's words) adopt standard commercial rhetorics - for example, by advertising sales for public holidays. These texts are more than just merchandise, however, in the rhetoric of these organizations. At right in Figure 5.5, an excerpt from a Stonewall campaigning page presages the wide-ranging, positive feeling purportedly invoked by wearable texts. In the wide smile of the woman pictured, there is a cheerful index of how influential one can be in wearing this 'come out for LGBT' t-shirt. It is sold as a way to 'change hearts and minds'. On the whole, no more effort is generally made to explain how such hearts and minds are changed, except for the somewhat obvious response: through sales numbers, and sassy visibility. 

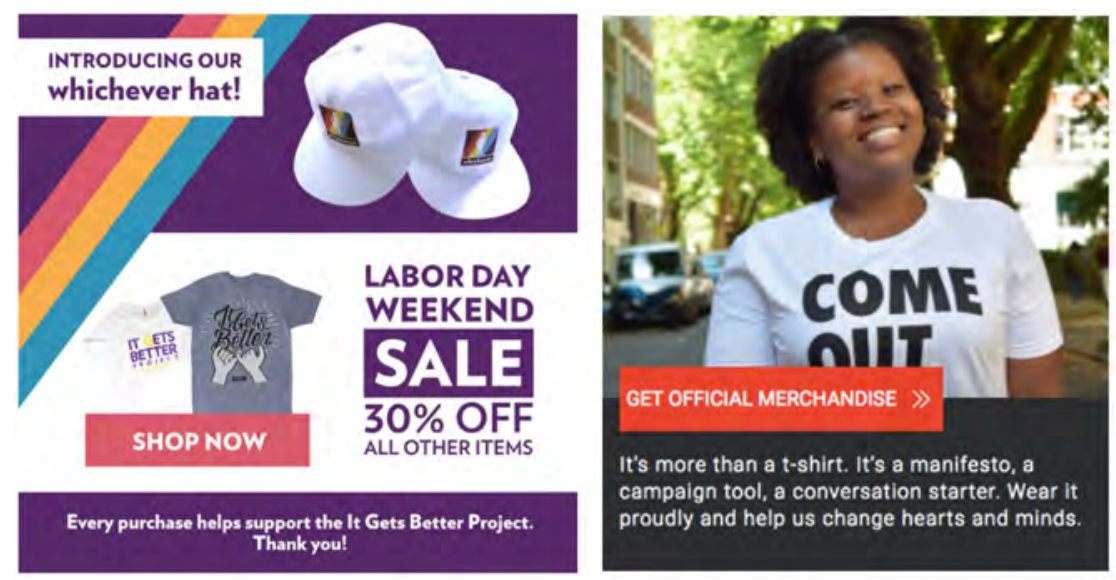

Figure 5.5 'Whichever' - 'a manifesto, a campaign tool, a conversation starter'.

In the 'whichever' hat, an ongoing habitus of defiant indifference as action is made tangible. It takes representational stances and styles, 'themselves ideologically and interactionally co-constitutive' (Jaworski and Thurlow 2009:195), and makes them real - an embodied, mobile text in the world, enlivened by the wearer, changing the world. The email from IGB in which this hat appeared introduces the strategy further:

\section{Extract 5.2: IGB email (31/8/2017)}

We love seeing photos of supporters in our gear, and today we're happy to share with you a brand new item you can wear to show your support - our 'whichever' hat.

Inspired by our supporters who have stood up against discriminatory legislation across America, our 'whichever' hat can help send a strong message of support to LGBTQ+ people everywhere.

The operation of materialization and mobilization is distilled in Extract 5.2's statement that the 'whichever' hat 'can help send a strong message of support to LGBTQ+ people everywhere'.

'Materialization' refers to the way in which a product is objectified and a 'message of support' is 'thingified'. In addition, the post-gay, progressive future the 'whichever hat' represents is 'wordified' and semioticized in the self-expressive practice of wearing the hat (Thurlow and Jaworski 2017). In short, it refers to how t-shirts, bumper stickers, tote bags, and other products (even jellybeans, as seen in Chapter 6) can be 'materializations of a politics of visibility' (Milani and Kapa 2015:80). 'Mobilization' refers to the way in 
which thingification makes the visible 'message of support' easy to circulate, easy to understand and apparently, more powerful - scaled 'everywhere' a supporter opts to self-brand and assert this blasé attitude. Of course, this occludes the extreme risk of wearing this hat or spreading this message in many contexts. Social change is reduced to a 'strong message' in an item of clothing.

Through the strategy of materialization and mobilization in the texts I examine, the supporter becomes a 'mobile text'; mobility becomes a semiotic resource in itself, and key to the strategic 'enworlding' elements of advocacy texts - the way they invoke lived-in space (Sebba 2010). These texts are a resource for crafting a habitus in which pride is salient and tangible, a matter of both self-expression and commercial interest. Fairclough (2003:159) saliently notes that

styles are the discoursal aspect of ways of being ... who you are is partly a matter of how you speak, how you write, as well as a matter of embodiment - how you look, how you hold yourself, how you move, and so forth.

Here, he points to how the materialization and mobilization of stylized 'language objects' like wearable texts frame acts of identity as hope for LGBTQ supporters worldwide. They offer an ersatz form of tangible changemaking, but importantly, they also offer expression and the actualization of self. In this respect, they resemble especially virtuous 'virtuous commodities' (cf. Žižek 2009; Hickel and Khan 2012). As many texts noted, they are ways to show you're part of the 'resistance'. In Stonewall's words, they are a 'manifesto'. A simple product is deemed to have the impact of a revolutionary, ur-political text.

Figures 5.6 presents a montage of more images from advocacy organization emails and social media feeds. They all exemplify iterations of materialization and mobilization, and the stylized, evocative language I described in the last section. What can be described as 'rainbow rhetoric' is evidenced in IGB's 2017 partnership with American Eagle Outfitters ('can't even think straight') and All Out's typically affective messaging - 'love always wins' - printed on a shirt and made a reward for donations above \$25 USD. To become an 'equality champion', one needs only to purchase a hoodie, tote bag or t-shirt as part of what is sold as a broad-spectrum \#FightBack. Even a generally staider organization like UNFE engages in private partnerships that exhort allies to \#WearYourPride, as seen in their partnering with Gap to produce clothing for Pride Month (June). They even made their own pins: like the small pin I bought in San Francisco, a materialized token of activism and allyship. Such private-public partnerships are of course highly reminiscent of the neoliberal altruism of the Product (RED) campaign that Richey and Ponte (2011) and Banet-Weiser and Lapansky (2008) have rightly criticized. Across all organizations' communications, \#PrideMonth is used as an ambient affiliative tool for 


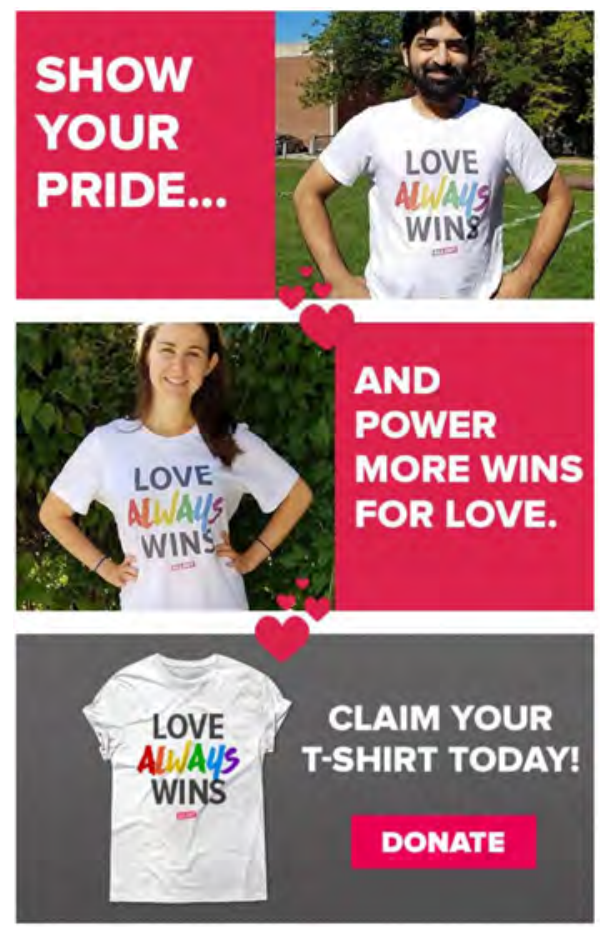

UN Free \& Equal

Folomine

Aspiring or full-fledged \#LGBTI ally?

\#WearYourPride \& support @ifree_equal with a @gapinc \#Pride2017 tee!

gap.com/browse/product ...
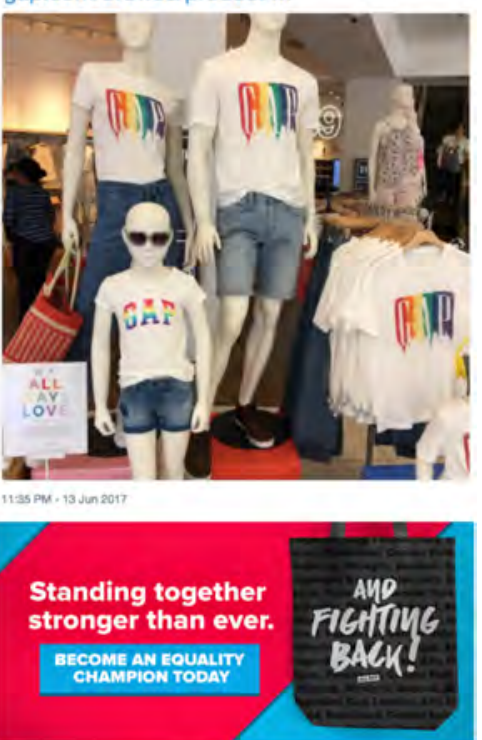

$\bullet$
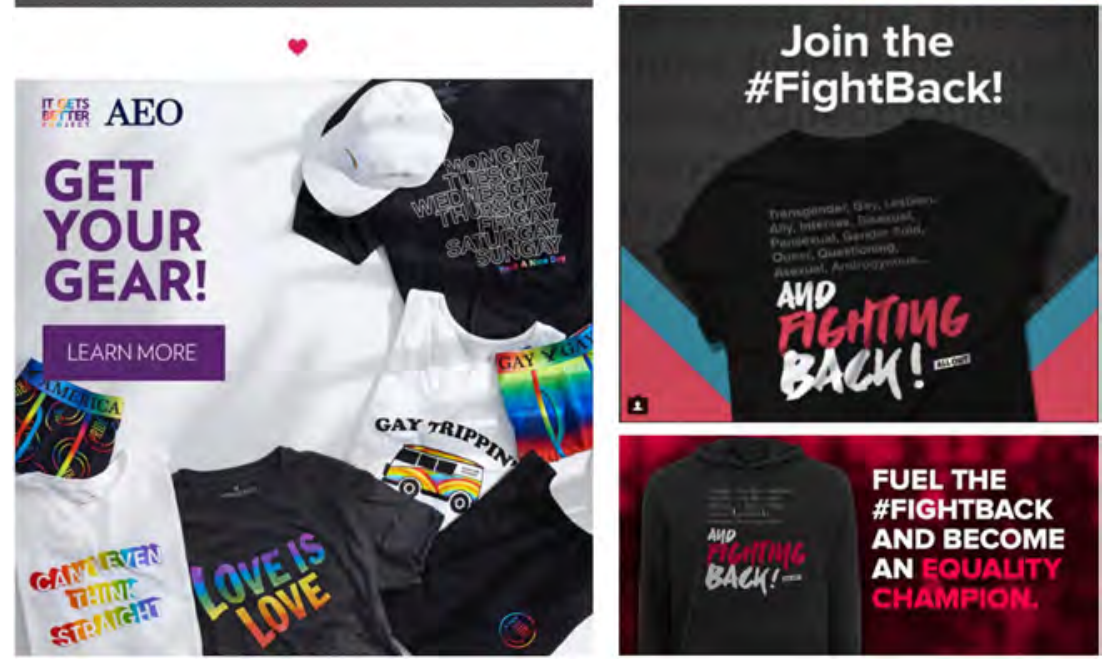

Figure 5.6 Montage of materialization and mobilization as a discursive strategy. 
the mobilization of LGBTQ advocates, and banal objects like wristbands are offered up as means of materializing change, imbricating subjects in an inherently marketized framework for solidarity.

Through materialization and mobilization texts, supporters of advocacy organizations are told to wear their pride - to assert their own self-expression as prideful, and thus manifest a mobile and material force for change. Extracts 5.3 and 5.4 demonstrate in more detail just how organizations like All Out frame these material items (and especially, clothing) as change in action - either indirectly, through the benefit of a donation that also functions as the purchase of clothing, or directly, through the metadiscursive framing of the wearing of that item as defiant and motivational.

\section{Extract 5.3: All Out email (18/9/2016; inclusive of Figure 5.12)}

\section{[Subject line] Want a Love Always Wins t-shirt?}

Did you see our awesome new t-shirt?

Donate $\$ 25$ or more and we'll send you one for free!

It's pretty cool ... but the coolest part is that your donation will help power real-life victories for LGBT people around the world.

Wear your pride with a Love Always Wins t-shirt by chipping in today.

\section{Extract 5.4: All Out email (13/1/2018)}

\section{[Subject line] What will you \#FightBack for in 2018?}

By wearing this hoodie, you can proudly let the world know that you won't sit idly by while anti-LGBT hate and violence continue to destroy LGBT communities around the world.

As I mentioned, the items described in Extracts 5.2-5.4 are, for the most part, all for sale - fundraising for each organization's campaigns or in-house costs. However, organizations regularly assert that any item they sell for fundraising is more than a material object, or piece of clothing. The passive purchase of a hoodie online (in just a few steps and clicks) thus becomes a way to be active, and not 'sit idly by' (Extract 5.4); a 'pretty cool', 'awesome' shirt becomes a tool that powers 'real-life victories' (Figure 5.3). Here, a clear equivalence is drawn between the work or the organizations in hostile locations for LGBTQ people, and the individual purchaser's political orientation, visibility, and mobility. The rhetorics used here are recognizable tools of salesmanship, effectively selling the act of financial support as a good deed, an act of solidarity and the purchase of something in return. Overall, the anticipated work of these items' materiality in the world, and the performative discussion of that work, together, are indicative of the increased co-constitution of discursive practices and material culture in late capitalism (cf. Shankar and Cavanaugh 2012). As well, they show evidence for how forms of humanitarian appeal are now defined by forms of self-oriented 'causumerism' and supposedly altruistic forms 


\section{Sloganizing and 'materializing' equality}

of consumer citizenship - as exemplified in the problematic Product (RED) campaign (Richey and Ponte 2011), and what Hickel and Khan (2012:221) call the 'profoundly depoliticized, consumerist passivity' of supposedly virtuous products like 'ethical', 'sustainable' bottled water. In effect, these entangled discourses of transnational solidarity, marketing, and self-stylization work to spectacularize acts of pride and identity while tying them to material processes of consumption and imbuing them with the logics of consumer culture. In and through these mediatized texts and the eventual wearing of the material text they describe, 'Pride season' becomes a way to '\#WalkProud against the Trump regime', where a pair of shoes can send 'a powerful message to those around you ... I reject his hate, I reject his bigotry' (as in another series of emails from All Out during 2017).

All in all, the texts describing the effect of these shoes, hoodies, and shirts promise that they create an affective-discursive regime wherever they go (cf. Wee 2015; Wetherell 2012, 2013). As this mobilization of the material is rhetorically framed by the organization, a shirt like the ones shown in Figures $5.5,5.6$ or 5.7 entails a 'language object' within the interactional site of the linguistic landscape, that hails - indeed, commands - passers-by to engage with the topic of the t-shirt, and its ideological stance (and consequence) in the sociocultural field (cf. Du Bois 2007). This stance, however defiant it seems, ultimately generally encourages social mooring and conviviality, in a wider affective economy (cf. Ahmed 2014). Sometimes blasé, sometimes conversational, the clothing items manifest as evocative language objects that promote the invincible power of love. Here, conviviality is defined as an attitude that enables people to accept different ways of life and 'creates a level of sharedness that can generate solidarity and sympathy with others' (Blommaert 2013:89; cf. Gilroy 2004). Because these mobile texts are sold worldwide, their conviviality is also banally cosmopolitan. Like other mobile texts, the materialized messages
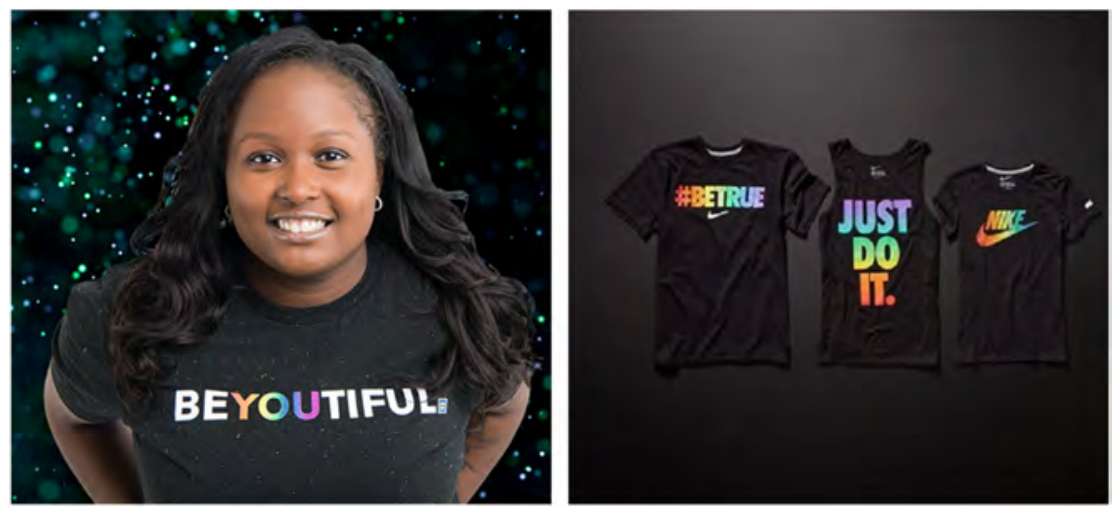

Figure 5.7 \#BETRUE, 'Be You' - similar sales pitches. 
of pride on t-shirts and other items 'circulate in large volumes and hence are "read" by many people on a daily basis' (Sebba 2010:61) - and that is precisely their purpose. As a form of strategic communication, they are no doubt effective. When these shirts are worn across the world, many people, whether allies or opponents of LGBTQ rights, must surely be interpellated: certainly, the latter may be reminded of the sheer, embodied weight of the pride movement's supporters. But is that embodied visibility the end-goal of LGBTQ activist work? Is that focus on conviviality and visibility a wise tactic for 'fightback'? My interest here lies less in countering that premise, or critiquing the strategic, pragmatic planning of the organizations - again, whose work is good for the world, and deeply meaningful for people like me. Rather, I wish to speak back to the deeper post-gay sensibility at work here, and its embrace of capitalist logics. Ultimately, as well, I wish to question their long-term efficacy - in an unsustainable capitulation to a neoliberal marketplace, can love always win? Whose love?

It is important to mention that there has been a marked proliferation of so-called 'pride gear' in recent years (often produced 'bottom-up', cf. Milani and Kapa 2015). This is because t-shirts and other rainbow rhetoric tidbits that are worn, thrown, drunk from and shown off (the breadth of which I cannot fully discuss here) serve as both a celebratory proclamation of pride, and an outstanding business opportunity. Convivial and agreeable clothing is produced by apparel companies like Nike themselves (see Figure 5.7), or through collaborations such as UNFE's in Figure 5.6. Indeed, it makes perfect sense that as the groundswell of support for LGBTQ rights has made these kinds of shirts valuable, apparel companies like Nike have jumped on board. And it is important not to be too cynical. After all, the growth of a marketplace of 'pride gear' does foreseeably boost advocacy organizations' fundraising; importantly, the feeling of wearing a Nike's \#BETRUE shirt is no doubt uplifting for many. In the strategic work of LGBTQ advocacy organizations, materialization is a matter of realization and self-actualization - and this is the very issue with it. The materialization of pride - and change, purportedly - in a t-shirt is a way of making one's orientation to the world real, virtuous, and of configuring one's embodied relations with it: of being true, of being you. Through the lived-in materialization and resemiotization of love, and of being a beautiful 'you' (see Figure 5.7), an extremely positively charged affectivediscursive regime is attached to the process of consumption. It is cultural capitalism - 'cool capitalism' - in which we consume forms of virtuous, feelgood commodities 'in order to render our lives pleasurable and meaningful' (Žižek 2009:52; McGuigan 2009).

Ultimately, it is the blurring of for-profit, capitalist enterprise and altruistic activity that I find concerning in advocacy discourse - especially, the blurry relations between them, and the burgeoning post-gay mindset they index. In other words, I am concerned by the diminished scale between charitable endeavours for queer liberation, on one hand, and self-oriented styling, and the valorization of 'authenticity', on the other. Figure 5.7 comes from a 
pre-Christmas email by HRC (9/12/2017) - effectively, a catalogue - which proclaims that every purchase (such as of this 'BEYOUTIFUL' shirt) 'fuels HRC's fight' for equality. As can be seen where Figure 5.7 is juxtaposed with the Nike products in Figure 5.6, there is very little difference between them. They mark status. Their textual forms affirm a defiant stance. And above all else, when worn, organizations like Nike and HRC would claim that they have the potential to affect an ersatz form of conviviality in the world - a (potentially) cosmopolitan, prideful mass.

It bears repeating that there is nothing especially wrong with wearing a t-shirt that tells me I am beautiful, or that others are too. Certainly, if it funds anti-homophobia campaigning, I am grateful for them. However, to my mind, the strategy of materialization and mobilization seems to signify an unsustainable orientation for LGBTQ equality, or a shaky foundation. It is an affirmation of human rights, and especially of the rights of non-heteronormative lives, that ignores the ways that capitalism privileges heteronormative lives, and ignores how 'gay' and other queer identities historically emerged through processes of abandonment, marginalization and exclusion made worse by capitalism (cf. D'Emilio 1983). In tying a post-gay future to forms of 'cool capitalism', advocacy organizations seem to erase the past. I will elaborate on this in concluding this chapter, but first, I must discuss the aforementioned scaling practices of advocacy organizations (e.g. between altruism and selfactualization) further.

\section{Scalar work: Enworlding 'love'}

I indicated at the beginning of this chapter's analysis that I see forms of scalar work as the driving strategy in LGBTQ advocacy. Indeed, it is perhaps more accurate to describe forms of scale as the driving ideology behind LGBTQ advocacy - its raison d'être.

For Gal (2016:110), scale is a 'relational procedure that starts with comparison', which is grounded in semiosis, and is hence ideological. I introduced scale in my opening discussion of the enworlding dimensions of queer mobility, so will not rehash the concept here. Rather, I present empirical evidence for three instances of scalar work which are especially informative with regard to the underlying teleology and metadiscursive frameworks of LGBTQ advocacy. In orienting to 'scalar work' as a theoretical framework, I am indebted to Järlehed and Moriarty (2018) who devise this term to describe the social practice we engage in when we imagine something as something else, position something or someone on a scale - for example, spatially, temporally or socioeconomically - and ascribe particular value and meaning to such positions. In my view, Järlehed and Moriarty (2018) lay groundwork for answering Gal's (2016) pertinent question: 'how do people do scale?' People in advocacy - and all us 'equality champions' - I argue, do scale through one or more of these three steps of imagining, positioning and ascribing value. The work organizations engage in underlines their driving narrative as a scale-making project: 
imagining a better, safer world as a destination-to-come, positioning the West as a kind of oasis/ideal for LGBTQ people and proclaiming the movements' global/transnational character.

Two ubiquitous scales of globality and collectivity are immediately salient in any investigation of these organizations' names and branding. At all times, their semioscaping actions continually build two ubiquitous scales: the world as one place, i.e. the ur-text and guiding rhetoric of all globalized habitus (communicating 'global reach' cf. Thurlow and Jaworski 2003); and the potentiality for the world to be equal, i.e. the scale from where we are now, to where we could be. This latter scale is essentially what turns equality from a utopian political vision into a material one tied to a politics of affirmation. In framing 'equality' as the basis of their identity and, in the case of All Out, bestowing the title of 'equality champion' on ordinary citizens, LGBTQ advocacy organizations seem to grant equality (the very premise) a tangible, but diminished, character. 'Equality' (and '=') become 'thingified'. Like 'diversity', a word-thing: feelgood, and accessible. A pin you can pick up at aift shop while in San Francisco. It is bestowed with value in a material-semiotic marketplace: currency, like 'diversity' in Chapter 6. In the process, it is wrought into alignment with post-gay sensibilities to produce a version of the effect that it is supposed to name: an ersatz 'equality', as simply and solely one's own recognition, opportunity and freedom. Perhaps this is natural, given that the liberal consensus that birthed human rights frameworks and notions of sexual citizenship also served as the foundation for market globalism (see Kollman and Waites 2009; Richardson 2015, 2017). Even names like OutRight and All Out mediate collective identities tied to a sociopolitical ideal of authentic, post-gayin-becoming, globalized sexual-cum-neoliberal citizenship. What they advocate for, in effect, is the quelling of queerness, in favour of an easy, inclusive 'outness' (Rao 2015).

A common trope in LGBTQ advocacy features the pseudo-social representation of everyday individuals as oppressed voices and agents of change. They hold placards lamenting a misrecognition of love, and advocating for progress. In economically productive and undeniably affective ways, this scale continually re-scales everyday people as the motor for LGBTQ rights. Figure 5.8 presents multiple examples. At top are two screenshots from the video All Out used to launch the hashtag \#GayisOK, which claimed to start 'a global conversation about the cruel laws in 76 countries that make it a crime to be gay'. ${ }^{6}$

This video begins with the phrase 'my love is illegal' being repeated/displayed in a number of languages (e.g. French, Arabic, Sinhalese, Mandarin, etc.), by a multi-racial collective of people from states which criminalize samesex relations. Their 'demand gazes' establish an intimate, imaginary relation with viewers (Kress and van Leeuwen 2006). Midway through, while maintaining the use of diverse speakers, the video shifts to English and the sloganesque sentence 'my love is illegal' is repeated. The video ends as a man adds the phrase 'in 76 countries ... my love is illegal'. Following this distressing 

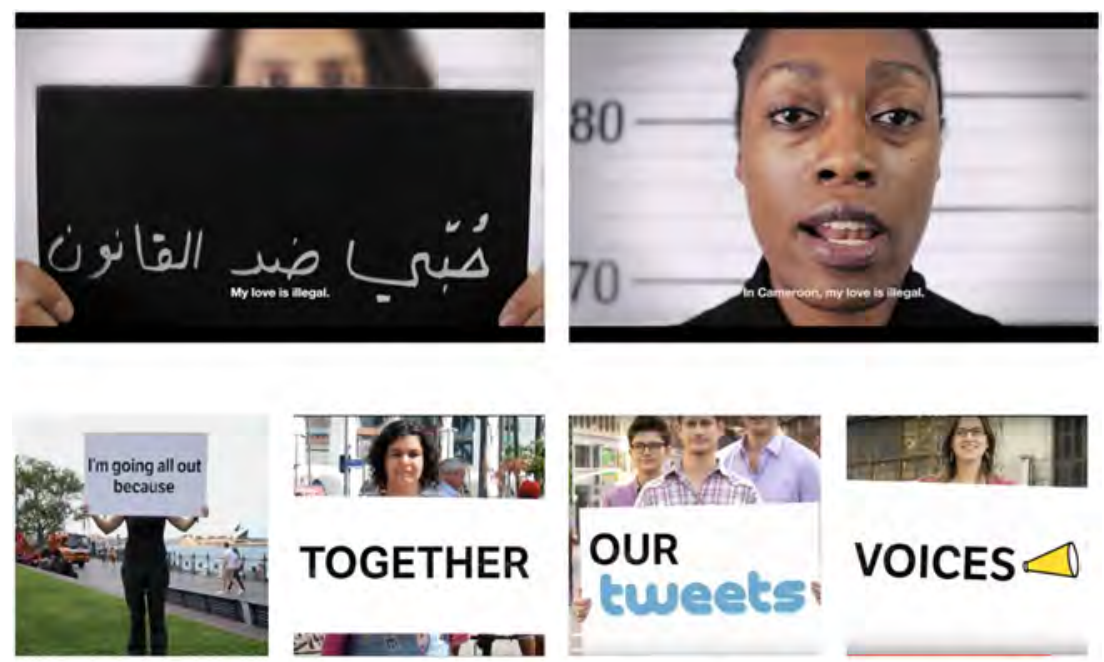

\section{TOGETHER}
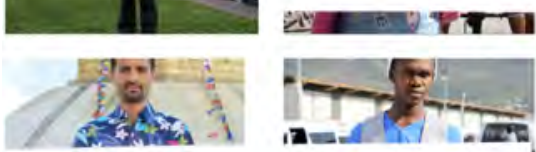

\& TEXTS
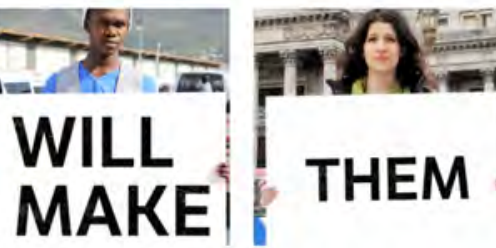

VOICES $\triangle 0$
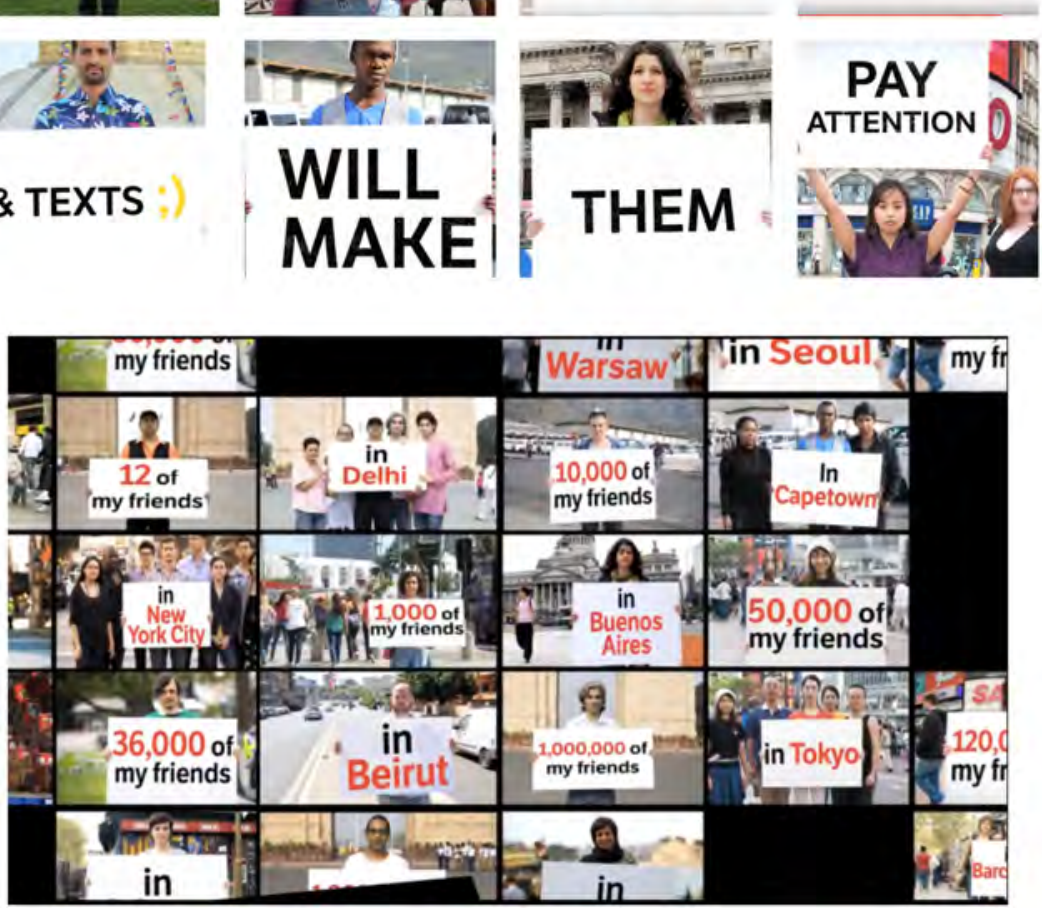

Figure 5.8 Montage of scalar work: building a transnational, convivial collective. 
series of intimate, direct addresses, this text re-scales to a (seemingly) form of transnational ambient affiliation, via a hypothetical question: 'What if your love was illegal? Tell the world why \#GayisOK' (Zappavigna 2011). In the 'what if, All Out explicitly address audiences outside of these 76 countries, scaling resolution to this problem at a level of hashtags and participatory metadiscourse (i.e. telling the world why 'gay is OK') and placing it in the hands of them, as enlightened consumer citizens. All Out's video does not mention that this campaign and hashtag were produced in collaboration with Lush Cosmetics, but elsewhere, this campaign ultimately enthusiastically celebrated Lush's role in spreading positivity through their production of a golden bar of soap stamped with the hashtag \#GayisOK.

On the 'Victories' section of All Out's website, the organization proclaims: 'The campaign was a hit! Lush customers worldwide fell in love with the product' (which is of course another materialization of advocacy). All Out continue by outlining how $\$ 425,000$ USD was raised by the campaign - 'a significant new source of funding for groups on the frontlines of our movement' - and how it 'marks one of the broadest conversations in history about LGBT rights'. This is a massive amount of money, but the site, unsurprisingly, does not discuss how much Lush profited from the campaign. One wonders how much was heard by those who need to hear it, rather than by the privileged customers of a high-end cosmetics chain. In questioning, incredulously, how 'love' could still be illegal in this world, All Out and Lush seem to occlude the very complex reasons for why that is, in favour of a simple, consumerist answer: \#GayisOK, a materialized index of purportedly global progress. As a hashtag and as soap, at the whim of individual consumer citizens, \#GayisOK thus does scalar work: imagined as support for equality on its way (if not already here); positioned as a step toward progress, which anyone can take; and given value as a banal, virtuous commodity.

As I noted, the use of diverse people, speaking diverse languages, from diverse states, is a common rhetorical trope within advocacy discourse. In all cases, they assert LGBTQ rights but also, often point to the fact that homophobia is unbelievable in the contemporary world. Messaging is distinguished through its slogan-like repetition, and the use of 'sassy' language: a metadiscursive stance which marks a somewhat disaffected relation to prejudicial discourse, tied to sensibilities of incredulity and inevitability. UNFE, for example, have produced videos with titles such as 'The Riddle' - the riddle being how queerness can be celebrated some places, and deserve capital punishment elsewhere. Another video is titled 'It's Time' - very succinctly framing the recognition of LGBTQ rights as overdue, and homophobic laws/politics as outdated, if not backward. Prejudice is presented not as a complex structural issue, but a matter of playing catch-up, fuelled by 'people power', as shown in the lower examples in Figure 5.8, excerpts from All Out's launch video in 2013: a/the founding text for the global movement the video itself rhetorically produces (the same video as in Figure 5.2). 
In this video, a transnational collection of spokespeople, 'our friends on five continents', assert the power of individual action on social media to change the world. The phrase that Figure 5.8 shows dynamically spelled out on multiple placards by 'everyday' individuals in Sydney, Mumbai, Barcelona, Cape Town, São Paulo and elsewhere - 'I'm going all out because together our tweets, voices, and texts ;) will make them pay attention' - is a simple expression of All Out's 'people-powered' social movement. This phrase effectively summarizes the guiding ethos of the organization. Although, on one hand, the video exists on a massive, global scale, it also valorizes the power of the individual to have an impact on the globe, scaling progress as an individual accomplishment. The 'them' being discussed are never explicitly described, or detailed; rather, the focus is on the winking, individual subjects who make up the movement. 'I' becomes 'our' in the rhetorical production of a diverse, convivial collective. 'Attention' becomes the objective - a proxy for describing the visibility of the ordinary people powering LGBTQ advocacy. As the video ends, as the lower image in Figure 5.8 shows, the video zooms out, showing a multitude of cities and 'friend' counts and signalling the vernacular, expansive scope of the organization's work. The immediate, uplifting effect of this gridlike representation of cosmopolitan collectivity is to engage the viewer in a sense of belonging - to a greater good.

Dynamism and movement are in fact utilized to great effect in All Out's outreach in order to evoke senses of scope and scale. As Figure 5.9 demonstrates,
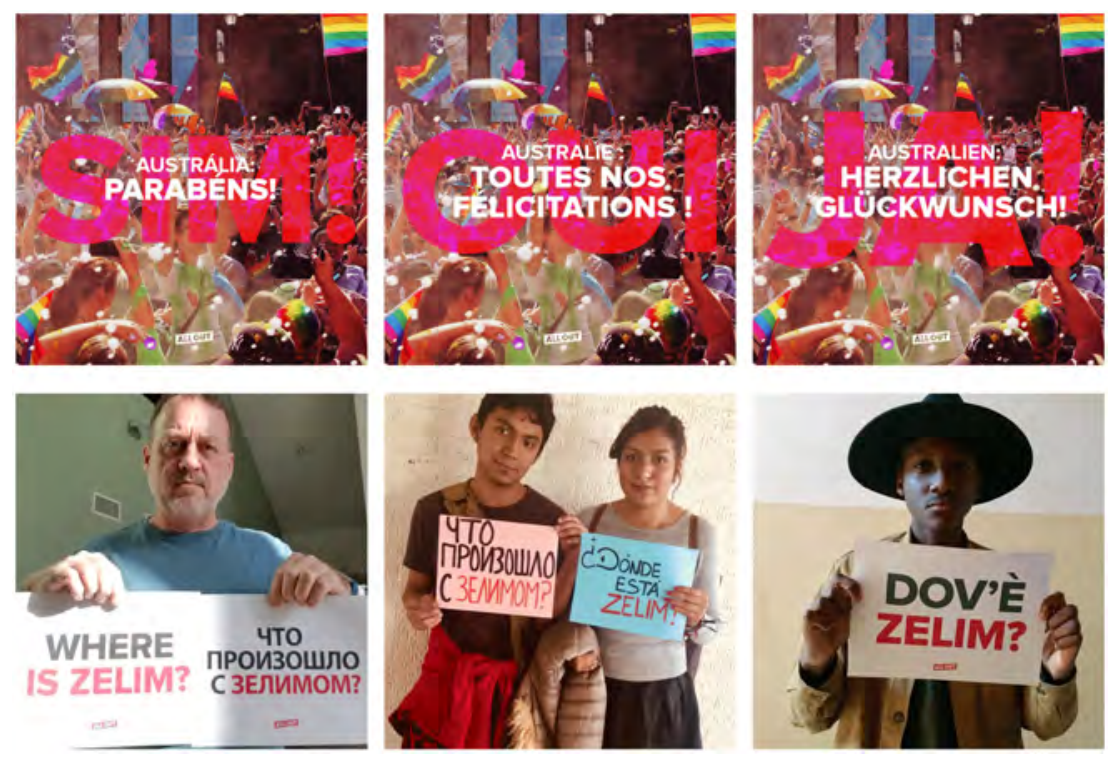

Figure 5.9 The scalar and embodied affordances of gifs. 
gifs are another resource through which 'everyday' defiance and transnational reach are indexed, in which 'looped animations of embodied actions' (Tolins and Samermit 2016:76) are used to visualize/demonstrate an action on behalf of an interlocutor. Gifs are a visualization of 'embodied enactment' in social interaction - essentially, a way to make one's affective 'investment' in a topic under discussion explicit (Tolins and Samermit 2016). As deployed by organizations like All Out, gifs are generally composed of images of numerous supporters, imbuing a sense of multiplicity, essentially 'flickering' between them; in the case of the series in Figure 5.9, to call for justice for a gay Chechnyan singer who is suspected of being murdered, and to provide a heteroglossic congratulations to Australia for its same-sex marriage survey results. Here, gifs are another means of producing transnational affect: a convivial stance for a defiant, diverse-bodied collective, scaled at high speed, with vast geographic reach. Their 'looping' quality seems to index the potential for infinite, individualized defiance: a better future, inexorably approaching, until it comes to pass.

My critical perspective on this kind of advocacy discourse essentially aligns with that of Aiello (2012), and of Page (2019) regarding synthetic collectivization. In her discussion of how multiplicity (of faces, grid-like arrangements, typographic conventions, etc.) is utilized to convey diversity, Aiello (2012) speaks to its rhetorical effect for creating the appearance of diversity - effectively standing in for 'diversity', despite diversity itself being an unknown, Janus-like entity - standing for all and nothing. There is no doubt that All Out and other advocacy organizations do recruit members from across the world, decoupled from their national origins. However, in many ways, the dynamic multiplicity present in these texts does not represent those members. Instead, it represents the idea/l of them; the strategic - and well-intentioned - 'exploitation of difference and diversity' (Aiello 2012:479). This is a kind of diversity which presupposes a cosmopolitan mindset - 'planetary conviviality' (Mignolo 2002). Diverse representations here function as a kind of ideologically grounded, teleological, positively charged scaling of the developed, 'enlightened' world as the model for progress. With particular regard to the use of multiple linguistic codes, the advocacy organizations also seem to engage in a form of 'linguistic fetish' with regard to visual/spoken multilingualism (cf. Kelly-Holmes 2014). That is, the diverse and multiple scales drawn by advocacy organizations, though seemingly multilingual, are inevitably tied to both global realpolitik and commercial (i.e. fundraising) concerns. In such a context, the fleeting encounters that a viewer has with languages other than English are essentially a stand-in for globality and diversity, rather than any real aspect of advocacy communication. ${ }^{7}$ Though the appearance of multiple languages grants advocacy texts a 'global' character, this is a façade for the strategic uses of English as a symbolically valuable index of globality, and cost-effective mode of communication (to reach the most, and most wealthy, potential donors).

Following Gal (2016), one might say that the advocacy texts under examination only exist because of the ideological frameworks created by the scalar and rhetorical project of market-driven, socio-economic globalization. The 
scales they draw are only drawable through the globalized, mediatized discourse which preceded it, in which transnational trade and collectivity is universally understood as a positive thing. Thus, these texts have no capacity to subvert these scales, nor the pro-growth, unsustainable vision of the globe that is scaled within them. Thus, I argue here that inasmuch as the planetary conviviality evident within them is positive, it is not possible to correct the wrongs in this scalar vision, and generate new norms for discourse and social life, while operating within its ideological framework. Put simply, though we need to enworld differently in order to do so justly as well as convivially, we are hamstrung by the scales that have already been drawn for these processes.

Importantly, in videos/gifs like those represented in Figures 5.8 and 5.9, the expectation is always that the positive outcomes of teleological, LGBTQfriendly, global relations will be scaled at the level of the individual. Individuals will be free to be themselves - authentic, themselves, and happy - in a 'pseudosocial' (Thurlow 2013) better world. In concluding this section, I lastly wish to highlight forms of pseudo-sociality through circling back to the 'technologization of action' evident in advocacy discourse (Chouliaraki 2010, 2013) through which mediated actions (such as following a hyperlink) are scaled as highly significant moments of equality in becoming - bigotry defeated, with ease. Thurlow's (2013:244) account of the pseudo-sociality of social media relates to the increased tendency for institutional agents to 'stylize themselves as participatory, interactive, or accessible'. By invoking apparently informal, familiar or 'democratic' gestures and textual practices, powerful agents are able to conceal that power; their influence and capacity for control of people's behaviour are masked by forms of communicative condescension (Bourdieu 1991). Praeter hoc hashtags are a fine example of this. Whether \#IGLTA2016, \#EconPride or \#GayisOK, these institutionalized forms of ambient affiliation are framed as interactive, positive, and participatory. I have already discussed the pseudosocial and synthetically personalizing rhetorical production of these members and donors as 'equality champions' - and there is no denying that these 'champions' are the lifeblood of advocacy work. But as those examples show, the action of clicking a link is characterized as 'becoming an equality champion'. I wish to briefly discuss this phenomenon further, following Chouliaraki (2010:117), who highlights that this multimodal aspect of altruistic action 'significantly simplifies the spectator/user's mode of engagement with the humanitarian cause'.

Returning to the excerpts in Figure 5.3, hyperlinks and touchpoints like those seen here seem to offer instantaneity and immediacy of resolution. They also, troublingly, seem to offer a sense of instant gratification to the actor (or 'spectator', in Chouliaraki's terms). You can ban Tunisian 'gay tests'. You can show Moroccan girls they're not alone. The geographic and political distance between the 'spectator' and the oppressed persons is elided. These examples seem to suggest that expectations of effortless immediacy, prominent within contemporary consumer culture, have populated the moral imagination of LGBTQ advocacy, just as it has humanitarian discourse. This 'effortless immediacy', I would argue can be imagined as another form of ideological scale-making (cf. 
Gal 2016; Carr and Lempert 2016). As I have argued throughout this chapter, following scholars like Chouliaraki and Vestergaard, the cosmopolitan habitus of transnational solidarity and care for others is increasingly seen as incremental and individual - the outcome of courageous 'equality champions'.

Although I am sympathetic to the pragmatic approach to campaigning that NGOs like All Out must take, I remain deeply sceptical about it - after all, when and if anti-queer authorities in Morocco and Tunisia do find out about incremental, technologized actions, I believe there is great reason to suspect that they will not care. In this respect, I follow Chouliaraki $(2010,2013)$ in expressing concern about the scaling of action at a fleeting, momentary, and to some extent narcissistic scope - it seems chiefly to function to ingratiate activist subjects to passively activist forms of 'sassy' defiance, guided by consumer citizenship. Organizations (and HRC especially) commonly frame materialized tokens of pride and equality - 'official merchandise' - as an added benefit of membership or donation. The mobilization of visible icons of the organizations and their work, and of LGBTQ pride more generally, is a good thing; however, the greater benefit seems to be directed to the consumer citizen, the person who gets to choose to support the organization, broadcasts that support and gets something material in return. Following marketplace logics, one could say that wearable/mobile texts made by IGB, HRC or Nike or Gap all fulfil the same key purpose, which is to gratify a purported need for authentic self-expression. The assertion of oneself as supportive, rather than the assertion of a need for social transformation. Once more, it is 'cool activism', following from McGuigan's (2009) description of ‘cool capitalism' (cf. Chouliaraki 2013), and the technologized action, the touchpoint, rather than being focused on the outcome of financial support, is focused on the supporter: 'Send me a flag'.

The simplification and technologization of support within LGBTQ advocacy are no doubt purposeful - the result of strategic decision-making regarding how such organizations communicate with the public, integrating forms of corporate-style branding in order to maximize fundraising and visibility (cf. Kaldor 2003; Vestergaard 2008; Ciszek 2017). The scale it draws, however of a click as much more - is ultimately very much tied to the same neoliberal mindset which centres an unyielding belief in 'the self-activating capacities of free human beings, citizens, [and] subjects' (Rose 1999:64; Dardot and Laval 2013). In this mindset, a click, the display of a flag, wearing of a shirt and one's belonging to a convivial collective of everyday activists - 'pain[s] in the butt', like Alex (cf. Figure 5.4) - are all 'cool' forms of activism.

In the forms of scalar work I have highlighted in this section, I have shown how (neoliberal) ideologies emerge in the dimensions and values that are accorded to advocacy practice. Firstly, ideologies of scale emerge in the very consideration of global LGBTQ equality as a possibility, as something on the horizon. Secondly, ideologies of scale emerge in how all-encompassing, global change is framed as incremental and individual. Thirdly, and following from this point, ideologies of scale emerge in how individuals are compelled to conceive of equality as technologized and effortless - beginning with a simple click. 


\section{Concluding discussion: The globalized scales of ironic sass and post-gay politics}

The humanitarian imaginary ... needs to reinvent itself as a communicative structure that is neither about our common humanity nor about our own feelings for distant others ... [we must] move the West beyond narcissistic and increasingly corporate discourses of solidarity.

(Chouliaraki 2013:203)

As Hickel and Khan (2012:225) have presciently noted, because globalized neoliberal capitalism is organized on an international scale ... real change will require a movement that is international in scope'. For them, 'collective wellbeing depends on forging global solidarities'. However, what are we as humankind to do if forms of global solidarity are themselves formed in and through what Chouliaraki, above, calls the 'narcissistic' logics of neoliberalism? Like many other scholars, Hickel and Khan themselves acknowledge that these logics themselves are perhaps inescapable: scaled and ideologically enforced from the wider lifeworld to 'innermost subjectivity' (Dardot and Laval 2013). It is, in reality, very hard to imagine their alternative. Strategies of affective legitimation, as seen in Figure 5.1 and Extract 5.5 (below), provide solid evidence for just how difficult it may be.

Figure 5.1 demonstrates how advocacy organizations engage in discursive adequation of 'the cost of exclusion' as a blurred moral and economic issue - in which a waste of 'talent' is just as tragic as mortal fear or a lack of love. Final focus on UNFE's video provides an opportunity to explore this in greater detail. ${ }^{8}$ Extract 5.5 provides an edited excerpt of the video's script and 'soundscape', as narrated by the gay Hollywood actor Zachary Quinto. A detailed analysis of this single text sheds light on the way affective legitimation functions as a strategy within advocacy: in effect, the very same way it functions within the private sector (cf. Chapter 4).

\section{Extract 5.5:}

[slow piano tune begins]

Individuality. It's something we all have in common. But for some, the thing that makes them different - being gay, lesbian, bi, trans or intersex - marks them out for abuse ... For the individuals in question, these are personal tragedies. For the wider community, they represent an enormous waste of human potential; of talent, of creativity, and productivity, that weighs heavily on society, and on the economy. A study that looked at 39 countries found a clear link between the marginalization of a country's LGBT community and a corresponding loss of potential economic output. The cost of homophobia and transphobia is simply colossal - from a shrunken labour force and a flight of talent, to lost productivity ... The drag on growth filters into lower tax receipts for the government, meaning 
less money for health, education, and other essential services. No wonder the UN calls combating homophobia and transphobia both a human rights priority and a development imperative.

[inspirational, uplifting electronic music kicks in]

The cycle can be broken. More and more countries and companies recognise the benefits that flow from tackling homophobia and transphobia. For companies, that might mean adopting new corporate policies to make the workplace safe, fair, and accepting for all LGBT people. And looking at their business practices up and down the supply chain for ways to reinforce anti-discrimination efforts. For countries, it means new laws, and effective public education and training. The result? A world that is free and equal, and more prosperous too.

Quinto's cool-headed narration evokes his role in Star Trek media as the extraordinarily logical being, Spock. His evocative rational-moral appeal is thus granted an innately (if inherently fictitious) common-sense sensibility. In UNFE's video, he is a figurehead with 'role model authority' within a 'theatrical' performance of cosmopolitan care (van Leeuwen 2007; Chouliaraki 2013). He lends UNFE authority as compassionate and 'common sense'; an institution with both a moral obligation to act and a pro-growth agenda. That latter agenda, however, is in fact appealed to as the reason to act. The video begins with appeals to the social cost of discrimination (up to line 5). Statistics and pictographic representations of prejudice are provided, before the video focuses on its clear conceit of 'the price of exclusion'. Here rationalized appeals to the 'colossal' cost of homophobia (line 10) are taken into account as if 'personal tragedies' are not significant enough (line 6). Through rhetorical appeals to 'a more prosperous world' (line 28) as the outcome of ending 'the drag on growth' (line 16) that is LGBTQ discrimination, and the constructed equivalence between countries and companies as agents of change, once more it can be seen how neoliberal citizenship is framed as the ideal political position for queer people to take. Moreover, this form of citizenship is framed as the only path to take. 'Personal tragedies' are strategically and troublingly framed as an 'enormous waste of human potential' that 'weighs heavily' on the economy (line 6). 'Potential', 'talent', 'creativity', and 'productivity' are what are lost, not lives or livelihoods. Thus, the moral imperative for action against homophobia becomes its effect on productivity - not just standing above all other imperatives, but presented as the ultimate imperative, without any alternative.

To be sure, UNFE mentions 'tragedies' as an individual moral injustice. However, such 'tragedies' become relevant when considered through an economic lens; this is where ideologies of scale are germane, for highlighting the fact that a viewer's relation to an oppressed LGBTQ other is scaled as relevant by virtue of the 'drag on growth'. In effect, we are told it matters because it costs us - a (potentially) convivial collective, certainly, but one guided by the 'global rationality' of neoliberal thinking (Dardot and Laval 2013). UNFE here underlines how an inchoate post-gay mindset subtly (but by no means 
categorically) frames LGBTQ oppression as a 'merely cultural' injustice committed upon individual subjects, dislodging it from its entanglement with other structural inequalities (cf. Butler 1997b). As the UNFE webpage hosting the video posits, 'do you know how much discrimination really costs?' Through stark quantification, neoliberal word-things like 'innovation', and colourful, dynamic infographics, the cost of discrimination is calculated and countered by UNFE, using the discourse and logos of the corporate sphere. They speak the language of the free market. Notably, the musical accompaniment of Quinto's narration becomes markedly more upbeat and uplifting as economic and corporate-minded solutions to homophobia are listed. The score of the video thus reinforces a positive outlook on the ways that a 'cycle' of homophobia/limited growth is being broken by the spirit of 'self-steering' neoliberal entrepreneurialism (line 17; Rose 1999). UNFE's presentation of vital facts in compact, often-quantified and easy-to-digest bytes, in relatively clear language, could reflect a democratic aim of making messages accessible to non-native speakers of English. However, it is evident that this message innately privileges economic needs over social ones, and ultimately, seems to advertise individual responsibility for wellbeing over any humanistic bonds. The 'drag on growth' of discrimination and subsequent lower tax receipts are blamed for social deficits with regard to health and education. This, in turn, seems to frame individuals as the cause of these deficits, and removes the prospect of unproductive selfhood from any inclusive hypothetical future. In simple terms, it seems to place the onus on the formerly discriminated-against to earn more, and thus pay more tax (once freed from discrimination), should they wish to contribute fully to the society that follows. Support for LGBTQ people is framed as reliant on people becoming 'more prosperous' (line 24). Wealth, not wellbeing, is privileged as most imperative for LGBTQ freedom.

In the LGBTQ advocacy texts in which affective legitimation emerges, overall, the future is undergirded by a vision of citizenship in which prejudice 'weighs heavily' on the economy. Lifting this burden, then, is an eminently logical, pro-business decision. No doubt, advocacy organizations' adoption of this type of language is strategic and purposeful. It is nonetheless concerning, however, that queers' purchasing power, and potential, rather than personhood, is what buys them a place in the future to come (cf. Park 2016, 2018). However, it does accord with the trend I have sought to highlight here: how purchasing power, individualist choice, and corporate citizenship are enshrined as the pillars of a soon-to-be-realized LGBTQ equality. In the LGBTQ advocacy texts examined here - websites, emails, social media, and materialized 'language objects' like t-shirts and 'equality flags' - I see great reason to be concerned with the teleological determinism, normative identity work and Westernized scale-making practices of 'mainstream' transnational LGBTQ activism. In this chapter, I have sketched out how the strategic communication of transnational LGBTQ rights organizations is imbricated with many of the same projective, enworlding discourses of global capitalism. I have also - importantly - tried to remain positive and pragmatic about 
why this communication is the way it is (Macgilchrist 2016). As a queer man, I cannot reject the work of advocacy organizations completely, nor would I ever impede them. Inasmuch as I might believe that 'love always wins', however, I remain curious as to the consequences of this rainbow rhetoric. I wonder where it leads. Jones (2015:337) has rightly pointed out that the work of IGB 'helps to erode the separation and detachment that often accompanies mediatized depictions of suffering' and helps to project a world in which diverse subjects can find 'common narratives around which to congregate'. While I do not disagree that IGB and others' work is invaluable, my question is, in light of Gal's (2016) discussion of comparative and relational procedures (like IGB videos) as inherently ideological: what are the consequences of insisting that 'out' is better, with all the attendant ideological baggage that 'out' brings? Is 'gay' OK for everyone? Echoing what I asked in the introduction, following Ahmed (2014): what does the language of love always winning really do?

Perhaps these are naive questions. The mediatized discourses which inform me about oppressed queer others in countries I will never visit, after all, are the same ones which establish the possibility of me helping them. Why should anyone expect them not to follow perhaps the guiding rationale of globalized media - that globalization (and growth) is good? And why should I challenge them, if these are the best we've got? These are difficult questions to answer. Indeed, I am not sure I can fully address them, or could ever.

Writing about the close relations of sexuality and neoliberal governmentality, however, Richardson (2015:267) has aptly noted the importance of 'recognising both the contradictions and the possibilities of activism under forms of contemporary neoliberalism'. If we are to better understand the broader possibilities and bounds of political agency and progressive action, Richardson implies, we must find a way to conceive of a brighter future for the world's queers that can recognize and make use of the historical ties between our identities, activism, and the emergence of global capital, and that does not stop there. We (humanity) must not settle. To this end, perhaps all this book is about is that lack of settling; an embrace of the innately unsettling aspects of queerness, to unsettle visions of a world on the horizon which are not enough (Muñoz 2009). One such vision is the object of this chapter's critique: the post-gay consumerist collective that reinforces and emerges from the texts of transnational advocacy. In this chapter, simply put, I have sought to ask whether the mediatized future it envisions (Park 2018), and the scales it draws, are enough. Figure 5.10 illustrates these scales, with final excerpts from media produced by UNFE, OutRight and All Out.

A chronotope emerges in Figure 5.10: an infinite, ultimate scaling for 'Equality. Everywhere'. These texts seem to index another place and time to the world we currently inhabit, but concretely linked to this world, and time, as well. These are statements of mission and purpose; teleological and extremely evocative. OutRight adopt the look of a generic, inspirational meme. (Or perhaps a mediatized Bible verse?) UNFE's graphic is accompanied 

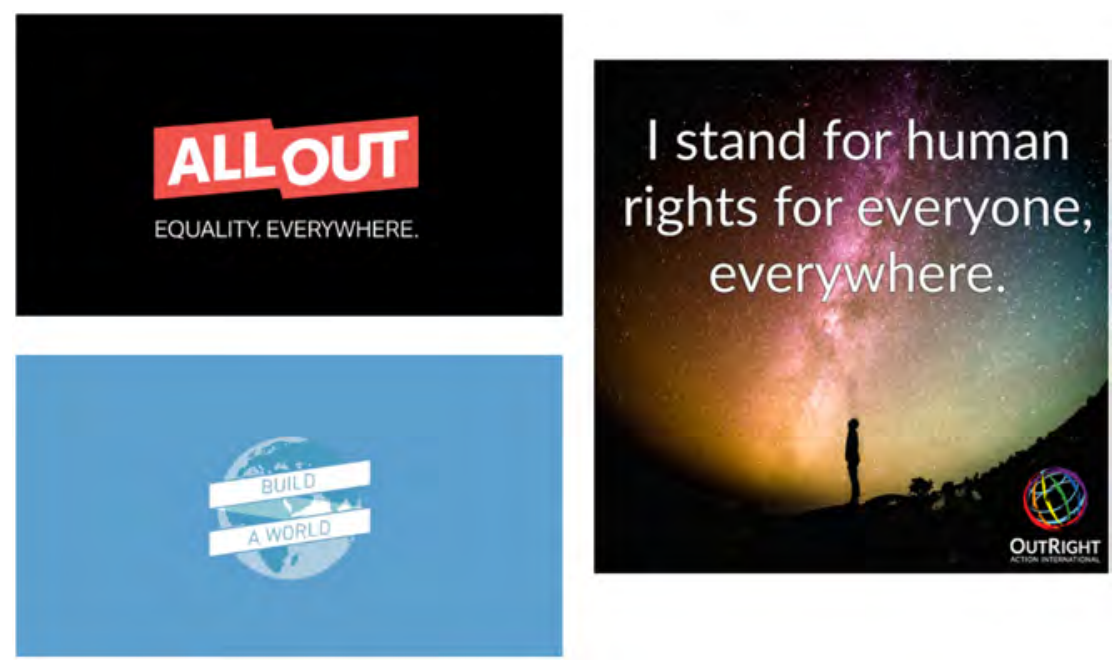

Figure 5.10 The infinite, ultimate scaling of/for LGBTQ futures.

by an inarguable sentiment (in which 'we' is the UN, its agencies and global citizenry at once): 'Together, we can build a world that is free and equal'. For their part, All Out present the phrase 'equality. everywhere' in multiple languages/scripts to rhetorically produce a diverse convivial collective once more (this is the final frame of the video analysed in Figure 5.8). There is an insistent predestination invoked in this chronotope - an inarguability - which is so broad as to seem universal. Like 'love always wins', it is instantly agreeable. If not 'meaningless', it is at least clearly performative - an affective-discursive practice designed to invoke feeling, and distribute it widely (Wetherell 2012, 2013). These kinds of texts, like much of the advocacy discourse I have studied, are fundamentally appealing enactments of scale. In texts like these, advocacy organizations scale our world as one place, scale themselves as legitimate and altruistic institutions, scale freedom, visibility, and attention as the final goal and scale equality as possible, incremental, and nearby. In other words, these texts are emblematic of the banal reproduction of post-gay sensibilities, ever so subtly, in advocacy discourse. They all point to where we've been, and where we're going, and at all times, they embrace a modern human rights framework - a scaling from positive affirmation to negative violation guided by Western individuals and institutions that operate in a competitive, neoliberal 'economy of scarcity' (Chouliaraki 2013:6). If equality is to be everywhere, All Out will have to compete to bring it into being. And they have to make supporters feel good about helping bring it into being.

Scale is nested below and within all of the other discursive strategies I highlighted in this chapter. They work interdependently to produce the other, 
but also work in their own ways, to reinforce the post-gay ideologies undergirding the project of transnational LGBTQ advocacy. In many ways, all of them point toward the universally desired outcome: for sexual identity and gender expression, one's freedom to choose lifestyles which accord with them, to eventually recede from the landscape of human rights discourse entirely (Ghaziani 2011). As scholars like Puar (2007) and Rao (2015) have discussed, this can increasingly be described as a 'folding' of queer people into neoliberal globalization - in essence, homonormativity. As Richardson (2017:216) notes, these increasingly blurred lines between neoliberal and sexual citizenship turn the right to live/exist/be into the right to choose, 'a discourse of individual entitlement ... [where] the focus is on the individual "choosing" subject (albeit as good neoliberal responsibilised consuming citizens)'. Each of the discursive strategies described in this chapter signals this equivalence of the right to life as the right to choose and express life - to self-actualize. Each also adds extra dimensions: the affective allure of profitability and sustained economic growth; ludic in-group sass and ironic stance-taking; embodied conviviality and live-in, material change; and lastly, an all-encompassing scale that is global yet individual, impactful yet effortless. Described another way, one could characterize affective legitimation as functioning as a moral-economic rationalization of advocacy discourse's neoliberal-citizen agenda, while audience design serves as a means for that citizen's stylization as an expressive, prideful person. Materialization and mobilization as a tool for the spatialization of pride - the living enactment of its (pre-) conception (cf. Lefebvre 1991). Scalar work always follows the dimensions, values, and imaginings that are iteratively formed in the scale-making projects preceding it, and always pursues a grander, more valuable version of itself - it is thus the end result of (and vehicle for) the three other strategies I describe. Overall, the global imaginary of transnational queer activism, then, can be seen as a complex network of beliefs about the nature and formation of identity, solidarity, economy, and society all tied to a common humanity, enacted by individuals and encapsulated in assertions of convivial collective potential. As All Out put it: 'I'm going all out because together our tweets, voices, and texts ;) will make them pay attention'.

Although I do not wish to adopt as strongly a critical perspective as Chouliaraki (2012) does in the quote beginning this conclusion, above, I am likewise perturbed by the tendency within LGBTQ advocacy discourse to engage in narcissistically and ironically motivated social action. ${ }^{9}$ It is clear in the data analysed in this chapter that there is increasingly a great deal of the 'post-humanitarian' within the workings of mainstream LGBTQ humanitarianism and advocacy. This 'post-humanitarian' sensibility (like post-gay and other mythologies of 'post', cf. Ghaziani 2011; Thurlow 2016) is less a realworld belief held by individuals than it is part of the over-arching guidance for life resulting from the mediatization of habitus in late modernity. It is 'a shift from the idea that doing good to others without expecting a response is both desirable and possible to the idea that doing good to others is desirable when there is something to gain from the act' (Chouliaraki 2013:179). It is a 
profoundly neoliberal 'utilitarian rationality'. As I already noted, post-humanitarian approaches to queer rights are perhaps inevitable in a context in which mediatization helps construct everyday citizens' relation to LGBTQ others in the first place. They are not necessarily the focus of my critique. Rather, the object of my concern is the ways in which universalist human rights discourse and a queer spirit of defiance cohere in mediatized post-humanitarianism, to produce versions of me as both the saviour and the oppressed. The person LGBTQ advocacy aims to help is imagined as a sassy, proud 'global gay' in becoming: 'young, upwardly mobile, sexually adventurous, with an in-yourface attitude toward traditional restrictions and an interest in both activism and fashion' (Altman 1996:77).

Cruz-Malavé and Manalansan (2002:6) have foreseen this phenomenon, in noting that although globalization is:

presumed to offer multiple avenues of intercultural contact, these contacts are often constructed in globalizing discourses as following a unidirectional path in which the West, Western cultures, and the English language stand in as the 'origin' of cultural exchanges and non-Western societies occupy the discursive position of 'targets' of such exchanges.

In this chapter I have provided empirical support to arguments such as CruzMalavé and Manalansan's - and in so doing, perhaps, pointed to the intractability of transnational advocacy's scalar project, and its consequence. The stylized and synthetically personalized framing of LGBTQ equality as an individually performed and consumerist process seems to foreground 'building a world' that is more prosperous, more prideful and indeed more sassy, but not necessarily any less unjust or materially unequal. This is an issue that arises across the data and experiences described in this book - as the South African activist at Spectrum said, 'You can't feed poor LGBT people with LGBT rights, they want food'. It seems, overall, that scale's innately ideological character has intertwined the building of transnational better futures for oppressed queer lives with the idea/ls of market globalism and its after-effect of post-humanitarianism. In short, transnational human rights discourse is only knowable through these idea/ls - and a global semioticized economy in which the shiftiness of 'equality' as a word-thing is completely natural.

As this chapter outlines, the globalization of LGBTQ equality occurs via banal actions, such as using a hashtag like \#GayIsOK, or wearing a t-shirt with that slogan on it. These banal tokens of advocacy are as much about synthetic collectivization, and about participating in consumer culture and a new commodity fetishism, as they are about engaging in meaningful change (cf. Page 2019; Žižek 2009; Hickel and Khan 2014). As Christensen and Jansson (2015:4) summarize, the moral, post-humanitarian cosmopolitan subject (a person like me), thus 'emerges as a self-benefiting, narcissistic agent who is first and foremost fulfilling a self-gratifying vision, rather than engaging politically'. This vision of one's own future inevitably co-occurs with the chronotopic vision of 
the future offered in these texts; scaled nearby, and soon, and achieved through market-based ends. Here, a 'chronotopic depiction formulates a sketch of personhood in time and place' (Agha 2007:321; Bakhtin 1981); a world over the horizon, in which queers are free, and secure. Through the invocation of various mediatized 'figures of personhood' (Agha 2007) - and, necessarily, of victimhood - the past is indexed and invoked as a time of oppression, the present is produced as a time of righteous, courageous individual action, and LGBTQ people are mobilized for a future for queer identity in which neoliberalism is not only normalized, but actively desired. In other words, as well as providing guidance for life now, mediatized texts about LGBTQ equality anticipate the future. Further sociolinguistic and social semiotic critique of this kind of mediatization of future chronotopes is vital. In Park's (2018:488) words, 'tracing the semiotic basis for the neoliberal construction of the future can point to concealed relations of inequality that neoliberalism reproduces and exacerbates'. Perhaps, in conclusion, one lesson of this chapter can be that we need to be more aware of what we have been trained to anticipate. Never should we be afraid to affirm the power of love. Perhaps, however, at times it makes sense to question the matter of whether, and how, love will win, and to question what comes after. What is being won? For whom does it get better? Who is left out, once we are encouraged to go 'all out'?

\section{Notes}

1 Available at: https://youtu.be/Dw5UTTnZQXY and https://youtu.be/ DvSxLH pyFOk.

2 Hashtags are a key tool for affiliative alignment in LGBTQ activist work, whether actually salient, searchable and clickable within computer-mediated communication, or brought into physical semiotic landscapes/streetscapes (cf. Zappavigna 2011; Heyd and Puschmann 2017).

3 That is not to say that these organizations are not cognizant of the negative outcomes of being limited linguistically, as Thoreson (e.g. 2013, 2014) discusses in some detail.

4 Once again my analysis is again especially situated and contextual, subject to a particular kind of 'filter bubble' (Pariser 2011). Ultimately, however, I believe this dataset is reasonably typical - a 'snapshot' of a typical supporter's inbox.

5 See https://youtu.be/Q9KTIkuh6Dw.

6 See https://youtu.be/zGP3c8BP_J4.

7 In keeping with my desire to engage in a generative critique (Macgilchrist 2016) of these organizations' communication practices, my aim here is not to ignore the clear currency of certain languages, and denigrate them for making use of them, but rather, to consider the consequences of an effective détente with forces of Eurocentrism and Anglophone capitalism.

8 See https://www.unfe.org/the-price-of-exclusion/.

9 Here, 'irony' is aligned with Chouliaraki's interpretation of the philosopher Richard Rorty. For Rorty, liberal society lives in a 'culture of irony', a suspicion toward claims to truth and universality. Rorty's 'liberal ironist' is sceptical of claims about the lived reality of others, but will nonetheless act on others' suffering as part of a desire for private selffulfilment. 
$\Longrightarrow$ Taylor \& Francis

Taylor \& Francis Group

http://taylorandfrancis.com 


\section{Sydney, February 2017}

Lying on the couch, scrolling through Twitter (probably procrastinating), I see the announcement: '11 Years On, We're Still Marching'. The Australian and New Zealand banking group, ANZ, have released details of their new campaign, \#HoldTight, 'as part of their ongoing commitment to the values of diversity, inclusion, and respect', and timed to coincide with Sydney's world-famous Mardi Gras.

In ANZ's words:

We're aiming to highlight what is a gesture that is difficult for many in the LGBTI community and turn it into a celebration of love and by asking people to 'hold tight,' when they feel like letting go.

Here we go, I think. More pinkwashed rhetorics. More homonormativity. And capitalizing on something so simple, and so painful - the fear that queer people have of public intimacy, even banal and 'innocent' forms of intimacy, like the holding of hands. On that couch, I was ready to decry ANZ's opportunistic, shameless exploitation of the LGBTQ community, justified under the dubious claim of 'corporate social responsibility'.

But then I watched the ad.

These are familiar actions, familiar settings. Folding laundry, going to a restaurant, visiting parents, relaxing by the pool, on the bus, at the park. ANZ's ad tells the story of people like me, in the place that I'm from, doing everyday things ... and they're in love. And by this time, February 2017, I am also in love, with somebody who is reluctant to hold hands, just like I am, and just like these people are.

As a soaring arrangement of contemporary (cliched) romanticism plays, the ad guides the viewer through the embodied trials of everyday queer love: the jerk-like movements away from one another, the sweaty palms, the side-eyed fear of appraisal and the potential for reprisal, for daring to be. For daring to hold hands.

Indeed, this ad has presented me with an honest vision of queer love, and one I didn't expect. This ad has touched me, in senses both haptic and affective. I can almost feel it my hands - that absence of touch, that longing. And when the ad speaks to me - 'when you feel like letting go, \#HoldTight' - there's no denying how moved I am.

Following the hashtag is no less evocative - I see how many other people the ad has touched, all the people who are thankful, affirmed and proud to call $A N Z$ their bank. 

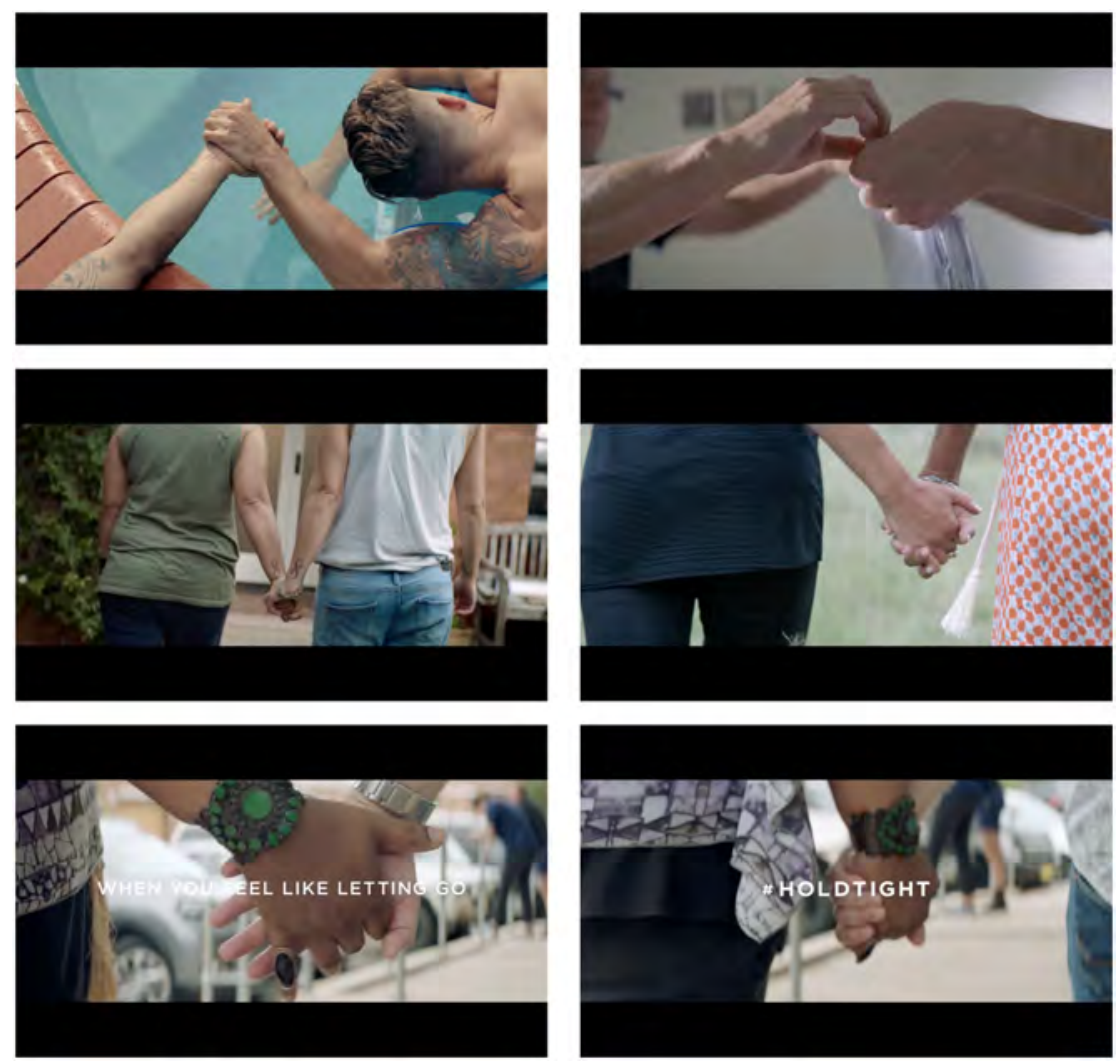

Who am I to be cynical about a social action which has brought people (people I feel like I know) so much happiness?

Even the tiny little emoji that accompanies the hashtag elicits emotion: a tiny little pair of holding hands. How cute. But not everyone on social media is happy, of course. There are many naysayers - bigots, homophobes, 'haters', to use All Out's words.

One person on Facebook's contribution: 'Can the ANZ bank please stick to banking and leave the sexual politics out of it'. And ANZ's response? 'No politics here' ... just promoting 'inclusion and respect for all'.

No politics here. Interesting.

How lovely. How inarguable. How hard to deny. How difficult it is to step outside of a discourse and point out its flaws, when that discourse has struck a chord inside me so deeply.

Hold tight - the world is about to change. Hold tight - one day soon me and my love can hold hands without fear. Hold tight, the future is around the corner. Hold tight. 


\section{Conclusion \\ Queer cosmopolitanism and the scaling of utopia}

\section{$\mathrm{Ga}(\mathrm{y})$ zing at utopia?}

A map of the world that does not include utopia is not worth glancing at.

-Oscar Wilde

I open this conclusion with the same Oscar Wilde quote that Jose Esteban Muñoz used as the epigraph for his book Cruising Utopia (Muñoz 2009). Muñoz's insistently hopeful, utopian stance establishes the theory of queer future-making that founds this conclusion.

This stance is informed by Muñoz's reading of the Marxist philosopher Ernst Bloch, and particularly, his concept of the 'not-quite-conscious'. ${ }^{1}$ For Muñoz (2009:21), the not-quite-conscious is a 'realm of potentiality', that must be 'called on, and insisted on, if we [a collective, queer humanity] are ever to look beyond the pragmatic sphere of the here and now, the hollow nature of the present'. Although I cannot outline this concept in detail, it suffices here to say that the 'not-quite-conscious' speaks to the latent potentiality of consciousness to adapt, articulate itself in new ways or arrive somewhere new. For Muñoz, the 'enduring indeterminacy' of hope (as Bloch describes it) is linked to a collective sense of 'not-quite' and 'not-yet' - a political and determinedly anticipatory stance. In his vision of queerness as a defiant rejection of the here-and-now, Muñoz commits specifically to 'concrete utopias'. Although concrete utopias 'can be daydream-like ... they are the hopes of the collective, an emergent group' (2009:3) - they are grounded in the affects of real people, desiring together. As I argue here, in conclusion, concrete utopias are best found in the contradictory moments through which knowledge of one's individual pride, alone, can be radically reoriented as a collective 'act of hope' for a pride to be proud of (Borba 2019). They are found in a hope for a world conscious to the ills of neoliberalism and committed to a language of 'love' ('diversity', 'equality', et al.) which rejects its disciplinary power.

Wilde's quote speaks to the necessity of desiring utopia, yearning for it, and Muñoz uses it to call on queer theory to build cognitive maps of the world that include its potentiality. At the same time, his is a clarion call to reject forms of 
'utopia' which too-narrowly accord with the here and now. As I asserted in the introduction, for Muñoz (2009:189), queerness is a 'resource for the political imagination', and especially, for insisting on the desire for something better. I invoke his work at the beginning of this conclusion for the same purpose: to insist upon semiotically grounded scalings of queerness, cosmopolitanism and political-economic relations which are better, kinder, and fairer.

The 'utopian' is nowadays a commonplace synonym for naive or impossible idealism. The notion has historically been used to describe social conditions which are alternately impossible, mythological or 'fundamentally unreal' (Foucault 1986; Waitt and Markwell 2006). The 'concrete' utopia Muñoz invokes, in contrast, is very much real, made up in the hopes and desires of individuals coming together as a larger whole. On first glance, then, the convivial collective I described emerging in LGBTQ advocacy discourse could be seen as utopian. As could the landscape of Spectrum. Muñoz (2009:26) himself stated that, "to live inside straight time and ask for, desire, and imagine another time and place is to represent and perform a desire that is both utopian and queer' and I am hence considerate of how radical even the most 'mainstream' (or homonormative) queer life still is, in many ways (cf. Cameron 2011). Certainly, there is a great deal that is beneficial in LGBTQ advocacy discourse (Chapter 5), the aspirational media produced through/at Pride and Prejudice (Chapter 4) and the cosmopolitan discourse of 'travel with pride'. But is the 'equality' envisioned in them - the future they articulate - truly equal? No. Is it enough? No. Thus, the object of my critique is simply the scalar processes whereby the mediatization of equality frames the here and now as the endpoint of queer becoming: in the embrace of market globalism.

Queerness is primarily about futurity and hope ... for queerness to have any value whatsoever, it must be viewed as being visible only on the horizon.

(Muñoz 2009:11)

My first goal with this conclusion is to summarize my analyses, hearkening back to the research questions established earlier. Overall, I consider how this critical discourse-ethnographic account of global queer mobilities reveals the troubling imbrication of lived, joyful, cosmopolitan LGBTQ lifestyles with the unjust, unsustainable practices of neoliberal governmentality, and provides insight into their increased interiority: how these ways of thinking and being get under the skin (cf. Thurlow 2016). In addition, through reference to some final analytical/autoethnographic interventions, I also want to elaborate on points made in closing Chapter 5, with regard to neoliberalism and mediatized frameworks for equality as 'anticipatory regimes' (Park 2018), questioning the chronotope that emerges in the discourses I have studied. Lastly, I wish to discuss the scales through which selves like mine are hailed, motivated, and even enchanted by the promise of this neoliberal future. In this closing argument, the purpose is not to talk about myself, but rather to advocate for a queer 
cosmopolitanism that undermines the anticipatory forces of market globalism; refusing to be enchanted by the mediatization of equality and its ersatz forms of fairness. Perhaps, I suggest, a 'queer alliance' (cf. Butler 2015) is the way forward: that gazes at the horizon, but never sees it coming closer; that recognises the homonormative politics of the present for the good work they do, while loudly and stubbornly insisting that the future not involve them; that we insist on a 'new future' that upholds transformative forms of caretaking (Heller and McElhinny 2017). Following Muñoz (2009:29) once more, my critique here is less of an attack, but rather 'an appraisal of how queerness is still forming, or in many crucial ways formless', and an insistence that it stay that way - there, on the horizon on where we could be. Not here. Not quite. Not yet.

In this book, I believe that I have 'tracked' a reasonably typical Foucauldian discursive formation - albeit one whose ruptures, multiplicities, and contradictions across the global semioscape merit its description as a rhizome (following Deleuze and Guattari 1987). Milani and Levon's (2016) study of the landscapes of homonationalism characterizes that phenomenon as a rhizome, and what I have tracked here certainly operates in a similar way. However, given 'it is impossible to give an all-encompassing, objective, and univocal description of any rhizome' (Milani and Levon 2016:73), I deign to refer to this formation as such. Queerly, perhaps, in conclusion I offer less of a precise description of what I am identifying here, than a sense of what this discursive formation is a resource for.

I said of critical discourse ethnography in the introduction that is 'a constant practice of undoing, stepping outside, and questioning' - a sidestepping of habitus. It does not and cannot fit neatly into a rigid dataset or stop at the close of each chapter, and encompasses one's imbrication with the discourses one studies: their positives and negatives, their 'mess', their allure. In this respect, the autoethnographic vignettes which punctuate this book sought to provide insight into my personal reflections on sexual/neoliberal citizenship and the proliferation of sloganized rainbow rhetoric within the global queer semioscape. In other words, these vignettes have been designed to sketch out the mediatization of equality in ways guided by my personal transnational habitus. The texts, practices, discourses and ideologies I focus on in this book constantly flow through and out of me, as a researcher, an affluent, white, male, bisexual Australian and someone who generally conceives of himself as a cosmopolitan, conscientious consumer. They also flow through and out of each other: when at Pride and Prejudice, Out2Africa is nominated as an exemplar for how LGBTQ business can thrive in Africa, and in banal moments, when I idly scroll through Instagram to find that a gay adventure tour company (a company whose founder I spoke to at Spectrum) is hosting a 'fabulous' South African escape. One of the men on the tour is proudly wearing a t-shirt made by HRC: 'Love Conquers Hate'. Here it is, then: travel with pride, worldwide. To destinations as fabulous as you. As me.

The enworlding affirmative discourses and scales explored in this book are thus all deeply interconnected across con/text, time and space. Echoing 
Coupland and Kristiansen's (2011) comments about mediatization from the introduction, it is 'inconceivable' that 'we' (Chad, Scott, I) are not impacted by what we 'see' as we scroll through Instagram, what we linger on, what we desire there, what is recorded by the technology we use. Certainly, for a networked cosmopolitan queer, there are many delights uplifting our prideful spirits - and selling us products - as we parade down a cordoned-off street; many destinations we are sold as places we can truly be free; much on a foreign or carnivalesque dancefloor that sits beside words, beside texts and before speech. All sends the message that equality is about pride - and in non-hierarchical, complex ways, Western citizens and 'global gays' are told that pride is about authenticity, that being authentic is about loving oneself fully, and loving oneself fully walks hand in hand with processes of consumption. In this way, the mediatization of equality is as exhilarating as it is ever-changing, as extreme as it is humane. Though it may feel close to utopia, this mediatization actually prevents us from reaching it. It turns us away from the horizon, by making us seem like we have arrived at it.

When considering each of the vignettes in retrospect, I am struck by how fondly I recall the moments they capture. Treasured memories, whether regarded as objects of a critical-discourse-ethnographic research agenda, or a liberated global gaze. Despite all there is to criticise in these moments, I instead dwell on joyous, uninhibited moments: my first sight of the Golden Gate Bridge in San Francisco, and of the gigantic flag in the Castro. Being transported from San Francisco to New York City to Toronto to Rio at Spectrum, from one 'gay capital' to the next, all while sitting in a conference crowd. Nights lost making out and getting off on the dancefloors of clubs worldwide that thrive in the wake of Stonewall. Pilgrimage, indeed. I think of the day out at London Pride living a convivial life, joyful beside thousands of others. A beer in hand, I live with the recommended \#NOFILTER: asking the Starbucks employee to stop and take a photo of me with the insta-friendly frame both as a sardonic (and research-minded) anti-corporatist statement, but also, because he was cute. I think of all the cuties at Pride, and how sweet it is to wink at them, to kiss their cheeks. \#NOFILTER. How times have changed. How I have changed, since turning that filter down. Never am I more fully aware that 'everyday life is not a mere conglomeration of routines and clear tactics' (Manalansan 2015:567) than when I recall the mediatized, situated, queer moments in these vignettes, revisiting how good they felt. During the agonising, infuriating build up to the legalization of same-sex marriage in Australia, ANZ's \#HoldTight campaign lifted my spirits. A long way from home, in a stressful era, and with a loving partner who still avoids holding hands in public, I can only hint at how much I was moved - how it felt to have a bank defend me to other Australians. When you feel like letting go, \#HoldTight. I was emboldened. I hold tight more often than I used to. Thanks, ANZ.

What I am alluding to here is not utopia. I assume that not even ANZ, Starbucks or NYC \& Company would claim that humanity is on the verge of some kind of egalitarian breakthrough (especially not, given global politics 
since 2016). What we have, instead, are the affects of 'concrete utopia' - an incessant hope - coming into contact with the affects elicited by complex material-semiotic representations of utopia. Aspiration meeting reality; met with a version of the world at its best. In light of this, critical discourse-ethnographic analysis can therefore focus on the way in which equality, progress and a chronotopic representation of the future as near to here are indexed in the discourse data discussed in this book. I am interested in how and why corporate/NGO institutional agents continually assert the power of queer mobility ('rainbow pilgrimage'), individuality ('\#NOFILTER') and anticipation ('\#HoldTight') for changing the world. All in all, it is safe to say that the discourses studied here frame a better world to come as the globalized world that is already here. You can visit it on a 'pilgrimage' to New York City; you can hashtag it when you \#WearYourPride; you are conditioned to its inevitability through the 'pseudo-social' enactment of support by firms like ANZ (Thurlow 2013).

In this mode of anticipation, there is resonance with the arguments of Park (2018), who discusses how 'neoliberal chronotopes' enshrine logics of human capital development within education. A similar neoliberal chronotope of the future undergirds all of the mediatized discourse of equality; valorizing 'anticipating the future and managing our selves in the present' (2018:479). Perhaps for progressive and/or queer politics, however, the best way forward is to not look forward - to properly live in the messy present, rather than imagine a perfect (post-gay) future. As this book illustrates, neoliberal capitalism nowadays commonly dislocates humanity's natural creative capacity from its sociohistorical embedding and recasts it exclusively as an economic resource - capital to be exploited, developed and value-added. Park astutely highlights how such human capital development 'presumes a particular orientation toward the future', where the future is a distinct chronotope - a globally scaled destination - 'defined through an ideological articulation of what type of people occupy the market-oriented time-space of the future' (Park 2018:480). Within a market-oriented time-space where 'goods are informational, work becomes affective, property becomes intellectual, and the economy more generally cultural' (Lash and Lury 2007:7), future freedom for a specific type of LGBTQ person is semiotized into a proxy for progress, and indeed, a way to exploit liberated cultural/sexual expression. Echoing Ahmed's (2012) discussion of nonperformativity (see below) the anticipatory chronotope of LGBTQ becoming in my discourse data can overall be seen as a way to limit change, and quell political-economic dissent. Within this chronotope, some LGBTQ people thrive - being true, holding tight, no filter - but because of it, many other people are left marginalized and silenced.

Throughout this book I have often referred to an 'ersatz equality': a thingified, commodified version of the true condition. (Like the pin from San Francisco.) The word 'ersatz' is derived from the German for 'replacement' - but it has also come to mean something kitschy or tacky. An inferior substitute. In this respect, one could describe the neoliberal chronotope's vision of 
equality in the same terms; a dynamic semioscape of mediatized word-things and affective phrases, promising a bright future for all LGBTQ people, while reinforcing relations of power and wealth which render that future impossible. The heterotopia that arose at Spectrum is a fine example of this 'ersatz' chronotope, in all its innate contradiction. At Spectrum, profitability and prosperity were enshrined as a moral framework, a 'force for good', and in the 'slices of time' (Foucault 1986) glimpsed on the poolside lunch and carnivalesque dancefloor, equality seems to surface, as if evidence for the moral weight of that force for good. Such heterochronous visions of a 'bright future', however, dissolve at once when you leave the guarded compound of the luxury hotel or take note of the majority black African staff silently cleaning up after the majority white crowd within its walls. ${ }^{2}$ In effect, the delegates at Spectrum both sell and are sold this inferior substitute for equality, at an event which in itself was said to signify the condition in becoming.

The end result of these chronotopic and discursive arrangements with regard to LGBTQ lives is further indication of the ways material conditions and communicative practices have begun to cohere in late capitalism. Following Thurlow and Jaworski (2017b), I have accounted for how the discourse of LGBTQ equality is 'thingified' in large-scale, embodied practices like tourism conventions, sponsored insta-frames that allow me to express my 'unfiltered' self and in small objects like lapel pins, t-shirts and the delicate, fleeting bubbles provided to me by Tesco - bursting with pride. This thingification in turn further compels LGBTQ people to follow neoliberal imperatives and to act as 'authentic' 'entrepreneurs of themselves, shaping their own lives through the choices they make among the forms of life available to them' (Rose 1999:230). By that same token, equality itself, as a material condition, becomes 'wordified'; manipulated into compliance with neoliberal ideals via (for example) metadiscursive regimes of diversity and diversity management, spoken about as something on the way. Equality and freedom are hailed as the outcome of corporate rhetoric. ANZ tells queers to 'hold tight' - their help will make it happen.

This push for ersatz equality in the place of a real utopian vision has heritage, of course. As just one eminent queer scholar has previously noted:

The market is constructed to be the filter of gay freedom and progress so much so that dominant discourses in the gay community disregard how this kind of freedom is predicated on the abjection of other groups of people who are not free to consume and do not have access to these symbolic and material forms of capital.

(Manalansan 2005:143)

What I hope to have provided in this book is an empirical, queer linguistic account of this 'dominant discourse'. In the following section, I outline how each of my analyses result in my thinking regarding ersatz equality: how the rhetorics of tourism, corporate social responsibility, global commerce, and 
advocacy cohere, to produce a vision of neoliberal citizenship as the ideal future for sexual minorities.

For now, Muñoz's (2009) sketch of queerness as a perpetual becoming is fundamentally at odds with the rhetoric of ersatz equality's institutional supporters, in which utopia is here, and joyful, and sassy, and 'equality' is as much a defiant attitude, as true societal transformation. There is an accord here between Rao's (2015) critique of 'homocapitalism', and many critiques of post-feminist views on female empowerment (Gill 2007; Lazar 2014; Gill and Kanai 2018). For example, writing about the liberalist 'Lean In' ethos of a great deal of 21st-century (post-)feminism, the Australian writer Eleanor Robertson has criticised what she calls the 'diversity' critique: post-feminism's central yet practically non-performative 'branding' strategy, pivoted on individual choice. For Robertson, these forms of critique have corrupted contemporary feminism, essentially, as merchandise; in which the push for diversity 'has as its functional terminus the "freedom" of consumers to purchase a picture of a utopia from a company whose interests lie in preventing any of these utopias from occurring' (Robertson 2016). Much the same process, and the same diminished, ersatz 'critique' can be seen in the data in this book. Although it may lead to an ersatz equality for the LGBTQ people who are able to survive, or thrive, in this world, like me, an era of pinkwashing (and greenwashing) and 'diversity' as a non-performative leaves the world little closer to redistributive justice, racial justice, justice for the disabled or (perhaps especially) environmental justice (cf. Fraser 1995; Stibbe 2015). Equality for some. Some equality.

What I seek to add in closing is a scalar account of the dimensions, values and teleology sustaining the mediatized habitus of ersatz equality, in which the feelings of pride and authenticity on show in my vignettes are central. Firstly, however, I offer the following chapter-by-chapter summary of my main analyses and conclusions.

\section{Summary: Tangled discourses of mobility and equality}

This critical discourse-ethnographic study focused on global queer mobilities in both material and textual forms, as the discourses and lived practices reflecting LGBTQ peoples' desire to be enworlded: to partake in, live across and succeed in a globalized world. My analytical approach was thus an empirical, critical and queer (and personal) account of movements both literal and social. At a time of rapid social upheaval and progressive change with regard to LGBTQ people - much of it propelled through mediatized texts, and centred on affirming the power of love - I have sought to problematize that which constitutes 'equality' in everyday media.

Chapters 2 and 3 examined mediatized and emplaced discourses of embodied LGBTQ mobility. Although such mobility is one that little of the world's population could ever hope to experience, it is a condition that Western LGBTQ individuals are increasingly compelled to embrace; they (or, we) are told to embrace being free, able to escape the shackles of heterosexist home lives. 


\section{Conclusion}

I sought to investigate the relation of LGBTQ tourism discourse to claims of homonormativity and queer complicity in material injustice: to find out how rhetorics of the neoliberal imaginary associated with global flows have infiltrated discourses of LGBTQ freedom, mobility and visibility. Marketing about Cape Town - the purported 'gay capital' of Africa - and a gathering of marketeers at Spectrum, the lavish annual convention of the International Gay and Lesbian Travel Association (IGLTA), were the empirical foundation for my analysis of so-called 'pink' tourism across these chapters. Ultimately, I argued that it is a fundamentally individualist, self-actualizing pursuit for mobile queer people; at once consumerist and liberatory. While this is not a new critique vis-à-vis global tourism (e.g. Thurlow and Jaworski 2010a), I argued that there is particular resonance for individualist rhetorics of authenticity and self-maximization for the historically marginalized LGBTQ community.

The escapist discourse of 'travel with pride' was central to Spectrum's staging. Indeed, it ongoingly justifies the entire LGBTQ tourism industry. Across these first two chapters, I identified how 'Africa's gay capital' is positioned as an elite and exclusive wonderland for the 'fabulous', prideful pursuit of happiness, and how Spectrum in its entirety served as a device for sustaining this globalizing ideology of 'travel with pride'. This ideology upholds an escapist idea/1 of tourism as a noble, even altruistic vehicle for cosmopolitan progress - a path to both enlightenment and enrichment. My argument pointed to how this superficially progressive ideology increasingly sloganizes equality, representing it as an individual attainment typified by privileged mobility rather than a true social condition. Cape Town's 'equality by the sea' is anything but. And in the lifeworld of Spectrum, a heterotopia emerged: an internally contradictory 'enacted utopia' (cf. Foucault 1986). The convention invoked an inconsistently finite and infinite chronotope, as both here and now and there and then (Bakhtin 1981; Muñoz 2009) - a site of alterity, 'love' and ersatz equality that juxtaposes a vision of another, better world for all LGBTQ people with sumptuous, camp and carnivalesque landscapes of luxury, fundamentally excluding those whose lack of material capital disallows mobility (cf. Kaufmann et al. 2009). Overall, through the discourse of 'travel with pride', equality indexes infinite consumption, in a finite world, and to travel is to celebrate one's authentic, sexually liberated self. Inasmuch as it is even considered, staying home may be to languish in oppression - to not escape. Perhaps, it is a capitulation to an unchanged, otherwise unequal world, given how strongly travel itself is framed as a fundamentally benevolent, 'change-making' endeavour.

In my latter analyses, I addressed a more abstract form of mobility; turning my attention more closely to the global circulation of texts and textual practices than of people. This is circulation across what I term the 'global queer semioscape' (following Thurlow and Aiello 2007): a banal, deterritorializing tool working alongside global capital, which both constitutes the mediatized expression of everyday queer life in the West and mediates authentic relationships among those who live those lives. (In earlier chapters, I have of course still commented on aspects of this semioscape relating to embodied mobility.) 
Where Chapters 2 and 3 invoked an only obliquely corporatist construction of capital as pride (encased within the mythologies of tourism, encapsulated in the discourse of 'travel with pride'), Chapters 4 and 5 honed in on ways in which this connection of capital and pride is at times much more overt. Chapter 4 centred on Pride and Prejudice (run by The Economist), a conference devoted to the topic of diversity management, aimed at cementing a leadership role for business in 'progress' for LGBTQ people. Chapter 5 took contemporary valorization of globalizing capitalist logics as an empirical-cum-theoretical foundation for an analysis of mediatized discourse produced by transnational LGBTQ advocacy NGOs.

In Chapters 4 and 5, I questioned transnational discourses that advocate for LGBTQ rights, often through appeals to the shifting, always-valorized recognition of 'diversity'. I was especially interested in exploring the non-performativity of 'diversity' and related words (following Ahmed 2012). More broadly, through all my analyses, I sought to demonstrate how 'equality', 'diversity', inclusion', 'pride', 'out', 'fabulous', and other word-thing fixtures of the global queer semioscape seem to systematically form an object which is not wholly repressive (in fact, anything but): global queer society, individual identities cohered by a solidarity. These are markers of distinction, identity, and added value. Yet, as fabulous as a 'fabulous life' might be, mediatized expressions of queer identity are nonetheless irrevocably tied to networks and structures of injustice and inequality. Thus, my interest was in what performances of pride and progress (in diversity management and LGBTQ rights discourse) do not perform, despite their apparent liberalism. All told, in my estimation, the nonperformativity of diversity management and discursive strategies structuring transnational advocacy lend credence to the ways in which even the most banally circulating rhetorics and word-things of modern-day LGBTQ inclusion are in fact a means for neoliberal institutions to govern through liberty: 'to actively exploit the freedom allowed individuals so that they end up conforming to certain norms of their own accord' (Dardot and Laval 2013:11). Pride and Prejudice can thus be seen as explicitly indexing the utility of LGBTQ 'diversity' in a market globalist era, and the reason why the discourse of 'travel with pride' is nowadays taken up so strongly. Very simply, this is because of how the 'folding into life' of LGBTQ people (cf. Puar 2007; Rao 2015) serves to enrich the powerful, as well as affirm that LGBTQ people can be powerful too - all of which serves to justify the exploitative and insolvent character of globalized neoliberal capitalism.

Organizations like those studied in Chapter 5 - whether oriented toward global poverty, disaster relief, education or LGBTQ rights, as just some examples - increasingly operate within an 'economy of scarcity', which tends to engender acquiescence with the political-economic 'script' of the Western donor market (Chouliaraki 2010, 2013; Vestergaard 2008, 2013). Though the strategic aims and communication practices of international development actors and LGBTQ advocacy organizations certainly differ to an extent, their shared deployment of affective attachments - most saliently, 'love' - and a 


\section{Conclusion}

broad, unquestioned positivity (cf. Ahmed 2014; Machin 2004; Ehrenreich 2010) means that Chouliaraki and Vestergaard's insights informed my analysis. Overall, my final substantive chapter was designed to examine the marketization of LGBTQ advocacy practice, and its imbrication with the logics of market globalism. In sum, I argued that the discursive strategies used by LGBTQ advocacy organizations ultimately reflect a 'post-humanitarian' mindset (cf. Chouliaraki 2010, 2012, 2013) in which Western individuals' relation to oppressed queer people (including my own) is centralized. This 'post-humanitarian' mindset is deeply connected to a burgeoning 'post-gay' one; an assumption, if always partial/provisional, that we are reaching a historical end-point with regard to how non-heteronormative lifestyles are recognised and freely lived. The final result of this scalar work is that solidarity with these marginalized people, hinging on a sense of 'global queer' community, itself seems to reinforce the unjust and unequal political-economic structures that entrench marginalization (Rao 2015; Carr and Lempert 2016).

Overall, where my former analyses tracked aspects of the living of a global queer life guided by mobile media in a global queer semioscape, using tourism as an empirical resource, my latter analyses aimed at apprehending the discursive strategies which undergird these mobile media in more 'macro' ways. The mobility of the media I've described contributes fundamentally to how we (i.e. 'ordinary' Western subjects) conceive of the world and our place in it. Such media provides 'guidance' for contemporary life (cf. Hjarvard 2013). They re-scale the world so that social connection, solidarity, social and physical mobility, and overall social difference are mapped at a transnational order, and affirm our complicity with this order, imbricating 'ordinary' lives in the political-economic realities (and inequalities) of market globalism.

Here I can reiterate the relation between 'rhetorical tactics' (or 'rhetorics') and 'discursive strategies' I use in this book, as adapted from de Certeau (1984). Essentially, this is premised upon the former as contingent actions 'determined by the absence of a proper locus' (de Certeau 1984:35), and the latter as situated, over-arching plans. In partial contrast to de Certeau's original distinction, as I use these terms, the two are somewhat hierarchically organized. Rhetorics operate in an unsteered, contextual and co-dependent manner, circulating globally, and can be creative ways for the non-powerful to engage with and contest dominant structures. Rhetorics of Africanness, the body, (post-apartheid) equality, escape, a 'force for good', cost, opportunity, and leadership all arose in the mediatized texts, events, and contexts I explored in this book. They were, at once, manifestations of legitimate queer pride, manifestations of the discourse of 'travel with pride' and capitulations to a globalizing neoliberal habitus: the world as one place, to consume (and package for consumption) at one's leisure. Discursive strategies (following de Certeau) are distinguishable from simple 'discourses' by virtue of their acting from a 'base', here figured in powerful institutions in the global North. I have explicitly named four. These strategies impose norms of political-economic relations, identity expression, and scalar dimension/evaluation. Thus the strategies of affective legitimation, 
audience design, materialization and mobilization, and scalar work listed in Chapter 5 cumulatively present neoliberal ideology's 'totalizing way of life ... [as] a virtually unassailable notion of morality' (Hickel and Khan 2012:205). To follow an example, one can see that the discourse of 'travel with pride' is sustained through a number of contingent, contextual rhetorics in Cape Town tourism media, in MisterBnB ads or at Spectrum. However, 'travel with pride' in fact only operates as just one part of the ongoing strategizing of global institutions like The Economist, IGLTA and UNFE, in which there is also a discourse of 'a business case for inclusion', of 'love always wins'. These are the banal discourses which have surfaced in this study, indexically, and strategically linked to a much larger formation: the mediatization of equality.

In this way, I hope to have presented a 'double hermeneutic' of global queer mobility (Giddens 1984): where people's very ideas of seemingly inarguable principles like 'equality' are able to narrowly and apolitically relate only to an equality of opportunity between LGBTQ people and heterosexuals, including the opportunity to be cosmopolitan. Each of my substantive chapters examined the implications of cosmopolitanized (i.e. planet-wide and convivial, following Mignolo 2000) queer identity formation in the context of globalization and pervasive neoliberal governmentality. Together, they underline the extent to which the shifting, positively charged, global queer semioscape is profoundly interlinked with the ideologies and representative practices of global capital. In itself, this is not necessarily surprising, given the ubiquity of mediatized discourse in contemporary life. However, I am greatly concerned by the extent to which this process constitutes an effective and affective quelling of LGBTQ politics. Overall, it certainly seems that the very resources which have been used to forge bonds and affirm LGBTQ identities since the latter half of the 20th century are nowadays used to naturalize a great many unequal power relations and privileges. My self-reflexive analysis indeed reveals the interiority of a mediatized, globalized, and consumer citizen sensibility: the way the allure of travel with pride gets under the skin (cf. Thurlow 2016). To return to the couple whose love, travel, and 'love's travel' began this book, it certainly seems that Chad and Scott's fabulous life is framed as a template for LGBTQ equality and sexual citizenship. Their enworlded life now seems a template for the development of an uneven future: one in which consumers' affective bonds, desires for cosmopolitan conviviality and sexual urges are subsumed by cohesion with a telos of unfettered economic growth and self-gratifying global solidarity. The 'ironic' stance that Chouliaraki (e.g. 2013) identifies in 'post-humanitarian' discourse - i.e. a doing good that is chiefly introspective and pleasurable, rather than pitiful or 'purely' altruistic - is thus expanded and scaled worldwide as the template for a 'fabulous life'.

Although a nuanced, generative perspective to these discourses must see the clear benefits to individual lives that the mediatization of equality spreads worldwide, the overall effect is precisely that: to benefit individual selves, and especially, those whose 'innermost beings' are already advantaged through the authoritative nature of Western queer cultural expression (Dardot and Laval 
2013:5). All in all, the mediatization of equality - as a dominant gaze at the horizon and hope for 'another world' - currently allows an apolitical form of neoliberal queer citizenship to supplant more transformative stances. As Fraser $(1995,2000)$ and Duggan (2003) forewarned, these homonormative politics of recognition can increasingly be understood as a smokescreen for the absorption of sexual alterity into neoliberalism in which forces of capital are made to appear altruistic, benevolent, and desirable. To do so, it has also incorporated its affective ties: the corporate world and even non-profit organizations now readily profit from selling feelings, and selling the satisfaction of mobilizing change through the purchase of virtuous commodities. The materiality of a cheaply produced t-shirt, tote bag or mug, the pleasure-giving illusion of resolving the 'merely cultural' issue of homophobia becomes a commodity itself (cf. Richey and Ponte 2011). And alongside, attacks on homophobia as a merely cultural disposition that can be resolved through the power of the free market allow for the political-economic underpinnings of such homophobia to go unquestioned. This strips us of potential for meaningful political critique, and quells activism into a depoliticized, consumerist passivity. It is an insolvent existence (to use Muñoz's word again). It is not enough.

\section{Equality and interiority: The imperfect scales of mediatized cosmopolitan progress}

Dardot and Laval (2013:18) refer to neoliberalism as the totalizing form of existence: 'the deployment of the logic of the market as a generalized, normative logic, from the state to innermost subjectivity'. Following them with my own strident critique, I have just begun to describe how neoliberalism now spans from the ends of every horizon, even down to our deepest desires (cf. Milani 2018). Although a hollow catch-cry of 'neoliberalism' can trivialize discussion of how pernicious forms of capitalist ideology now dominate the world. I have offered my own perspective on what is 'new' about neoliberal phenomena - what their impacts are and how worldviews cohere with them. I now wish to say something about what might be done to combat them.

The answer to the question of 'where to from here' - a 'new future' (Heller and McElhinny 2017) - I believe, lies in turning inward. We must gaze within, at how good it feels to be affirmed, and loved, and to affirm and love, if we are to escape the hermeneutic cycle where those affects' potentiality to lead to equality is diminished. We have to queer the scales; to gaze within and imagine queer equality for ourselves and for others differently, if we are to truly fix our gaze at the ideal, real, horizon - a place, as Muñoz defines it, where queerness is a permanent becoming.

\section{Neoliberalism and the 'merely cultural'}

Many considerations of neoliberalism have tended to focus on examining forms of capitalist 'accumulation by dispossession' (Harvey 2005): the centralization 
of power and wealth in the hands of the few, through processes like the privatization of public goods, waves of financialization (including of discourse) and the manipulation of crisis. Certainly, accumulation of wealth by the few is a defining characteristic of neoliberalism. As the discourse data in this book demonstrates, however, neoliberalism has furthermore 'become incorporated into the common-sense way many of us interpret, live in, and understand the world' (Harvey 2005:3). A mediatized habitus now establishes neoliberal values as a guiding morale and rationale for late modern life, which 'in the name of liberty and relying on the leeway afforded individuals, orientates their conduct, choices, and practices in a new way' (Dardot and Laval 2013:3). There is no doubt that this 'new way' affects the intersubjective realization of sexual identity, sexual practices, and how these are both represented in the media and enlivened in space. In my analyses, there is evidence for 'homonormativity', in broad strokes: a power dynamic whereby neoliberal capitalism (and heteropatriarchy and neo-colonial logics) work to empower some queer subjects and marginalize others (Duggan 2003; Rao 2015). A nuanced perspective on this so-called 'assimilative' behaviour is always required (e.g. Smith 2016; Brim 2020). However, we should also pay attention to how deeply sexuality is now involved in the renewal and strengthening of market globalism (cf. Bockman 2012; Rao 2015; Ludwig 2016; Milani 2018).

Yet, for Harvey and other seminal theorists of political economy, queer theory and the politics of identity are a 'merely cultural' matter. As Harvey (2005:46) puts it, 'the narcissistic exploration of self, sexuality, and identity become the leitmotif of bourgeois urban culture'. In Chapter 6, I already touched upon Butler's (1997) rebuttal to such claims:

Whereas class and race struggles are understood as pervasively economic, and feminist struggles to be sometimes economic and sometimes cultural, queer struggles are understood not only to be cultural struggles, but to typify the 'merely cultural' form that contemporary social movements have assumed.

(Butler 1997:38)

Similarly, as Muñoz pithily states of Harvey, 'the experiences of working class or ethnic-racial queers are beyond his notice or interest' (2009:31). Muñoz suggests the hopeful theory of Bloch as a bridge between queer and feminist politics and the thinking of Marxist scholars like Harvey. In his stead we can say that while 'identity politics' are increasingly tied up with neoliberal governmentality, the solution is not to dismiss the importance of identity and the 'merely cultural' entirely. We must rather understand its articulation in the experiences and mediatized lives of marginalized people, following Bourdieu's insights on how symbolic goods are a key marker of class.

Sociolinguistics and discourse studies seem improperly divided into 'camps' following Harvey or Butler. From a 'cultural' perspective, Thurlow and Jaworski (2012:490) readily acknowledge that 'class distinctions and social 
inequalities hinge on and arise through enculturated symbolic economies as much as they do on material or political ones'. However, in his recent book devoted to neoliberalism, political economy and sociolinguistics, Block (2018:22) dismisses this claim and those like it off-hand 'because it is hard for [him] to imagine how discourse and other symbolic activity could actually cause material inequalities'. In endorsing his own Marxist positioning, he seems to assert a narrow and anachronistic interpretation of Marx's thinking as the only option (cf. Martín Rojo and Del Percio 2019). Like Harvey's above, Block's is an overly normative statement - fundamentally at odds with recent insight into the ways class necessarily intersects with modes of identity (Butler 1997; Crenshaw 1991; Levon and Mendes 2016). It contradicts insights such as Bockman's (2012:315) regarding 'the multiple political projects [that have been] incorporated in distorted form within neoliberalism'. So-called identity politics is just another leftist/progressive political project subject to the endlessly predatory aspects of neoliberalism - as exemplified in t-shirts emblazoned with Che Guevara's face (Chun 2016). Neoliberal consumer identity intertwines with genuinely emancipatory impulses in complex, uncomfortable ways, and it is vital that scholars recognise this interwovenness in their accounts of it. Certainly, putting class 'back on the radar' (cf. Block et al. 2012; Block 2018; Thurlow and Jaworski 2017) in sociolinguistics and discourse studies is important. At the same time, however, it should not prevent us from exploring the material consequences of 'cultural', seemingly intangible, often affective (but not immaterial) dimensions of queerness and non-normative/ marginalized identity. In fact it cannot, for it to be properly effective. Rather, to use Duggan's (2003:83) term, sociolinguists and discourse analysts need to take heed of how this economic/cultural distinction is a 'ruse of capitalist liberal discourse', that plays into the hands of neoliberal agents, maintaining the status quo.

In order to combat the strength and totalizing scope of neoliberal society, radical political actors and progressive scholars must continue to closely monitor the ways in which market globalist ideology incorporates - indeed, seduces - non-normative identities, while sustaining its in-built injustices (cf. Milani 2018, citing Mieli 1980). With specific regard to LGBTQ people, following Fraser (1995:83), we need not only to denounce the insufficient affirmation of queer subjectivity via 'substantive, cultural, identificatory positivity', but also to denounce discourses of 'productivity' that tie the implied value (and legitimacy) of affirmation, love and equality to unfettered, exploitative and unsustainable economic growth. In this way, we reject Foucauldian governmentality as 'a political rationality that informs the contemporary governance of populations, institutions, and practices, including language and subjects' (Martín Rojo and Del Percio 2019:3) - a rationality that informs our 'fabulous' selves, and the way we articulate them. Such a step would be the first in building a generative 'queer alliance', emboldening queer theory as 'a resource for the political imagination' (Muñoz 2009:189) and a continual gaze somewhere else. Somewhere better. 


\section{Scaling a global reach: Discourses of affirmation and aspiration}

Scale bleeds into and out of every aspect of human life - in Carr and Lempert's (2016:18) words, 'social existence is radically scalable'. Indeed, across this book I have articulated a vast range of scales which are taken-for-granted within social existence, for example, between: me and others like me; media, social institutions, and subjectivity; affect and rationality (i.e. legitimacy); affluence and wellbeing; affluence and aspiration toward affluence; individual and community; and consumption and altruism. Through the discourse-ethnographic data explored in this book, the global North is perpetually framed as a community of like-minded, compassionate selves whose duty is to explore and improve the world. There is evidence here for how 'scales can problematically fix our view, add weight to some dimensions of cultural life and not others, and propel some social projects at others' expense' (Carr and Lempert 2016:19). A scale that represents queer suffering as elsewhere privileges Western subjectivities and orientations in LGBTQ rights discourse, at the expense of alternatives to the unsustainable imagining of post-gay queer futurity (as posited here). Like Ghaziani (2011:104), I want to leverage our burgeoning 'post-gay moment' as 'a theoretical opportunity to rethink conceptual frameworks of collective identity'. This requires rethinking of the scales between ourselves and the world, and conterminously, between cosmopolitan vision and mediatized social life.

Reflexive sociological research encourages us to think within but beyond the neoliberal age ... one of the first things to do is decolonize our mind by objectifying our own neoliberal dispositions' (Hilgers 2013:86 [my emphasis]; Bourdieu and Wacquant 1992). Accordingly, this book's genealogy this queer critical discourse ethnography - illustrates the benefits of resisting clear separation of mind and body, reason and affect, and detachment and desire. This is especially germane for the research questions set in this book's introduction. Many theorists, following the Foucauldian principle of governmentality, suggest that neoliberal forces increasingly regulate people's desires, forging a willingness within people to regulate themselves according to the will of the powerful: a 'contact' between technologies of domination and of the self (Dardot and Laval 2013; Martín Rojo and Del Percio 2019).

Key to the success of such 'technologies of the self' is the uncomfortable fact that power can imbue positive affects. It induces pride. Power, despite its harmful consequences, and resulting inequalities, still manages to arouse, seduce and satisfy; capitalist power is an especially enchanting regime.

If power were never anything but repressive, if it never did anything but to say no, do you really think one would be brought to obey it? What makes power hold good, what makes it accepted, is simply the fact that it doesn't only weigh on us as a force that says no, but that it traverses and produces things, it induces pleasure, forms knowledge, produces discourse. It needs to be considered as a productive network which runs through the 
whole social body, much more than as a negative instance whose function is repression.

(Foucault 1980:119, my emphasis)

Following Foucault's points, it is possible to highlight that it is precisely how good the mediatization of equality and its enworlding vision feels that grants it success in inducing productive psyches in the service of capital. 'The modern subject, constituted by power, speaks in the affirmative' (Ferguson 2008:159): such are the positive affects and affirmations I have pointed to in autoethnographic moments in this book. Throughout this text, I have provided a mere glimpse of the discourses and strategies which operate through the mediatization of equality: the true currency of feeling proud, loved, and perched at the making of a better world. Affirmation embeds a global(ist) reach: an affective, blurred moral/rational legitimacy for an unsustainable future.

In short, it feels really good to not be alone in my alterity, to assert alterity as uniqueness and to entrepreneurially assert that uniqueness in authentic, selfmaximizing actions like 'travel with pride'. It actually feels good to be a neoliberal citizen. It now stimulates the flesh in ways that are at once pleasurable, transgressive, and self-actualizing (cf. Milani 2018). Critics of neoliberalism must apprehend not only these pernicious facts, but also the continuous circulation of affective-semiotic resources: indeterminate word-things like 'love', 'equality', 'diversity', 'pride', and other sloganized rainbow rhetoric that commodify articulations associated with 'the existence of homophobia, and the pleasure-giving illusion of fixing it' (to paraphrase Hickel and Khan 2012:217). This mediatized circulation increases the resonance of the movement of such affective signs: 'the more they circulate, the more affective they become, and the more they appear to "contain" affect' (Ahmed 2014:120). Not only has neoliberal capitalism's hegemony colonized our inwardly felt relation to the world, and our capacity to imagine alternatives to capitalist development, but we seem increasingly distant from the 'edge' of ourselves - that is, from any non-narcissistic, 'non-ironic' equality. In a world increasingly all about you, it is increasingly hard to forge relations that aren't.

Beginning this book, I was already aware of the affirmative qualities of disciplinary power and neoliberal capital - \#LoveTravels was clear evidence. Closing it, I can readily speak to the extent of its reach - how much it gets under the skin, how much it tugs at the heartstrings. Based on my analysis, it seems reasonable to say that the dominant discourse of neoliberalism is not simply monolithic, but also transposable, adaptable (Hilgers 2013): the scale between any given Western queer subject, their desires and a global (indeed universal) neoliberal project has been increasingly 'invisibilized'. A total investment in neoliberalism's insolvent 'delirium of the unlimited' (Lordon 2014) is a natural reflection of how this 'unlimited' scope accords with an uninhibited selfhood (and self-actualization). Neoliberalism offers up unlimited potential to queer people, when until recently, their lifeworlds were too often defined by limits, silences, and withdrawal from oppressive societies. Ferguson (2008) has 
called this 'drive' to extinguish the difference between marginalized subjects and neoliberal institutions the 'will to institutionality', but I prefer to conceive of this more evocatively: less as 'will', than as a totalitarian 'possession of souls' (following Lordon 2014). In Lordon's view, the neoliberal enterprise nowadays seeks to abolish the difference between itself and the individual entirely, through enchantment and ecstasy: 'in an almost shamanistic sense ... [it] demands the complete surrender of "interiority" (Lordon 2014:79). This is a dissolved scale between the subject and neoliberal enterprise. Thankfully, however, this 'possession' does not and need not work wholly one-way. There may still be ways to counteract it, and one such way may be to remake this dissolved scale, in such a way as to dislodge queer identity from a telos of unfettered growth, a scale of unlimited, self-steered life. In Dardot and Laval's (2013:318) words, 'the main lesson of neoliberalism [is] that the subject is always to be constructed. The whole question is then how to articulate subjectification with resistance to power'. The answer, I believe, lies very much in attention to the media - or more specifically, in reorganizing processes of mediatization so that they focus less on grand narratives, and more on the day-by-day construction of free, just livelihoods for subjects and their 'interiors'.

All cosmopolitan projects and scales subsist (at least and only ever partially) on the media (Christensen and Jansson 2015). As I have been arguing, the mediatization of equality is in effect tied to a broad, hyper-positive cosmopolitan vision that is in fact unjust and insolvent: 'a contract ... of fake futurity ... an assimilation that is forever over the rainbow' (Muñoz 2009:55). This vision accords with the 'cosmopolitan lite' mythologies which support globalizing discourses like tourism (Thurlow and Jaworski 2010a), but it also represents a colonization of more critical visions of planet-wide conviviality, those guided by an 'ethos of making connections and exchanging and sharing cultural meaning in the name of social and moral change' (Christensen and Jansson 2015:159; Mignolo 2000). The vision I describe genuinely represents a desire to impact the world for the better (for better or worse); simply put, it comes about from an effective commodification of altruism. It is an exploitation of good intent, and the use of that intent to renew a central source of the social ills that good intent seeks to resolve (cf. Bockman 2012). A properly constituted cosmopolitan vision (surpassing Christensen and Jansson's) therefore needs to be more than a simple 'ethos of making connections' - rather, it needs to surmount the ways in which such connections are fundamentally established through mediatized means.

To be clear, echoing the epigraphic quote from Wilde, a vision of the world like the one premised in this book is worth no more of a glance than one which offers no utopia at all. But an alternative cannot be found through turning our back on the world. Our task, overall, is to remake the cosmopolitan vision supporting global LGBTQ solidarity - to think otherwise about the scalar relation between a world of mes and a world of oppressed others. Following Mignolo (2000:724), a sufficiently critical cosmopolitan stance begins from the 'exteriority of modernity'. But this is easier said than done. Neoliberalism colonizes 
the interiority of individuals in the current day, and thus makes reaching an exteriority rather difficult. For Western queers, the intersubjective act of living a queer life - orienting to a sexual orientation, granting meaning to the body as an 'eroticized site' (Bucholtz and Hall 2004) - nowadays only follows from equality's mediatization. For the most part, it only comes after we have already sought out love, equality, and pride as material-semiotic products in the global marketplace. There is no reason to believe that media's role in scaling and thereby containing queer identity and LGBTQ equality will recede any time soon. And here lies the pressing question: how else might we imagine equality?

If discourses of LGBTQ affirmation are really part of the problem facing many of the world's underprivileged and marginalized queers - an intrinsically alluring, and hence productive element of neoliberal governmentality - they should no doubt be replaced, no matter how good it feels to be affirmed. However, it is important that a critique of affirmation gets us somewhere, or at least takes us beyond the ersatz equality described here - equality for some the 'fake futurity' Muñoz speaks of. It remains to be seen what exactly they could be replaced by. I fall short of offering a precise recommendation here. However, in closing this book, I wish to suggest that the current arrangements of the global queer semioscape can be re-purposed - and in their re-purposing, can fix our relation to the horizon as a permanent becoming, rather than a becoming we've arrived at. In a 'queer alliance' based on an 'ethics of cohabitation' (Butler 2015:70), we can ditch a hollow, commodified 'language of love', and focus in more profound ways on reshaping the material, affective and semiotic creation of 'pride'. We can build a pride to be truly proud of.

\section{'... with pride': Hopeful chronotopes, affective attachments, and global heterotopia}

In his seminal paper from 1983, 'Capitalism and Gay Identity', John D’Emilio highlighted a fundamental contradiction between capitalism and the bonds of family: on the one hand, capitalism weakens the family as a structuring framework, enabling life outside the heteronormative order. On the other, capitalism is reliant on the reproduction of workers via institutions like the heterosexual family - or in more strident, poststructuralist terms, perhaps, on reproducing 'willing slaves of capital' one way or the other (Lordon 2014). (A family such as Chad and Scott's works just as well.) This fundamental contradiction lies under the surface of this book's analyses, and conclusions, in their entirety. How reliant on capitalism is any contemporary understanding of 'gayness' or 'queerness'? And with regard to this book's arguments, how does this dampen hopes of building queer alliance, or obstruct forms of global queer mobility (textual and embodied) which imagine equality differently? A pride to be proud of cannot begin, unless we untangle ourselves from mediatized habitus (or at least try to), and unlearn a vocabulary built up from the get-go by the value-adding, sloganized word-things of contemporary queer subjectification (and distinction). 
In noting how 'we' as a community have created support networks that are 'freely chosen and nurtured', D'Emilio (1983:475) encouraged the development of an 'affectional community', that '[prefigures] the shapes of personal relationships in a society grounded in equality and justice rather than exploitation and oppression'. Suffice to say, the preceding analyses have shown how the hopeful chronotope invoked by D'Emilio's words has yet to come to pass. The building of affectional attachments has not followed D'Emilio's guidance (and of course, he could not have easily imagined the scope of recognition for queer people since the early 1980s). At a time when our profound bonds could ideally be grounded in anti-exploitation, they are instead so often themselves implicitly exploitative: materializing in inarguable, iterative slogans and commercialized rhetorics about coming together 'with pride', which scale my love, joy and defiance as a non-performative improvement to the status quo of millions of oppressed others.

In the Castro, where this book began, pizza is 'served with pride'. Through \#HoldTight, I am told to 'walk with pride'. At London Pride 2016, Tesco told me and others to spread word that we (or indeed, the company) are 'bursting with pride'. Colgate told me I could 'smile with pride'. And so on. Do it all, '... with pride'. But this is not enough. We can go without 'out'. We can appreciate forms of 'fabulous' identity 'sashaying' worldwide without demanding them through globalized media. We can take pride, but not 'with pride'. To do so, I suggest, we can re-purpose these rhetorics in all their contradiction. Capitalizing on the inherent contradiction of queer identity, enlivened by the conditions that demand its suppression, and expanding the scale of what I witnessed at Spectrum, we can rework this contradiction into a form of global heterotopia.

If a contradiction lies at the heart of queer identity, then contradictory sites, scales and sources of intersubjectivity can form the basis of queer alliance. I follow from Milani and Levon (2019:625) here, whose description of Israel as a 'homotopia' captures it as 'a space of ambiguous juxtapositions where [Palestinian gay men] feel simultaneously attached and unmoored, liberated and deeply constrained'. Where Spectrum was an unequal site, framed as otherwise, a global heterotopia can be an unequal site, framed as otherwise, reframed as unequal: a site of constant un/moooring, of constraint and liberation. Importantly, the heterotopia I envision is not a site of liberation through discursive strategies like affective legitimation, but liberation from discursive order itself. It signifies freedom from the constraining, normative conditions of mediatized life, through an iterative rejection of the ways we are compelled to dislodge the word 'equality' from the deed of making the world more equal and fair. Like Israel for the men in Milani and Levon's study, a global heterotopia would be a space that 'claws and gnaws' (Foucault 1986:23) as well as comforts: a place where \#LoveTravels, but where attention to the venal nature of the global queer semioscape can just as easily hail us and make us say, 'fuck that'. Our love is not your resource. This heterotopia is a queer time and space confined to our imaginations - where we can find space to breathe in the 
present, as well as uphold queerness as 'collective temporal distortion' (Muñoz 2009). In our pride and appreciation within the here and now, we can reject it, and thus commit 'acts of hope', following Borba (2019), which 'disrupt established oppressive orders by creating a sense of possibility, of a reconfigured present and of a future that has no place as of yet, but can acquire one' (Borba 2019:174). But it is vital that that such acts uphold collective hope, and a hope grounded in what is absent in the present - the not-quite-conscious - rather than present in the future.

To reject a fake futurity in becoming today is to 'create a new future' (Heller and McElhinny 2017). A new form of enworlding. Pride is thus viable as cosmopolitan action, a collective practice of hope (not individual aspiration) functioning as a 'radical reorientation of knowledge' (Miyazaki 2004:5, following Borba 2019), rather than its individualization - its quelling. The imperfect, dissolved scale of progress currently drawn from innermost subjectivity to infinite prosperity means that D'Emilio's 'affectional community' can only come about through reconfiguring our use of it. Put simply, reducing reliance on this scale would let us step away from a totalizing neoliberalism, and find meaningful ways to say 'fuck no', or in broad terms, 'fuck neoliberalism' (see Springer 2016).

The fact that neoliberalism so readily incorporates non-normative orientations and practices - to put it bluntly, non-normative ways of fucking (cf. Milani 2018) - makes it difficult to find ways to say this. The neoliberal chronotope upheld within 'global homocapitalism' is innately appealing. Hard to resist. And although it is right to reject such a template for living, all queer struggle still needs something to aspire to. As Ahmed (2010:120) puts it,

we need to think more about the relationship between the queer struggle for a bearable life and aspirational hopes for a good life ... it is hard to struggle without aspirations, and aspirations are hard to have without giving them some form.

Ahmed goes on to point out that 'aspire', etymologically, derives from a way to describe breathing - a basic sign of life. And perhaps that is all we need, and all we should aspire for - to breathe. Alongside, we must question how and why we might be asked to burst, smile or walk 'with pride', as well. To answer the question above, perhaps the best way to imagine equality is simply as a mode of scaling down, and finding space to breathe; we may opt to party at pride, sweat on a dancefloor or engage in a rainbow 'pilgrimage', certainly, but this must never be the full aspiration. Basking in affective attachments can be the goal, in an active opposition to their resemiotization and (re)deployment as resources for Muñoz's 'pragmatic presentism': neoliberalism's offer of ersatz equality, here and now, for individuals.

Perhaps this is a limited, modest goal - a failure to 'dream bigger' than the routine, collegial, and generally uncompetitive world of the everyday. In a contradictory way, given how seemingly joyful the mediatization of equality is, this failure also reflects, like being a 'killjoy', a spoilsport tendency of queer 
theory, a willingness to be an 'affect alien' who ruins others' fun (Ahmed 2010). But in fact, this is a 'failure' to revel in - a falling short of grand teleological narratives, in favour of a simple, bearable, breathing life (Halberstam 2011). Any grand scale of cosmopolitan (lite) aspiration must be refused, in favour of something simpler: inwardly oriented, but committed to transnational justice. As Ahmed (2010:120) continues: "with breath comes possibility ... if queer politics is about freedom, it might simply mean the freedom to breathe'. Following Springer (2016:286) it is 'precisely in the everyday, the ordinary, the unremarkable, and the mundane' that a politics of refusal - fuck neoliberalism must be located. Utopia, rather than a transcendental promise, can thus be rescaled in the glory of breathing freely, and in knowing others breathe freely. Rather than being scaled at the glory of globalist consumer citizenship and a great 'beyond' evidenced by \#LoveTravels and all that has followed on in this book, utopia can be found just around the corner - in a constant drive to make our collective identity a space for all, where all are treated fairly. Our insolvent and precarious era means it is time, more than ever, to draw new scales. To imagine new ways to aspire. To think 'equality' otherwise. Only then will we move toward a bright future for global queerness as an everlasting state of becoming, as a genuine convivial collective engaged in a perpetual demand not for more and more, not for the world, but for just enough.

\section{Notes}

1 Muñoz uses the term 'not quite conscious' where many translations of Bloch's original German use 'not yet conscious'. Informed as I am by Muñoz's reading, rather than Bloch directly, I use his term here. However, see Borba (2019) for further discussion and application of Bloch's theory within a sociolinguistic framework, focused on hope as a driving force of social agency.

2 See Milani and Levon (2019) for an enlightening account of the relation of Bakhtin's chronotope to Foucault's (1986) découpage du temps, the nuanced detail of which is unfortunately absent in my own discussion. 
$\Longrightarrow$ Taylor \& Francis

Taylor \& Francis Group

http://taylorandfrancis.com 


\section{Melbourne, August 2020}

Don't travel with pride. Take pride in staying still. Staying home.

This is, it should be noted, quite the time to have written a book about tourism and global mobility. But it is more important to note how the profound immobility of the world today as a result of the COVID-19 pandemic brings its own forms of turbulence. There is a great deal to be concerned about.

Regardless of its topic, this has been a difficult year to complete a book. Every new day seems to bring a new reason to despair, to grieve, to be infuriated by the short-sightedness, greed, narcissism, misguidedness, and hate of so many. (And so many in power.)

It is hard not to feel like we are hurtling toward catastrophe, even while we're all stuck at home.

(And I am, of course, far less 'stuck' and far more privileged than most. I have a home. It is safe. I am loved.)

I sit in my bedroom in locked-down Melbourne, separated from my partner in Europe for I'm-not-sure-how-long, thankful that my mum lives within $5 \mathrm{~km}$ of my own home, desperately missing bars, clubs, parties, the beach, long bike rides, the frisson of a new passport stamp.

I miss it all. But it is gone now. We have in fact moved, to a new time, a new place: the beginning of the world after this virus. But which virus?

Without trying to be too clever, it is valuable to recall Tim Cresswell's description of mobility itself from a number of years ago: 'both centre and margin - the lifeblood of modernity and the virus that threatens to hasten its downfall' (Cresswell 2006:21).

The urge to move, its realization and the socioeconomic changes that accommodate this urge - mobility - are in Cresswell's terms the foundations of the modern world, but also that which most threatens to tear those foundations down. To cause the world to fall ill, casting it and us asunder. At the very least, mobility begets turbulent times: imbalance, disruption, discord, inequality. In short, mobility begets the uneven transnational flows that I've written about in this book, and the media that facilitate those flows and propel them onward.

However, this pandemic and its immobile lifestyle (a laudable, fraternal immobility, to be sure) also beget its own forms of media. Those media maintain their ability to shape our habitus: our dispositions, our orientations, and our fabulous lives.

June came and went - I think? - and with it the normative practices of Euro-Atlantic pride months. But in turbulent times, it is still possible to wear your pride - scrolling 
Instagram and Twitter, I am shown ads for masks of countless designs. Some say 'born to love'. Some say 'be kind'. The rainbow is (unsurprisingly) ubiquitous. Many raise funds for organizations providing for those in the community who need care. One I have seen shows a fist raised high, the sine qua non sign of racial justice.

And in fairness, it is only fair that you may wear your pride while taking to the streets in protest, fighting for justice. There is probably no better time to do it, no better way to do so. This is, in fact, pride to be proud of.

But an ad for the Australian car insurance company AAMI also pops up on my social media feed. It features two drag queens, 'teaching you how to take your mask from drab to fab'... 'so they're fit for a queen' ... '[with] fabulous feathers, fierce flowers, stunning sequins' ... and so on.

\section{Stay Safe and Stay Sparkly! Yaaaassss!}

\section{(andtag@AAMI_Insurance)}

Which isn't to say crafting a fab mask isn't fun, nor that AAMI can't offer us ideas on how to occupy our time in lockdown having fewer car accidents, nor that those drag queens don't need work... All of those things are true. Above all else, I hope that this book has offered a nuanced critique of the intrusion of corporate logics and mediatized practices into the simple living of a queer life.

But it is also true that this is, in my view, an intrusion. And as Cresswell has noted, writing in the wake of COVID-19, turbulence is not necessarily a bad thing ... 'but a positive and creative moment that can occur when that which is mostly taken-for-granted becomes suddenly visible' (Cresswell 2020).

It is good that ersatz equality is made visible, in this turbulent time.

The mediatization of equality is both a natural, intersubjective process which brightens up queer life, and a threat to the viability of substantive (material) equality in the long term. It is a lifeblood, and a virus. We can and should 'move' elsewhere.

If equality has until now been wrapped up in mobility, what happens when we all stand still? And how can that standing still create the new future we need, founded on the fight for a fairer present? How can we continue to strive for - to reach for, to struggle for-enough? For all?

I don't have the answer, but now is not the time to take mobility for granted, or take freedom for granted. Nor to confuse them with what they're not.

The equality we seek can only be won when we all have enough room to breathewhen we can all breathe freely, masks on or off, whether they're drab or fab.

And it must be fought for, even when we are all standing still. 


\section{References}

Adams, T., Holman Jones, S. and Ellis, C. (2014) Autoethnography. Oxford University Press. Agha, A. (2007) Language and Social Relations. Cambridge University Press. https://doi.org /10.1017/CBO9780511618284

Agha, A. (2011a) Large and small scale forms of personhood. Language and Communication 31(3): 171-180. https://doi.org/10.1016/j.langcom.2011.02.006

Agha, A. (2011b) Meet mediatization. Language and Communication 31(3): 163-170. https:/ /doi.org/10.1016/j.langcom.2011.02.006

Ahmed, S. (2004) Affective economies. Social Text 79(22): 117-139. https://doi.org/10.1 215/01642472-22-2_79-117

Ahmed, S. (2007) The language of diversity. Ethnic and Racial Studies 30(2): 235-256. https ://doi.org/10.1080/01419870601143927

Ahmed, S. (2010) The Promise of Happiness. Duke University Press. https://doi.org/10.1215 19780822392781

Ahmed, S. (2012) On Being Included: Racism and Diversity in Educational Life. Duke University Press. https://doi.org/10.1215/9780822395324

Ahmed, S. (2014) The Cultural Politics of Emotion. 2nd ed. Routledge. https://doi.org/10 $.4324 / 9780203700372$

Aiello, G. (2012) All Tögethé $®$ now: The recontextualization of branding and the stylization of diversity in EU public communication. Social Semiotics 22(4): 459-486. https://doi .org/10.1080/10350330.2012.693291

Aiello, G. and Pauwels, L. (2014) Difference and globalization. Visual Communication 13(3): 275-285. https://doi.org/10.1177/1470357214533448

Aiello, G. and Woodhouse, A. (2016) When corporations come to define the visual politics of gender: The case of Getty Images. Journal of Language and Politics 15(3): 352-368. https://doi.org/10.1075/jlp.15.3.08aie

Althusser, L. (1971) Lenin and Philosophy. New Monthly Review Press.

Altman, D. (1996) Rupture or continuity? The internationalization of gay identities. Social Text 48(3): 77-94. https://doi.org/10.2307/466787

Altman, D. (1997) Global gaze/global gays. GLQ: A Journal of Gay and Lesbian Studies 3: 417-436. https://doi.org/10.1215/10642684-3-4-417

Anaïs, S. (2013) Genealogy and critical discourse analysis in conversation: Texts, discourse, critique. Critical Discourse Studies 10(2): 123-135. https://doi.org/10.1080/17405904.20 12.744321

Anderson, B. (1991) Imagined Communities: Reflections on the Origin and Spread of Nationalism. Verso.

Anderson, L. (2006) Analytic autoethnography. Journal of Contemporary Ethnography 35(4): 373-395. 
Anzaldúa, G. (1991) To(o) queer the writer: Loca, escrita y chicana. In B. Warland (ed.) InVersions: Writing by Dykes, Queers and Lesbians. Press Gang.

Appadurai, A. (1996) Modernity at Large: Cultural Dimensions of Globalization. University of Minnesota Press.

Appadurai, A. (2001) Grassroots globalization and the research imagination. Public Culture 12(1): 1-19. https://doi.org/10.1215/08992363-12-1-1

Appleby, R. and Pennycook, A. (2017) Swimming with sharks, ecological feminism and posthuman language politics. Critical Inquiry in Language Studies 14(2-3): 239-261. https ://doi.org/10.1080/15427587.2017.1279545

Awondo, P., Geschiere, P. and Reid, G. (2012) Homophobic Africa? Toward a more nuanced view. African Studies Review 55: 145-168. https://doi.org/10.1017/S00020206 00007241

Badgett, M.V.L, Nezhad, S., Waaldijk, K. and van der Meulen Rodgers, Y. (2014) The Relationship Between LGBT Inclusion and Economic Development: An Analysis of Emerging Economies. The Williams Institute.

Baker, P. (2005) Public Discourses of Gay Men. Routledge. https://doi.org/10.4324 19780203643532

Bakhtin, M. (1968) Rabelais and His World. Indiana University Press.

Bakhtin, M. (1981) The Dialogic Imagination: Four Essays (ed. M. Holquist). University of Texas Press.

Banet-Weiser, S. and Lapansky, C. (2008) RED is the new black: Brand culture, consumer citizenship and political possibility. International Journal of Communications 2: $1248-1268$.

Barrett, R. (2002) Is queer theory important for sociolinguistic theory? In Campbell-Kibler, L., Podesva, R.J., Roberts, S.J. and Wong, A. (eds.) Language and Sexuality: Contesting Meaning in Theory and Practice. Stanford, CA: CSLI.

Barrett, R. (2003) Models of gay male identity and the marketing of 'gay language' in foreign-language phrasebooks for gay men. Estudios de Sociolingüistica 4(2): 533-562.

Bauman, Z. (1998) Globalization: The Human Consequences. Polity.

Bauman, Z. (2000) Liquid Modernity. Polity.

Bauman, Z. (2003) Liquid Love: On the Frailty of Human Bonds. Polity.

Bell, A. (1984) Language style as audience design. Language in Society 13(2): 145-204. https ://doi.org/10.1017/S004740450001037X

Bell, A. (2001) Back in style: Reworking audience design. In P. Eckert and J. Rickford (eds.) Style and Sociolinguistic Variation. Cambridge University Press. https://doi.org/10.1 017/CBO9780511613258.010

Bell, D. and Binnie, J. (2000) The Sexual Citizen: Queer Politics and Beyond. Polity.

Bell, D. and Binnie, J. (2004) Authenticating queer space: Citizenship, urbanism and governance. Urban Studies 41(9): 1807-1820. https://doi.org/10.1080/00420980420 00243165

Benedicto, B. (2014) Under Bright Lights: Gay Manila and the Global Scene. University of Minnesota Press.

Bennett, S. (2017) Whose line is it anyway? The diffusion of discursive frames in Pride movements of the South. Journal of Language and Politics 16(3): 345-366. https://doi.org /10.1075/jlp.16008.ben

Benschop, Y. (2001) Pride, prejudice and performance: Relations between HRM, diversity and performance. International Journal of Human Resource Management 12(7): 1166-1181. https://doi.org/10.1080/09585190110068377 
Berlant, L. and Warner, M. (1995) What does queer theory teach us about X? PMLA: Publications of the Modern Language Association of America 110(3): 343-349. https://doi.org /10.1632/S003081290005937X

Berrey, E. (2015) The Enigma of Diversity: The Language of Race and the Limits of Racial Justice. University of Chicago Press. https://doi.org/10.7208/9780226246376

Billig, M. (1995) Banal Nationalism. SAGE. https://doi.org/ 10.4135/9781446221648

Binnie, J. (2004) The Globalization of Sexuality. SAGE. https://doi.org/. $10.4135 / 9781446218341$

Binnie, J. and Skeggs, B. (2004) Cosmopolitan knowledge and the production and consumption of sexualized space: Manchester's gay village. The Sociological Review 39-61. https://doi.org/10.1111/j.1467-954X.2004.00441.x

Block, D. (2018) Political Economy and Sociolinguistics: Neoliberalism, Inequality and Social Class. Bloomsbury. https://doi.org/10.5040/9781474281478

Block, D., Gray, J. and Holborow, M. (2012) Neoliberalism and Applied Linguistics. Routledge. https://doi.org/10.4324/9780203128121

Blommaert, J. (2005) Discourse: A Critical Introduction. Cambridge University Press. https:// doi.org/10.1017/CBO9780511610295

Blommaert, J. (2010) The Sociolinguistics of Globalization. Cambridge University Press. https://doi.org/10.1017/CBO9780511845307

Blommaert, J. (2013) Ethnography, Superdiversity and Linguistic Landscapes: Chronicles of Complexity. Multilingual Matters. https://doi.org/10.21832/9781783090419

Bockman, J. (2012) The political projects of neoliberalism. Social Anthropology 20(3): 310-317.

Boelstorff, T. and Leap, W. (2004) Introduction: Globalization and 'new' articulations of desire. In Leap, W. and Boellstorff, T. (eds.) Speaking in Queer Tongues: Globalization and Gay Language. University of Illinois Press.

Borba, R. (2019) Injurious signs: The geopolitics of hate and hope in the linguistic landscape of a political crisis. In Peck, A., Stroud, C. and Williams, Q. (eds.) Making Sense of People and Place in Linguistic Landscape. Bloomsbury. https://doi.org/ http://dx.doi.org /10.5040/9781350037977.ch-010

Bourdieu, P. (1990) The Logic of Practice. Polity.

Bourdieu, P. (1991) Language and Symbolic Power. Polity.

Bourdieu, P. and Wacquant, L. (1992) An Invitation to Reflexive Sociology. Polity.

Bourdieu, P. and Wacquant, L. (2001) Commentary: NewLiberal speak: Notes on the new planetary vulgate. Radical Philosophy 105: 2-5.

Breeze, R. (2012) Legitimation in corporate discourse: Oil corporations after Deepwater Horizon. Discourse and Society 23(1): 3-18. https://doi.org/10.1177/0957926511431511

Brett, P., Wood, E. and Thomas, G. (eds.) (1994) Queering the Pitch: The New Gay and Lesbian Musicology. Routledge. https://doi.org/10.4324/9780203944189

Brim, M. (2020) Poor Queer Studies: Confronting Elitism in the University. Duke University Press. https://doi.org/10.1215/9781478009146

Brown, G. (2009) Thinking beyond homonormativity: Performative explorations of diverse gay economies. Environment and Planning A 41: 1496-1510. https://doi.org/10.1068/a4162

Brown, G. (2012) Homonormativity: A metropolitan concept that denigrates "ordinary" gay lives. Journal of Homosexuality 59(7): 1065-1072. https://doi.org/10.1080/00918369 .2012 .699851

Brown, W. (2005) Neoliberalism and the end of liberal democracy. In W. Brown (ed.) Edgework: Critical Essays on Knowledge and Politics. Princeton University Press. https://doi .org/10.1515/9781400826872 


\section{References}

Browne, K. (2006) Challenging queer geographies. Antipode 38: 885-93. https://doi.org /10.1111/j.1467-8330.2006.00483.x

Browne, K. and Nash, C. (2010) Queer methods and methodologies: An introduction. In K. Browne and C. Nash (eds.) Queer Methods and Methodologies: Intersecting Queer Theories and Social Science Research. Ashgate. https://doi.org/10.4324/9781315603223

Brubaker, R. and Cooper, F. (2000) Beyond 'identity'. Theory and Society 29: 1-47. https:// doi.org/10.1023/A:1007068714468

Bruns, A. and Stieglitz, S. (2012) Quantitative approaches to comparing communication patterns on Twitter. Journal of Technology in Human Services 30(3-4): 160-185. https://do i.org/10.1080/15228835.2012.744249

Bucholtz, M. and Hall, K. (2004) Theorizing identity in language and sexuality research. Language in Society 33: 469-515. https://doi.org/10.1017/S0047404504334020

Bucholtz, M. and Hall, K. (2016) Embodied sociolinguistics. In N. Coupland (ed.) Sociolinguistics: Theoretical Debates. Cambridge University Press. https://doi.org/10.1017 /CBO9781107449787

Butler, J. (1990) Gender Trouble: Feminism and the Subversion of Identity. Routledge. https:// doi.org/10.4324/9780203824979

Butler, J. (1993) Critically queer. GLQ 1(1): 17-32. https://doi.org/10.1215/10642684-1 $-1-17$

Butler, J. (1997a) Excitable Speech: A Politics of the Performative. Routledge. https://doi.org /10.4324/9780203948682

Butler, J. (1997b) Merely cultural. New Left Review 227: 33-44. https://doi.org/10.2307 $/ 466744$

Butler, J. (2015) Notes Toward a Performative Theory of Assembly. Harvard University Press. https://doi.org/10.4159/9780674495548

Caldas-Coulthard, C. (2008) Body branded: Multimodal identities in tourism advertising. Journal of Language and Politics 7(3): 451-470. https://doi.org/10.1075/jlp.7.3.06ros

Cameron, D. (2000) Styling the worker: Gender and the commodification of language in the globalized service economy. Journal of Sociolinguistics 4(3): 323-347. https://doi.org /10.1111/1467-9481.00119

Cameron, D. (2011) Sociophonetics and sexuality: Discussion. American Speech 86(1): 98103. https://doi.org/10.1215/00031283-1277537

Cameron, D. and Kulick, D. (2003) Language and Sexuality. Cambridge University Press. https://doi.org/10.1017/CBO9780511791178

Cameron, D., Fraser, E., Harvey, P., Rampton, B. and Richardson, K. (1999) Power/ knowledge: The politics of social science. In N. Coupland and A. Jaworski (eds.) The Discourse Reader. Routledge.

Cammaerts, B (2015) Neoliberalism and the post-hegemonic war of position: The dialectic between invisibility and visibilities. European Journal of Communication 30(5): 522-538. https://doi.org/10.1177/0267323115597847

Carling, J. (2002) Migration in the age of involuntary immobility: Theoretical reflections and Cape Verdian experiences. Journal of Ethnic and Migration Studies 28(1): 5-42. https:/ /doi.org/10.1080/13691830120103912

Carpenter, C.S. and Eppink, S.T. (2017) Does it get better? Recent estimates of sexual orientation and earnings in the United States. Southern Economic Journal 84: 426-441. https://doi.org/10.1002/soej.12233

Carr, E.S. and Lempert, M. (2016) Introduction: Pragmatics of scale. In E.S Carr and M. Lempert (eds.) Scale: Discourse and Dimensions of Social Life. University of California Press. https://doi.org/10.1525/luminos.15 
Cavanaugh, J. and Shankar, S. (2014) Producing authenticity in global capitalism: Language, materiality, and value. American Anthropologist 116: 51-64. https://doi.org/10.1111/ aman. 12075

Chasin, A. (2000) Selling Out: The Gay and Lesbian Movement Goes to Market. St. Martin's Press.

Chirrey, D. (2003) 'I hereby come out': What sort of speech act is coming out? Journal of Sociolinguistics 7(1): 24-37. https://doi.org/10.1111/1467-9481.00209

Chouliaraki, L. (2006) The Spectatorship of Suffering. SAGE. https://doi.org/10.4135 19781446220658

Chouliaraki, L. (2010) Post-humanitarianism: Humanitarian communication beyond a politics of pity. International Journal of Cultural Studies 13(2): 107-126. https://doi.org/10 $.1177 / 1367877909356720$

Chouliaraki L (2012) The theatricality of humanitarianism: A critique of celebrity advocacy. Communication and Critical/Cultural Studies 9(1): 1-21. https://doi.org/10.1080/147914 20.2011.637055

Chouliaraki L (2013) The Ironic Spectator: Solidarity in the Age of Post-Humanitarianism. Polity.

Christensen, M. and Jansson, A. (2015) Cosmopolitanism and the Media: Cartographies of Change. Palgrave Macmillan. https://doi.org/10.1057/9780230392267

Chun, C.W. (2016) Exploring neoliberal language, discourses and identities. In S. Preece (ed.) The Routledge Handbook of Language and Identity. Routledge. https://doi.org/10.4 324/9781315669816.ch35

Ciszek, E.L. (2017) Activist strategic communication for social change: A transnational case study of lesbian, gay, bisexual, and transgender activism. Journal of Communication 67(5): 702-718. https://doi.org/10.1111/jcom.12319

Colgan, F. (2011) Equality, diversity and corporate responsibility: Sexual orientation and diversity management in the UK private sector. Equality, Diversity and Inclusion: An International Journal 30(8): 719-34. https://doi.org/10.1108/02610151111183225

Comaroff, J. and Comaroff, J.L. (2012) Theory from the South: Or, How Euro-America Is Evolving toward Africa. Routledge. https://doi.org/10.4324/9781315631639

Comer, J. (in preparation) Event ethnography: A 'messy' methodology for studying events as texts. Submitted to Critical Discourse Studies.

Coupland, N. and Kristiansen, T. (2011) SLICE: Critical perspectives on language (de) standardisation. In T. Kristiansen and N. Coupland (eds.) Standard Languages and Language Standards in a Changing Europe. Novus Press.

Crenshaw, K. (1991) Mapping the margins: Intersectionality, identity politics, and violence against women of color. Stanford Law Review 43: 1241-1279. https://doi.org/10.2307 /1229039

Cresswell, T. (2006) On the Move: Mobility in the Modern Western World. Routledge. https:// doi.org/10.4324/9780203446713

Cresswell, T. (2010) Towards a politics of mobility. Environment and Planning D 28: 17-31. https://doi.org/10.1068/d11407

Cresswell, T. (2020, March 18) Mobility: The lifeblood of modernity and the virus that threatens to undo it. Forum Vies Mobiles. https://en.forumviesmobiles.org/printfvm $/ 13266$

Cruz-Malavé, A. and Manalansan IV, M.F. (ed.) (2002) Queer Globalizations: Citizenship and the Afterlife of Colonialism. NYU Press. https://doi.org/10.18574/9780814790182

Currid, B. (1995) We are family: House music and queer performativity. In S.E. Case, P. Brett and S. Foster (eds.) Cruising the Performative: Interventions into the Repression of Ethnicity, Nationality and Sexuality. Indiana University Press. 


\section{References}

Dardot, P. and Laval, C. (2013) The New Way of the World: On Neoliberal Society. Verso.

Deacon, D. and Stanyer, J. (2014) Mediatization: Key concept or conceptual bandwagon? Media Culture and Society 36(7): 1032-1044. https://doi.org/10.1177 /0163443714542218

de Certeau, M. (1984) The Practice of Everyday Life. University of California Press.

D’Emilio, J. (1983) Capitalism and gay identity. In A. Snitow, C. Stansell, and S. Thompson (eds.) Powers of Desire: The Politics of Sexuality. Monthly Review.

Del Percio, A. and Sokolovska, Z. (2016) Discourses of diversity. Language and Communication 51: 1-4. https://doi.org/10.1016/j.langcom.2016.07.007

Deleuze G. and Guattari F. (1987) A Thousand Plateaus: Capitalism and Schizophrenia. University of Minnesota Press.

Djonov, E. and Knox, J.S. (2014) How to analyse webpages. In S. Norris and C.D. Maier (eds.) Interactions, Images and Texts: A Reader in Multimodality. De Gruyter Mouton. https://doi.org/10.1515/9781614511175

Du Bois, J.W. (2007) The stance triangle. In Englebretson, R. (ed.) Stancetaking in Discourse: Evaluation, Interaction. John Benjamins. https://doi.org/10.1075/pbns.164.07du

Duchêne, A. and Heller, M. (2012) Language in Late Capitalism: Pride and Profit. Routledge. https://doi.org/10.4324/9780203155868

Duggan, L. (2003) The Twilight of Equality: Neoliberalism, Cultural Politics and the Attack on Democracy. Beacon Press.

Dunmire, P. (2005) Preempting the future: Rhetoric and ideology of the future in political discourse. Discourse and Society 16(4): 481-513.

Duranti, A. (1997) Journal of Linguistic Anthropology. Cambridge University Press. https://doi .org/10.1017/CBO9780511810190

Duranti, A. and Goodwin, C. (eds.) (1992) Rethinking Context: Language as an Interactive Phenomenon. Cambridge University Press.

Edelman, L. (2004) No Future: Queer Theory and the Death Drive. Duke University Press. https://doi.org/10.1215/9780822385981

Edensor, T. (2001) Performing tourism, staging tourism: (Re)producing tourist space and practice. Tourist Studies 1: 59-81. https://doi.org/10.1177/146879760100100104

Ehrenreich, B. (2010) Smile or Die: How Positive Thinking Fooled America and the World. Granta.

Elder, G.S. (2004) Love for sale: Marketing gay male p/leisure space in contemporary Cape Town, South Africa. In L. Nelson and J. Seager (eds.) A Companion to Feminist Geography. Wiley-Blackwell. https://doi.org/10.1002/9780470996898.ch38

Escobar, A (1995) Encountering Development: The Making and Unmaking of the Third World. Princeton University Press. https://doi.org/10.1515/9781400839926

Evans, D. (1993) Sexual Citizenship: The Material Construction of Sexualities. Routledge. https://doi.org/10.4324/9780203412398

Evers, C. (2009) 'The point': Surfing, geography and a sensual life of men and masculinity on the Gold Coast, Australia. Social and Cultural Geography. 10(8): 893-908. https://doi .org/10.1080/14649360903305783

Fabrício, B.F., Borba, R., Lewis, E.S. and de Souza Pinto, D. (2014) Introduction: A queer postcolonial critique of (queer) knowledge production and activism. In E.S. Lewis, R. Borba, B.F. Fabrício, and D. de Souza Pinto (eds.) Queering Paradigms IV: South-North Dialogues on Queer Epistemologies, Embodiments and Activisms. Peter Lang. https://doi.org /10.3726/978-3-0353-0644-6

Fairclough, N. (1989) Language and Power. Longman.

Fairclough, N. (2001) Language and Power. 2nd ed. Longman.

Fairclough, N. (2002) Language in new capitalism. Discourse and Society 13(2): 163-166. 
Fairclough, N. (2003) Analysing Discourse. Routledge.

Farmer, B. (2005) The fabulous sublimity of gay diva worship. Camera Obscura 20(2): 165195. https://doi.org/10.1215/02705346-20-2_59-165

Faudree, P. and Schulthies, B. (2015) "Diversity talk" and its others. Language and Communication 44: 1-6. https://doi.org/10.1016/j.langcom.2015.01.004

Favero, P. (2007) 'What a wonderful world!': On the 'touristic ways of seeing', the knowledge and the politics of the 'culture industries of otherness'. Tourist Studies 7: 51-81. https://doi.org/10.1177/1468797607079804

Featherstone, M. (1991) Consumer Culture and Postmodernism. SAGE. https://doi.org/10 $.4135 / 9781446288399$

Ferguson, J. (2006) Global Shadows: Africa in the Neoliberal World Order. Duke University Press. https://doi.org/10.1215/9780822387640

Ferguson, J. (2010) The uses of neoliberalism. Antipode 41: 166-84. https://doi.org/10.1 111/j.1467-8330.2009.00721.x

Ferguson, R.A. (2008) Administering sexuality; or, the will to institutionality. Radical History Review 100: 158-169.

Field, N. (2016) Over the Rainbow: Money, Class, and Homophobia. 2nd ed. Dog Horn Publishing.

Florida, R. (2002) The Rise of the Creative Class and How it's Transforming Work, Leisure, Community and Everyday Life. Basic Books.

Foucault, M. (1972) The Archaeology of Knowledge. Routledge.

Foucault, M. (1978) The History of Sexuality (Vol. I). Random House.

Foucault, M. (1980) Power/Knowledge: Selected Interviews and Writings, 1972-1977. Pantheon.

Foucault, M. (1986) [1967] Of other spaces. Diacritics 16: 22-7.

Foucault, M. (2007) The Politics of Truth. Semiotext(e).

Franklin, A. (2003) The tourist syndrome: An interview with Zygmunt Bauman. Tourist Studies 3(2): 205-217. https://doi.org/10.1177/1468797603041632

Franklin, A. and Crang, M. (2001) The trouble with tourism and travel theory. Tourist Studies 1: 5-22. https://doi.org/10.1177/146879760100100101

Fraser, N. (1995) From redistribution to recognition? Dilemmas of justice in a 'postsocialist' age. New Left Review 212: 68-93.

Fraser, N. (2000) Social justice in the age of identity politics: Redistribution, recognition, and participation. In N. Fraser and A. Honneth (eds.) Redistribution or Recognition? A Political- Philosophical Exchange. Verso.

Frello, B. (2008) Towards a discursive analytics of movement: On the making and unmaking of movement as an object of knowledge. Mobilities 3(1): 25-50. https://doi.org/10.1080 /17450100701797299

Gal, N., Shifman, L. and Kampf, Z. (2016) "It Gets Better": Internet memes and the construction of collective identity. New Media and Society 18(8): 1698-1714.

Gal, S. (1989) Language and political economy. Annual Review of Anthropology 18: 345-367. https://doi.org/ 10.1146/annurev.an.18.100189.002021

Gal, S. (2016) Scale-making: Comparison and perspective as ideological projects. In E.S. Carr and M. Lempert (eds.) Scale: Discourse and Dimensions of Social Life. University of California Press. https://doi.org/10.1525/luminos.15

Gardner, B. (2017) Elite discourses of conservation in Tanzania. Social Semiotics 27(3): 348358. https://doi.org/10.1080/10350330.2017.1301799

Geertz, C. (1973) The Interpretation of Cultures. Basic Books.

Ghaziani, A. (2011) Post-gay collective identity construction. Social Problems 58(1): 99-125. https://doi.org/10.1525/sp.2011.58.1.99 
Giddens, A. (1984) The Constitution of Society. Polity.

Giddens, A. (1992) The Transformation of Intimacy: Sexuality, Love, and Eroticism in Modern Societies. Polity.

Gill, R. (2007) Postfeminist media culture: Elements of a sensibility. European Journal of Cultural Studies 10(2): 147-66. https://doi.org/10.1177/1367549407075898

Gill, R. (2009) Mediated intimacy and postfeminism: A discourse analytic examination of sex and relationships advice in a women's magazine. Discourse and Communication 3(4): 345-69. https://doi.org/10.1177/1750481309343870

Gill, R. and Kanai, A. (2018) Mediating neoliberal capitalism: Affect, subjectivity and inequality. Journal of Communication 68: 318-326. https://doi.org/10.1093/joc/jqy002

Gilroy, P. (2004) After Empire: Melancholia or Convivial Culture? Routledge.

Giorgi, G. (2002) Madrid en tránsito: Travelers, visibility and gay identity. GLQ: A Journal of Lesbian and Gay Studies 8(1-2): 57-80. https://doi.org/10.1215/10642684-8-1-2-57

Goebel, Z. and Manns, H. (2020) Chronotopic relations: Chronotopes, scale, and scalemaking. Language and Communication 70: 82-93. https://doi.org/10.1016/j.langcom.2 019.03 .002

Goffman, E. (1959) The Presentation of Self in Everyday Life. Doubleday.

Gogia, N. (2006) Unpacking corporeal mobilities: The global voyages of labour and leisure. Environment and Planning A 38: 359-375. https://doi.org/10.1068/a37274

Green, A.I. (2002) Gay but not queer: Toward a post-queer study of sexuality. Theory and Society 31(4): 521-545. https://doi.org/10.1023/A:1020976902569

Green, A.I. (2010) Remembering Foucault: Queer theory and disciplinary power. Sexualities 13(3): 316-337. https://doi.org/10.1177/1363460709364321

Gregson, N. and Rose, G. (2000) Taking Butler elsewhere: Performativities, spatialities and subjectivities. Environment and Planning D 18: 433-452.

Guaracino, J. (2007) Gay and Lesbian Tourism: The Essential Guide for Marketing. Oxford.

Gupta, A. and Ferguson, J. (1992) Beyond 'culture': Space, identity and the politics of difference. Cultural Anthropology 7(1): 6-23.

Halberstam, J. (2005) In a Queer Time and Place: Transgender Bodies, Subcultural Lives. New York University Press.

Halberstam (2011) The Queer Art of Failure. Durham, NC: Duke University Press.

Hall, K. (2013) 'It's a hijra!' Queer linguistics revisited. Discourse and Society 24(5): 634-642. https://doi.org/10.1177/0957926513490321

Halperin, D. (1995) Saint Foucault: Towards a Gay Hagiography. Oxford University Press.

Hanauer, D. (2013) Transitory linguistic landscapes as political discourses: Signage at three political demonstrations in Pittsburgh, USA. In C. Hélot, M. Barni, R. Janssens and C. Bagna (eds.) Linguistic Landscapes, Multilingualism and Social Change. Peter Lang.

Haritaworn, J., Tauqir, T. and Erdem, E. (2008) Gay imperialism: Gender and sexuality discourse in the "War on Terror." In Kuntsman, A. and Miyake, E. (eds.) Out of Place: Interrogating Silences in Queerness/Raciality. London: Raw Nerve Books.

Harvey, D. (1995) Globalization in question. Rethinking Marxism 8(4): 1-17. https://doi.org /10.1080/08935699508685463

Harvey, D. (2005) A Brief History of Neoliberalism. Oxford University Press.

Harvey, K. (2000) Describing camp talk: Language/pragmatics/politics. Language and Literature 9(3): 240-260. https://doi.org/10.1177/096394700000900303

Heller, M. (2003) Globalization, the new economy, and the commodification of language and identity. Journal of Sociolinguistics 7(4): 473-492. https://doi.org/10.1111/j.1467 $-9841.2003 .00238 . x$ 
Heller, M. (2010) The commodification of language. Annual Review of Anthropology 39: 101-114. https://doi.org/10.1146/annurev.anthro.012809.104951

Heller, M. and McElhinny, B. (2017) Language, Capitalism, Colonialism: Toward a Critical History. Toronto University Press.

Heller, M., Jaworski, A. and Thurlow, C. (2014) Introduction: Sociolinguistics and tourism: Mobilities, markets and multilingualism. Journal of Sociolinguistics 18(4): 425-458. https:// doi.org/10.1111/josl.12091

Heller, M., Pujolar, J. and Pietikäinen, S. (2018) Critical Sociolinguistic Research Methods: Studying Language Issues That Matter. Routledge.

Hennessy, R. (2000) Profit and Pleasure: Sexual Identities in Late Capitalism. Routledge. https://doi.org/10.4324/9781315270142

Heyd, T. and Puschmann, C. (2017) Hashtagging and functional shift: Adaptation and appropriation of the \#. Journal of Pragmatics 116: 51-63. https://doi.org/10.1016/j.prag ma.2016.12.004

Hickel, J. and Khan, A. (2012) The culture of capitalism and the crisis of critique. Anthropological Quarterly 85: 203-27. https://doi.org/10.1353/anq.2012.0003

Hilgers, M. (2013) Embodying neoliberalism: Thoughts and responses to critics. Social Anthropology 21(1): 75-89. https://doi.org/10.1111/1469-8676.12010

Hjarvard, S. (2013) The Mediatization of Culture and Society. Routledge. https://doi.org/10 $.4324 / 9780203155363$

Hoad, N. (2000) Arrested development or the queerness of savages: Resisting evolutionary narratives of difference. Postcolonial Studies 3(3): 354-354. https://doi.org/10.1080/1 3688790050115277

Holt, M. and Griffin, C. (2003) Being gay, being straight and being yourself: Local and global reflections on identity, authenticity and the lesbian and gay scene. European Journal of Cultural Studies 6(3): 404-425. https://doi.org/10.1177/13675494030063008

Hooks, B. (1992) Black Looks: Race and Representation. South End Press. https://doi.org/10 $.4324 / 9781315743226$.

Howe, A.C. (2001) Queer pilgrimage: The San Francisco homeland and identity tourism. Cultural Anthropology 16: 35-61. https://doi.org/10.1525/can.2001.16.1.35

Iqani, M. (2016) Consumption and Media in the Global South: Aspiration Contested. Palgrave Macmillan. https://doi.org/10.1057/9781137390134

Jaffe, A. (2009) Introduction: The sociolinguistics of stance. Stance: Sociolinguistic Perspectives. Oxford University Press. https://doi.org/ 10.1093/acprof:oso/9780195331646.003. 0001

Jagose, A. (1996) Queer Theory: An Introduction. NYU Press.

Järlehed, J. and Moriarty, M. (2018) Culture and class in a glass: Scaling the semiofoodscape. Language and Communication 62: 26-38. https://doi.org/10.1016/j.langcom.2018.05.003

Jaworski, A. (2015a) Globalese: A new visual-linguistic register. Social Semiotics 25(2): 217235. https://doi.org/10.1080/10350330.2015.1010317

Jaworski, A. (2015b) Word cities and language objects: 'Love' sculptures and signs as shifters. Linguistic Landscape 1(1/2): 75-94. https://doi.org/10.1075/11.1.1-2.05jaw

Jaworski, A. and Lou, J.J. (2020): \#wordswewear: mobile texts, expressive persons, and conviviality in urban spaces. Social Semiotics 31(1): 108-135. https://doi.org/10.1080/1 0350330.2020 .1810545

Jaworski, A. and Thurlow, C. (2009) Taking an elitist stance: Ideology and the discursive production of social distinction. In Jaffe, A. (ed.) Stance: Sociolinguistic Perspectives. Oxford University Press. https://doi.org/ 10.1093/acprof:oso/9780195331646.003.0009 
Jaworski, A. and Thurlow, C. (2010) Language and the globalizing habitus of tourism: Toward a sociolinguistics of fleeting relationships. In N. Coupland (ed.) The Handbook of Language and Globalization. Wiley-Blackwell. https://doi.org/10.1002/97814443240 68.ch11

Jaworski, A. and Thurlow, C. (2017) Mediatizing the 'super rich', normalizing privilege. Social Semiotics 27(3): 276-287. https://doi.org/10.1080/10350330.2017.1301792

Johnson, P. (2013) The geographies of heterotopia. Geography Compass 7(11): 790-803. https://doi.org/10.1111/gec3.12079

Jones, R. (2015) Generic intertextuality in online social activism: The case of the It Gets Better project. Language in Society 44(3): 317-339. https://doi.org/10.1017/S00474045 15000214

Jurafsky, D. (2014) The Language of Food: A Linguist Reads the Menu. W.W. Norton and Company.

Kaldor, M. (2003) Global Civil Society: An Answer to War. Polity.

Kaufmann, V., Bergman, M.M. and Joye, D. (2004) Motility: Mobility as capital. International Journal of Urban and Regional Research 28(4): 745-756. https://doi.org/10.1111/j.0309 $-1317.2004 .00549 . \mathrm{x}$

Kelly-Holmes, H. (2014) Linguistic fetish: The sociolinguistics of visual multilingualism. In D. Machin (ed.) Visual Communication. de Gruyter. https://doi.org/10.1515/978311 0255492.135

Kerr, R. (2008) Discourse and leadership: Using the paradigm of the permanent state of emergency. Critical Discourse Studies 5(3): 201-216. https://doi.org/10.1080/174059008 02131702

Koch, N. (2018) The geopolitics of sport beyond soft power: Event ethnography and the 2016 cycling world championships in Qatar. Sport in Society 21(12): 2010-2031. https:/ /doi.org/10.1080/17430437.2018.1487403

Koller, V. (2008) "Not just a colour": Pink as a gender and sexuality marker in visual communication. Visual Communication 7(4): 395-422. https://doi.org/10.1177 /1470357208096209

Koller, V. (2013) Constructing (non-)normative identities in written lesbian discourse: A diachronic study. Discourse and Society 24(5): 572-589. https://doi.org/10.1177 /0957926513486166

Kollman, K. and Waites, M. (2009) The global politics of lesbian, gay, bisexual and transgender human rights: An introduction. Contemporary Politics 15(1): 1-17. https://do i.org/10.1080/13569770802674188

Kress, G.R. and van Leeuwen, T. (2006) Reading Images: The Grammar of Visual Design. 2nd ed. London: Routledge. https://doi.org/10.4324/9781003099857

Krzyżanowski, M. (2011) Ethnography and critical discourse analysis: Towards a problemoriented research dialogue. Critical Discourse Studies 8: 231-238. https://doi.org/10.1080 $/ 17405904.2011 .601630$

Kulick, D. (2003) Language and desire. In J. Holmes and M. Meyerhoff (eds.) The Handbook of Language and Gender. Wiley-Blackwell. https://doi.org/10.1002/978047 0756942.ch5

Lash, S. and Lury, C. (2007) Global Culture Industry: The Mediation of Things. Polity.

Lash, S. and Urry, J. (1994) Economies of Signs and Spaces. SAGE. https://doi.org/10.4135 19781446280539

Law, J and Urry, J. (2004) Enacting the social. Economy and Society 33(3): 390-410. https:// doi.org/10.1080/0308514042000225716 
Lazar, M. (2014) Recuperating feminism, reclaiming femininity: Hybrid postfeminist I-dentity in consumer advertisements. Gender and Language 8(2): 205-224. https://doi .org/10.1558/genl.v8i2.205

Lazar, M. (2017) Homonationalist discourse as a politics of pragmatic resistance in Singapore's Pink Dot movement: Towards a southern praxis. Journal of Sociolinguistics 21(3): 420-441. https://doi.org/10.1111/josl.12239

Leap, W. (2015) Queer linguistics as critical discourse analysis. In Tannen, D., Hamilton, H. and Schiffrin, D. (eds.) The Handbook of Discourse Analysis. Wiley-Blackwell. https:// doi.org/10.1002/9781118584194.ch31

Lees, L. (2003) The ambivalence of diversity and the politics of urban renaissance: The case of youth in downtown Portland, Maine. International Journal of Urban and Regional Research 27(3): 613-34. https://doi.org/10.1111/1468-2427.00469

Lefebvre, H. (1991) The Production of Space. Wiley-Blackwell.

Lentin, A. and Titley, G. (2008) More Benetton than barricades: The politics of diversity in Europe. In G. Titley and A. Lentin (eds.) The Politics of Diversity in Europe. Strasbourg: Council of Europe.

Levon, E. and Mendes, R.B. (2016) (eds.) Language, Sexuality, and Power: Studies in Intersectional Sociolinguistics. Oxford University Press. https://doi.org/ 10.1093/acprof: oso/9780190210366.001.0001

Liang, A.C. (1997) The creation of coherence in coming out stories. In Livia, A. and Hall, K. (eds.) Queerly Phrased. Oxford University Press.

Littlewood, I. (2001) Sultry Climates: Travel and Sex Since the Grand Tour. De Capo Press.

Livermon, X. (2012) Queer(y)ing freedom: Black queer visibilities in post-apartheid South Africa. GLQ: A Journal of Gay and Lesbian Studies 18(2/3): 297-322. https://doi.org/10 $.1215 / 10642684-1472908$

Livia, A. and Hall, K. (eds.) (1997) Queerly Phrased. Oxford University Press.

Lorbiecki, A. and Jack, G. (2000) Critical turns in the evolution of diversity management. British Journal of Management 11:S17-S31. https://doi.org/10.1111/1467-8551.11.s1.3

Lordon, F. (2014) Willing Slaves Of Capital: Spinoza And Marx On Desire. Verso.

Lou, J. (2007) Revitalising Chinatown into a heterotopia. Space and Culture 10(2): 107-194. https://doi.org/10.1177/1206331206298547

Ludwig, G. (2016) Desiring neoliberalism. Sexuality Research and Social Policy 13(4): 417427. https://doi.org/10.1007/s13178-016-0257-6

MacCannell, D. (1976) The Tourist: A New Theory of the Leisure Class. Schocken.

Macgilchrist, F. (2016) Fissures in the discourse-scape: Critique, rationality and validity in post-foundational approaches to CDS. Discourse and Society 27(3): 262-277. https://doi .org/10.1177/0957926516630902

Machin, D. (2004) Building the world's visual language: The increasing global importance of image banks in corporate media. Visual Communication 3(3): 316-336. https://doi.org $/ 10.1177 / 1470357204045785$

Machin, D. (2013) What is multimodal critical discourse studies? Critical Discourse Studies 10(4): 347-355. https://doi.org/10.1080/17405904.2013.813770

Makoni, S. (2014) 'The Lord is my shock absorber': A sociohistorical integrationist approach to mid-twentieth-century literacy practices in Ghana. In Blackledge, A. and Creese, A. (eds.) Heteroglossia as Practice and Pedagogy. Springer. https://doi.org/10.1007/978-94 -007-7856-6_5

Manalansan, M. (1995) In the shadows of Stonewall: Examining gay transnational politics and the diasporic dilemma. GLQ 2(4):425-438. https://doi.org/10.1215/10642684-2-4-425 
Manalansan IV, M.F. (2005) Race, violence and neoliberal spatial politics in the global city. Social Text 84-85: 141-156. https://doi.org/10.1215/01642472-23-3-4_84-85 $-141$

Manalansan IV, M.F. (2015) Queer worlding: The messy art of being global in Manila and New York. Antipode 47(3): 566-579. https://doi.org/10.1111/anti.12061

Mapes, G. (2018) (De)constructing distinction: Class inequality and elite authenticity in mediatized food discourse. Journal of Sociolinguistics 22(3): 265-287. https://doi.org/10 $.1111 /$ josl.12285

Marcus, G.E. (1995) Ethnography in/of the world system: The emergence of multi-sited ethnography. Annual Review of Anthropology 24: 95-117. https://doi.org/10.1146/a nnurev.an.24.100195.000523

Markwell, K. and Waitt, G. (2009) Festivals, space and sexuality: Gay pride in Australia. Tourism Geographies 11(2): 143-68. https://doi.org/10.1080/14616680902827092

Martin, J.R. (2004) Positive discourse analysis: Power, solidarity and change. Revista Canaria de Estudios Ingleses 49: 179-202.

Martín Rojo, L. and Del Percio, A. (eds.) (2019) Language and Neoliberal Governmentality. Routledge. https://doi.org/10.4324/9780429286711

Massad, J.A. (2002) Re-orienting desire: The gay international and the Arab world. Public Culture 14(2): 361-385. https://doi.org/10.1215/08992363-14-2-361

Massey, D.B. (1994) Space, Place, and Gender. University of Minnesota Press.

McDermott, E. (2011) The world some have won: Sexuality, class and inequality. Sexualities 14: 63-78. https://doi.org/10.1177/1363460710390566

McGuigan, J. (2009) Cool Capitalism. Pluto Press.

McLuhan, M. (1964) Understanding Media. Routledge.

Mieli, M. (1980) Homosexuality and Liberation: Elements of a Gay Critique. London: Gay Men's Press.

Mignolo, W.D. (2000) The many faces of Cosmo-polis: Border thinking and critical cosmopolitanism. Public Culture 12(3): 721-48. https://doi.org/10.1215/08992363-12 $-3-721$

Milani, T. (2013) Expanding the queer linguistic scene: Multimodality, space and sexuality at a South African university. Journal of Language and Sexuality 2(2): 206-234. https://doi .org/10.1075/j1s.2.2.02mil

Milani, T. (2014) Sexed signs: Queering the scenery. International Journal of the Sociology of Language 228: 201-225. https://doi.org/10.1515/ijsl-2014-0011

Milani, T. (2015) Sexual citizenship: Discourses, spaces and bodies at Joburg Pride 2012. Journal of Language and Politics 14(3): 431-454. https://doi.org/10.1075/jlp.14.3.06mil

Milani, T. (2018) Is the rectum a goldmine? Queer theory, consumer masculinities, and capital pleasures. In Baker, P. and Balirano, G. (eds.) Queering Masculinities in Language and Culture. Palgrave Macmillan. https://doi.org/10.1057/978-1-349-95327-1_2

Milani, T. (forthcoming) Queer performativity. In Barrett, R. and Hall, K. (eds.). The Oxford Handbook of Language and Sexuality. Oxford University Press. https://doi.org/10 .1093/oxfordhb/9780190212926.013.15

Milani, T. and Kapa, K. (2015) Ready-to-wear sexual politics: The semiotics of visibility on wits pride T-shirts. Stellenbosch Papers in Linguistics 46: 79-103. https://doi.org/10 $.5842 / 46-0-671$

Milani, T. and Lazar, M. (2017) Seeing from the South: Discourse, gender and sexuality from southern perspectives. Journal of Sociolinguistics 21(3): 307-319. https://doi.org/10 .1111/josl.12241 
Milani, T. and Levon, E. (2016) Sexing diversity: Linguistic landscapes of homonationalism. Language and Communication 51: 69-86. https://doi.org/10.1016/j.langcom.2016.07 .002

Milani, T. and Levon, E. (2019) Israel as homotopia: Language, space, vicious belonging. Language in Society 48(4): 607-628. https://doi.org/10.1017/S0047404519000356

Miyazaki, H. (2004) The Method of Hope: Anthropology, Philosophy and Fijian Knowledge. Stanford University Press.

Modan, G. (2007) Turf Wars: Discourse, Diversity, and the Politics of Place. Blackwell.

Morozov, E. (2013) To Save Everything Click Here. Allen Lane.

Mosco, V. (2005) Digital Sublime: Myth, Power, and Cyberspace. MIT Press.

Motschenbacher, H. (2020) Walking on Wilton Drive: A linguistic landscape analysis of a homonormative space. Language and Communication 72: 25-43. https://doi.org/10.1016 /j.langcom.2020.02.002

Motschenbacher, H. (forthcoming) Language and sexual normativity. In Barrett, R. and Hall, K. (eds.) The Oxford Handbook of Language and Sexuality. Oxford University Press. https://doi.org/ 10.1093/oxfordhb/9780190212926.013.14

Motschenbacher, H. and Stegu, M. (2013) Queer linguistic approaches to discourse. Discourse and Society 24(5): 519-535. https://doi.org/10.1177/0957926513486069

Mowforth, M. and Munt, I. (2009) Tourism and Sustainability: Development and New Tourism in the Third World. 3rd ed. Routledge. https://doi.org/10.4324/9781315795348

Mühlmann, M. (2015) Slippery subjects: Intersecting economies of genre in comingout films, 1995-2015. In Conference Presentation at SAUTE: Economies of English, Université de Genève, Geneva, Switzerland. 24-25 April 2015.

Muñoz, J.E. (2009) Cruising Utopia: The Then and There of Queer Futurity. New York University Press. https://doi.org/10.18574/9781479868780

Murray, D. (2007) The civilized homosexual: Travel talk and the project of gay identity. Sexualities 10(1): 49-60. https://doi.org/10.1177/1363460707072953

$\mathrm{Ng}$, E. (2013) A 'post-gay' era? Media gaystreaming, homonormativity, and the politics of LGBT integration. Communication, Culture and Critique 6: 258-283.

Ní Mhaoileoin, N. (2017) The ironic gay spectator: The impacts of centring Western gay subjects in international LGBT rights campaigns. Sexualities 22(1-2): 148-164. https:// doi.org/10.1177/1363460717699778

Obrador-Pons, P. (2007) A haptic geography of the beach: Naked bodies, vision and touch. Social and Cultural Geography 8(1): 123-141. https://doi.org/10.1080/14649360701 251866

Ong, J.C. (2009) The cosmopolitan continuum: Locating cosmopolitanism in media and cultural studies. Media Culture and Society 31(3): 449-466. https://doi.org/10.1177 /0163443709102716

Oswin, N. (2005a) Researching gay Cape Town, finding value-added queerness. Social and Cultural Geography 6: 567-586. https://doi.org/10.1080/14649360500200304

Oswin, N. (2005b) Towards radical geographies of complicit queer futures. ACME: An International Journal for Critical Geographies 3(2): 79-86.

Oswin, N. (2007) The end of queer (as we knew it): Globalization and the making of a gay-friendly South Africa. Gender Place and Culture 14(1): 93-110. https://doi.org/10.1 080/09663690601122358

Oswin, N. (2014) Queer theory. In Adey, P., Bissell, D., Hannam, K., Merriman, P. and Sheller, M. (eds.) The Rouledge Handbook of Mobilities. Routledge. https://doi.org/10 $.4324 / 9781315857572$ 


\section{References}

Özler, B. (2007) Not separate, not equal: Poverty and inequality in post-apartheid South Africa. Economic Development and Cultural Change 55(3): 487-529. https://doi.org/10 $.1086 / 511191$

Page, R, (2012) Self-branding and micro-celebrity: The linguistic potential of hashtags. Discourse and Communication 6(2): 1-21. https://doi.org/10.1177/1750481312437441

Page, R. (2019) Group selfies and Snapchat: From sociality to synthetic collectivisation. Discourse, Context and Media 28: 79-92. https://doi.org/10.1016/j.dcm.2018.10.003

Pariser, E. (2011) The Filter Bubble. Penguin.

Park, J.S-Y. (2013) Metadiscursive regimes of diversity in a multinational corporation. Language in Society 42(5): 557-577. https://doi.org/10.1017/S0047404513000663

Park, J.S-Y. (2016) Language as pure potential. Journal of Multilingual and Multicultural Development 37(5): 453-466. https://doi.org/10.1080/01434632.2015.1071824

Park, J.S-Y. (2018) Mediatizing neoliberalism: The discursive construction of education's 'future'. Language and Intercultural Communication 18(5): 478-489. https://doi.org/10.1 080/14708477.2018.1501843

Paternotte, D. (2015) The NGOization of LGBT activism: ILGA-Europe and the treaty of Amsterdam. Social Movement Studies 15(4): 388-402. https://doi.org/10.1080/147428 37.2015.1077111

Paternotte, D. and Seckinelgin, H. (2015) "Lesbian and gay rights are human rights": multiple globalizations and LGBTI activism. In Paternotte, D. and Tremblay, M. (eds.) The Ashgate Research Companion to Lesbian and Gay Activism. Ashgate. https://doi.org/10 .4324/9781315613147

Peck, A. and Stroud, C. (2015) Skinscapes. Linguistic Landscape 1(1/2): 133-151. https://doi .org/10.1075/11.1.1-2.08pec

Pellegrini, A. (2002) Consuming lifestyle: Commodity capitalism and transformations in gay identity. In A. Cruz-Malavé and M.F. Manalansan IV (ed.) Queer Globalizations: Citizenship and the Afterlife of Colonialism. New York University Press. https://doi.org /10.18574/9780814790182-009

Pennycook, A. (2012) Language and Mobility: Unexpected Places. Multilingual Matters. https://doi.org/10.21832/9781847697653

Plummer, K. (1995) Telling Sexual Stories: Power, Change and Social Worlds. Routledge. https://doi.org/10.4324/9780203425268

Povinelli, E.A. and Chauncey, G. (1999) Thinking sexuality transnationally: An introduction. GLQ: A Journal of Lesbian and Gay Studies 5(4): 439-449. https://doi.org /10.1215/10642684-5-4-439

Puar, J. (2007) Terrorist Assemblages: Homonationalism in Queer Times. Duke University Press. https://doi.org/10.1215/9780822390442

Puar, J.K. (2002a) A transnational feminist critique of queer tourism. Antipode 34(5): 935946. https://doi.org/10.1111/1467-8330.00283

Puar, J.K. (2002b) Circuits of queer mobility: Tourism, travel and globalization. GLQ: A Journal of Lesbian and Gay Studies 8(1-2): 101-138. https://doi.org/10.1215/106426 84-8-1-2-101

Rao, R. (2014) The locations of homophobia. London Review of International Law 2(2): 175-81. https://doi.org/ 10.1093/lril/lru010

Rao, R. (2015) Global homocapitalism. Radical Philosophy 194: 38-49.

Reyes, A. (2011) Strategies of legitimization in political discourse: From words to actions. Discourse and Society 22(6): 781-807. https://doi.org/10.1177/0957926511419927

Richardson, D. (2005) Desiring sameness: The rise of a neoliberal politics of normalization. Antipode 37(3): 515-53. 
Richardson D. (2015) Neoliberalism, citizenship and activism. In Paternotte, D. and Tremblay, M. (eds.) The Ashgate Research Companion to Lesbian and Gay Activism. Ashgate. https://doi.org/10.4324/9781315613147

Richardson D. (2017) Rethinking sexual citizenship. Sociology 51(2): 208-224. https://doi .org/10.1177/0038038515609024

Richey, L.A. and Ponte S. (2011) Brand Aid: Shopping Well to Save the World. University of Minnesota Press.

Rink, B. (2008) Community and utopia: Reflections on De Waterkant. Urban Forum 19(2): 208-220. https://doi.org/10.1007/s12132-008-9031-z

Rink, B. (2013) Que(e)rying Cape Town: Touring Africa's gay capital with the Pink Map. In J. Sarmento and E. Brito-Henriques (eds.) Tourism in the Global South: Heritages, Identities and Development. Centre for Geographical Studies.

Rist, G. (2008) The History of Development: From Western Origins to Global Faith. 3rd ed. Zed Books.

Robertson, E. (2016, March 16) Get mad and get even. Meanjin. https://meanjin.com.au/ essays/get-mad-and-get-even-liberal-feminism-and-the-second-wave-undertow/

Rose, N. (1999) Powers of Freedom: Reframing Political Thought. Cambridge University Press. https://doi.org/10.1017/CBO9780511488856

Seals, C. (2017) Analysing the linguistic landscape of mass-scale events. Linguistic Landscape 3(3): 267-285. https://doi.org/10.1075/11.17012.sea

Sebba, M. (2010) Discourses in transit. In Jaworski, A. and Thurlow, C. (eds.) Semiotic Landscapes: Language, Image, Space. Continuum.

Sedgwick, E.K. (1990) Epistemology of the Closet. University of California Press.

Sender, K. (2004) Business, Not Politics: The Making of the Gay Market. Columbia University Press. https://doi.org/10.7312/send12734

Shankar, S. (2015) Advertising Diversity. Duke University Press. https://doi.org/10.1515 19780822375616

Shankar, S. and Cavanaugh, J. (2012) Language and materiality in global capitalism. Annual Review of Anthropology 41: 355-369. https://doi.org/10.1146/annurev-anthro-092611 $-145811$

Sheller, M. and Urry, J. (2006) The new mobilities paradigm. Environment and Planning A 38: 207-226. https://doi.org/10.1068/a37268

Sicurella, F.G. (2016) The approach that dares speak its name: Queer and the problem of 'big nouns' in the language of academia. Gender and Language 10(1): 73-84. https://doi .org/ 10.1558/genl.v10i1.20895

Skeggs, B. (2004) Class, Self, Culture. Routledge. https://doi.org/10.4324 19781315016177

Smith, N. (2016) Toward a queer political economy of crisis. In True, J. and Hozic, A. (eds.) Scandalous Economics: Gender and the Politics of Financial Crisis. Oxford University Press. https://doi.org/10.1093/acprof:oso/9780190204235.003.0013

Springer, S. (2016) Fuck neoliberalism. ACME: An International Journal for Critical Geographies 15(2):285-292.

Steger, M. (2008) The Rise of the Global Imaginary. Oxford University Press. https://doi.org /10.1093/acprof:oso/9780199286942.001.0001

Steger, M. (2009) Globalisation and social imaginaries: The changing ideological landscape of the twenty-first century. Journal of Critical Globalisation Studies 1: 1-30.

Steger, M. and James, P. (2013) Levels of subjective globalization: Ideologies, imaginaries, ontologies. Perspectives on Global Development and Technology 12(12): 17-40. https://doi .org/10.1163/15691497-12341240 


\section{References}

Stibbe, A. (2015) Ecolinguistics: Language, Ecology and the Stories We Live By. Routledge. https://doi.org/10.4324/9780367855512

Stillwagon, R. and Ghaziani, A. (2019) Queer pop-ups: A cultural innovation in urban life. City and Community 18(3): 874-895. https://doi.org/10.1111/cico.12434

Szerszynski, B. and Urry, J. (2002) Cultures of cosmopolitanism. The Sociological Review 50(4): 461-481. https://doi.org/10.1177/003802610205000401

Tannen, D. (1989) Talking Voices: Repetition, Dialogue, and Imagery in Conversational Discourse. Cambridge University Press. https://doi.org/10.1017/CBO9780511618987

Taylor, C. (2004) Modern Social Imaginaries. Duke University Press. https://doi.org/10.1215 19780822385806

Thornton, S. (1999) An academic Alice in Adland: Ethnography and the commercial world. Critical Quarterly 41(1): 58-68. https://doi.org/10.1111/1467-8705.00213

Thoreson R. (2011) The queer paradox of LGBTI human rights. InterAlia: Pismo pos wiecone studiom queer 6: 1-27.

Thoreson, R. (2013) Power, panics, and pronouns: The information politics of transnational LGBT NGOs. Journal of Language and Sexuality 2(1): 145-177.

Thoreson, R. (2014) Transnational LGBT Activism: Working for Sexual Rights Worldwide. Minneapolis: University of Minnesota Press.

Thurlow, C. (2013) Fakebook: Synthetic media, pseudo-sociality and the rhetorics of Web 2.0. In D. Tannen and A. Trester (eds.) Discourse 2.0: Language and New Media. Washington, DC: Georgetown University Press.

Thurlow, C. (2016) Queering critical discourse studies or/and performing 'post-class' ideologies. Critical Discourse Studies 13(5): 485-514. https://doi.org/10.1080/17405904 .2015 .1122646

Thurlow, C. (2020a) Expanding our sociolinguistic horizons? Geographical thinking and the articulatory potential of commodity chain analysis. Journal of Sociolinguistics 24(3):350368. https://doi.org/10.1111/josl.12388

Thurlow, C. (2020b) When globalese meets localese: Transformational tactics in the typographic landscape: A Bernese case study. Social Semiotics. https://doi.org/10.1080 /10350330.2020.1810544

Thurlow, C. and Aiello, G. (2007) National pride, global capital: A social semiotic analysis of transnational visual branding in the airline industry. Visual Communication 6(3): 305344. https://doi.org/10.1177/1470357207081002

Thurlow, C. and Jaworski, A. (2003) Communicating a global reach: Inflight magazines as a globalizing genre in tourism. Journal of Sociolinguistics 7(4): 581-608. https://doi.org/10 $.1111 / \mathrm{j} .1467-9841.2003 .00243 . \mathrm{x}$

Thurlow, C. and Jaworski, A. (2010a) Tourism Discourse: Language and Global Mobility. Palgrave Macmillan.

Thurlow, C. and Jaworski, A. (2010b) Silence is golden: Elitism, linguascaping and 'anticommunication' in luxury tourism discourse. In A. Jaworski and C. Thurlow (eds.) Semiotic Landscapes: Language, Image, Space. Continuum.

Thurlow, C. and Jaworski, A. (2012) Elite mobilities: The semiotic landscapes of luxury and privilege. Social Semiotics 22(4): 487-516. https://doi.org/10.1080/10350330.2012.721592

Thurlow, C. and Jaworski, A. (2014a) Visible-invisible: The social semiotics of labour in luxury tourism. In T Birtchnell and J. Caletrío (eds.) Elite Mobilities. Routledge. https:// doi.org/10.4324/9780203078532

Thurlow, C. and Jaworski, A. (2014b) 'Two hundred ninety-four': Remediation and multimodal performance in tourist placemaking. Journal of Sociolinguistics 18(4): 459-494. https://doi.org/10.1111/josl.12090 
Thurlow, C. and Jaworski, A. (2015) On top of the world: Tourist's spectacular self-locations as multimodal travel writing. In Kuehn, J. and Smethurst, P. (eds.) New Directions in Travel Writing Studies. Palgrave. https://doi.org/10.1057/9781137457257_3

Thurlow, C. and Jaworski, A. (2017a) Word-things and space-sounds: The transmodal production of privilege and status. In Cavanaugh, J. and Shankar, S. (eds.) Language and Materiality: Ethnographical and Theoretical Explorations. Cambridge University Press. https ://doi.org/10.1017/9781316848418.010

Thurlow, C. and Jaworski, A. (2017b) The discursive production and maintenance of class privilege: Permeable geographies, slippery rhetorics. Discourse and Society (28)5: 535-558. https://doi.org/10.1177/0957926517713778

Tolins, J. and Samermit, P. (2016) Gifs as embodied enactments in text-mediated conversation. Research in Language and Social Interaction 49(2): 75-91. https://doi.org/10 $.1080 / 08351813.2016 .1164391$

Trilling, L. (1972) Sincerity and Authenticity. Harvard University Press. https://doi.org/10 $.2307 /$ j.ctvjhzrdp

Tucker, A. (2009) Queer Visibilities: Space, Identity and Interaction in Cape Town. WileyBlackwell. https://doi.org/10.1002/9781444306187

UN WTO (2012) Global Report on LGBT Tourism. UN World Tourism Organization. Retrieved on 26 October 2015 from www.e-unwto.org/doi/pdf/10.18111/9789284 414581

UN World Tourism Organization (2017) UN WTO Annual Report 2016. UN World Tourism Organization. https://doi.org/10.18111/9789284418725

Urciuoli, B. (2003) Excellence, leadership, skills, diversity: Marketing liberal arts education. Language and Communication 23: 385-408. https://doi.org/10.1016/S0271-5309(03)00014-4

Urciuoli, B. (2016) The compromised pragmatics of diversity. Language and Communication 51: 30-39. https://doi.org/10.1016/j.langcom.2016.07.005

Urry, J. (2002) The Tourist Gaze. 2nd ed. SAGE. https://doi.org/10.4135/9781446251904

van Dijk, T. (2006) Discourse and manipulation. Discourse and Society 17: 359-383. https:// doi.org/10.1177/0957926506060250

van Leeuwen, T. (2007) Legitimation in discourse and communication. Discourse and Communication 1(1): 91-112. https://doi.org/10.1177/1750481307071986

van Leeuwen, T. and Wodak, R. (1999) Legitimizing immigration control: A discoursehistorical analysis. Discourse Studies 1(1): 83-118. https://doi.org/10.1177/14614456990 01001005

Vertovec, S. (2015) (ed.) Introduction: Formulating diversity studies. The Routledge Handbook of Diversity Studies. Routledge. https://doi.org/10.4324/9781315747224

Vestergaard, A. (2008) Humanitarian branding and the media: The case of Amnesty International. Journal of Language and Politics 7(3): 471-493. https://doi.org/10.1075/ jlp.7.3.07ves

Vestergaard, A. (2013) Humanitarian appeal and the paradox of power. Critical Discourse Studies 10(4): 444-467. https://doi.org/10.1080/17405904.2012.744322

Vestergaard, A. (2014) Mediatized humanitarianism: Trust and legitimacy in the age of suspicion. Journal of Business Ethics 120(4): 509-525. https://doi.org/10.1007/s10551 -013-2002-x

Vincent, L. and Howell, S. (2014) 'Unnatural', 'un-African' and 'ungodly': Homophobic discourse in democratic South Africa. Sexualities 17(4): 472-482. https://doi.org/10 $.1177 / 1363460714524766$

Visser, G. (2003a) Gay men, tourism and urban space: Reflections on Africa's 'gay capital'. Tourism Geographies 5(2): 168-189. 


\section{References}

Visser, G (2003b) Gay men, leisure space and South African cities: The case of Cape Town. Geoforum 34(1): 123-137. https://doi.org/10.1016/S0016-7185(02)00079-9

Waitt, G. and Markwell, K. (2006) Gay Tourism: Culture and Context. Haworth Press. https://doi.org/10.4324/9780203824993

Ward, J. (2008) Respectably Queer: Diversity Culture in LGBT Activist Organizations. Vanderbilt University Press.

Warner, M. (1992) Introduction. In Warner, M. (ed.) Fear of a Queer Planet: Queer Politics and Social Theory. University of Minnesota Press.

Wee, L. (2016) Situating affect in linguistic landscapes. Linguistic Landscape 2(2): 105-126. https://doi.org/10.1075/11.2.2.01wee

Weeks, J. (2007) The World We Have Won. Routledge. https://doi.org/10.4324 19780203956809

Weston, K. (1995) Get thee to a big city: Sexual imaginary and the great gay migration. GLQ 2: 253-77. https://doi.org/10.1215/10642684-2-3-253

Wetherell, M. (2012) Affect and Emotion: A New Social Science Understanding. SAGE. https:// doi.org/10.4135/9781446250945

Wetherell, M. (2013) Affect and discourse: What's the problem? From affect as excess to affective/ discursive practice. Subjectivity 6(4): 349-368. https://doi.org/10.1057/sub .2013 .13

Wiegman, R. (2012) Object Lessons. Duke University Press. https://doi.org/10.1215 19780822394945

Wodak, R. and Meyer, M. (eds.) (2016) Methods of Critical Discourse Studies. 3rd ed. SAGE. http://doi.org/10.4135/9780857028020

Woodward, K. (1999) Statistical panic. Differences 11(2): 177-203. https://doi.org/10.1215 /10407391-11-2-177

Zappavigna, M. (2011) Ambient affiliation: A linguistic perspective on Twitter. New Media and Society 13(5): 788-806. https://doi.org/10.1177/1461444810385097

Zevin, A. Liberalism at Large: The World According to the Economist. Verso.

Žižek, S. (2009) First as Tragedy, Then as Farce. Verso. 


\section{Index}

\#HoldTight, 203-204, 208-209, 223

\#LoveTravels, 5-6, 8-9, 13, 19, 22, 24, 31-32, 39-41, 53, 220, 223, 225

acronyms (of/for LGBTQ people), xiii, 64, 104, 125

Ahmed, Sara, 6, 8-9, 11, 26, 29, 31, 45, 50-51, 96, 119, 125-126, 130-136, 152-153, 154, 156-158, 168-169, 197, 213-214, 220, 224-225

affect, 6-7, 9, 25, 27, 33, 45, 50-51, 64, 68-78, 92, 96, 100, 108-109, 116, 119, 121-122, 125-126, 132, 134-136, 138, 144-147, 148, 151, 153-159, 161-162, 168, 170, 174-176, 179, 181-187 191, 199, 203-204, 213-216, 219-222, 224-225

'affect alien', 45, 224-225

affective-discursive practices, 7, 46, 49, 50-51, 134, 179, 184-185, 198, 203-204

affective economies, 9, 125-126, 134-135, 184

affective legitimation, see legitimation; affective

Africa, 52, 59, 62-70, 75-76, 78-83, 88-89, 98-102, 108, 109, 117-118, 125, 207, 212, 214

as exotic, 67, 69, 75, 89, 98

representations of, 66-67, 69, 72, 76, 80, 89, 111

All Out, 171, 173, 175-179, 181-184, 187-191, 193, 197-199, 204

allure, see also desire, 31, 40, 41, 46, 54, 57, 61, 73, 80, 98, 109-110, 118, 126, 155-156, 199, 207, 215, 220-221 appadurai, Arjun, 9, 13-15, 18, 40 apartheid, 52, 62, 80, 83, 89, 99, 214 audience design, 53, 167, 172-179, 199, 215 authenticity, 6-7, 8, 40, 55, 57, 66, 80, 98, 103, 106, 117-118, 121-122, 136, 143-144, 150-153, 155-158, 167-168, 173, 185, 187, 192-193, 208-212, 220

autoethnography, 11, 34, 41, 45-46, 49-51, 91-93, 130, 136-138, 169, 172, 206-208, 215, 220

belonging, see identity

Blommaert, Jan, 5, 11, 23, 42, 117, 123 , $132,169,184$

bodies, 9, 13, 20-21, 27, 49-51, 52, 58, 63-64, 66, 69-70, 72, 74-78, 79, 82, 89-90, 92, 107-108, 110-111, 114-116, 179-186, 191, 199, 214, 220, 222

and sunlight, 74, 78, 109-110

as sexual/sensual, 70, 72-74, 115-116, 220 able-bodiedness, 82, 142,

Butler, Judith, 7, 24, 26-27, 31, 33, 54, 95, 103, 133-135, 155, 159, 162, 207, 217-218, 222

camp, 1, 74, 92, 108, 110-116, 118, 126, 167, 174, 212

Cape Town, 12, 31, 39, 52, 57-58, 59-83, 85-86, 88, 94-95, 99, 110-111, 117-118, 190, 212, 215

as gay capital, 12, 52, 59-70, 72, 74, 79, $82-83,94,112,118$

as unequal, $52,58,63,68,75,79,82$, 117-118, 212

capitalism, see also market globalism, 7-9, 13, 17-18, 22, 30-32, 34, 37, 44, 59, 61-62, 78-79, 82, 86-88, 94, 117-118, 121-122, 123, 126, 132, 134, 143, 145, 155, 171, 183, 185-186, 194, 209-211, 216-218, 220, 222

carnivalesque, 50, 53, 85, 110-116, 118, 208, 210, 212 
Chouliaraki, Lilie, 38, 53, 95, 162, 166, 169-172, 174-177, 179, 192-193, 198-200, 213-215

chronotope/s, 8, 37, 41-43, 47, 53, 106, 145, 160, 165, 197-201, 206-207, 209-210, 212, 224-225,

and heterotopias, 53, 116-120, 209-210, 224-225

in/and neoliberalism, 43, 206-207, 209, 224-225

class, see political economy

colonialism, 20, 44, 89, 117, 163

neo-colonial practices, 17, 19-20, 27, 89, $98,117,217$

coming out, 8, 104, 143, 150-151, 156, 173, 179-180, 187, 223

conservation discourses, see also environmental degradation, 75

consumer culture, 9, 11, 20-21, 29, 61, 110, 164, 179-186, 192, 200, 215-216, 218, 219, 225

'convivial collective', 174, 175-179, 184-186, 188, 190-193, 195, 198, 215, 221, 225

cosmopolitanism, 8-9, 13-14, 18-20, 22, $33,37-38,41,62,67,70,82,86,88$, 98, 118-120, 131, 171-172, 175, 184186, 190-191, 193, 195, 200, 206-208, 215, 221-222, 225

as idea/l, 11, 14-16, 19, 22, 59, 62, 95, 185

ironic, 176-177, 199-200, 215, 220, 225

COVID-19 pandemic, 227-228

Critical Discourse Studies (CDS), 18-19, 25, 36, 45-49, 51, 64, 136, 166, 169-170

'critical discourse ethnography', 38-39, 45-51, 64, 206-208, 211, 219

D'Emilio, John, 7, 30, 62, 103, 126, 134, 136, 222-224

De Certeau, Michel, 53-54, 214

desire, 6, 8, 23-24, 26, 28-30, 33-34, 40, $46,65,69,78,81,117-119,135-136$, 144, 153, 154, 157, 174, 201, 205-206, 208, 211, 215-216, 219-221

De Waterkant, 31, 63, 114

development (and theories of), 75, 94-96, 117, 125-126, 160, 195, 213-214, 220

digital discourse, see also social media, 21, $49,65,70,72,81,83,92,167,171-172$, 173-177, 183, 196, 207-208

discourse (definition of), 23, 41-42, 46, 48, 53-54 discursive formation/s, 11-12, 16, 37, 46-47, 50, 54, 63, 65, 68, 78, 94, 108-109, 116, 207

discursive strategies, 43, 47, 53-54, 154-155, 158, 161, 167, 172, 198-199, 213-215, 223

divas, see also music, 115, 118, 173-174

diversity, $8,10,12,20,40-41,53,81-82$, 89, 119, 125-126, 130-135, 138, 142-143, 145, 154-159, 168, 170, 189, $191,211,213,220$

as 'metadiscursive regime', 132, 135, 144, 155-157, 210

as 'non-performative', see performativity; 'non-performativity'

double hermeneutic, 14, 24, 215-216

dress code; clothing, see bodies

embodiment, see bodies

entrepreneurialism, 17, 95, 117, 119, 132, 142, 144-146, 156, 161, 173, 196, 210, 220

environmental degradation, 16, 44, 96, 130, 211

'enworlding', 13, 41-45, 47, 49, 59, 81, 98, 162-163, 186-187, 192, 196-197, 207, 211-216, 220, 224

equality, 8-9, 11, 26, 34, 35-37, 39, $40-45,52,54-55,57-58,61,66$, 68-70, 79-83, 98, 106, 116, 118-120, 133, 143, 154, 162-167, 175-176, 187, 192-193, 199-201, 211, 215-218, 222, 223-225

as idea/l, 2-3, 186-187, 227-228

and capitalism/market globalism, 6, 8-9, 55, 118-119, 121-122, 140, 162-165, 184-186, 209-214, 216, 218, 222 'ersatz equality', 53, 106, 118, 166-168, 181, 187, 207, 209-212, 222, 224, 228 ethnography, 45, 47-48, 92-93, 137-139 events, 47-49, 88-91, 124-130, 139 148-154, 214 as texts, 48 event ethnography, 48-49, 51, 52-53, 91-93, 104, 124, 137-138, 154

fairclough, Norman, 6, 17, 18, 41-42, 47, $76,129,132,145,168,175,181$

'fabulous', 3, 57, 60-61, 63, 65, 70, 76-78, $79,82,84,87,105,114-115,122,170$, 172-174, 207, 212-213, 215, 218, 223, 227-228

feminism, 6, 24, 125, 131, 154, 162, 164, 211, 217-218 
Foucault, Michel, 7, 15, 17, 23-24, 33, 44-45, 53, 54, 83, 93, 117-118, 206, 210, 212, 219-220, 223

Fraser, Nancy, 26, 40, 42, 123, 125, 131, 132, 155, 157, 211, 216, 218

futurity, $8,12,25,30,37,39-45,88$, 106-108, 118-119, 145-146, 156, 159, $160,163,165,173-174,186,196-201$, 204, 205-207, 222-225

'fake futurity', 42, 222, 223-224

'gay capital'/s, 12, 52, 57-58, 59-65, 67-68, 70, 74, 76, 79, 82-83, 87, 94, 111-112, 118, 208, 212

gender, xiii, 7, 23, 25, 27-30, 61, 63, 69, $71,78,103,116,125,132,163,177$. $179,199,216-217$

genealogy, 44-45, 49, 51, 219

globalization, 6-11, 14, 16-19, 21, 24, 26, $33,35,37-38,42-44,51,68,81-82$, 94, 123-124, 128-130, 131, 136, 143, 156, 160, 165-166, 170, 187, 191-192, 194-197, 200-201, 211, 221, 222-225 sociolinguistics of, 11-12, 18, 41-44, 94, 131, 201, 217-218

'banal globalization', 13-15, 18-19, 22, 30, 44, 81, 98, 160, 200, 211-212, 215

'global citizenship', 12, 15-16, 18-19, 22,37

global imaginary, 9, 17-18, 21, 26, 163 'globalizing habitus', 18-19, 42, 50, 98, 104-105, 143, 187, 214

global culture industry, 7, 9, 15, 20, 36, 209

global semioscape, 9-12, 15, 19, 31, 38-39, $53,103,123-124,165,167-168,187$, $207,210,212-215,222,223$

habitus, 10, 18-19, 25, 34, 35-42, 46, 50-51, 53, 81, 91, 96, 98, 104-105, 123, $135,143,145,158,160,168,175,181$, 187, 191, 193, 199, 207, 211, 214, 217 , 222, 227

happiness, 9, 45, 51, 118, 119, 145, 192, 204, 212, 224

hashtags, 5, 9, 15, 19, 49, 91, 92, 121, 129, 137, 138, 150, 168, 181,

184-185, 187-189, 192, 200, 203-204, 208-209, 223

heterotopia, 53, 83, 93, 110, 116-120, 210, $212,222-225$

homonationalism, 1, 31-32, 40, 41, 49, 163, 207 homonormativity, 28-34, 40, 63, 156-157, 162, 163, 164, 199, 203, 206-207, 212, 216-218

homophobia, 30, 43, 62, 67, 75, 125, 130 , 138-143, 145-147, 154-157, 160-162, 165-167, 170-171, 175, 177, 186, 189-190, 194-196, 204, 216, 220

hope, 5-6, 9, 10, 27, 30, 42, 54, 62, 101, 145, 165-167, 168, 205, 209, 215-216, 217, 222-225

Hong Kong, 128-129, 138, 140

horizon/s, 1, 55, 72, 83, 96, 106, 110-111, 165, 193, 197, 201, 206-208, 216, 222

human rights, 12, 41-43, 160-167, 171, 186, 187, 198-200, 219

Human Rights Campaign (HRC), 2, 171, 174-175, 186, 193, 207

Hyatt, 7

identity, 1-2, 11-12, 15, 23-26, 28-29, 34, 36-37, 42, 64, 78-83, 101-104, 106, 108, 115, 132, 134, 150, 156-157, 160-165, 167-169, 171, 187, 193, 199, 215, 217-218, 219, 223, 225

'Identity politics', 31, 132, 217-218

IGLTA (International LGBTQ+ Travel Association), 48, 52-53, 54, 70, 84-93, 99, 101, 103, 104, 109-110, 116, 118-120, 192, 212, 215

image banks, 9, 15, 72, 84-85

'imperial elite', 89

It Gets Better, 171, 179-180, 193, 197

Jaworski, Adam, 7, 8, 10, 13, 14-15, 18-21, 36, 48, 49, 53, 59, 61, 63, 72, 74-76, 78, 85, 89-91, 93, 94, 98, 105, 148, 157, 167-168, 179, 180, 187, 210, $212,217-218,221$

'Killjoy', see affect; alien

Kress, Gunther, 47, 72, 74, 84, 95, 111, 140, 148, 150, 177, 187

language commodification, see also 'wordthings', 7, 35-36, 41, 61, 121, 131, 166, 168, 173-174, 220, 222

'language objects', 7-8, 168, 184-185, 196-197, 216

'language work', see also marketing, 54 legitimation, 44, 53, 96, 97, 117, 119, 130, 135-136, 138, 143, 145, 147-151, 153-159, 194-196, 199 affective, 53, 96, 119, 147, 148, 153-159, 161-162, 194-196, 199, 214-215, 223 
LGBTQ, xiii, 11-12 see also acronyms of/ for LGBTQ people

advocacy organizations, 148, 162-167, 171-172, 186-187, 194-201, 213-214

discrimination, see homophobia identity, 1-2, 12, 24, 26, 30, 32, 37, 39, 63-64, 66, 76, 102-103, 119, 123, 150, 156-157, 160-165, 171-174, 199, 201, 213-219, 221-225

lifestyles, 7, 34, 43-44, 59-60, 103-104, 121-122, 138, 156-157, 161-162, 166-168, 206-207

tourism ('pink tourism'), 59-61, 64-65, 69, 78-83, 87-88, 91, 94, 102-106, 116-120, 156-157, 169-170, 212 visibility, 1, 61, 82, 88, 103, 105-106, 179-180, 185, 190, 193, 212

linguistic diversity, 69, 145, 171, 187, 191 London, 121-122, 128-130, 138, 208, 223 love, 5-9, 11, 26, 29, 39-41, 51, 53, 54, $61,125,153,165,168-169,174-176$, 181-185, 186-189, 194, 197, 201, 203-204, 211, 213-216, 222, 223

luxury, 70, 72, 75, 89-91, 115, 129-130, 148-150, 210, 212

marketing, 10-11, 15, 39, 42-43, 48, 69, 82, 89-91, 106, 118, 125, 129, 148, 150, 174, 184, 212-214

market globalism, 9, 13, 17-18, 124, 153, 155, 158, 166, 187, 200, 206-207, 210, 213-214, 217, 218

Marriott International, 5-6, 8, 13 materiality, 27, 70, 86, 91, 116, 179-186, 209, 216

'materialization and mobilization', 172, 179-186, 196-197, 199-200, 214-216 mediatization, 10, 12, 14, 18, 27-29, 32, $34,35-41,44,47,61,64,78,80-83$, 104-105, 123-124, 129, 132, 155-157, 163, 165, 197, 200-201, 206-208, 215, 217, 220-222

Milani, Tommaso, 6, 17, 27, 30, 31, 46, 49, 50, 51, 52, 54, 59, 64, 65, 67, 69, 72, 79, 93, 104, 108, 110, 112, 180, 185, 207, 216-218, 220, 223-224

MisterBnB, 80-82, 215

mobile phone apps, 102, 105, 114

mobility, 9-16, 19-20, 22-23, 33-34, $38,40,59,61,81,92,94,109,114$, $117,119,123,163,171,181-183,209$, 211-214, 227-228 as 'escape', 60-61, 78, 88, 94, 102-110, $112,117-118,151,211-212$

as 'virus', 227-228

immobility, 14, 16, 19, 81, 102, 104, 123, 129, 227

modernity, 14-16, 38, 164, 199, 221-222, 227

multilingualism, see linguistic diversity multimodality, 45-46, 47, 64, 72, 75, 105, 130, 148-150, 156, 187-191, 192

Muñoz, Jose Esteban, 27, 30, 34, 39, 42, 45, 51, 53, 83, 87, 96, 106, 112, 116, 118, 165, 197, 205-207, 211, 212, 216-218, 221, 222, 224

music, 47, 76, 90, 109, 110, 115, 118, 121-122, 195, 196, 203

'new mobilities paradigm', 14, 16, 21-22, 33 neoliberalism, 8, 17, 30-32, 95-96, 101,

117-120, 124, 126, 134, 135, 137, 139-147, 154-159, 165, 170-171, 177, 195-197, 216-221

and 'market globalism', 17

as 'anticipatory regime', 37, 43-44, 145, 165, 196-201, 206, 209

as mediatized, 44, 79, 200-201, 206-207, 217

neoliberal governmentality, 15, 17, 32-33, 44, 47, 54, 119, 144-145, 153-157, $165,170,193,195-201,215-221$

New York, 57-58, 88, 105, 114, 128-129, 138, 208-209

normativity, see also homonormativity, 11-12, 17, 25, 28-31, 42, 44, 64, 70, 79, 114-115, 118, 130, 131, 166, 196, 218,223

Out2Africa, 70-78, 207

OutRight International, 171

'people like me', 11, 34, 41, 46, 80, 169, 185, 203, performativity, 7, 29, 54, 95, 104, 110-114, 116, 118, 132, 167, 'non-performativity', 11, 31, 53, 125, 133-136, 157-158, 211, 213, 223

pink, 66, 71-72, 76, 81, 103, 114, 115,173

political economy, 5-6, 14, 17, 19, 26-34, $62,63,78,79,102-103,132,134,136$, $139,158,164,217-218$ positivity, 9-10, 44, 78, 96, 116-117, 119, 123, 132-133, 136, 145, 155-156, 162, 
176-177, 179, 189, 192, 196, 198, 214, 215, 218, 219-221

Positive Discourse Analysis (PDA), 166, 169-170, 196-197

'post-gay', 160-166, 173-174, 177-178, 180, 185-187, 197-200, 209, 214, 219

post-humanitarianism, see also development (and theories of), 162, 170, 194, 199-200, 214

poverty, 95-96, 101, 118, 200

power, $7,10,13,16,20,23,25,27,31$, $33,46-48,54,59,96,123,133,155$, 165, 183-184, 189-190, 219-220, 227 'pride to be proud of, 54, 205, 222, 228

Pride and Prejudice, 44, 124-130, 137-138, 148-150, 156-158, 160, 206, 207, 213

queer, 6, 25, 26-27, 33, 54, 64, 72, 88, 130, 153-154, 158-159, 162-164, 205-207, 216-218, 222-225

'alliance', 26, 54-55, 159, 207, 218, 222 capitalization of, xiii

linguistics, xiii, 11, 23-25, 27-28, 30, 54, 64, 210

methods, 27, 46, 64

theory, xiii, 25-28

'queer mobilities', 5, 11-13, 22, 34, 38, 41-42, 54, 57, 117, 163, 206, 209, 211-216, 222

race, xiii, 11, 26, 27, 30, 39, 61, 63, 66, 68-70, 74-75, 77-78, 87, 89-90, 116, 117207,210

reflexive sociology, 45-46, 51, 219

rhetorical tactics, 43, 53-54, 93, 137-154, 214-215

rhizome, 54, 207

same-sex marriage, 62, 177, 191, 203-204, 208

San Francisco, 1-3, 61, 64, 67, 74, 81, 82, 181, 187, 208, 209

scale, 41-44, 54, 81, 150, 168-169, 175, 186-193, 197-201, 214, 219-222

'scalar work', 172, 186-193, 199, 214-215

'scapes', 9, 15, 18, 38, 124

semiotic landscape, 105, 112-114, 121

sexuality, see also queer, 9, 24-25, 28, 29-30, 62-63, 74, 82, 104, 112, 156, 164, 197, 217, 221-222

Sexual citizenship, 30, 62, 140, 156, 162, 199 sexual inhibition, 58, 66, 74-75, 105, 112, 119

sexual innuendo and flirting, 1, 69, 74, 92, 107-108, 109, 112, 114, 190, 208

silence, 72, 75-76, 89, 130, 210

sloganization, 10, 13, 19, 36, 42, 53-54, 79-80, 84, 103, 108, 170, 187-189, 200, 222-207, 212, 223

social media, 36-37, 129, 159, 172, 187-191, 203-204, 207-208, 228

South Africa, 34, 52, 62-63, 79, 98-101, 111, 207

space/spatialization, 21, 31-32, 43, 50, 63, 86, 89, 92-93, 104-105, 106, 110, 112-114, 117-118, 137-138, 148, 181, 199, 207, 217, 223-225

spectrum, 52, 57-58, 88-93, 208, 210, 223

stance, 167-168, 174, 176-179, 180-181, 184-186, 189, 191, 199, 215-216

stock photography, see image banks stonewall (organization), 171, 179-181 subjectivity, 11, 17, 24, 28, 33, 37, 43, 49, $69,93,153,154,166,169,216,218$, 219,224

Sydney, 66, 67, 105, 190, 203-204

technological advancement, 6, 7, 13-14, 19, 37-38, 123, 137, 208

Tel Aviv, 67, 79, 81

telelogy, 10, 14, 18, 38, 126, 160, 163, 186, 191-192, 196-197, 211, 225

The Economist, 44, 124-126, 130, 132, 138, 139, 147, 148, 157-158, 213, 215

'thingified' language, see 'word-things'

Thurlow, Crispin, 5, 9, 10, 12, 13, 14-19, $21,25,33,36,40,46-49,50,53,54$, 59, 61-64, 69, 72, 74-76, 78, 83, 85, 89, 90-94, 97, 98, 105, 123, 129, 136, 148, 151, 153, 157, 165-169, 175, 180, 187, 192, 199, 206, 209-210, 212, 215, 217-218, 221

tourism, 6, 8, 11-12, 19-22, 54, 59, 91, 94-99, 101-102, 105, 114, 124, 157. 164, 165, 210-212, 215, 221

backpackers, 20, 102

LGBTQ ('pink') tourism, see LGBTQ, tourism

sociolinguistics of, 20-22, 61, 63-64, 70, 81-82, 94, 105

'tourist syndrome', 20-21, 68, 145

vs. 'travel', 72, 97-98

'travel with pride', 52, 60, 70, 88, 207, 214-215 


\section{Index}

Ubuntu, 99-102, 118

UN Free \& Equal (UNFE), 171, 181, 185 , 194-196, 197-198, 215

urbanity, 32, 40, 66, 74, 88, 105-106, 118, 145,217

utopia, 73, 75, 82-83, 103, 116, 205-206, 208-211, 223-225 van Leeuwen, Theo, 43, 47, 72, 74, 84, 95, 97, 110, 135-136, 138, 140, 147. 148, 150, 151, 177, 187, 195

'word-things', 9-10, 19, 43, 48, 53, 157, 168-169, 173-174, 187, 209, 220, 222-223 